Juliana Jerônimo de Araújo

\title{
Estudo do Impacto de Veículos Pesados sobre a Infra-Estrutura Rodoviária através de Simulação Microscópica de Tráfego
}

Tese apresentada à Escola de Engenharia de São Carlos da Universidade de São Paulo como parte dos requisitos para obtenção do título de Doutor em Engenharia Civil. Área de concentração: Planejamento e Operação de Sistemas de Transportes

Orientador: Prof. Associado José Reynaldo Anselmo Setti 
AUTORIZO A REPRODUÇÃO E DIVULGAÇÃO TOTAL OU PARCIAL DESTE TRABALHO, POR QUALQUER MEIO CONVENCIONAL OU ELETRÔNICO, PARA FINS DE ESTUDO E PESQUISA, DESDE QUE CITADA A FONTE.

Ficha catalográfica preparada pela Seção de Tratamento da Informação do Serviço de Biblioteca - EESC/USP

\section{A663e}

Araújo, Juliana Jerônimo de

Estudo do impacto de veículos pesados sobre a infraestrutura rodoviária através de simulação microscópica de tráfego / Juliana Jerônimo de Araújo ; orientador José Reynaldo Anselmo Setti. -- São Carlos, 2007.

Tese (Doutorado) - Programa de Pós-Graduação em Engenharia de Transportes e Área de Concentração em Planejamento e operação de Sistemas de Transportes - Escola de Engenharia de São Carlos da Universidade de são Paulo.

1. Tráfego rodoviário. 2. Simulação de Tráfego.

3. Calibração. 4. Algoritmo genético. 5. Veículos pesados. 6. Cargas móveis em pontes. I. Título. 


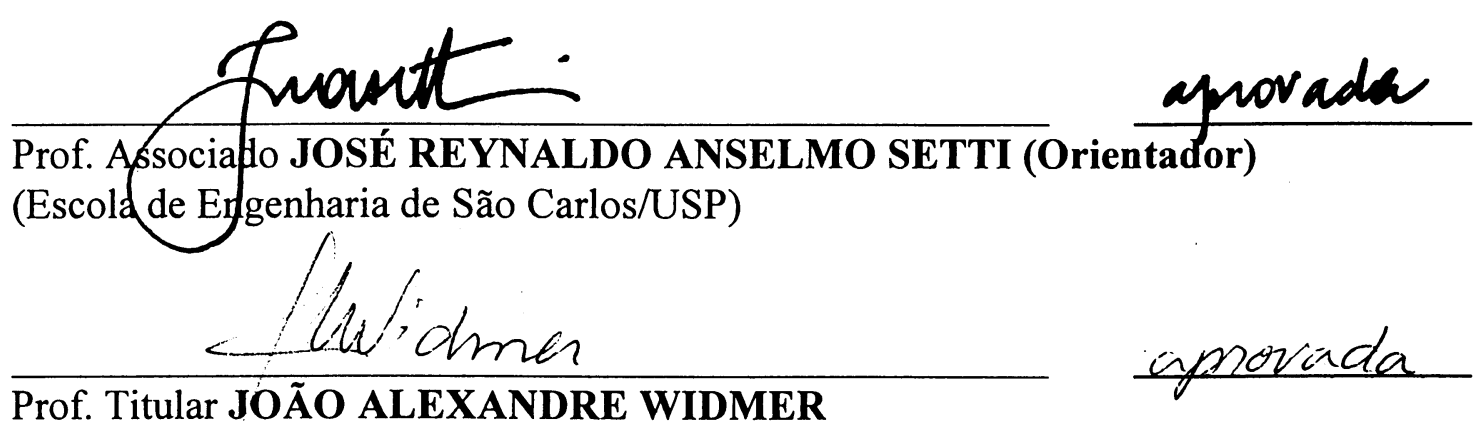

Prof. Titular JOÃO ALEXANDRE WIDMER

(Escola de Engenharia de São Carlos/USP)
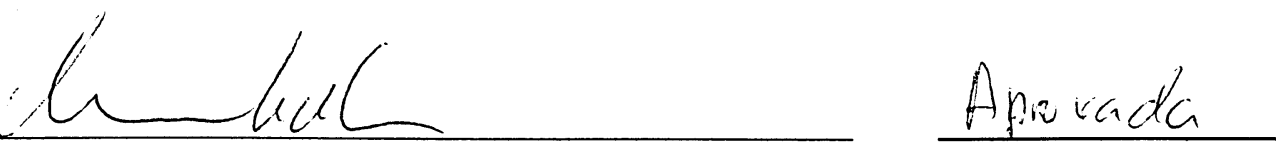

Prof. Titular MOUNIR KHALIL EL DEBS

(Escola de Engenharia de São Carlos/USP)

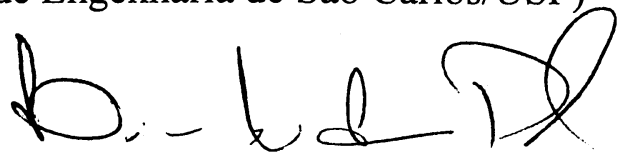

Prof. Titular LICÍNIO DA SILVA PORTUGAL

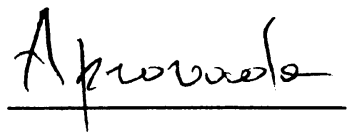

(Universidade Federal do Rio de Janeiro/UFRJ)

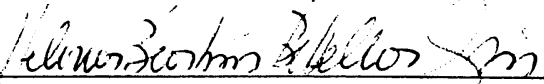

Prof $^{\mathrm{a}}$. $\mathrm{Dr}^{\mathrm{a}}$. HELENA BEATRIZ BETELLA CYBIS

(Universidade Federal do Rio Grande do Sul/UFRGS)

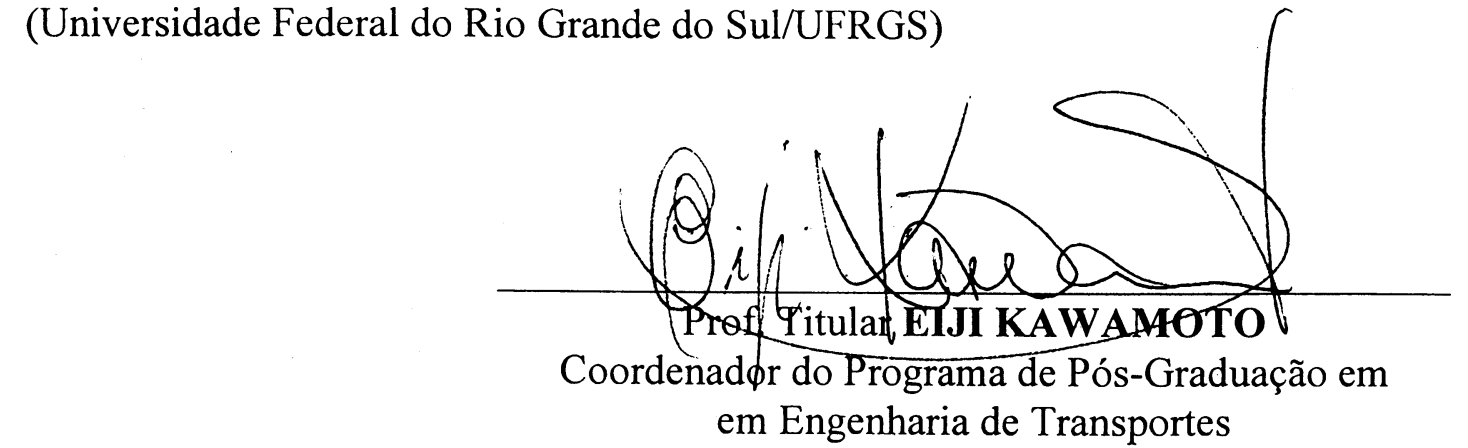

Coordenadør do Programa de Pós-Graduação em em Engenharia de Transportes
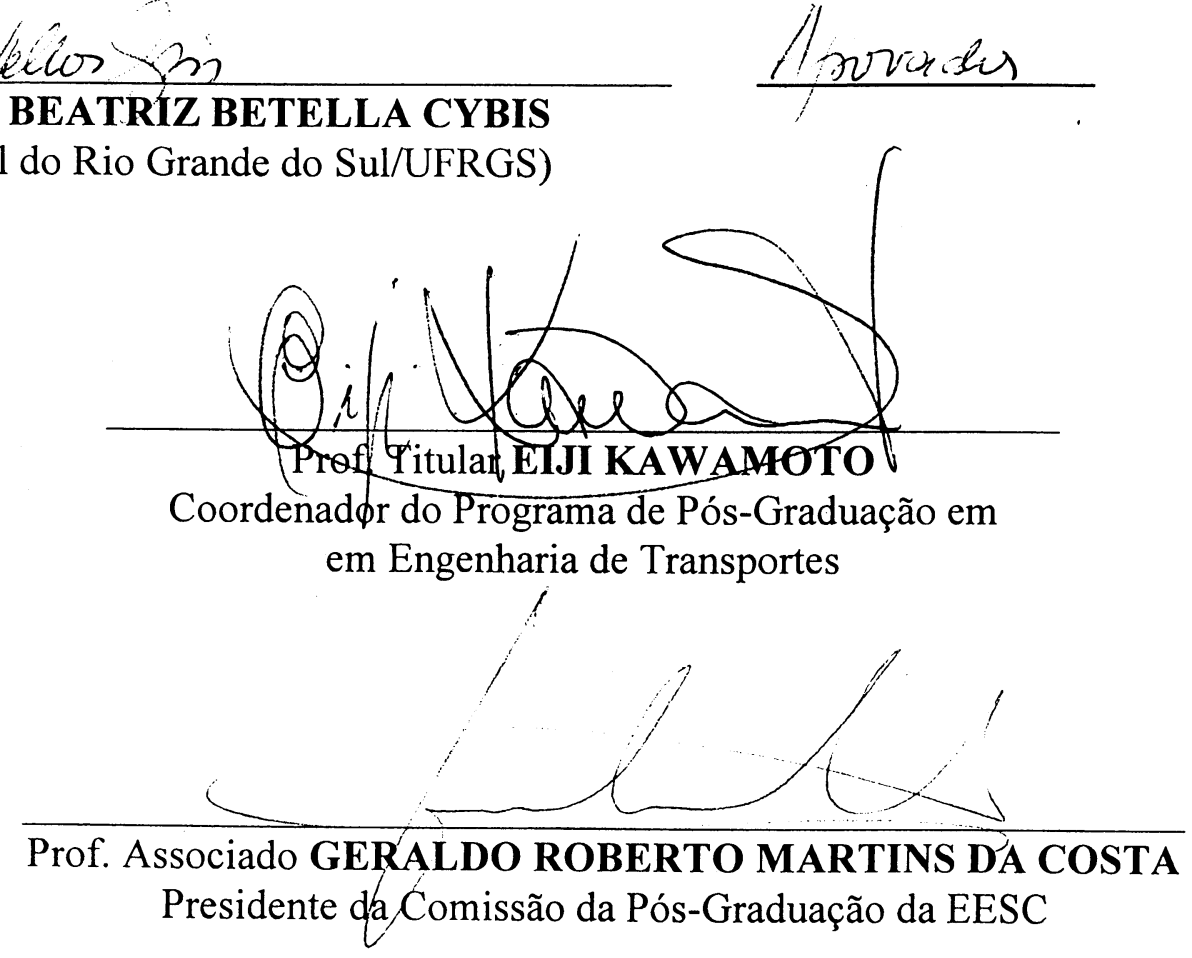

Dedico este trabalho ao meu pai, aos meus irmãos, aos meus sobrinhos e, in memoriam, à minha querida mãe. 



\section{AGRADECIMENTOS}

Ao Prof. Dr. José Reynaldo A. Setti, por toda a orientação fornecida durante a elaboração deste trabalho, pelas palavras de incentivo nas horas difíceis e, principalmente, pela paciência.

Ao Prof. Dr. Laurence R. Rilett, pela receptividade e apoio indispensáveis durante o ano em que freqüentei a Texas A\&M University.

Ao Prof. Dr. Mounir Khalil El Debs e ao Dr. Luciano Maldonado Ferreira, pelas sugestões e ensinamentos transmitidos para que fosse conduzido o estudo de caso.

À CAPES, pela concessão de uma bolsa de doutorado no Brasil e de uma bolsa PDEE no exterior.

Ao CNPq, pela concessão de uma bolsa de doutorado no Brasil.

Às concessionárias de rodovias Triângulo do Sol, AutoBAn, Centrovias e Intervias, pela permissão para que fossem realizadas as coletas de dados e pelo fornecimento de dados essenciais para a pesquisa.

Aos alunos do curso de graduação em Engenharia Civil da EESC-USP que viabilizaram as coletas de dados na SP-310.

Aos colegas e funcionários do Departamento de Transportes da EESC-USP e do Texas Transportation Institute-TAMU que, de alguma forma, contribuíram para o desenvolvimento desta pesquisa.

Aos companheiros de sala, Cíntia Yumiko Egami, Diogo Artur Tocacelli Colella e Flávio Satoshi Utimura, pela ótima convivência e constante troca de informações. Em especial, à Márcia Lika Mon-Ma e André Luiz Barbosa Nunes da Cunha, sem os quais certamente este trabalho não teria sido concluído.

Ao meu noivo, Márcio Augusto de França Corrêa, que percorreu comigo toda essa longa jornada e meu apoiou em todos os momentos. 



\title{
RESUMO
}

\author{
ARAÚJO, J. J. Estudo do impacto de veículos pesados sobre a infra-estrutura rodoviária \\ através de simulação microscópica de tráfego. 2007. 160p. Tese (Doutorado) - Escola \\ de Engenharia de São Carlos, Universidade de São Paulo, São Carlos, 2007.
}

O objetivo desta pesquisa foi desenvolver um método para estabelecer o efeito das características e da operação dos veículos pesados sobre a infra-estrutura rodoviária através do uso de resultados de simulação microscópica de tráfego. Para tanto, foram definidos dois objetivos secundários. $\mathrm{O}$ primeiro deles envolveu a obtenção de um banco de dados detalhado sobre as características de 6.253 veículos pesados. Esses dados foram coletados em sete balanças localizadas em rodovias de pista dupla do estado de São Paulo. O segundo objetivo secundário consistiu na calibração e validação do simulador de tráfego CORSIM com o auxílio de um algoritmo genético, que adaptou simultaneamente 19 parâmetros do simulador para que ele reproduzisse adequadamente as características e o comportamento do tráfego observado em um trecho de rodovia de pista dupla paulista. A metodologia desenvolvida é demonstrada através da realização de um estudo de caso em que foram simulados dois cenários de tráfego e em que foi considerada uma ponte hipotética com 100 m de extensão. Nele, foram determinadas as probabilidades de ocorrências simultâneas dos veículos pesados sobre a ponte. As conclusões da pesquisa indicam que o método de calibração de simuladores de tráfego com uso de um algoritmo genético mostrou-se eficaz, reduzindo o erro médio de $9,11 \%$ para $6,32 \%$. Além disso, as conclusões revelam que a obtenção de um carregamento móvel a partir de dados extraídos de um simulador de tráfego é possível e que a associação dos dados simulados a um banco de dados detalhado permite o cálculo do efeito do tráfego dos veículos pesados sobre a infra-estrutura rodoviária. Do estudo de caso, pode-se concluir que: (1) a probabilidade de ocorrência simultânea de veículos pesados sobre a ponte é muito freqüente e está diretamente relacionada às características do fluxo de tráfego e; (2) a distribuição das cargas e seus respectivos valores são fatores determinantes para o cálculo dos esforços. Os resultados do estudo de caso demonstram a viabilidade do procedimento proposto.

Palavras-chave: Simulação de tráfego; calibração; algoritmo genético; veículos pesados; cargas móveis em pontes. 



\begin{abstract}
ARAÚJO, J. J. Study of heavy vehicles impact on highway infra-structure through microscopic traffic simulation. 2007. 160p. Thesis (Doctoral) - Escola de Engenharia de São Carlos, Universidade de São Paulo, São Carlos, 2007.
\end{abstract}

The objective of this research was to develop a method for establishing the effect of heavy vehicles characteristics and operation on highway infra-structure by using the results of a microscopic traffic simulation model. Therefore, two secondary objectives were defined. The first of them involved the attainment of a detailed database containing the characteristics of 6,253 heavy vehicles. This data was collected at seven weight stations located on the state of São Paulo multilane highways. The other secondary objective was to calibrate and validate CORSIM by using a genetic algorithm, which simultaneously adapted 19 model parameters in order to appropriately reproduce the characteristics and the behavior of the observed traffic flow. The developed methodology is demonstrated through a case study in which two traffic scenarios were simulated and in which a hypothetic $100 \mathrm{~m}$ bridge was considered. In the case study, the probabilities of simultaneous presence of heavy vehicles on the bridge were determined. The conclusions of this research indicate that the method of calibrating a traffic simulation model utilizing a genetic algorithm was efficient, reducing the mean error from $9.11 \%$ to $6.32 \%$. Additionally, the conclusions reveal that the attainment of a live load from extracted data through a traffic simulation model is possible and that the association of simulated data with a detailed database allows the estimation of heavy vehicle traffic effect on highway infra-structure. From the case study, it can be concluded that: (1) the probability of simultaneous presence of heavy vehicles on the bridge is very frequent and; (2) the loads distribution and its respective values are determinant in calculating efforts. The case study results demonstrate the proposed procedure viability.

Keywords: Traffic simulation; calibration; genetic algorithm; heavy vehicles; live load on bridges. 



\section{SUMÁRIO}

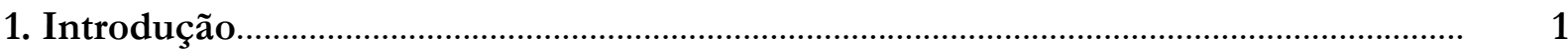

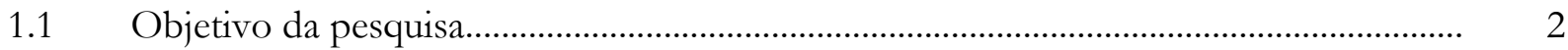

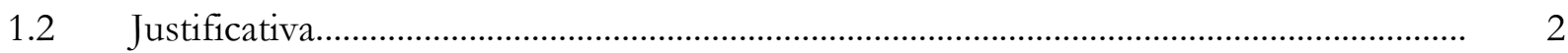

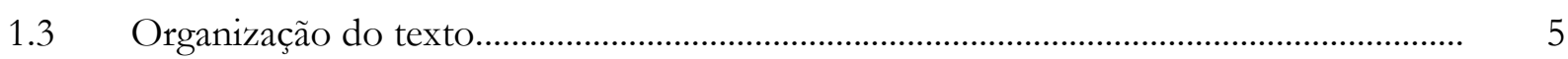

2. Carregamento Móvel para Análise Estrutural de Pontes................................................... 7

2.1 O modelo de Ghosn e Moses.......................................................................................... 8

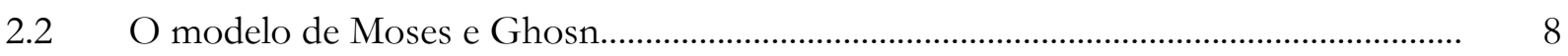

2.3 Os modelos de Nowak................................................................................................

2.4 O modelo de Crespo-Minguillón e Casas........................................................................... 12

$2.5 \quad$ O estudo de Hwang e Koh.................................................................................................. 13

2.6 O estudo de Ferreira...................................................................................................... 14

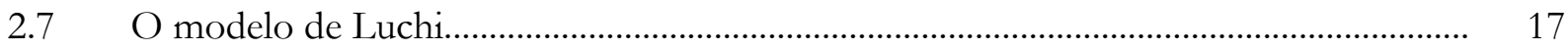

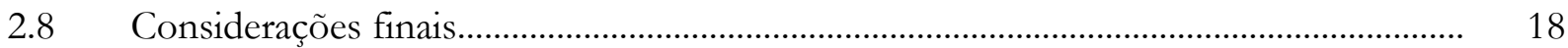

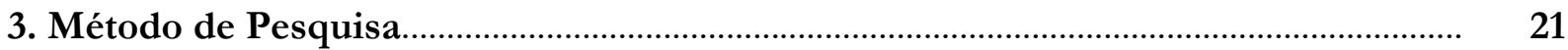

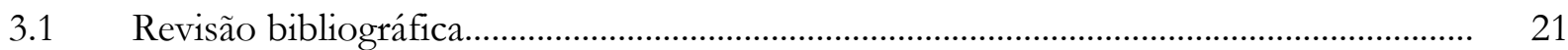

3.2 Estudo do modelo de simulação CORSIM e determinação do procedimento para

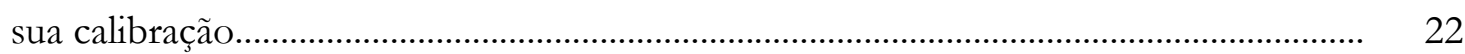

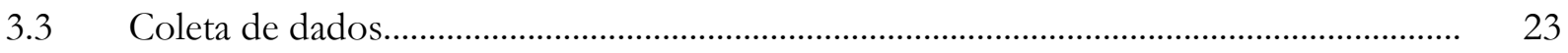

3.4 Calibração e validação do CORSIM............................................................................... 23

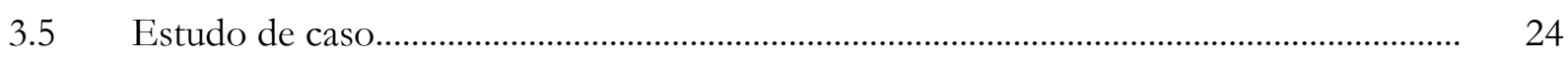

4. O Modelo de Simulação CORSIM..................................................................................... 25

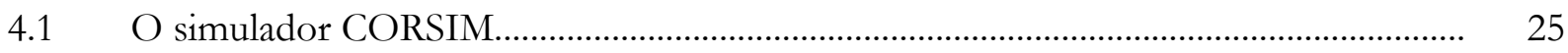

4.2 Codificação de uma rede de transportes no CORSIM....................................................... 27

4.3 Dados de entrada relacionados à oferta............................................................................. 28

4.4 Dados de entrada relacionados à demanda.......................................................................... 28

4.5 Dados de saída............................................................................................................... 30

4.6 Descrição da rede simulada no CORSIM............................................................................ 30

4.7 Parâmetros de calibração do CORSIM.............................................................................. 32

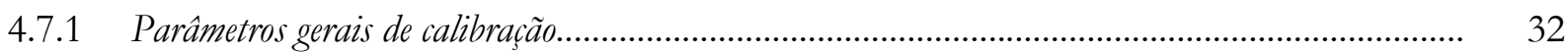

4.7.1.1 Fatores de sensibilidade para a lógica do car-following................................................................. 33 


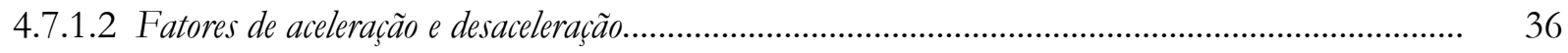

4.7.1.3 Fatores de mudança de faixa.................................................................................................... 36

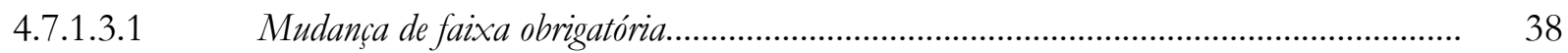

4.7.1.3.2 Mudança de faixa arbitrária ...................................................................................... 39

4.7.1.3.3 Mudança de faixa antecipatória................................................................................... 43

4.7.2 Parâmetros de calibração por tipo de veículo................................................................................ 43

4.7.2.1 Desaceleração máxima não emergencial....................................................................................... 44

4.7.2.2 Características da velocidade e da aceleraşão...................................................................................

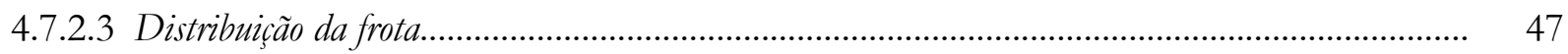

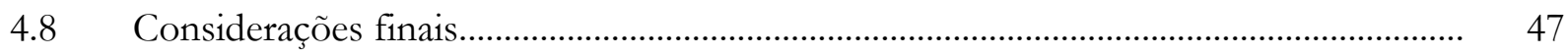

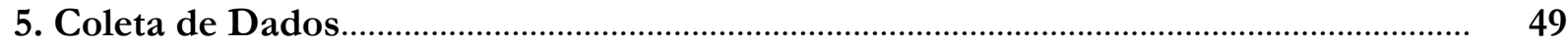

5.1 Dados para caracterização do tráfego e estimativa da matriz origem/destino............... 50

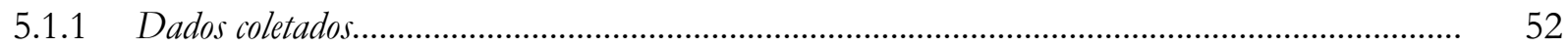

5.1.1.1 Fluxo de tráfego..................................................................................................................

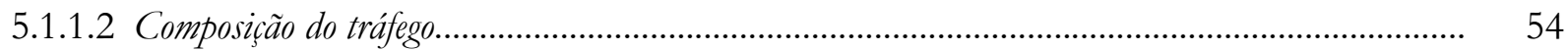

5.1.1.3 Matriz, origem/ destino............................................................................................................ 56

5.1.1.4 Velocidade média da corrente de tráfego................................................................................... 59

5.2 Dados sobre as características dos veículos pesados.......................................................... 61

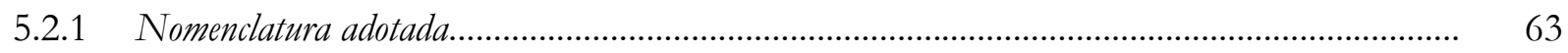

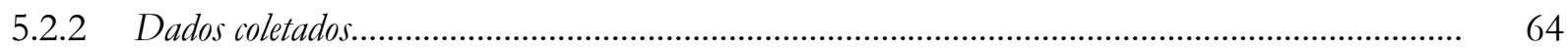

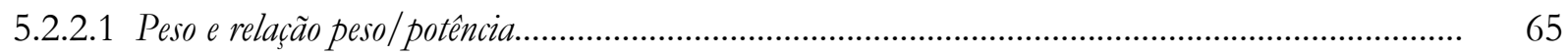

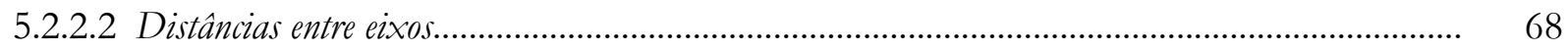

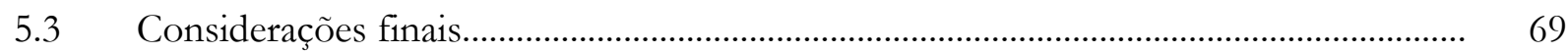

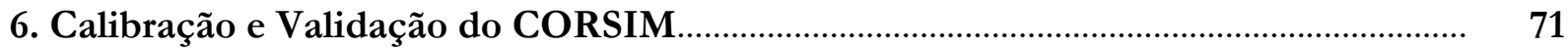

6.1 Definição dos termos “calibração" e "validação"................................................................ 71

6.2 Calibração manual versus calibração automática..................................................................... 73

6.3 Calibração automática usando algoritmo genético................................................................ 74

6.3.1 Método de calibração....................................................................................................

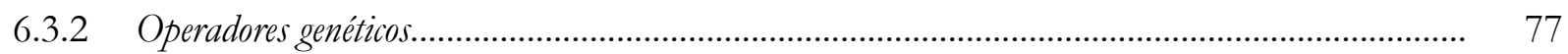

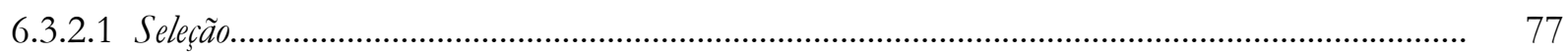

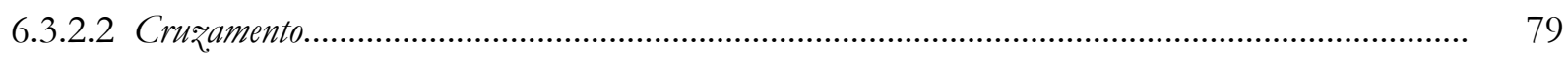

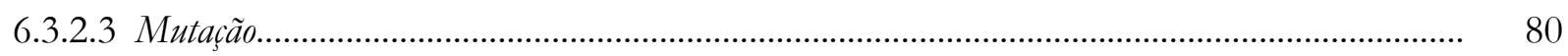

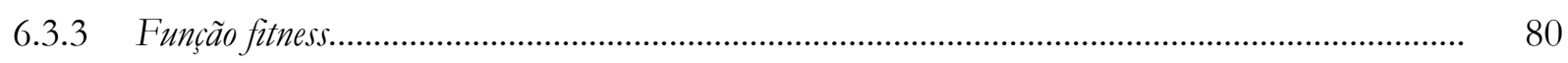

6.3.4 Codificação do algoritmo genético............................................................................................. 82 
6.4 Algoritmo genético para calibração do CORSIM................................................................. 83

6.4.1 Escolha das medidas de desempenho......................................................................................... 84

6.4.2 Escolha dos parâmetros do modelo a serem calibrados...............................................................

6.4.3 Escolha dos parâmetros do algoritmo genético.............................................................................. 89

6.5 Resultado da calibração................................................................................................... 90

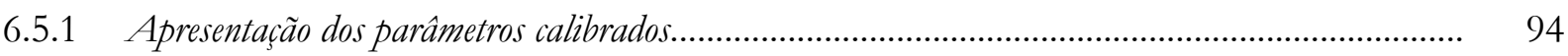

6.6 Validação do modelo calibrado para a rede estudada............................................................ 96

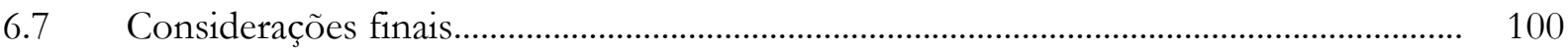

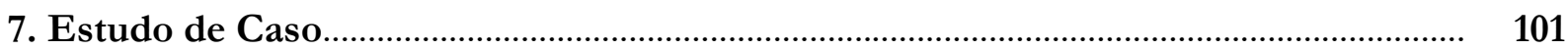

7.1 Definição dos cenários simulados....................................................................................... 101

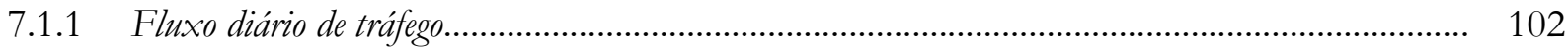

7.1.2 Localização da ponte na rede de tráfego...................................................................................... 105

7.2 Extração de dados do CORSIM.......................................................................................... 105

7.3 Definição do número de dias simulados............................................................................... 110

7.4 Probabilidades de ocorrência............................................................................................... 112

7.5 Efeito do tráfego de veículos pesados sobre a ponte.......................................................... 113

7.5.1 Carga móvel da NBR-7188.............................................................................................. 113

7.5.1.1 Momento fletor máximo causado pelo trem-tipo........................................................................... 115

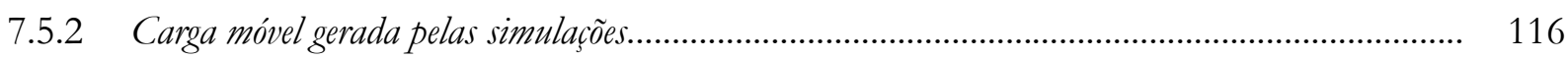

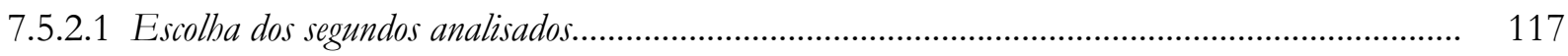

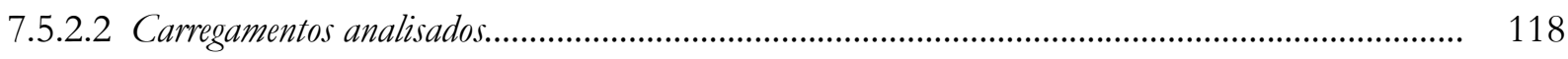

7.5.2.3 Momento fletor máximo causado pelos veículos simulados.............................................................. 123

7.6 Considerações finais...................................................................................................... 124

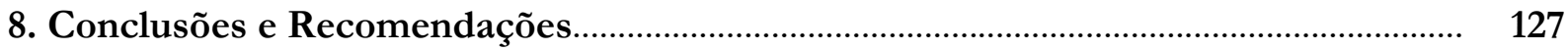

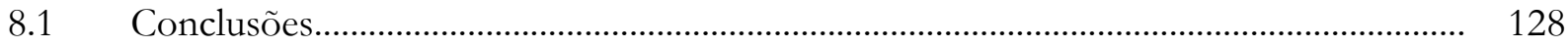

8.1.1 Calibração do modelo de simulação.......................................................................................... 128

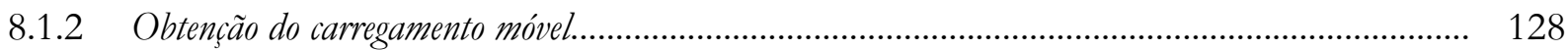

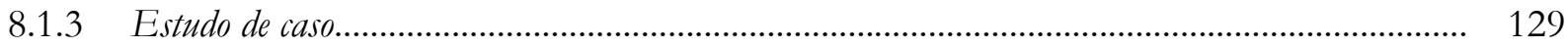

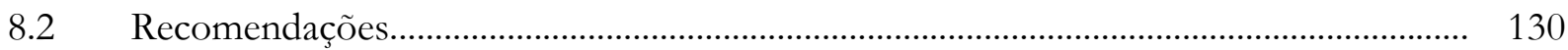

Referências Bibliográficas.................................................................................................... 133

Apêndice A 



\section{Introdução}

Segundo a Confederação Nacional do Transporte (2006), no ano de 2005 o transporte de 47,5\% da carga brasileira foi feito pelo modo rodoviário, com mais de 790 milhões de toneladas transportadas por uma frota que ultrapassa os dois milhões de veículos pesados. Esses veículos trafegam por uma malha rodoviária de cerca de 1,6 milhões de quilômetros (DENATRAN, 2006).

A importância do transporte rodoviário para a economia do Brasil é evidente. Diante de um cenário em que quase metade de toda a produção nacional é transportada através de rodovias, os veículos pesados desempenham um papel relevante, suscitando a necessidade de analisar o impacto que eles ocasionam não somente em termos de operação, como também no projeto e manutenção da infra-estrutura rodoviária.

De forma geral, as leis que regulamentam os pesos e as dimensões dos veículos pesados visam reduzir o impacto provocado pelo seu tráfego. Na fase de projeto da infra-estrutura rodoviária, fatores tais como largura de faixas de rolamento, extensão de faixas de aceleração/desaceleração, alinhamento horizontal e vertical de curvas e espessura do pavimento estão diretamente relacionados às características dos veículos pesados. Na fase de manutenção, essas características estão ligadas principalmente aos desgastes dos pavimentos e pontes (TRB, 2002).

Um aspecto a ser notado é que o constante desenvolvimento da indústria de transporte rodoviário e o conseqüente aumento das cargas transportadas pelos veículos podem ocasionar des- 
gastes maiores do que os previstos tanto para a pavimentação quanto para as obras de arte especiais (ponte e viadutos). Portanto, é desejável aperfeiçoar a determinação de como a ação do carregamento móvel (tráfego) é levada em consideração durante o processo de dimensionamento da infra-estrutura rodoviária.

\subsection{Objetivo da pesquisa}

A meta principal desta pesquisa é desenvolver uma metodologia para estabelecer o efeito das características e da operação dos veículos pesados sobre a infra-estrutura rodoviária através do uso de resultados de simulação microscópica de tráfego. Para tanto, foram estabelecidos dois objetivos secundários:

- Aquisição de um conjunto de dados com amostra de tamanho significativo sobre as diversas características de veículos pesados; e

- Obtenção de um modelo de simulação de tráfego calibrado para um trecho de rodovia de pista dupla.

A metodologia proposta combina esses dois aspectos na medida em que associa dados microscópicos extraídos de um simulador a um banco de dados detalhado sobre as características dos veículos pesados para obter um carregamento móvel decorrente do tráfego desses veículos.

Para demonstrar como a metodologia desenvolvida pode ser utilizada, efetuou-se um estudo de caso que calculou o momento fletor ocasionado pela presença simultânea de veículos pesados sobre uma ponte, a fim de compará-lo com o provocado pelo trem-tipo normativo.

\subsection{Justificativa}

O dimensionamento de pontes leva em conta vários fatores, sendo a ação do tráfego um dos mais significativos. O valor real do carregamento do tráfego é considerado difícil de modelar de uma forma precisa devido à sua aleatoriedade e, por isso, os engenheiros estruturais costumam fazer várias simplificações para tornar essa tarefa possível (Crespo-Minguillón e Casas, 1997).

De acordo com a norma brasileira (NBR-7188), a ação das cargas móveis no processo de análise estrutural de pontes não corresponde aos veículos reais que trafegam sobre as mesmas, 
mas a um carregamento hipotético que tenta reproduzir as solicitações provocadas pelo tráfego. Esse carregamento consta de um veículo-tipo de peso e geometria estabelecidos pela própria norma e de cargas uniformemente distribuídas. A esse carregamento total dá-se o nome de tremtipo (Santos, 2003).

Segundo Santos (2003), a maior parte das pontes rodoviárias brasileiras foi construída entre 1960 e 1970, época em que o Brasil experimentou o seu maior desenvolvimento na construção da malha rodoviária. A norma então em vigência, NB-6 - Cargas Móveis em Pontes Rodoviárias, previa como cargas de projeto veículos-tipo em que o peso bruto total máximo permitido era de $360 \mathrm{kN}$ (ABNT, 1960).

Em 1984, com a publicação da NBR-7188 - Carga Móvel em Ponte Rodoviária e Passarela de Pedestres, o peso bruto total máximo considerado para os veículos-tipo sofreu uma alteração e foi estabelecido em $450 \mathrm{kN}$ (ABNT, 1984).

A norma NBR-7188 especifica três classes de pontes rodoviárias: 45, 30 e 12. A utilização das diferentes classes fica a critério dos órgãos com jurisdição sobre a via, já que não é definida na norma. De forma geral, nas principais vias rurais e urbanas as pontes são projetadas para a classe 45, sendo as demais classes utilizadas apenas em rodovias secundárias (Luchi, 2006).

Em cada uma das classes de pontes é considerado um veículo-tipo, sendo o peso bruto total desse veículo de $450 \mathrm{kN}$ para a ponte de classe 45, $300 \mathrm{kN}$ para a classe 30 e $120 \mathrm{kN}$ para a classe 12. Nas classes 45 e 30, o veículo-tipo é composto por três eixos simples, espaçados de $1,5 \mathrm{~m}$ e com o peso bruto total dividido igualmente em cada uma das seis rodas. $\mathrm{Na}$ classe 12 , o veículo-tipo possui dois eixos simples espaçados de 3,0 m, com cada uma das duas rodas dianteiras pesando $20 \mathrm{kN}$ e cada uma das duas rodas traseiras pesando $40 \mathrm{kN}$. Em todas as classes, o veículo-tipo possui 6,0 $\mathrm{m}$ de comprimento e 3,0 $\mathrm{m}$ de largura.

A NBR-7188 prevê que, além do veículo-tipo, a carga móvel nas pontes rodoviárias também deve ser constituída por cargas $q$ e q’ uniformemente distribuídas. A carga $q$ é aplicada em todas as faixas da pista de rolamento, nos acostamentos e afastamentos, descontando-se apenas a 
área ocupada pelo veículo. Ela varia entre $4 \mathrm{kN} / \mathrm{m}^{2}$ e $5 \mathrm{kN} / \mathrm{m}^{2}$, de acordo com a classe da ponte. A carga q'é aplicada nos passeios e possui um valor de $3 \mathrm{kN} / \mathrm{m}^{2}$, independente da classe da ponte. Essas cargas são fictícias e procuram levar em consideração a ação de multidão e de outros veículos mais leves ou mais afastados das zonas onde as cargas produzem maiores esforços solicitantes, com um esquema de carregamento mais cômodo para o cálculo (El Debs e Takeya, 1995).

Um fato importante a ser observado é que, apesar das combinações de carga apresentadas tanto na NB-6 quanto na NBR-7188 terem como objetivo reproduzir as solicitações provocadas pelo tráfego real sobre as pontes, em nenhuma delas é prevista a passagem simultânea de dois ou mais veículos-tipo, ao contrário do que acontece nas situações reais de carregamento. Além disso, com base em pesquisas realizadas na Alemanha, pode-se afirmar que durante o processo de consideração do carregamento móvel em uma ponte, as variáveis mais desfavoráveis são aquelas que contemplam o tráfego simultâneo de mais de um veículo pesado (Santos, 2003).

Logo, o que se pode perceber é que, por um lado, a norma brasileira mostra-se bastante conservadora, levando em conta para efeito de dimensionamento de pontes veículos pesados que não representam a frota que efetivamente circula nas rodovias do país e sim veículos-tipo com elevadas cargas concentradas muito próximas entre si. Em contrapartida, pode-se dizer que o valor da carga $q$ uniformemente distribuída pode não ser suficiente para representar as solicitações de carregamento decorrentes da existência de outros veículos pesados sobre a ponte.

Dessa forma, esta pesquisa propõe como ferramenta de análise o uso de um modelo de simulação de tráfego capaz de representar adequadamente os fluxos observados em campo e que possua um bom nível de detalhamento. Os resultados da simulação fornecem dados importantes, como a probabilidade de ocorrência simultânea de veículos pesados na ponte e a posição relativa desses veículos. A associação dessas informações a um banco de dados que contém as características dos veículos pesados (tais como pesos por eixo e distâncias entre eixos) permite obter os carregamentos totais nas pontes e as localizações dessas cargas de uma forma mais realística, uma vez que leva em consideração os efeitos da composição do tráfego e da mecânica de car-following 
sobre o espaçamento e o headway entre veículos na corrente de tráfego. Portanto, o método proposto é uma contribuição inovadora para a análise das cargas móveis, uma vez que elimina os problemas que podem advir de algumas das simplificações comumente adotadas pelos engenheiros estruturais neste processo.

A hipótese adotada nesta tese é a de que é possível analisar o impacto ocasionado pelo tráfego de veículos pesados sobre componentes da infra-estrutura rodoviária a partir da obtenção de um carregamento móvel que associa dados extraídos de um modelo de simulação microscópica de tráfego a um banco de dados detalhado sobre as características desses veículos.

\subsection{Organização do texto}

Este texto está organizado em oito capítulos. O Capítulo 1 é essa introdução, que apresenta o objetivo da pesquisa e uma justificativa para o seu desenvolvimento. O Capítulo 2 versa sobre o carregamento móvel para a análise estrutural de pontes. O Capítulo 3 descreve o método de pesquisa adotado, enquanto o Capítulo 4 trata do modelo de simulação CORSIM.

O Capítulo 5 relata as coletas de dados realizadas e apresenta os dados coletados. Os procedimentos de calibração e validação do CORSIM são descritos no Capítulo 6. O Capítulo 7 apresenta um estudo de caso que demonstra a aplicação do método proposto e o Capítulo 8 contém as conclusões e recomendações da pesquisa. 



\section{Carregamento Móvel para Análise Estrutural de Pontes}

O projeto de componentes estruturais das pontes deve considerar todas as cargas às quais elas podem ser submetidas ao longo de sua vida útil. Essas cargas são derivadas de três tipos de ações: ações permanentes, ações variáveis e ações excepcionais (ABNT, 1986).

Dentre as ações variáveis, as cargas móveis (que provêm do tráfego de veículos) representam a contribuição mais significativa na análise estrutural das pontes. A ação do tráfego também é considerada o efeito mais importante para a análise da fadiga de pontes com vãos pequenos e médios (Crespo-Minguillón e Casas, 1997).

Apesar da sua importância, considera-se que o valor real do carregamento do tráfego nas pontes é difícil de modelar de uma forma precisa devido à sua aleatoriedade (Crespo-Minguillón e Casas, 1997). Por isso, foram desenvolvidos alguns modelos que tratam do carregamento móvel na análise estrutural de pontes.

Este capítulo apresenta uma revisão sobre os principais modelos e estudos realizados sobre o assunto. De forma geral, eles se baseiam na teoria dos processos estocásticos, na concepção de configurações estáticas do tráfego ou na simulação do fluxo de tráfego. 


\subsection{O modelo de Ghosn e Moses}

Ghosn e Moses (1985) propuseram um modelo para calcular o máximo efeito do tráfego para uma determinada vida útil da ponte. Eles destacam que a teoria dos processos estocásticos pode ser uma ferramenta muito útil para a análise de estruturas submetidas a carregamentos aleatórios.

A técnica utilizada no modelo se baseia em um processo de renovação de Markov, capaz de ser adaptado tanto para representar o padrão de chegada de caminhões à ponte (medido ou idealizado) quanto para representar as características dos caminhões (pesos e espaçamento dos eixos). Nesse modelo, todas as possíveis localizações dos caminhões na ponte e seus pesos são testados.

Segundo os autores, as principais restrições do modelo estão relacionadas ao fato de que, nele, as características dos caminhões são independentes da seqüência de chegadas dos veículos à ponte.

Ghosn e Moses (1985) sugerem que para vãos grandes os caminhões devem ser considerados como cargas pontuais, mas para vãos pequenos e médios (menores que 150 m), o comprimento do veículo e a sua distribuição de carga pelos eixos são importantes. Moses e Ghosn (1985) fornecem maiores informações sobre o processo de renovação de Markov.

\subsection{O modelo de Moses e Ghosn}

Em Moses e Ghosn (1985) são desenvolvidos programas de simulação para o estudo do carregamento de caminhões em pontes de vãos pequenos e médios. Nesses programas, a superfície da ponte é dividida em regiões e um evento de carregamento ocorre quando há pelo menos um caminhão em qualquer uma das regiões. $O$ primeiro caminhão que chega à ponte e que faz parte de um evento de carregamento é chamado de caminhão principal, cuja probabilidade de estar em uma certa faixa de tráfego é obtida a partir das estatísticas do tráfego para a localidade. Por exemplo, o estudo cita que na rodovia de pista dupla I-90, no estado americano de Ohio, $83 \%$ dos caminhões viajam pela faixa da direita. 
As possíveis combinações de veículos são obtidas e associadas a uma probabilidade de ocorrência, calculada a partir de dados de campo, que podem ser conseguidos, por exemplo, através de pesagens em movimento (weight-in-motion). Essa probabilidade está associada à localidade $\mathrm{e}$ ao fluxo de tráfego. Devido ao fato de as medidas de campo se restringirem às rodovias com duas faixas de tráfego, os resultados obtidos por Moses e Ghosn (1985) são válidos apenas para pontes de rodovias de pista dupla.

De acordo com os autores, na I-90, se um caminhão está na faixa da direita, a probabilidade de um outro caminhão também estar na faixa da direita é de $83,5 \%$. E, se um caminhão estiver na faixa da direita e existir um outro caminhão na faixa da esquerda, a probabilidade de eles estarem lado a lado é de 5,8\%.

Moses e Ghosn (1985) consideram apenas dois tipos de caminhões nos eventos de carregamento. Dependendo do tipo, cada caminhão é associado a um peso e a uma probabilidade obtida dos histogramas de peso bruto. Com as posições dos caminhões e o peso deles, o máximo efeito é calculado e associado a uma probabilidade. Esse procedimento assume que tanto as posições relativas dos caminhões e os pesos brutos quanto os pesos brutos dos diferentes caminhões são independentes.

Assim, o cálculo do esforço na seção mais solicitada é feito para todas as combinações de caminhões na ponte e para todos os pesos dos caminhões. Seguindo essa metodologia, é obtido um histograma que fornece o efeito (por exemplo, momento fletor) associado a sua probabilidade.

Em geral, considera-se uma vida útil de projeto para as pontes de 50 ou 75 anos, embora Moses e Ghosn (1985) demonstrem que o máximo efeito atinge um valor limite com aproximadamente 25 anos, mantendo-se praticamente inalterado a partir daí.

\subsection{Os modelos de Nowak}

Nowak é um dos autores que mais dispõe de trabalhos sobre modelagem de cargas móveis (Luchi, 2006). Em seu primeiro trabalho que aborda o assunto, são utilizados dados de uma ins- 
peção no tráfego de caminhões realizada em 1975 pelo Ministério do Transporte de Ontário (Canadá), cuja amostra era de cerca de 10 mil caminhões. Nessa base de dados foram incluídos apenas caminhões que pareciam possuir elevado peso bruto (Nowak e Lind, 1979).

Os momentos fletores foram calculados para cada um dos veículos observados em campo para que pudesse ser feita uma comparação com os momentos relativos à norma do Departamento de Ontário, com extrapolação para 50 anos de vida útil.

Em outro estudo que utiliza os mesmos dados de Ontário, Nowak e Hong (1991) criaram um método para a verificação da norma americana. Segundo os autores, na época, as características da população de caminhões de Ontário eram consideradas similares às dos caminhões que circulavam nos Estados Unidos. Esse trabalho calcula os momentos fletores considerando uma distribuição normal para as probabilidades.

Segundo Nowak e Hong (1991), para pontes com uma faixa de tráfego, o máximo efeito (momento fletor ou força cortante) é causado por um caminhão isolado ou por dois (ou mais) caminhões em fila. No caso de múltipla presença, é necessário o conhecimento da distância entre os veículos e a relação entre seus pesos. Por exemplo, os autores alertam que os caminhões podem possuir similaridades (pertencerem a uma mesma empresa, com a mesma configuração de eixos e carga similar), podem viajar em grupos e, portanto, podem ser altamente correlacionados quanto ao peso. Salienta-se que grau de correlação é entendido como o grau de dependência linear entre duas variáveis aleatórias. Os coeficientes de correlação $(\rho)$ adotados pelo modelo são:

- $\rho=0$, se não há correlação entre dois caminhões subseqüentes;

- $\rho=0,5$, se há correlação parcial entre dois caminhões subseqüentes; e

- $\rho=1$, se há correlação total entre dois caminhões subseqüentes.

As seguintes hipóteses foram assumidas no modelo com base em observações e julgamento técnico: 
- A cada 10 caminhões, um caminhão é seguido por outro a uma distância inferior a $15 \mathrm{~m}$;

- A cada 50 caminhões, um caminhão é seguido por outro com correlação parcial de peso; e

- A cada 100 caminhões, um caminhão é seguido por outro com correlação total de peso.

Os momentos fletores máximos foram calculados e os resultados indicaram que para vãos únicos, um caminhão isolado é crítico para comprimentos de até $40 \mathrm{~m}$. Para vãos maiores, dependendo do espaçamento entre os veículos, o caso de dois caminhões totalmente correlacionados é o mais crítico.

Para pontes com duas faixas de tráfego, considerou-se que:

- A cada 50 caminhões, um caminhão está na ponte simultaneamente com outro (lado a lado);

- Considerando as ocorrências simultâneas, a cada 50 vezes os caminhões são parcialmente correlacionados e a cada 10 vezes eles estão totalmente correlacionados com relação ao peso.

Os resultados indicaram que o caso com dois caminhões totalmente correlacionados lado a lado é crítico.

Em Nowak (1993), o autor utiliza os mesmos dados de 1975 em Ontário e analisa novamente obras isostáticas, incluindo em suas análises os momentos negativos em vigas contínuas. Os coeficientes de correlação entre os veículos adotados são os mesmos de Nowak e Hong (1991) e as conclusões são similares.

De acordo com Nowak (1999), são várias as incertezas na análise do carregamento móvel devido às limitações nos dados obtidos do tráfego. Entre elas estão: o pequeno número da amostra de caminhões estudada (comparada com o número real de caminhões durante a vida útil), a evasão de alguns caminhões sobrecarregados das estações de pesagens e o desconhecimento das tendências futuras das distribuições de pesos e eixos. 
Em Nowak (1999) admite-se que a legislação quanto aos pesos e dimensões dos veículos pesados não sofrerá alteração com o passar dos anos e que a população de caminhões irá permanecer inalterada. Nesse estudo, para cada caminhão da amostra são calculados os momentos fletores e as forças cortantes. Nele, são considerados vãos simplesmente apoiados e dois vãos idênticos contínuos.

\subsection{O modelo de Crespo-Minguillón e Casas}

Segundo Crespo-Minguillón e Casas (1997), os modelos de carregamento móvel existentes não são completos, uma vez que são orientados para a previsão dos efeitos máximos em um período de tempo definido ou para a definição dos efeitos de fadiga. De acordo com os autores, as suposições e as simplificações adotadas em modelos que tentam tratar das duas possibilidades não os tornam suficientemente confiáveis. Essas simplificações estão relacionadas principalmente às ferramentas computacionais utilizadas e aos dados de tráfego necessários para a análise (Crespo-Minguillón e Casas, 1997).

Assim, Crespo-Minguillón e Casas (1997) concluem que um modelo completo, válido para todo efeito de carregamento (carregamento máximo em um período de referência, fadiga, carregamento freqüente para a verificação dos estados limites de utilização) e que considere as variáveis mais importantes presentes no tráfego real, não está disponível.

Dessa forma, os autores desenvolveram um modelo para o estudo da ação do tráfego nas pontes com os seguintes objetivos:

- Disponibilizar um modelo amplo, válido para a análise dos estados limites último e de serviço mais importantes, além do estado limite de fadiga. Esta meta é atingida através da simulação do efeito do fluxo real de tráfego sobre a ponte em função do tempo e da extrapolação dos máximos resultados obtidos na simulação para valores máximos representativos de longos períodos de retorno; 
- Incluir as correlações mais importantes existentes no tráfego real: correlações entre veículos em uma faixa, entre diferentes faixas, entre o dia da semana e as condições do tráfego, entre os tipos dos veículos, etc.;

- Ser adaptável às características específicas de uma certa localidade;

- Dispensar grandes quantidades de dados sobre o fluxo real de tráfego;

- Proibir sobreposição de veículos;

- Possibilitar a análise do efeito do carregamento em pontes de vão pequeno, médio e grande.

Nesse modelo, o efeito do tráfego sobre a ponte é simulado a cada 0,20 segundos durante uma semana. A simulação é feita através de um algoritmo que gera fluxos de tráfego que representam situações muito próximas do tráfego real (Crespo-Minguillón e Casas, 1997).

Dentre os diversos modelos de carregamento móvel existentes, o trabalho de CrespoMinguillón e Casas (1997) é considerado o mais completo e abrangente, revelando o grande potencial dos modelos de simulação do tráfego para a análise estrutural de pontes.

\subsection{O estudo de Hwang e Koh}

Hwang e Koh (2000) utilizam como base para o desenvolvimento de seu estudo dados de pesagem em movimento em três localidades. No total, o trabalho dispõe de aproximadamente 100 mil pesagens. Os dados sobre múltipla presença de veículos sobre as pontes foram obtidos através de gravações em vídeo. Foram considerados na análise apenas os tipos de caminhões mais pesados e que aparecem em maior número; os demais foram desprezados. No total, foram considerados sete tipos de caminhões.

Utilizando regressão linear e considerando a relação entre o número de caminhões observados e o previsto para a vida útil da estrutura (75 anos), os máximos pesos brutos foram extrapolados. Esse procedimento é similar ao utilizado por Nowak (1999).

Os maiores pesos brutos provenientes da extrapolação para cada tipo de caminhão foram usados para o cálculo de máximos momentos fletores em estruturas simplesmente apoiadas. A 
presença simultânea de veículos foi considerada apenas em uma mesma faixa e quando a distância entre eles era igual ou menor a $15 \mathrm{~m}$. No entanto, no cálculo dos momentos fletores os veículos foram dispostos a $5 \mathrm{~m}$ de distância um do outro. As probabilidades de ocorrência de presença simultânea consideradas em Hwang e Koh (2000), obtidas através de gravações em vídeo, são apresentadas na Tabela 2.1 .

Tabela 2.1 - Probabilidade de ocorrência de dois caminhões na mesma faixa de tráfego

\begin{tabular}{ccc}
\hline \multirow{2}{*}{ Pesos } & \multicolumn{2}{c}{ Condições de Tráfego } \\
\cline { 2 - 3 } & Normal & Congestionado \\
\hline Não correlacionados & $1 / 85$ & $1 / 37$ \\
Correlação total & $1 / 403$ & $1 / 207$ \\
\hline
\end{tabular}

Utilizando essas probabilidades juntamente com a porcentagem de cada veículo e a vida útil desejada, a extrapolação dos pesos brutos permite o cálculo dos momentos fletores para o caso dos pesos não correlacionados e dos pesos com correlação total. No primeiro caso, o caminhão principal é seguido por um caminhão com peso médio e no segundo caso os caminhões possuem pesos iguais.

Os resultados demonstram que um único caminhão produz o máximo esforço para vãos pequenos e dois caminhões com correlação total de peso governam no caso de vãos maiores.

Os autores sugerem uma combinação de caminhão e carga distribuída para a obtenção dos esforços em projetos (normas), mas ressaltam que a carga distribuída deve ter sua magnitude diminuída com o aumento do vão, de modo que os momentos fletores calculados não superestimem o efeito do tráfego real. Eles recomendam ainda que os dados do tráfego sejam obtidos em diferentes localidades devido à sua elevada variabilidade.

\subsection{O estudo de Ferreira}

No Brasil, Ferreira (2006) realizou um estudo sobre o carregamento móvel que utiliza dados de balanças rodoviárias coletados entre 2001 e 2002 nas rodovias SP-310 e SP-225. Nesse estudo são utilizados somente os caminhões que aparecem com maior carga e em maior número nas planilhas de pesagem, mesmo procedimento adotado por Hwang e Koh (2000). O autor con- 
sidera que a não inclusão de todos os caminhões na análise não traz prejuízo ao trabalho, uma vez que ele utiliza veículos críticos e representativos da amostra. No total, cinco configurações de caminhões são analisadas.

Inicialmente são feitas extrapolações das cargas brutas totais para alguns veículos. Nessa extrapolação, que adota o método desenvolvido por Nowak (1999), são considerados somente os 100 caminhões mais pesados da amostra. As situações analisadas são as de um caminhão isolado e a presença simultânea de dois ou três caminhões na ponte.

Ferreira (2006) lembra que a análise de dois caminhões sobre as pontes requer a determinação de sua posição relativa e da proporção entre seus pesos e que dados estatísticos brasileiros sobre a probabilidade da ocorrência simultânea sobre as pontes não estão disponíveis. Ele ressalta ainda que a obtenção desse tipo de dados é bastante trabalhosa, justificando a opção de usar probabilidades de ocorrência simultânea obtidas por pesquisadores estrangeiros.

Assim, a probabilidade de ocorrência simultânea de dois caminhões sobre a ponte foi adotada com base nos trabalhos de Hwang e Koh (2000) e Nowak (1999), assumindo que não existe correlação entre os pesos dos veículos. As probabilidades adotadas em Ferreira (2006) estão contidas na Tabela 2.2. As pontes de tabuleiro estreito (TE) representam rodovias de pista simples e as de tabuleiro largo (TL), rodovias de pista dupla.

Tabela 2.2 - Probabilidade de ocorrência simultânea adotada por Ferreira (2006)

\begin{tabular}{ccccc}
\hline \multirow{2}{*}{ Cenário } & \multicolumn{2}{c}{ Caminhões em Fila } & \multicolumn{2}{c}{ Caminhões Lado a Lado } \\
\cline { 2 - 5 } & TE & TL & TE & TL \\
\hline 1 & $1 / 75$ & $1 / 75$ & $1 / 50$ & $1 / 75$ \\
2 & $1 / 500$ & $1 / 500$ & $1 / 500$ & $1 / 500$ \\
\hline
\end{tabular}

No caso dos caminhões em fila, duas alternativas foram verificadas por Ferreira (2006):

1. Distância entre os caminhões igual a $5 \mathrm{~m}$ ou $10 \mathrm{~m}$; e

2. Distância entre os caminhões variando entre $15 \mathrm{~m}$ e $30 \mathrm{~m}$, com incrementos de $5 \mathrm{~m}$.

O autor lembra que a literatura não faz referência à probabilidade da presença de três ou mais caminhões sobre as pontes e afirma que a sua incidência é considerada muito baixa e de 
difícil investigação. Além disso, ele ressalta que esse caso é pertinente apenas em pontes longas e/ou pontes com várias faixas de tráfego e, em se tratando de pontes longas, o peso próprio é predominante e o efeito da carga móvel torna-se secundário.

Assim, Ferreira (2006) considera que o caso de três ou mais caminhões não é imprescindível para a análise do carregamento móvel e que a segurança das pontes pode ser confiavelmente medida através do posicionamento de apenas um ou dois veículos. Entretanto, a autor faz uma análise complementar em que insere um terceiro caminhão em pontes de tabuleiro largo.

Com base na teoria da confiabilidade, Ferreira (2006) desenvolve equações para a verificação da compatibilidade de veículos críticos com as obras de arte analisadas no trabalho. Essas equações são chamadas de ECPLs (equações comprimento-peso limite) e têm o mesmo propósito da bridge formula americana, que é impor limites para o peso de um grupo de dois ou mais eixos. Ferreira (2006) afirma que, mesmo sendo considerada excessivamente restritiva, a bridge formula (apresentada na Equação 2.1) é bastante conveniente e de fácil uso, pois determina o peso máximo em função da distância entre o grupo de eixos.

$$
W=2,224 \cdot\left[\frac{B \cdot N}{0,3048(N-1)}+12 \cdot N+36\right]
$$

em que: $\quad W$ : peso bruto total para qualquer grupo de dois ou mais eixos consecutivos $(\mathrm{kN})$;

B: $\quad$ comprimento do grupo de eixos consecutivos (m); e

$N$ : número de eixos do grupo em análise.

As equações propostas por Ferreira (2006) se dividem em função da classe da ponte (36 ou 45) e do estado limite (último ou de serviço). As equações 2.2 e 2.3 se referem à análise do estado limite último, enquanto as equações 2.4 e 2.5, ao estado limite de serviço.

$$
\begin{aligned}
& W_{36}=23,9 \cdot B+195,1 \\
& W_{45}=26,2 \cdot B+233,9 \\
& W_{36}=20,2 \cdot B+319,1
\end{aligned}
$$




$$
W_{45}=20,1 \cdot B+213,6
$$

em que: $\quad W$ máximo peso bruto para qualquer grupo eixos consecutivos $(\mathrm{kN})$; e

B: $\quad$ comprimento do grupo de eixos (m).

\subsection{O modelo de Luchi}

Luchi (2006) apresenta um modelo para a verificação do trem-tipo de projeto de pontes e viadutos da norma brasileira a partir de dados de pesagens e de fluxos de tráfego de uma rodovia de pista dupla (SP-310). O modelo é baseado em simulações das passagens e cargas de veículos através do método de Monte Carlo.

Nesse estudo, são efetuadas análises de pontes com vãos de 20 m a 300 m, sendo calculados os momentos fletores no meio do vão e as forças cortantes adjacentes aos apoios para as estruturas isostáticas e os momentos fletores no apoio central de pontes contínuas de dois vãos. O estudo dá uma maior ênfase às situações de congestionamento sobre a ponte e são feitas extrapolações estatísticas para a obtenção dos esforços característicos, levando em conta as diferentes situações de tráfego possíveis.

O modelo de Luchi (2006) consiste em gerar, por simulação de Monte Carlo, carregamentos aleatórios que podem ocorrer ao longo da vida útil da estrutura, através das distribuições de probabilidade de passagem e de pesos para cada uma das categorias de veículos. Os esforços solicitantes característicos são obtidos da extrapolação da distribuição de máximos anuais. O estudo considera 19 configurações de eixos para os caminhões, obtidas a partir de 121.078 pesagens.

O autor destaca que existem diversas variáveis aleatórias para o problema analisado, entre elas: probabilidade de passagem diária de veículos, distância entre os eixos dos veículos, cargas dos eixos dos veículos e distância entre os veículos. Assim, em virtude da grande diversidade nas variáveis citadas, Luchi (2006) adota valores determinísticos para todas elas. Além disso, são feitas as seguintes considerações como forma de simplificação: 
- As distâncias entre eixos têm como base a média dos veículos reais para cada configuração;

- As medidas de comprimento utilizadas são múltiplas de 0,5 m; e

- Os eixos adjacentes são agrupados.

O autor considera que a principal contribuição do trabalho é a elaboração de procedimentos sistematizados de simulação de passagens de veículos em pontes. No entanto, o uso de uma simulação de Monte Carlo, ainda que incorpore valores de carregamentos observados, não significa que os carregamentos obtidos sejam representativos da realidade, uma vez que este tipo de modelo não consegue incorporar os efeitos da corrente de tráfego sobre o espaçamento e as velocidades dos veículos.

\subsection{Considerações finais}

O desenvolvimento de modelos de carregamento móvel vem sendo tema de vários estudos, principalmente no exterior. O interesse no assunto resulta da preocupação com a evolução da indústria de transporte rodoviário, que busca otimizar esse modo de transporte através do uso de veículos cada vez mais pesados, comprometendo a segurança das obras de arte especiais.

No Brasil, os principais trabalhos que tratam das cargas móveis para a análise estrutural de pontes são recentes, uma vez que o foco principal das pesquisas realizadas sempre foi a análise e o dimensionamento de pavimentos (Luchi, 2006).

Os modelos teóricos desenvolvidos adotam hipóteses simplificadoras para possibilitar o uso de expressões analíticas e esse fato restringe muito as análises que podem ser realizadas.

Os modelos que se baseiam na configuração estática do tráfego, em geral, consideram duas situações básicas: fluxo livre e fluxo congestionado. Eles fazem uma combinação dos resultados das situações básicas e a extrapolam para obter o efeito máximo para a vida útil da ponte. Para isso, eles consideram algumas variáveis (comprimentos dos veículos, cargas por eixo, probabilidades de localizações dos veículos e correlações entre essas possíveis localizações) e definem o número de situações de fluxo livre ou congestionado esperado para a vida útil da ponte. 
O fato de eles serem baseados na observação das probabilidades da presença múltipla de veículos sobre a estrutura os tornam válidos somente para a análise de pontes com vãos pequenos, onde acontecem menos combinações de posições de veículos. Além disso, as correlações encontradas nos fluxos de tráfego, como por exemplo, entre tipos de veículos em uma faixa, entre faixas diferentes, entre as condições de tráfego e o dia da semana, etc. não são bem representadas nesses modelos (Crespo-Minguillón e Casas, 1997).

Os modelos de simulação de tráfego são considerados mais completos que os modelos teóricos e os baseados na configuração estática do tráfego. Porém, uma característica desses modelos, que pode ser considerada como um aspecto negativo, é a grande quantidade de dados que são necessários para a obtenção de um bom resultado (Crespo-Minguillón e Casas, 1997). Quanto maior a precisão na modelagem da correlação entre os tipos de veículos pesados em uma faixa e entre faixas diferentes, maior é a extensão do vão da ponte que pode ser analisado (CrespoMinguillón e Casas, 1997).

Esta pesquisa utiliza um modelo de simulação microscópica de tráfego rodoviário para avaliar o impacto do tráfego de veículos pesados sobre pontes e outros elementos da infra-estrutura rodoviária e procura levar em consideração um grande número de variáveis para que o modelo simule de forma realística o tráfego observado em uma rodovia de pista dupla típica no estado de São Paulo. A abordagem proposta evita os efeitos causados por suposições simplificadoras e incorpora os efeitos de car-following na modelagem do posicionamento de caminhões sobre as pontes. 

O método usado para o desenvolvimento desta pesquisa consistiu das seguintes atividades:

1. Revisão bibliográfica;

2. Estudo do modelo de simulação CORSIM e determinação do procedimento para a sua calibração;

3. Coleta de dados;

4. Calibração e validação do CORSIM; e

5. Estudo de caso.

A seguir, cada uma dessas atividades é detalhada.

\subsection{Revisão bibliográfica}

A revisão bibliográfica foi realizada fundamentalmente através de consultas a artigos em periódicos especializados sobre os seguintes tópicos: os modelos de simulação microscópica de tráfego, a consideração do carregamento móvel na análise estrutural de pontes rodoviárias, a utilização de algoritmos genéticos para calibração dos modelos de simulação microscópica de tráfego e o processo de validação de simuladores de tráfego. 


\subsection{Estudo do modelo de simulação CORSIM e determinação do procedimento para sua calibração}

O modelo de simulação de tráfego usado nesta pesquisa foi o CORSIM, que tem sido extensivamente utilizado em aplicações práticas e pesquisas por ser considerado eficiente para a análise da operação do tráfego em uma grande variedade de situações (Owen et al., 2000). O estudo do modelo visou o conhecimento de sua lógica e das variáveis e parâmetros relacionados à simulação do fluxo de tráfego. Com isso, foi possível determinar os dados de entrada necessários, quais resultados poderiam ser obtidos do modelo e, conseqüentemente, realizar um planejamento adequado da coleta de dados.

A calibração de um modelo de simulação é o processo de ajuste dos valores dos parâmetros do modelo para que ele represente realisticamente os componentes do sistema que está sendo simulado (Brockfeld et al., 2004). Esse processo pode ser feito de duas formas: manual ou automática. A forma manual é mais simples, entretanto, pode se tornar muito demorada. Além disso, na calibração manual existe uma maior possibilidade de ocorrerem erros, já que o processo é iterativo. A calibração simultânea de alguns parâmetros é mais trabalhosa e requer mais tempo do que a calibração de um único parâmetro por vez. A calibração de um único parâmetro por vez deve ser evitada, pois os parâmetros de calibração são, muitas vezes, inter-relacionados. Uma pesquisa realizada por Egami (2000) evidenciou as limitações da calibração manual de um simulador de rodovias de pista simples.

Nesta pesquisa, optou-se pela utilização de um processo automatizado de calibração, feito através de um programa computacional que realiza as etapas (iterações) do processo manual. O processo escolhido apresenta algumas vantagens: permite que um número maior de parâmetros seja calibrado de forma individual ou simultânea; reduz o tempo de calibração; diminui significativamente a possibilidade de ocorrência de erros, visto que tem como base um algoritmo compilado e testado. 


\subsection{Coleta de dados}

O uso de modelos de simulação tem como requisito básico a entrada de dados referentes ao tráfego e à geometria da rodovia estudada. Os dados de tráfego são obtidos, geralmente, através de observações em campo. Os dados referentes à geometria podem ser obtidos através de projetos ou, em certos casos, através de levantamentos realizados em campo. A qualidade dos dados coletados é muito importante para que fique assegurado, após os processos de calibração e validação do modelo, que o simulador está reproduzindo adequadamente o fluxo de tráfego e que os resultados gerados são confiáveis.

Nesta pesquisa, a coleta dos dados relativos ao tráfego foi feita com o auxílio de câmeras de vídeo e pesquisadores. Os dados relacionados à geometria da via foram obtidos através do projeto geométrico do trecho.

Os dados de tráfego foram coletados em um trecho da Rodovia Washington Luiz (SP-310) que margeia o município de São Carlos e foram usados com o propósito de calibrar e validar o modelo de simulação CORSIM.

Um segundo tipo de coleta de dados usado nesta pesquisa está relacionado às características dos veículos pesados, tais como peso bruto total, peso por eixo e distância entre eixos. Esses dados foram obtidos em balanças do estado de São Paulo, também com a utilização de câmeras de vídeo e pesquisadores.

\subsection{Calibração e validação do CORSIM}

A calibração de um modelo de simulação garante uma representação adequada do fluxo de tráfego simulado. A validação do modelo calibrado tem o intuito de comprovar a eficiência da calibração e, para isso, é indispensável o uso de um conjunto de dados de tráfego diferente daquele usado para a calibração. Ambos os processos se baseiam na análise das diferenças entre os resultados fornecidos pelo simulador de tráfego e os dados observados em campo.

A medida estatística utilizada para a análise foi o erro médio absoluto percentual, que é comumente usada na calibração e na validação de modelos de simulação (Toledo e Koutsopou- 
los, 2004). Além disso, a sua formulação elimina o risco de existir a compensação entre erros positivos e negativos, o que poderia acarretar um julgamento incorreto do grau de precisão dos resultados.

O processo de calibração utilizado nesta pesquisa foi automatizado e usou um programa computacional baseado em um algoritmo genético. Essa abordagem foi escolhida por ser considerada mais eficiente se comparada à utilização de procedimentos manuais.

\subsection{Estudo de caso}

O estudo de caso realizado nesta pesquisa analisou o efeito da operação do tráfego de veículos pesados em uma ponte simplesmente apoiada de $100 \mathrm{~m}$. Nele, foram obtidas as probabilidades de presença simultânea de caminhões sobre uma ponte hipotética no trecho de rodovia de pista dupla simulado e os carregamentos móveis decorrentes dessas presenças. Dois cenários de tráfego foram usados na simulação.

Foram também comparados os momentos fletores originados pelo trem-tipo da classe de ponte 45 e pelo tráfego simulado. Essa análise permitiu verificar a adequabilidade da norma atualmente em vigor (NBR-7188) quanto às considerações da ação das cargas móveis no processo de análise estrutural das pontes. 


\section{O Modelo de Simulação CORSIM}

Este capítulo descreve as principais características do simulador de tráfego usado neste trabalho, o CORSIM. São apresentados também a rede simulada e os parâmetros de calibração contidos no simulador.

O CORSIM (abreviação de CORridor SIMulation) é um dos modelos de microsimulação de tráfego mais usados nos Estados Unidos e é considerado um modelo de alta fidelidade, devido às representações espacial e temporal contínuas da interação interveicular.

\subsection{O simulador CORSIM}

O CORSIM é um modelo de simulação microscópica de tráfego sofisticado e potente projetado para simular fluxos de tráfego em redes integradas de rodovias e áreas urbanas. Uma aplicação apropriada do CORSIM requer um bom entendimento da sua capacidade e das suas limitações, bem como das suposições nele contidas relacionadas à modelagem do fluxo de tráfego.

O modelo CORSIM foi desenvolvido e é mantido pelo Federal Highway Administration (FWHA) e consiste em uma integração de dois modelos de simulação microscópica de tráfego: NETSIM e FRESIM. O NETSIM faz a representação do tráfego em áreas urbanas, enquanto o FRESIM fornece a representação em freeways (Milam e Choa, 2002). 
O CORSIM é capaz de simular tipos diferentes de controle de interseção (por exemplo, semáforos atuados ou de ciclos predefinidos); diferentes geometrias de vias, incluindo variação no número de faixas; e uma grande variedade de condições de tráfego.

No CORSIM cada veículo é modelado individualmente e pode ser identificado pela sua frota (automóvel, caminhão, ônibus e carpool). Além disso, um total de nove tipos diferentes de veículos pode ser especificado para caracterizar as quatro frotas.

O CORSIM é um modelo estocástico em que tanto as características dos motoristas e veículos como os processos de tomada de decisão são definidos de forma aleatória. A natureza estocástica e dinâmica do modelo permite uma representação mais precisa da rede simulada.

O CORSIM é baseado em um modelo de rede com nós e tramos. Os nós podem representar interseções entre duas vias ou quaisquer outros pontos onde ocorra mudança nas características das vias, tais como redução ou aumento no número de faixas. Os tramos promovem a ligação entre os nós e representam as vias por onde os veículos trafegam.

O modelo CORSIM é implementado em ambiente Windows através do TSIS (Traffic Software Integrated System), a interface do usuário. Um elemento chave do TSIS é o pós-processador TRAFVU (TRAF Visualization Utility), que permite que o usuário visualize a rede simulada graficamente e acompanhe seu desempenho através da animação (Bloomberg e Dale, 2000). A versão utilizada nesta pesquisa é a mais recente: TSIS 5.1.

A resolução do CORSIM para descrever as operações do tráfego é de um segundo, ou seja, cada veículo é modelado como um objeto que se move a cada segundo, enquanto cada tipo de controle de tráfego na rede também é atualizado a cada segundo.

Para a execução de uma simulação no CORSIM é necessário que os dados de entrada estejam estruturados através de arquivos numerados reunidos em um único arquivo geral. Esses arquivos são chamados de Record Type (RT) e alguns deles são obrigatórios para o funcionamento do simulador, enquanto outros são opcionais ou se aplicam somente ao FRESIM ou NETSIM. 
O arquivo geral de entrada do CORSIM possui extensão TRF e, após a simulação, um arquivo de resultados (ou arquivo de saída) é criado com o mesmo nome do arquivo de entrada, porém com a extensão OUT. Esse arquivo contém um relatório global da simulação. Ambos podem ser manipulados em programas editores de texto.

Um segundo arquivo de resultados, usado pelo TRAFVU para realizar a animação, também é criado após a simulação. Esse arquivo possui extensão TSD (time step data) e contém informações detalhadas sobre cada um dos veículos simulados em intervalos de um segundo. Este arquivo permite a obtenção de resultados efetivamente microscópicos da simulação.

Uma vez que a aplicação do CORSIM nesta pesquisa refere-se à simulação de tráfego de uma rodovia, o componente utilizado é o FRESIM. Dessa forma, no decorrer deste trabalho, o termo CORSIM faz alusão ao FRESIM.

\subsection{Codificação de uma rede de transportes no CORSIM}

À exemplo de outros modelos de simulação microscópica de tráfego, a arquitetura básica do CORSIM compreende dados de entrada sobre a oferta e a demanda. Entre os dados de oferta, podem ser relacionados os nós, os tramos e os sistemas de controle de tráfego, que caracterizam a rede viária modelada. Os atributos dos nós envolvem as suas coordenadas $(x, y)$. Os atributos dos tramos incluem comprimento, rampa e vários outros aspectos tais como número de faixas, velocidade de fluxo livre, tipo de pavimento, etc. O sistema de controle de tráfego abrange o tipo de controle existente na interseção (semáforos, placas de pare ou interseções sem controle) e os atributos apropriados de cada tipo de controle (localização do semáforo, tempo de ciclo, etc.). Os dados de demanda compreendem as informações de origem/destino ou as informações do fluxo necessárias para a geração do tráfego dentro do simulador e as rotas dos veículos.

Alguns aspectos relacionados aos dados de entrada de um modelo de simulação variam em função do tempo ou do espaço. As características que variam com o tempo estão, em geral, relacionadas tanto à demanda quanto à oferta. Como exemplos dessa variação temporal podem ser citados as matrizes origem/destino (demanda) e os ciclos semafóricos (oferta). As características 
que variam com o espaço englobam basicamente dados de oferta, sendo o exemplo mais clássico a geometria dos tramos.

\subsection{Dados de entrada relacionados à oferta}

Os dados básicos para a simulação de uma rede de transportes incluem a geometria dos tramos, os atributos dos nós e as informações sobre o controle de tráfego. No CORSIM, os principais dados de entrada são:

- Números dos nós e suas coordenadas $(x, y)$;

- Configuração dos tramos entre cada par de nós;

- Tipo e extensão das faixas de aceleração e desaceleração;

- Geometria dos tramos (número de faixas, inclinação de rampas, etc.); e

- Dispositivos de controle de tráfego entre os tramos.

\subsection{Dados de entrada relacionados à demanda}

Os dados de demanda incluem as viagens entre pontos, representadas por uma matriz origem/destino, e também os fluxos de tráfego nos nós de entrada da rede. No CORSIM, esses dados podem ser inseridos através de dois métodos, apresentados a seguir.

O primeiro método inclui a identificação dos fluxos de tráfego nos nós de entrada (RT50) e os dados sobre os movimentos de conversão em cada acesso de saída da rede (RT25). A partir dessas informações, o CORSIM utiliza um modelo gravitacional para transformar as porcentagens dos movimentos de conversão em uma tabela com dados percentuais de origem/destino.

O segundo método usado para gerar a demanda no CORSIM é uma estimativa de uma matriz origem/destino sintética em que o usuário especifica um par origem/destino em porcentagem. Nessa alternativa, o usuário é responsável por garantir que o fluxo de tráfego em cada nó de destino é condizente com o calibrado na alternativa anterior, usando os fluxos e as porcentagens de movimentos de conversão do RT50 e do RT25. Para ambos os métodos, os fluxos de tráfego devem ser gerados em cada nó de entrada da rede. 
O CORSIM pode gerar os veículos na rede de forma estocástica ou determinística. As distribuições normal e de Erlang podem ser usadas para gerar os headways de forma estocástica. A distribuição normal é apresentada na Equação 4.1 e a distribuição de Erlang é apresentada na Equação 4.2:

$$
f(t)=\frac{1}{\sigma \sqrt{2 \pi}} e^{-\frac{1}{2}\left(\frac{t-\mu}{\sigma}\right)^{2}} \quad-\infty<t<\infty
$$

em que: $\quad f(t)$ : função densidade de probabilidade para os beadways;

$\mu$ : média dos headways (s);

o. desvio padrão dos headways; e

t. headways (s).

$$
f(t)=\frac{(q a)^{a}}{(a-1) !} t^{(a-1)} e^{(-a q t)} \quad 0<t<\infty
$$

em que: $\quad f(t)$ : função densidade de probabilidade para os beadways;

q: fluxo de tráfego médio por faixa (veíc/h);

a: grau de aleatoriedade para a distribuição, variando de 1 (totalmente aleatório) a $\infty$ (totalmente uniforme); e

t. headways (s).

No CORSIM, o valor de a pode variar entre 1 e 4. Um caso especial da distribuição de Erlang ocorre quando $a=1$. Nesse caso, ela é conhecida como a distribuição exponencial negativa, apresentada na Equação 4.3:

$$
f(t)=q e^{(-q t)}
$$

De fato, o resultado do uso dessa distribuição é uma distribuição exponencial negativa alterada, pois no CORSIM a distância mínima para a geração de veículos fica proibida de incidir abaixo de um determinado valor mínimo especificado pelo usuário. 


\subsection{Dados de saída}

O arquivo de resultados do CORSIM apresenta dados estatísticos da rede simulada em função dos tramos que formam a rede. As principais informações que compõem esse arquivo são:

- Número de veículos que entraram e saíram do tramo;

- Quantidade de mudanças de faixa ocorridas no tramo;

- Tempo médio gasto pelos veículos para percorrer o tramo;

- Atraso médio sofrido pelos veículos no tramo;

- Fluxo de tráfego no tramo;

- Velocidade média dos veículos no tramo; e

- Densidade média de tráfego no tramo.

Essas informações também são apresentadas no arquivo de saída em função de cada faixa de tráfego existente nos tramos da rede.

Um importante aspecto observado ao analisar os dados de saída do CORSIM é o fato de que as informações fornecidas pelo arquivo OUT possuem um caráter macroscópico, já que englobam todos os veículos dentro de um tramo, sem estratificação por tipo de veículo.

\subsection{Descrição da rede simulada no CORSIM}

Neste trabalho, o modelo desenvolvido para a simulação faz a representação da Rodovia Washington Luís (SP-310), em seus dois sentidos de tráfego, no trecho que margeia a cidade de São Carlos - SP. A rede simulada tem extensão de aproximadamente 7,5 km e possui vários acessos de entrada e saída, tanto no sentido Norte (capital-interior) quanto no sentido Sul (interiorcapital).

A interface gráfica TRAFVU com a representação geral da rede simulada está apresentada na Figura 4.1. Na Figura 4.2, pode-se visualizar um trecho da rede de forma mais detalhada. 


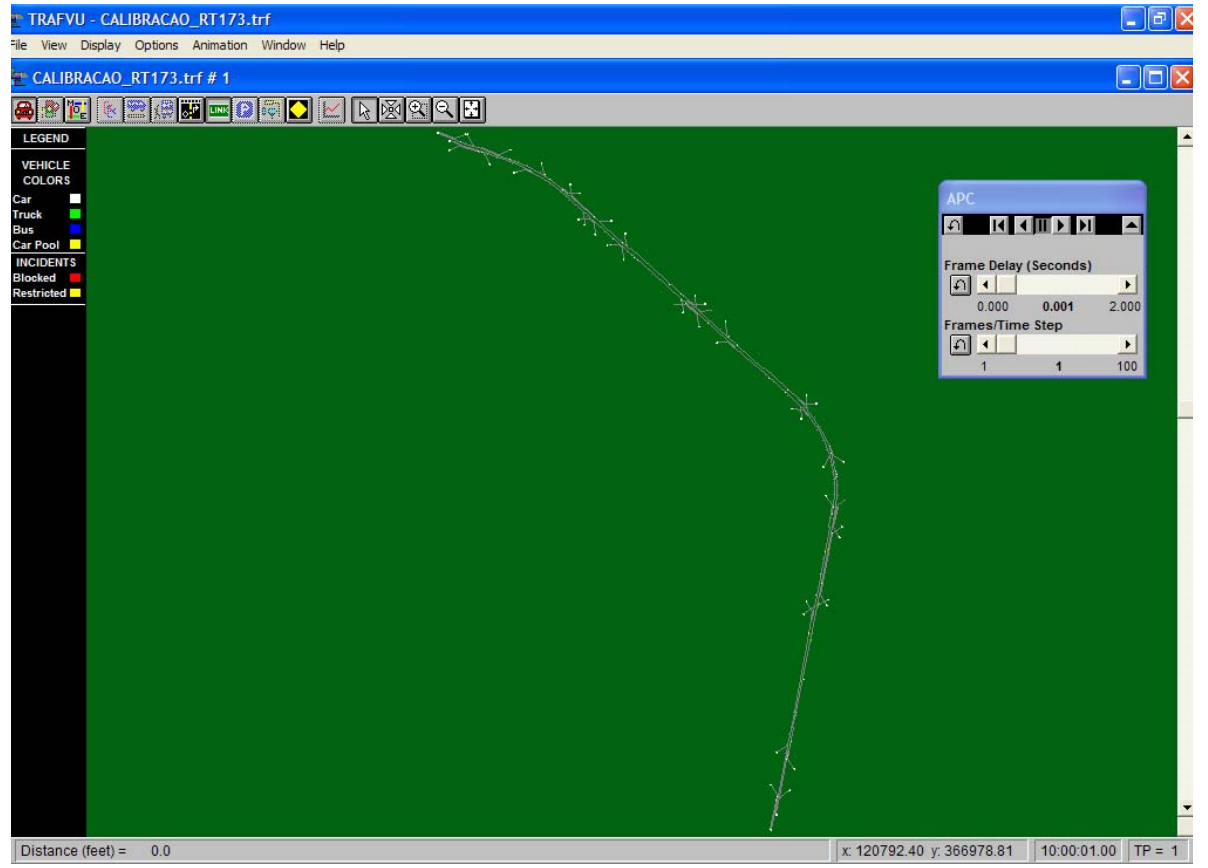

Figura 4.1 - Representação gráfica da rede simulada no CORSIM

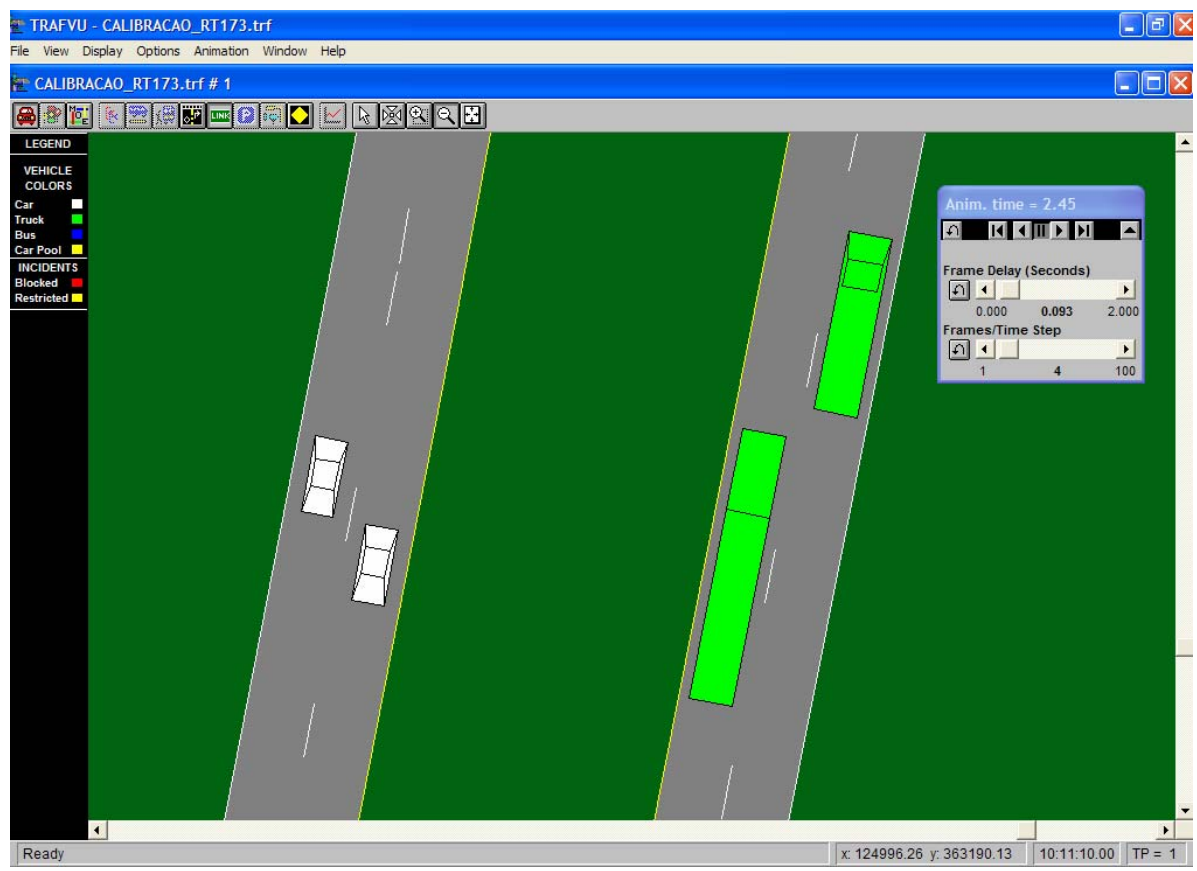

Figura 4.2 - Representação gráfica detalhada de um trecho da rede simulada no CORSIM

A construção da rede foi baseada no projeto geométrico da rodovia, que inclui dados importantes tais como extensão e inclinação das rampas. Outros dados que não puderam ser obtidos através do projeto geométrico (por exemplo, os comprimentos das faixas auxiliares de aceleração e desaceleração) foram obtidos em campo. 


\subsection{Parâmetros de calibração do CORSIM}

O CORSIM possui uma grande variedade de parâmetros de calibração que permitem que o usuário ajuste o simulador para que ele possa refletir as condições de tráfego existentes. Esses parâmetros de calibração do CORSIM podem ser classificados em duas categorias gerais: 1) comportamento dos motoristas e 2) desempenho dos veículos.

Uma pesquisa recente mostrou que dentro dessas categorias os parâmetros mais críticos e com comprovado efeito nos resultados da simulação estão relacionados à lógica do car-following. Adicionalmente, são considerados importantes na análise os fatores de aceleração, desaceleração e mudança de faixa (Schultz, 2003).

Alguns parâmetros de calibração do CORSIM estão relacionados à rede simulada como um todo, enquanto outros são específicos para cada tipo de veículo. A seguir, apresenta-se cada um desses parâmetros de calibração.

\subsubsection{Parâmetros gerais de calibração}

Os parâmetros gerais de calibração do CORSIM estão descritos na Tabela 4.1. A primeira coluna da tabela identifica o número do parâmetro $\left(\mathrm{P}_{1}\right.$ a $\left.\mathrm{P}_{20}\right)$, a segunda coluna fornece a descrição sumária do parâmetro baseada no manual do CORSIM, a terceira coluna lista a unidade de cada parâmetro, enquanto a quarta coluna identifica o valor default de cada parâmetro considerado pelo CORSIM. A quinta e a sexta colunas apresentam, respectivamente, os valores mínimo e máximo para o parâmetro que são aceitos pelo simulador. Vale ressaltar que alguns desses limites de valores, tanto mínimo como máximo, não são definidos no manual do simulador e foram adotados com base em um estudo anterior (Schultz, 2003).

Os parâmetros gerais para calibração do modelo de simulação podem ser classificados em três categorias:

1) fatores de sensibilidade para a lógica do car-following $\left(\mathrm{P}_{1}\right.$ a $\left.\mathrm{P}_{11}\right)$, que compõem o RT68;

2) fatores de aceleração e desaceleração $\left(\mathrm{P}_{12}\right.$ e $\left.\mathrm{P}_{13}\right)$, contidos no RT69; e

3) fatores relacionados à mudança de faixa $\left(\mathrm{P}_{14}\right.$ a $\left.\mathrm{P}_{20}\right)$, especificados no RT70. 
As lógicas do car-following e da mudança de faixa são consideradas a essência de um modelo de simulação microscópica de tráfego (Owen et al., 2000).

Tabela 4.1 - Parâmetros gerais de calibração do CORSIM

\begin{tabular}{|c|c|c|c|c|c|}
\hline Parâmetro & Descrição & Unidade & $\begin{array}{c}\text { Valor } \\
\text { Default } \\
\end{array}$ & $\begin{array}{c}\text { Valor } \\
\text { Mínimo } \\
\end{array}$ & $\begin{array}{c}\text { Valor } \\
\text { Máximo } \\
\end{array}$ \\
\hline $\mathrm{P}_{1}$ & $\begin{array}{l}\text { Fator de sensibilidade para o car-following } \\
\text { (motoristas do tipo 1) }\end{array}$ & $1 / 100 \mathrm{~s}$ & 125 & 110 & 140 \\
\hline $\mathrm{P}_{2}$ & $\begin{array}{l}\text { Fator de sensibilidade para o car-following } \\
\text { (motoristas do tipo 2) }\end{array}$ & $1 / 100 \mathrm{~s}$ & 115 & 100 & 130 \\
\hline $\mathrm{P}_{3}$ & $\begin{array}{l}\text { Fator de sensibilidade para o car-following } \\
\text { (motoristas do tipo 3) }\end{array}$ & $1 / 100 \mathrm{~s}$ & 105 & 90 & 120 \\
\hline $\mathrm{P}_{4}$ & $\begin{array}{l}\text { Fator de sensibilidade para o car-following } \\
\text { (motoristas do tipo 4) }\end{array}$ & $1 / 100 \mathrm{~s}$ & 95 & 80 & 110 \\
\hline $\mathrm{P}_{5}$ & $\begin{array}{l}\text { Fator de sensibilidade para o car-following } \\
\text { (motoristas do tipo 5) }\end{array}$ & $1 / 100 \mathrm{~s}$ & 85 & 70 & 100 \\
\hline $\mathrm{P}_{6}$ & $\begin{array}{l}\text { Fator de sensibilidade para o car-following } \\
\text { (motoristas do tipo 6) }\end{array}$ & $1 / 100 \mathrm{~s}$ & 75 & 60 & 90 \\
\hline $\mathrm{P}_{7}$ & $\begin{array}{l}\text { Fator de sensibilidade para o car-following } \\
\text { (motoristas do tipo } 7 \text { ) }\end{array}$ & $1 / 100 \mathrm{~s}$ & 65 & 50 & 80 \\
\hline $\mathrm{P}_{8}$ & $\begin{array}{l}\text { Fator de sensibilidade para o car-following } \\
\text { (motoristas do tipo 8) }\end{array}$ & $1 / 100 s$ & 55 & 40 & 70 \\
\hline $\mathrm{P}_{9}$ & $\begin{array}{l}\text { Fator de sensibilidade para o car-following } \\
\text { (motoristas do tipo 9) }\end{array}$ & $1 / 100 s$ & 45 & 30 & 60 \\
\hline $\mathrm{P}_{10}$ & $\begin{array}{l}\text { Fator de sensibilidade para o car-following } \\
\text { (motoristas do tipo 10) }\end{array}$ & $1 / 100 \mathrm{~s}$ & 35 & 20 & 50 \\
\hline $\mathrm{P}_{11}$ & Constante de Pitt para o car-following & pé & 10 & 3 & 10 \\
\hline $\mathrm{P}_{12}$ & Tempo de reação para acelerar & $1 / 10 \mathrm{~s}$ & 3 & 1 & 15 \\
\hline $\mathrm{P}_{13}$ & Tempo de reação para desacelerar & $1 / 10 \mathrm{~s}$ & 3 & 1 & 15 \\
\hline $\mathrm{P}_{14}$ & Tempo para completar uma mudança de faixa & $1 / 10 \mathrm{~s}$ & 20 & 10 & 60 \\
\hline $\mathrm{P}_{15}$ & Tempo mínimo para geração de veículos & $1 / 10 \mathrm{~s}$ & 16 & 10 & 30 \\
\hline $\mathrm{P}_{16}$ & $\begin{array}{l}\text { Aceitação de gap para mudança de faixa obriga- } \\
\text { tória }\end{array}$ & - & 3 & 1 & 6 \\
\hline $\mathrm{P}_{17}$ & $\begin{array}{l}\text { Porcentagem de motoristas que cedem o direito } \\
\text { de passagem para veículos mudando de faixa }\end{array}$ & $\%$ & 20 & 5 & 40 \\
\hline $\mathrm{P}_{18}$ & $\begin{array}{l}\text { Multiplicador para o desejo de realizar uma } \\
\text { mudança de faixa arbitrária }\end{array}$ & $1 / 10$ & 5 & 1 & 10 \\
\hline $\mathrm{P}_{19}$ & $\begin{array}{l}\text { Valor limite do benefício para realizar uma mu- } \\
\text { dança de faixa arbitrária }\end{array}$ & $1 / 10$ & 4 & 1 & 10 \\
\hline $\mathrm{P}_{20}$ & $\begin{array}{l}\text { Desaceleração máxima do veículo líder percebi- } \\
\text { da pelo seu seguidor }\end{array}$ & pé/s ${ }^{2}$ & 15 & 5 & 20 \\
\hline
\end{tabular}

\subsubsection{Fatores de sensibilidade para a lógica do car-following}

Os fatores de sensibilidade para a lógica do car-following são baseados na idéia de que o desejo de um motorista de seguir o veículo à sua frente varia de acordo com um nível de sensibilidade 
específico para cada tipo de motorista. Para levar em conta essa variabilidade do comportamento dos motoristas, o CORSIM permite que 10 fatores diferentes de sensibilidade sejam definidos, ou seja, 10 tipos de motoristas são considerados, cada um com um nível diferente de agressividade.

O CORSIM designa aleatoriamente um fator de sensibilidade para o motorista ao inserir o veículo na rede e esse fator permanece constante durante toda a simulação. Khan et al. (2000) afirmam que o ideal seria que o fator de sensibilidade pudesse variar ao longo da simulação, uma vez que os motoristas tendem a se comportar de maneira diferente em situações de fluxo livre e congestionado.

No CORSIM, a unidade dos fatores de sensibilidade para o car-following é centésimo de segundo. Assim, para um fator de sensibilidade de 1,05 s, o valor a ser inserido é 105.

O CORSIM usa o modelo de Pitt para modelar o car-following. Esse modelo, adotado no modelo microscópico de simulação de rodovias INTRAS (Integrated TRAffic Simulation), foi desenvolvido na Universidade de Pittsburgh (Rakha e Crowther, 2002). O modelo de Pitt assume que o motorista do veículo seguidor tentará manter uma distância em relação ao veículo líder de acordo com a Equação 4.4 (Aycin e Benekohal, 1999). A ilustração dos componentes dessa equação é apresentada na Figura 4.3.

$$
H=L+P_{j} v_{t}+P_{11}+b P_{j}\left(\mu_{t}-v_{t}\right)^{2} \quad \forall j=1, N
$$

$$
\begin{array}{ll}
\text { em que: } & \text { distância (pé); } \\
L: & \text { comprimento do veículo líder (pé); } \\
P_{j} & \text { fator de sensibilidade para o motorista do veículo seguidor }(\mathrm{s}) ; \\
P_{11}: & \text { constante de Pitt (pé); } \\
\mu_{i}: & \text { velocidade do veículo líder no instante } t(\text { pé } / \mathrm{s}) ; \\
v_{i} & \text { velocidade do veículo seguidor no instante } t(\text { pé } / \mathrm{s}) ; \\
N: & \text { número de tipos de motoristas (no CORSIM, } N=10) ; \mathrm{e} \\
b: & \text { constante de calibração }\left(0,1 \text { se } \mu_{t}<v_{t} \text { ou } 0 \text { se } \mu_{t} \geq v_{t}\right) .
\end{array}
$$




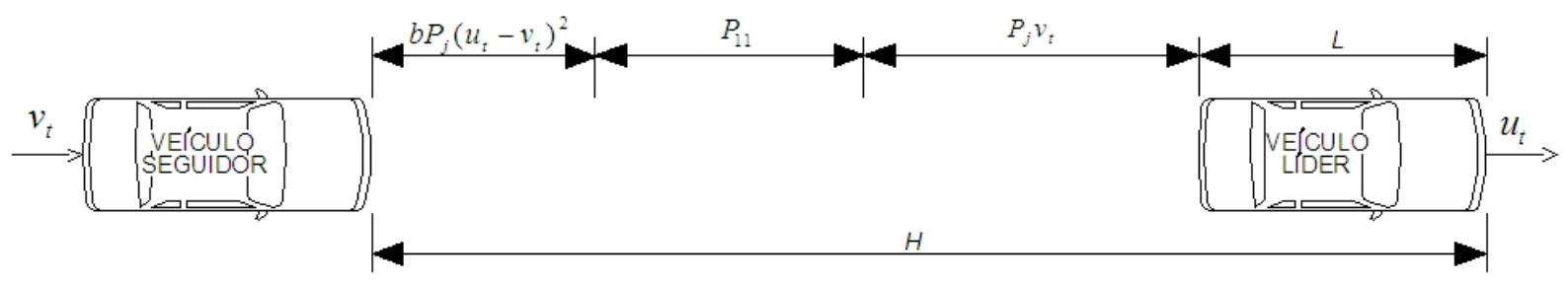

Figura 4.3 - Representação dos componentes do modelo de car-following de Pitt

Os primeiros três termos da equação $\left(L+P_{j} v_{t}+P_{11}\right)$ são necessários para garantir uma distância mínima entre os veículos. O primeiro termo $(L)$ leva em conta o comprimento do veículo líder, enquanto o segundo termo $\left(P_{j} v_{t}\right)$ é usado para representar a variabilidade na distância entre os veículos através do uso dos fatores de sensibilidade dos motoristas definidos anteriormente. $\mathrm{O}$ terceiro termo, a constante de Pitt $\left(P_{11}\right)$, é usado para determinar a distância absoluta mínima e pode ser calibrado para qualquer valor inteiro entre 3 pés e 10 pés. O termo final da equação, $b P_{j}$ $\left(\mu_{t}-v_{t}\right)^{2}$, foi introduzido para permitir uma velocidade de aproximação relativamente alta baseada em estudos empíricos e a inclusão de uma constante de calibração, $b$, que assume o valor de 0,1 ou 0 dependendo da relação entre as velocidades do veículo líder e do veículo seguidor. O valor de $b$ também é documentado de outra maneira, assumindo o valor de 0,1 se $\mu_{t}-v_{t} \leq 10$ ou 0 se essa condição não for atendida (Halati et al., 1997).

Com base na Equação 4.4, a aceleração do veículo seguidor pode ser obtida como uma função do comprimento do veículo, da distância mínima e das relações entre velocidade e posição dos veículos seguidor e líder. A relação resultante é apresentada na Equação 4.5, cuja dedução pode ser encontrada na literatura (Aycin e Benekohal, 1999):

$$
a_{f}=\frac{2\left(x_{t+T}-y_{t}-L-P_{11}-v_{t}\left(P_{j}+T\right)-b P_{j}\left(\mu_{t+T}-v_{t}\right)^{2}\right)}{T^{2}+2 P_{j} T} \quad \forall j=1, N
$$

em que: $\quad a_{f} \quad$ aceleração do veículo seguidor no intervalo entre $t$ e $t+T\left(\right.$ pé $\left./ \mathrm{s}^{2}\right)$;

$y_{i} \quad$ posição do veículo seguidor no instante $t$ (pé); 


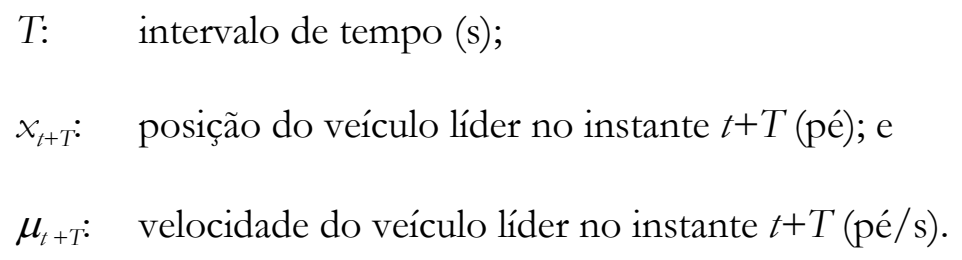

O headway entre veículos é diretamente proporcional ao fator de sensibilidade do motorista. Dessa forma, um fator de sensibilidade alto resulta num headway maior e, conseqüentemente, em uma menor capacidade da via que está sendo simulada.

\subsubsection{Fatores de aceleração e desaceleração}

Os fatores de aceleração e desaceleração são usados pelo modelo para calcular o tempo de reação para acelerar e desacelerar o veículo, decorrente de uma mudança de faixa obrigatória. Esses fatores são introduzidos nas equações do car-following depois que a aceleração do veículo seguidor é calculada e quando a nova velocidade e posição dele já estão definidas, como pode ser visto nas equações 4.6 e 4.7 (Aycin e Benekohal, 1999):

$$
\begin{gathered}
v_{t+T}=v_{t}+a_{f}\left(T-P_{j}\right) \\
y_{t+T}=y_{t}+v_{t} T+\frac{1}{2} a_{f}\left(T-P_{j}\right)^{2}
\end{gathered}
$$

em que: $\quad v_{t+T}: \quad$ velocidade do veículo seguidor no instante $t+T($ pé/s);

$y_{t+T}: \quad$ posição do veículo seguidor no instante $t+T$ (pé);

$P_{j} \quad$ tempo de reação $(\mathrm{s})\left(P_{j}<T\right)$; e

j: $\quad$ índice da variável $P(j=12$ para aceleração e $j=13$ para desaceleração).

O valor default para os parâmetros de aceleração e desaceleração é $0,3 \mathrm{~s}\left(\mathrm{P}_{12}\right.$ e $\left.\mathrm{P}_{13}\right)$.

\subsubsection{Fatores de mudança de faixa}

O CORSIM utiliza um algoritmo para mudança de faixa que inclui os dois lados do processo de decisão, ou seja, a oferta (avaliação de gap) e a demanda (aceitação de gap). O algoritmo inclui aspectos relacionados ao comportamento dos motoristas ao permitir uma variedade de valores de entrada usados para determinar o desejo de um motorista de melhorar a sua situação na 
corrente de tráfego através de uma manobra de mudança de faixa. A Figura 4.4 ilustra o processo de mudança de faixa, identificando a posição do veículo líder e do veículo seguidor em relação ao veículo que deseja realizar a manobra.

Figura 4.4 - Ilustração do processo de mudança de faixa

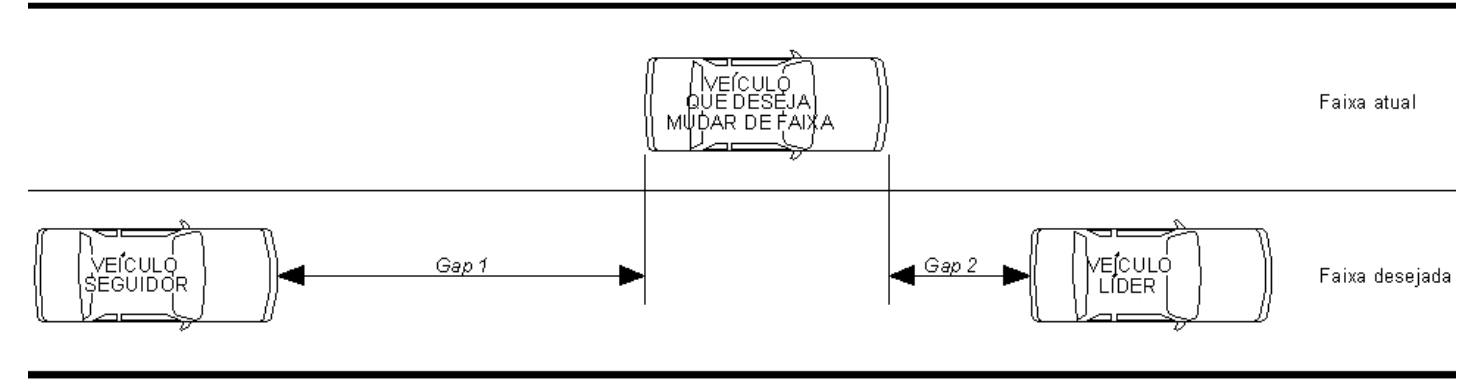

Os principais aspectos a serem levados em consideração na manobra de mudança de faixa são os gaps existentes entre o veículo que quer realizar a mudança de faixa e os veículos líder e seguidor. A decisão de mudar de faixa é tomada através da avaliação desses dois gaps. O gap em relação ao veículo líder é avaliado com base na desaceleração necessária durante o tempo da mudança de faixa e com base na habilidade do motorista de manter uma posição segura entre os dois veículos (líder e seguidor). Algumas equações têm sido desenvolvidas para identificar a desaceleração necessária para que um veículo que esteja realizando uma mudança de faixa a faça de forma segura (Halati et al., 1997).

Alguns parâmetros do algoritmo de mudança de faixa podem ser ajustados, como os apresentados anteriormente na Tabela 4.1. Um desses parâmetros é o tempo para completar uma mudança de faixa $\left(\mathrm{P}_{14}\right)$, que é um valor de entrada usado nas equações de aceleração para mudança de faixa e que tem um valor default no CORSIM de $2 \mathrm{~s}$. Esse valor foi determinado com base em um estudo que mostrou que o tempo para mudar de faixa era uma função da velocidade, mas que essa relação não era muito significativa. Esse estudo concluiu que uma constante para representar o tempo de mudança de faixa seria uma suposição razoável (Wicks e Lieberman, 1980). Como resultado, valores entre 1 s e 6 s podem ser usados pelo CORSIM. 
O segundo parâmetro relacionado à mudança de faixa é o tempo mínimo para geração de veículos $\left(\mathrm{P}_{15}\right)$, utilizado para controlar a taxa máxima em que os veículos podem ser inseridos na rede em uma mesma faixa de tráfego (FHWA, 2001). O valor default para esse parâmetro é 1,6 s (indicando uma capacidade por faixa de tráfego de 2.250 veíc/h), com limites mínimo e máximo de 1 s e 3 s, respectivamente.

Apesar de a premissa da equação básica da mudança de faixa ser baseada na aceitação de gap, um outro aspecto comportamental também faz parte dessa análise. Esse aspecto é o grau de cooperação do motorista do veículo seguidor da faixa adjacente para permitir a manobra $\left(\mathrm{P}_{17}\right)$. A taxa de desaceleração máxima aceitável por um motorista que deseja cooperar com a manobra é fixada em 10 pés $/ \mathrm{s}^{2}$ (ou seja, 3,04 m/s²), enquanto que para um motorista que não deseja cooperar com a manobra é fixada em 8 pés $/ \mathrm{s}^{2}\left(2,44 \mathrm{~m} / \mathrm{s}^{2}\right)$. O valor default no modelo assume que $20 \%$ dos motoristas cooperam com os veículos que querem mudar de faixa. O CORSIM permite que esse percentual varie entre $5 \%$ e $40 \%$.

A mudança de faixa é modelada no CORSIM através de três categorias diferentes: 1) mudança de faixa obrigatória; 2) mudança de faixa arbitrária; e 3) mudança de faixa antecipatória. A seguir, serão detalhadas cada uma dessas três categorias.

\subsection{Mudança de faixa obrigatória}

As mudanças de faixa obrigatórias são consideradas as mais rigorosas pois, devido à necessidade da manobra, os motoristas aceitam um maior nível de risco. As seguintes situações estão incluídas nessa categoria:

- Veículos emergindo de um acesso;

- Veículos que precisam chegar a uma faixa apropriada para sair da via;

- Veículos que devem deixar uma faixa bloqueada por um acidente; e

- Veículos que precisam deixar uma faixa que se encerra mais à frente. 
O risco aceitável, ou seja, a desaceleração aceitável por um motorista que sai de um acesso em uma faixa auxiliar e quer entrar no fluxo de tráfego principal é determinado pela Equação 4.8 (Halati et al., 1997):

$$
a=a_{\min }+\left(e-a_{\min }\right) \sqrt{\frac{d}{l}}
$$

em que: $\quad a$ : $\quad$ taxa de desaceleração aceitável $\left(p e ́ / \mathrm{s}^{2}\right)$;

$a_{\text {min }}: \quad$ taxa de desaceleração mínima aceitável $\left(\mathrm{pé} / \mathrm{s}^{2}\right)$;

$e: \quad$ taxa de desaceleração emergencial $\left(\mathrm{pé} / \mathrm{s}^{2}\right)$;

d: distância entre o veículo e o fim da faixa auxiliar (pé); e

l: $\quad$ comprimento da faixa auxiliar (pé).

Para os veículos que tentam alcançar a faixa apropriada para sair da via, a desaceleração aceitável é calculada de acordo com a Equação 4.9 (Halati et al., 1997):

$$
a=\left\{\begin{array}{l}
e \rightarrow d>200 \\
a_{\min }+\left(e-a_{\min }\right) \sqrt{\frac{d}{l}} \rightarrow d \leq 200
\end{array}\right.
$$

O CORSIM permite que o usuário estabeleça o gap aceitável para mudanças de faixa obrigatórias através do parâmetro de calibração $\mathrm{P}_{16}$, que é utilizado para identificar o grau de agressividade dos motoristas, podendo variar de 1, o mais agressivo, a 6, o menos agressivo (FHWA, 2001).

\subsection{Mudança de faixa arbitrária}

As mudanças de faixa arbitrárias são aquelas realizadas com o intuito de ultrapassar veículos mais lentos, visando a obtenção de uma posição mais favorável na corrente de tráfego ou atingir uma velocidade mais alta. A lógica desse tipo de mudança de faixa se baseia em fatores comportamentais dos motoristas: motivação, vantagem e urgência (Schultz, 2003). 
A mudança de faixa por motivação é incorporada no modelo através da especificação de uma velocidade "intolerável", abaixo da qual o motorista se torna altamente motivado a efetuar a manobra. Essa velocidade intolerável pode ser calculada pela Equação 4.10 (Halati et al., 1997):

$$
v_{i}=v_{f f} \frac{50+2 c}{100}
$$

em que: $\quad v_{i}: \quad$ velocidade intolerável (pé/s);

$v_{f f^{:}} \quad$ velocidade de fluxo livre desejada (pé/s); e

c. tipo de motorista (1 a 10).

Uma vez que a velocidade intolerável é calculada, o desejo de realizar a manobra de mudança de faixa é então modelado pela Equação 4.11 (Halati et al., 1997):

$$
D=\left\{\begin{array}{l}
100 \rightarrow v \leq v_{i} \\
100\left[1-\frac{\left(v-v_{i}\right)}{\left(v_{f f}-v_{i}\right)}\right] \\
0 \rightarrow v \geq v_{f f}
\end{array}\right.
$$

em que: $\quad D: \quad$ desejo de realizar uma mudança de faixa arbitrária; e

v. $\quad$ velocidade do veículo mudando de faixa (pé/s).

A mudança de faixa por vantagem fornece aos motoristas a oportunidade de melhorar sua situação na corrente de tráfego e é modelada através de dois fatores, $F_{l}$ e $F_{p}$. O fator $F_{l}$ representa a desvantagem para o motorista de permanecer na faixa em que se encontra, enquanto $F_{p}$ representa o ganho em mudar para uma outra faixa. $O$ fator $F_{l}$ é calculado pela Equação 4.12, enquanto o beadway existente na faixa em que o veículo se encontra é calculado pela Equação 4.13 (Halati et al., 1997):

$$
F_{l}=\left\{\begin{array}{l}
1 \rightarrow b \leq b_{\min } \\
1-\frac{b-b_{\min }}{b_{\max }-b_{\min }} \rightarrow b_{\min }<b<b_{\text {max }} \\
0 \rightarrow b \geq b_{\max }
\end{array}\right.
$$




$$
h=\frac{s-F_{s} v_{d}}{v_{f f}}
$$

em que: $\quad F_{i} \quad$ fator de desvantagem;

b: $\quad$ beadway existente na faixa em que o veículo se encontra (s);

$h_{\text {min: }} \quad$ headway mínimo (s);

$h_{\text {max }}: \quad$ headway máximo (s);

s: $\quad$ distância entre o veículo e seu líder na faixa em que se encontra (pé);

$F_{s}: \quad$ fator para velocidade (s); e

$v_{d:} \quad$ diferencial de velocidade entre o veículo e seu líder (pé/s).

O fator $F_{p}$ representa o ganho em mudar para uma outra faixa e é calculado para as faixas adjacentes a que o veículo se encontra, sendo a escolhida aquela que tiver o maior $F_{p}$. O método para o cálculo desse fator é idêntico ao do $F_{l}$ apresentado anteriormente, com uma exceção: no $F_{p}$, o cálculo do headway é feito em relação ao veículo líder na faixa para a qual o motorista deseja mudar e não em relação ao veículo líder na faixa em que ele se encontra.

O benefício global para a realização de uma mudança de faixa arbitrária é então calculado pela diferença entre $F_{p}$ e $F_{b}$, sendo a mudança de faixa permitida se essa diferença exceder o valor limite do benefício $\left(\mathrm{P}_{19}\right)$. O parâmetro $\mathrm{P}_{19}$ no CORSIM tem um valor default de 0,4 e limites inferior e superior de 0,1 e 1,0, respectivamente (FHWA, 2001).

O último tipo de mudança de faixa arbitrária é o causado pela urgência. Ele se baseia na suposição de que o motorista que deseja mudar de faixa e não consegue irá gradualmente se tornar impaciente e, conseqüentemente, passará a aceitar um risco maior para realizar a manobra. A metodologia básica por trás dessa decisão se baseia no fator de urgência $(U)$, que é obtido através da Equação 4.14, e no fator de impaciência (IMP), calculado com auxílio da Equação 4.15 (Halati et al., 1997):

$$
U=\left(1-F_{l}\right) \operatorname{IMP}(t)
$$




$$
\operatorname{IMP}(t)=\operatorname{IMP}(t-\Delta t)+\frac{c+1}{20} X(t)
$$

em que: $\quad U: \quad$ fator de urgência;

$\operatorname{IMP}(t)$ : fator de impaciência;

t. instante corrente;

$\Delta t$ tempo de atualização da simulação (s) ( $\Delta \mathrm{t}=1 \mathrm{~s}$ no CORSIM);

c. $\quad$ tipo de motorista (1 a 10);

$X(t): \quad 0$ se o motorista não deseja mudar de faixa e 1 se ele deseja mudar de faixa; e

F: $\quad$ fator de desvantagem (definido na Equação 4.12).

A desaceleração aceitável pelo motorista que deseja mudar de faixa de forma arbitrária baseada no fator de urgência é computada de acordo com a Equação 4.16, em que o valor default mínimo aceitável para a desaceleração é 5 pés $/ \mathrm{s}^{2}\left(1,52 \mathrm{~m} / \mathrm{s}^{2}\right)$ e o valor default máximo aceitável é 10 pés $/ \mathrm{s}^{2}\left(3,04 \mathrm{~m} / \mathrm{s}^{2}\right)$ (Halati et al., 1997):

$$
a=\left\{\begin{array}{l}
a_{\min } \rightarrow U<1-0,05 c \\
a_{\text {min }}+\left(a_{\text {max }}-a_{\min }\right) \frac{U+0,05 c-1}{0,05 c} \rightarrow U \geq 1-0,05 c
\end{array}\right.
$$

em que: $\quad a$ a $\quad$ taxa de desaceleração aceitável pelo motorista que deseja realizar uma mudança de faixa arbitrária $($ pé/s²);

$a_{\text {min }}$ taxa de desaceleração mínima aceitável pelo motorista que deseja realizar uma mudança de faixa arbitrária $\left(p e ́ / \mathrm{s}^{2}\right)$; e

$a_{\max }:$ taxa de desaceleração máxima aceitável pelo motorista que deseja realizar uma mudança de faixa arbitrária (pé/s²).

Nenhum dos valores e equações usadas no algoritmo da mudança de faixa arbitrária pode ser alterado pelo usuário do CORSIM. Entretanto, o multiplicador para o desejo de realizar uma 
mudança de faixa arbitrária $\left(\mathrm{P}_{18}\right)$ e o valor limite do benefício para realizar uma mudança de faixa arbitrária $\left(\mathrm{P}_{19}\right)$ podem ser ajustados durante a calibração do modelo.

\subsection{Mudança de faixa antecipatória}

A última categoria de mudança de faixa usada no modelo CORSIM se refere às manobras realizadas para evitar um congestionamento existente à frente. A principal diferença entre a mudança de faixa antecipatória e a arbitrária é o método utilizado, que para a antecipatória é baseado no fluxo de tráfego e na velocidade média das faixas de tráfego adjacentes a que o veículo se encontra e no desejo de realizar a manobra. Na mudança de faixa antecipatória, $\mathrm{P}_{18}$ é fixado em 0,1, o que indica um alto desejo de mudar de faixa. $\mathrm{O}$ valor de $\mathrm{P}_{18}$ varia entre 0,1 e 1,0.

\subsubsection{Parâmetros de calibração por tipo de veículo}

Todo veículo modelado no CORSIM pode ser identificado através de uma frota (automóvel, caminhão, ônibus e carpool) e através do tipo de veículo existente em cada uma das frotas. O CORSIM permite que o usuário se utilize de até nove tipos diferentes de veículos para caracterizar as quatro frotas básicas de veículos. A definição que o modelo usa para identificar os tipos de veículos está contida na Tabela 4.2.

Tabela 4.2 - Frotas e tipos de veículos usados pelo CORSIM

\begin{tabular}{ccl}
\hline Frota de Veículo & Tipo & \multicolumn{1}{c}{ Descrição do Veículo } \\
\hline \multirow{2}{*}{ Automóvel } & 1 & Carro de passeio de baixo desempenho \\
& 2 & Carro de passeio de alto desempenho \\
\hline \multirow{3}{*}{ Caminhão } & 3 & Caminhão leve \\
& 4 & Caminhão médio \\
& 5 & Caminhão pesado \\
& 6 & Caminhão extra-pesado \\
\hline Onibus & 7 & Onibus convencional \\
\hline \multirow{2}{*}{ Carpool } & 8 & Carro de passeio de baixo desempenho \\
& 9 & Carro de passeio de alto desempenho \\
\hline
\end{tabular}

Enquanto os parâmetros gerais de calibração afetam principalmente o comportamento do motorista, os parâmetros de calibração por tipo de veículo fornecem uma oportunidade de calibrar as características operacionais dos veículos. Esses parâmetros de calibração podem ser classificados em três categorias gerais: 1) desaceleração máxima não emergencial por tipo de veículo; 2) 
características da velocidade e aceleração; e 3) distribuição da frota. Cada um desses parâmetros será discutido a seguir.

\subsubsection{Desaceleração máxima não emergencial}

$\mathrm{O}$ valor da desaceleração máxima não emergencial (parâmetros $\mathrm{P}_{21}$ a $\mathrm{P}_{29}$ ) é o maior valor para a desaceleração permitido pela metodologia do car-following descrita anteriormente. Esses parâmetros estão contidos no RT70 e podem conter valores distintos para cada uma dos nove tipos de veículos. O valor default para os nove parâmetros é de 8 pés $/ \mathrm{s}^{2}\left(2,44 \mathrm{~m} / \mathrm{s}^{2}\right)$, como indicado na Tabela 4.3 (FHWA, 2001). Com base na definição usada pelo CORSIM e apresentada na Tabela 4.2, os tipos 1 e 2 representam automóveis, os tipos de 3 a 6 representam caminhões, o tipo 7 representa ônibus e os tipos 8 e 9 representam veículos com alta ocupação (carpools).

Tabela 4.3 - Parâmetros de calibração do CORSIM por tipo de veículo

\begin{tabular}{|c|c|c|c|c|c|}
\hline Parâmetro & Descrição & Unidade & $\begin{array}{c}\text { Valor } \\
\text { Default }\end{array}$ & $\begin{array}{c}\text { Valor } \\
\text { Mínimo } \\
\end{array}$ & $\begin{array}{c}\text { Valor } \\
\text { Máximo }\end{array}$ \\
\hline $\mathrm{P}_{21}$ & $\begin{array}{l}\text { Desaceleração máxima não emergencial } \\
\text { para o veículo do tipo } 1\end{array}$ & 1/10 pé/s 2 & 80 & 70 & 120 \\
\hline $\mathrm{P}_{22}$ & $\begin{array}{l}\text { Desaceleração máxima não emergencial } \\
\text { para o veículo do tipo } 2\end{array}$ & $1 / 10 \mathrm{pé} / \mathrm{s}^{2}$ & 80 & 70 & 120 \\
\hline $\mathrm{P}_{23}$ & $\begin{array}{l}\text { Desaceleração máxima não emergencial } \\
\text { para o veículo do tipo } 3\end{array}$ & 1/10 pé/s² & 80 & 40 & 100 \\
\hline $\mathrm{P}_{24}$ & $\begin{array}{l}\text { Desaceleração máxima não emergencial } \\
\text { para o veículo do tipo } 4\end{array}$ & $1 / 10 \mathrm{pé} / \mathrm{s}^{2}$ & 80 & 40 & 100 \\
\hline $\mathrm{P}_{25}$ & $\begin{array}{l}\text { Desaceleração máxima não emergencial } \\
\text { para o veículo do tipo } 5\end{array}$ & $1 / 10 \mathrm{pé} / \mathrm{s}^{2}$ & 80 & 40 & 100 \\
\hline $\mathrm{P}_{26}$ & $\begin{array}{l}\text { Desaceleração máxima não emergencial } \\
\text { para o veículo do tipo } 6\end{array}$ & 1/10 pé/s & 80 & 40 & 100 \\
\hline $\mathrm{P}_{27}$ & $\begin{array}{l}\text { Desaceleração máxima não emergencial } \\
\text { para o veículo do tipo } 7\end{array}$ & 1/10 pé/s² & 80 & 40 & 100 \\
\hline $\mathrm{P}_{28}$ & $\begin{array}{l}\text { Desaceleração máxima não emergencial } \\
\text { para o veículo do tipo } 8\end{array}$ & $1 / 10$ pé/s ${ }^{2}$ & 80 & 70 & 120 \\
\hline $\mathrm{P}_{29}$ & $\begin{array}{l}\text { Desaceleração máxima não emergencial } \\
\text { para o veículo do tipo } 9\end{array}$ & $1 / 10 \mathrm{pé} / \mathrm{s}^{2}$ & 80 & 70 & 120 \\
\hline
\end{tabular}

\subsubsection{Características da velocidade e da aceleração}

O modelo INTRAS foi desenvolvido originalmente para representar quatro tipos diferentes de veículos. Alguns estudos identificam as fontes que foram usadas pelo modelo para a caracterização do desempenho dos veículos e uma variedade de características descritivas para padrões 
de desempenho que são utilizados pelo CORSIM (Huff e Scrivner, 1955; St. John e Kobett, 1978; ITE, 1965).

No CORSIM, a maioria das considerações sobre o desempenho dos veículos é derivada do procedimento apresentado no estudo realizado por St. John e Kobett (1978), que tem como base a relação peso/potência para cada tipo de veículo. Os perfis da aceleração dos veículos no modelo INTRAS foram baseados na hipótese de que ela é influenciada pela velocidade, pela existência de rampa e pelas características dos veículos. Sendo assim, intervalos de velocidade de 20 pés/s foram definidos, nos quais a aceleração foi assumida como constante. A aceleração média para os automóveis foi baseada em estudos publicados no Traffic Engineering Handbook (ITE, 1965). As acelerações dos veículos foram desenvolvidas com base em duas categorias de desempenho: baixa e alta. As taxas de aceleração resultantes foram então ajustadas com base no efeito de rampas, gerando os perfis da aceleração. As acelerações dos caminhões também foram geradas com base em estudos anteriores para serem classificadas em função do tipo de veículo, das rampas e da velocidade. Os resultados das taxas de aceleração iniciais para rodovias em nível são fornecidos na Tabela 4.4 (Wicks e Lieberman, 1980).

Tabela 4.4 - Taxas de aceleração para calibração no INTRAS por tipo de veículo (pé/s²)

\begin{tabular}{lccccc}
\hline \multirow{2}{*}{ Tipo de Veículo } & \multicolumn{5}{c}{ Velocidade (pé/s) } \\
\cline { 2 - 7 } & $\mathbf{0 ~ a ~ 2 0}$ & $\mathbf{2 0}$ a 40 & $\mathbf{4 0}$ a 60 & $\mathbf{6 0}$ a 80 & $\mathbf{> 8 0}$ \\
\hline Carro de passeio de baixo desempenho & 6,0 & 6,0 & 6,0 & 3,0 & 2,0 \\
Carro de passeio de alto desempenho & 11,0 & 11,0 & 10,0 & 5,0 & 3,0 \\
Caminhão leve & 3,0 & 2,0 & 1,0 & 1,0 & 1,0 \\
Caminhão extra-pesado & 1,0 & 1,0 & 1,0 & 1,0 & 1,0 \\
\hline
\end{tabular}

Com os avanços realizados, o número de tipos de veículos disponíveis no INTRAS aumentou de quatro para nove, apesar de as características operacionais dos tipos 1 e 2 se igualarem às dos tipos 8 e 9, o que resulta em características operacionais diferentes para apenas sete tipos de veículos. Com esse aumento no número de tipos de veículos, as acelerações também sofreram ajustes para refletir as características dos novos veículos. No TSIS 5.1, a aceleração máxima para os veículos segue os valores contidos na Tabela 4.5, que indica algumas das alterações feitas com 
relação aos perfis da aceleração, bem como apresenta os perfis atuais em função de cada um dos sete índices de desempenho, definidos na Tabela 4.6. Os dados que compõem essa tabela fazem parte do RT173.

Tabela 4.5 - Aceleração máxima por índice de desempenho (pé/s²)

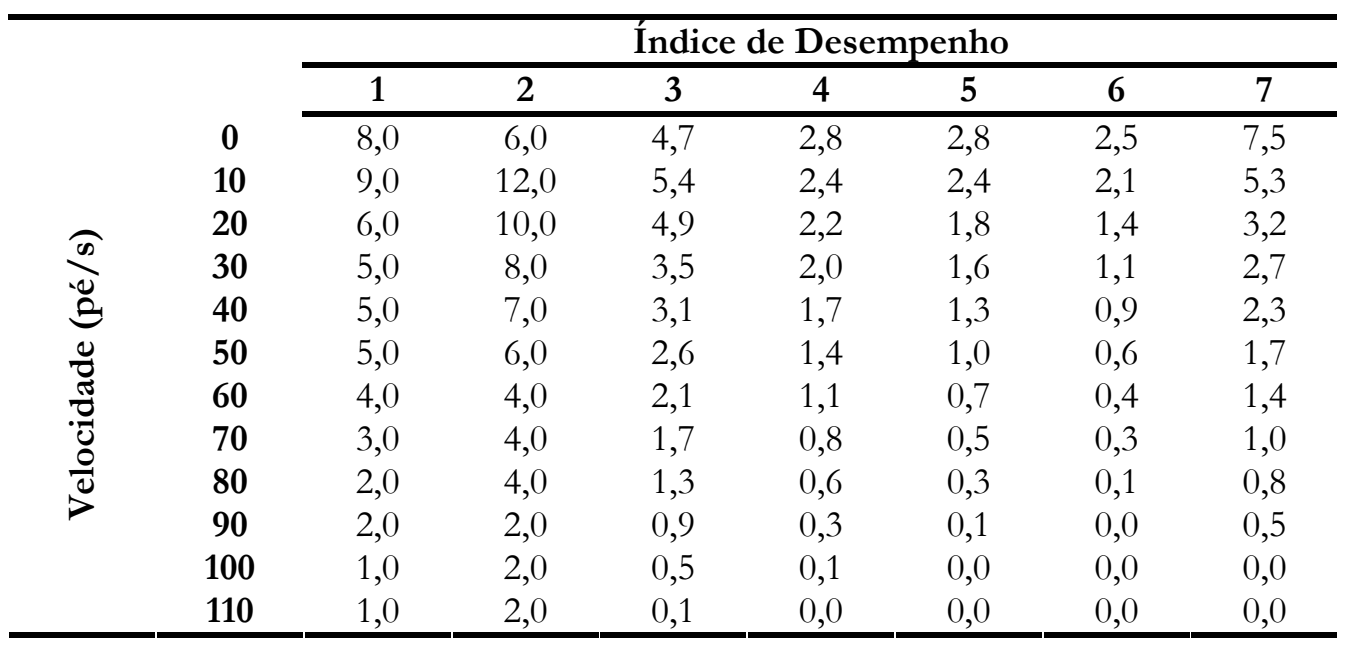

Tabela 4.6 - Definições dos índices de desempenho no CORSIM

\begin{tabular}{cl}
\hline Índice de Desempenho & \multicolumn{1}{c}{ Definição } \\
\hline 1 & Automóvel de baixo desempenho \\
2 & Automóvel de alto desempenho \\
3 & Caminhão leve \\
4 & Caminhão médio \\
5 & Caminhão pesado \\
6 & Caminhão extra-pesado \\
7 & Ônibus convencional \\
\hline
\end{tabular}

Uma característica adicional da aceleração usada pelo modelo CORSIM é a taxa de mudança de aceleração. Essa taxa é utilizada para controlar a mudança máxima na aceleração permitida durante o intervalo de atualização da simulação $(1$ s). O CORSIM considera que essa taxa é de 7 pés $/ \mathrm{s}^{3}$. A literatura disponível possui pouca informação a respeito dessa taxa e do seu efeito no desempenho no modelo de simulação. Um estudo feito por Botzow (1974) com a finalidade de desenvolver um conceito de nível de serviço para o transporte público apresenta valores aceitáveis com base no conforto do passageiro e afirma que uma taxa em torno de $0,19 \mathrm{~g} / \mathrm{s}\left(6\right.$ pés $\left./ \mathrm{s}^{3}\right)$ é indesejada para passageiros. 
Em um outro estudo desenvolvido por Frankel et al. (1996), relacionado à tecnologia de sistemas inteligentes de rodovias, uma taxa de $0,25 \mathrm{~g} / \mathrm{s}\left(8,2 \mathrm{pés} / \mathrm{s}^{3}\right)$ foi recomendada. Esse estudo indicou também que a literatura sugere que essa taxa esteja entre $0,20 \mathrm{~g} / \mathrm{s}\left(6,6\right.$ pés $\left./ \mathrm{s}^{3}\right)$ e $0,25 \mathrm{~g} / \mathrm{s}$ $\left(8,2\right.$ pés $\left./ \mathrm{s}^{3}\right)$.

\subsubsection{Distribuição da frota}

Os parâmetros finais para a calibração do CORSIM são os de distribuição da frota, especificados no RT71 do modelo. Esse arquivo permite que o usuário modifique os valores default usados pelo CORSIM para representar os componentes de cada frota de acordo com a distribuição dos dados obtidos para a rede simulada (FHWA, 2001). A Tabela 4.7 mostra os valores default contidos no CORSIM para caracterizar as quatro frotas de veículos.

Tabela 4.7 - Valores default para os componentes das frotas de veículos

\begin{tabular}{ccc}
\hline Frota de Veículo & Tipo & Participação na Frota (\%) \\
\hline \multirow{2}{*}{ Automóvel } & 1 & 25 \\
& 2 & 75 \\
\hline \multirow{3}{*}{ Caminhão } & 3 & 31 \\
& 4 & 36 \\
& 5 & 24 \\
Onnibus & 6 & 9 \\
\hline \multirow{2}{*}{ Carpool } & 7 & 100 \\
\hline
\end{tabular}

Se o usuário considera que esses valores não são aceitáveis para a rede simulada, ele pode estabelecer diferentes distribuições dos veículos em cada frota. Entretanto, o limite de nove tipos de veículos e o índice de desempenho de cada um deles, apresentado na Tabela 4.6, devem ser respeitados.

\subsection{Considerações finais}

Este capítulo apresentou as características principais do simulador de tráfego escolhido para uso nesta pesquisa, o CORSIM. A identificação dos dados necessários para o uso do simulador permitiu que fosse realizado um planejamento adequado das coletas de dados, descritas no Capítulo 5 . 
Os parâmetros que permitem que o usuário ajuste o simulador de forma a representar apropriadamente as condições de campo foram usados para calibrar o CORSIM para a rede de tráfego estudada, conforme apresentado no Capítulo 6. 


\section{Coleta de Dados}

O uso de modelos de simulação torna altamente desejável a obtenção de um conjunto de dados que sirva de entrada para o modelo e que represente as condições observadas em campo. Contudo, na maioria dos estudos em que simuladores de tráfego são usados os recursos para a obtenção de dados em campo são limitados e, mesmo quando eles existem, alguns dados são muito difíceis de serem obtidos diretamente (Hellinga, 1998). Então, é importante que se faça um planejamento em que sejam definidos os tipos de dados necessários e os níveis de agregação temporal e espacial desses dados, além da cobertura temporal e espacial que se deseja obter. De forma geral, pode-se afirmar que coletar dados de tráfego em campo é uma tarefa difícil, onerosa e que consome muito tempo (Kim et al., 2005).

Este capítulo trata das coletas de dados que foram realizadas para o desenvolvimento da pesquisa. Dois tipos de coletas foram necessários: o primeiro deles estava relacionado aos dados de tráfego usados na simulação, que serviram para calibrar e validar o CORSIM, e o segundo, à caracterização da frota de veículos pesados que trafega no estado de São Paulo. Essa caracterização tornou possível o conhecimento de dados essenciais para a realização do estudo de caso proposto nesta pesquisa, tais como os pesos por eixos, as distâncias entre eles e as relações peso/potência dos veículos pesados. A seguir, são apresentados os locais escolhidos para as coletas de dados, os métodos de coleta empregados e as análises dos dados coletados. 


\subsection{Dados para caracterização do tráfego e estimativa da matriz origem/destino}

Um único trecho de rodovia de pista dupla foi selecionado para a coleta de dados de tráfego. Esse trecho está localizado no município de São Carlos - SP, é parte da Rodovia Washington Luiz (SP-310) e é operado sob o regime de concessão. Uma característica desse trecho é a presença de um tráfego misto, combinando tráfego urbano com tráfego interurbano. Ele possui uma extensão aproximada de 7,5 km e, além da via principal, compreende 11 acessos no sentido capital-interior (Norte) e 16 acessos no sentido oposto. A geometria do trecho é considerada ondulada, com a presença de rampas curtas de até 5\%. Uma foto aérea de São Carlos - SP com a localização do trecho estudado da SP-310 pode ser vista na Figura 5.1.

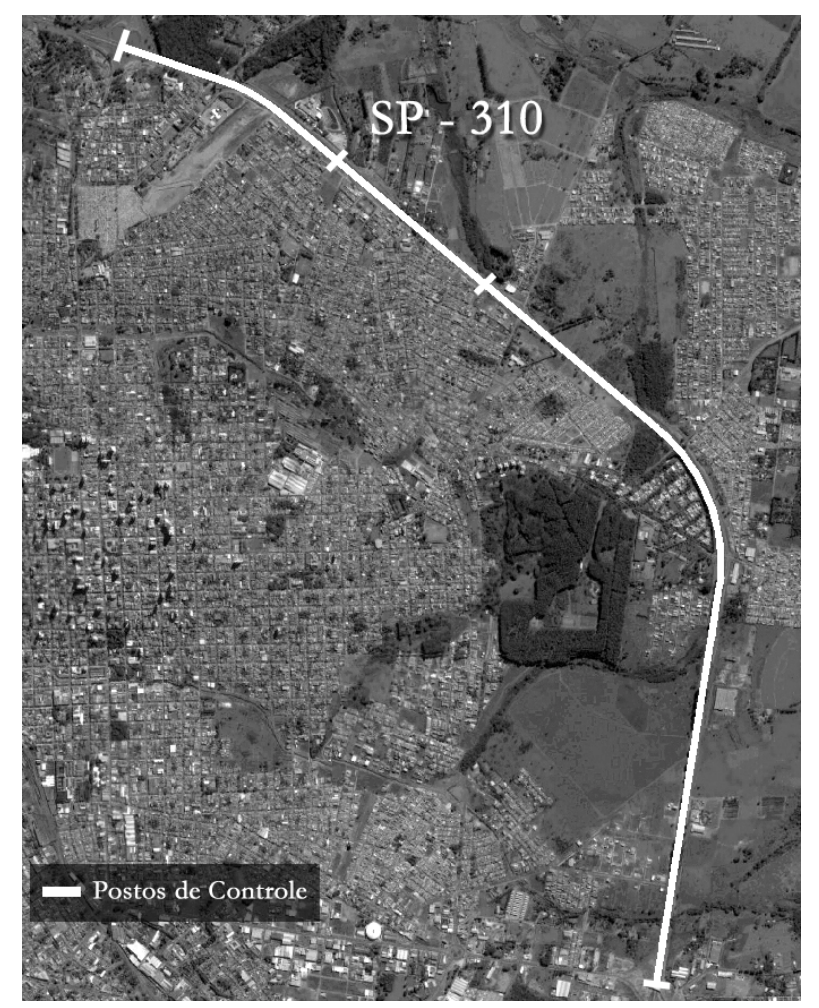

Figura 5.1 - Foto aérea com a localização do trecho estudado da SP-310

Para esta pesquisa, além de dados caracterizando o fluxo e a composição do tráfego, também foram coletados dados de origem/destino e da velocidade da corrente de tráfego. A obtenção da matriz origem/destino foi considerada necessária para que pudesse representar o tráfego observado com o grau de fidelidade desejado. As observações de velocidade média da corrente de 
tráfego em postos de controle ao longo do trecho foram necessárias para o processo de calibração e validação do simulador.

Os dados para caracterização dos fluxos de tráfego e para a estimativa das matrizes origem/destino foram coletados simultaneamente. O método de coleta utilizado foi a observação e o registro em planilhas, em intervalos de 15 minutos, do tipo de veículo e dos algarismos existentes em sua placa. Este método, chamado "método das placas", é comumente utilizado em pesquisas do tipo origem-destino e é recomendado para trechos em que o fluxo de tráfego é muito elevado para ser paralisado para entrevistas e/ou onde o número de entradas e saídas é grande (Robertson et al., 1994).

Nele, alguns postos de controle estratégicos são selecionados na rede de tráfego e, no instante em que o veículo passa por esses postos, o número de sua placa é registrado, permitindo com isso o seu rastreamento. Para a aplicação desse método, é recomendado que os postos de controle estejam localizados nos extremos da rede e, se possível, também em pontos intermediários. Dessa forma, tem-se que a origem de um determinado veículo é primeiro posto em que sua placa foi registrada e o seu destino é o último posto com registro de sua passagem.

A grande vantagem desse método é a amostra obtida que, em alguns casos, pode chegar a $100 \%$ da população, dependendo da corrente de tráfego observada e do número de pesquisadores envolvidos. Em contrapartida, a sua principal desvantagem consiste no trabalho de tabulação dos dados, geralmente muito grande. A tarefa de combinação das placas pode ser manual ou computadorizada, mas em qualquer um dos casos ela é muito custosa (DNIT, 2006).

Nesta aplicação do método, foram escolhidos como postos de controle os viadutos localizados nos extremos do trecho de rodovia selecionado, as passarelas de pedestres localizadas em pontos intermediários e também os acessos de entrada e saída da rodovia. Dessa forma, puderam ser obtidos os dados de fluxo e composição do tráfego e a matriz origem-destino. As informações relacionadas às coletas de dados estão contidas na Tabela 5.1. 
Tabela 5.1 - Informações sobre as coletas de dados

\begin{tabular}{ccccc}
\hline Data da Coleta & Horário & $\begin{array}{c}\text { Postos de Controle } \\
\text { (SP-310) }\end{array}$ & $\begin{array}{c}\text { Postos de Controle } \\
\text { (Acessos) }\end{array}$ & $\begin{array}{c}\text { Pesquisadores } \\
\text { Envolvidos }\end{array}$ \\
\hline $6 / 6 / 2005$ & $10: 00-12: 00$ & 6 & 27 & 23 \\
$13 / 6 / 2005$ & $09: 00-12: 00$ & 6 & 27 & 23 \\
$1 / 7 / 2005$ & $14: 00-17: 00$ & 8 & 27 & 25 \\
\hline
\end{tabular}

Os postos de controle ao longo da rodovia foram monitorados por um pesquisador em cada sentido do tráfego. Nos acessos, um único pesquisador coletou dados dos veículos que entravam e saíam, em função dos baixos fluxos de tráfego observados.

Além disso, devido ao volume de tráfego e à alta velocidade dos veículos na SP-310, os pesquisadores localizados ao longo da rodovia utilizaram câmeras de vídeo juntamente com as planilhas. Foram usadas seis câmeras de vídeo nas duas primeiras coletas de dados e oito câmeras de vídeo na última coleta. Essas câmeras são digitais e possuem baterias com autonomia de gravação suficiente para os períodos planejados de coleta. Elas possuem relógios internos com informação sobre hora, minuto e segundo que foram sincronizados antes do início de cada coleta de dados.

\subsubsection{Dados coletados}

A seguir, são apresentados os dados obtidos nas três coletas de dados. Para caracterizar a flutuação da demanda de tráfego no decorrer da simulação, os dados coletados foram agregados em intervalos de 15 minutos. As análises dos resultados da simulação também tiveram como base intervalos de 15 minutos.

\subsubsection{Fluxo de tráfego}

A partir das anotações registradas nas planilhas e das imagens gravadas em vídeo foram obtidos os fluxos de tráfego apresentados nas Figuras 5.2, 5.3 e 5.4. Esses fluxos são referentes aos postos de controle da SP-310 que representam o início da rede em cada sentido de tráfego. Os dados são apresentados isoladamente para cada uma das coletas de dados e para cada um dos dois sentidos de tráfego da rede estudada. 


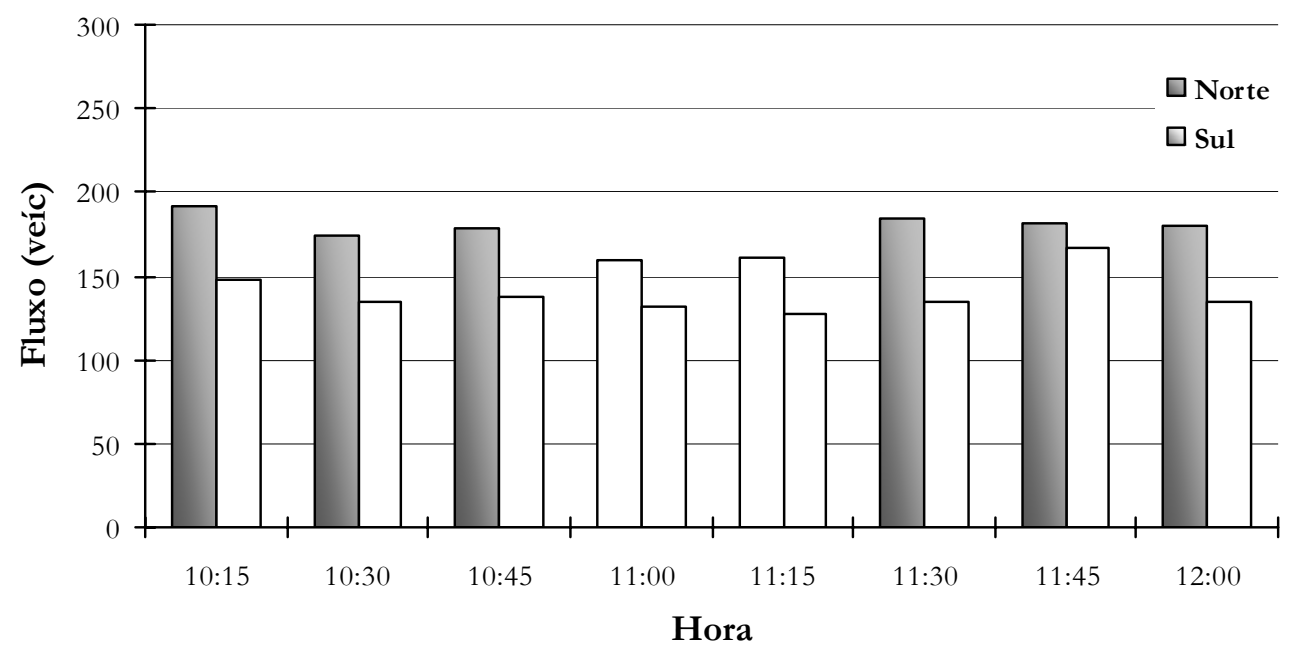

Figura 5.2 - Fluxo de tráfego na primeira coleta de dados (6/6/2005)

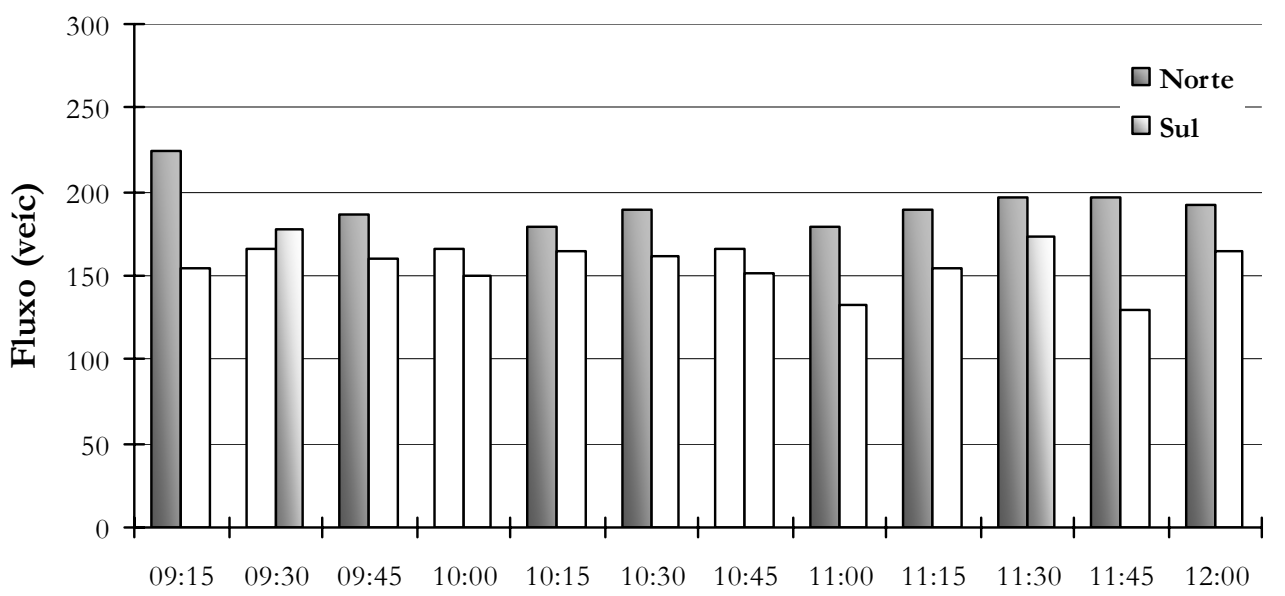

Hora

Figura 5.3 - Fluxo de tráfego na segunda coleta de dados (13/6/2005)

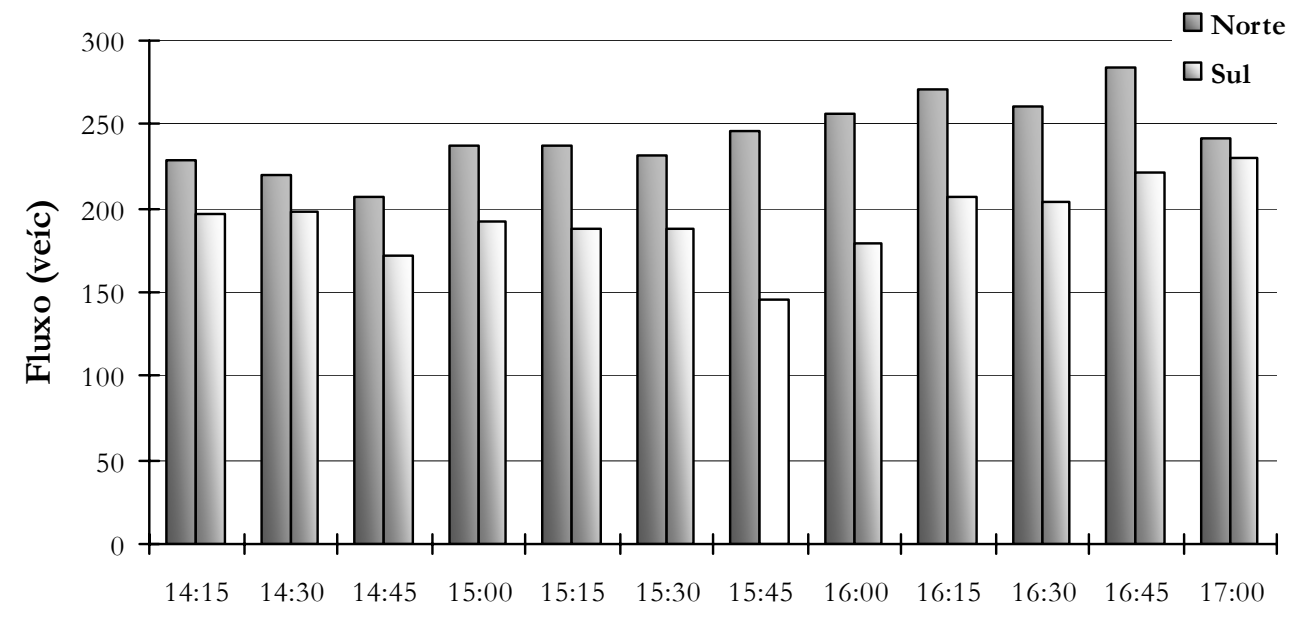

Hora

Figura 5.4 - Fluxo de tráfego na terceira coleta de dados (1/7/2005) 
A análise dos fluxos evidencia que, à exceção de um único intervalo de 15 minutos na segunda coleta de dados, o fluxo no sentido Norte é superior ao do sentido Sul. A diferença média calculada foi de $27 \%$ para a primeira coleta de dados, $20 \%$ para a segunda coleta de dados e $27 \%$ para a terceira coleta de dados. A Tabela 5.2 apresenta os fluxos horários médios observados por coleta de dados.

Tabela 5.2 - Fluxos médios observados (veíc/h)

\begin{tabular}{ccc}
\hline \multirow{2}{*}{ Coleta de Dados } & \multicolumn{2}{c}{ Sentido } \\
\cline { 2 - 3 } & Norte & Sul \\
\hline $6 / 6 / 2005$ & 705 & 558 \\
$13 / 6 / 2005$ & 744 & 625 \\
$1 / 7 / 2005$ & 974 & 774 \\
\hline Média & $\mathbf{8 0 8}$ & $\mathbf{6 5 2}$ \\
\hline
\end{tabular}

A Tabela 5.2 permite verificar a ocorrência de um crescimento nos fluxos médios ao longo das coletas de dados, nos dois sentidos de tráfego. Além disso, os dados da primeira e da segunda coletas de dados apresentam uma maior similaridade se comparados aos da terceira coleta. A explicação para esse fato é que as duas primeiras coletas foram realizadas no mesmo dia da semana e no mesmo período, diferentemente da terceira coleta. Então, diante da necessidade de segregar os dados coletados em dois conjuntos isolados para fins de calibração e validação do modelo de simulação CORSIM, os dados da primeira e da segunda coletas de dados foram selecionados para a calibração e os dados da terceira coleta, para a validação.

\subsubsection{Composição do tráfego}

O tráfego observado em todos os postos de controle foi classificado em três categorias: automóveis, caminhões e ônibus. Entretanto, devido à combinação de alta velocidade, alto fluxo e posicionamento dos observadores e das câmeras de vídeo em viadutos e passarelas, tornou-se inviável verificar o modelo e a configuração de eixos dos caminhões. Como esse dado é considerado de fundamental importância para o estudo de caso realizado, optou-se pela suposição de que a distribuição dos veículos pesados na rede simulada segue a observada em balanças localizadas em rodovias de pista dupla no estado de São Paulo (ver item 5.2). As Figuras 5.5, 5.6 e 5.7 mos- 
tram as composições de tráfego observadas nos postos de controle da SP-310 que representam o início da rede em cada sentido de tráfego. A Tabela 5.3 apresenta as composições horárias médias por coleta de dados.

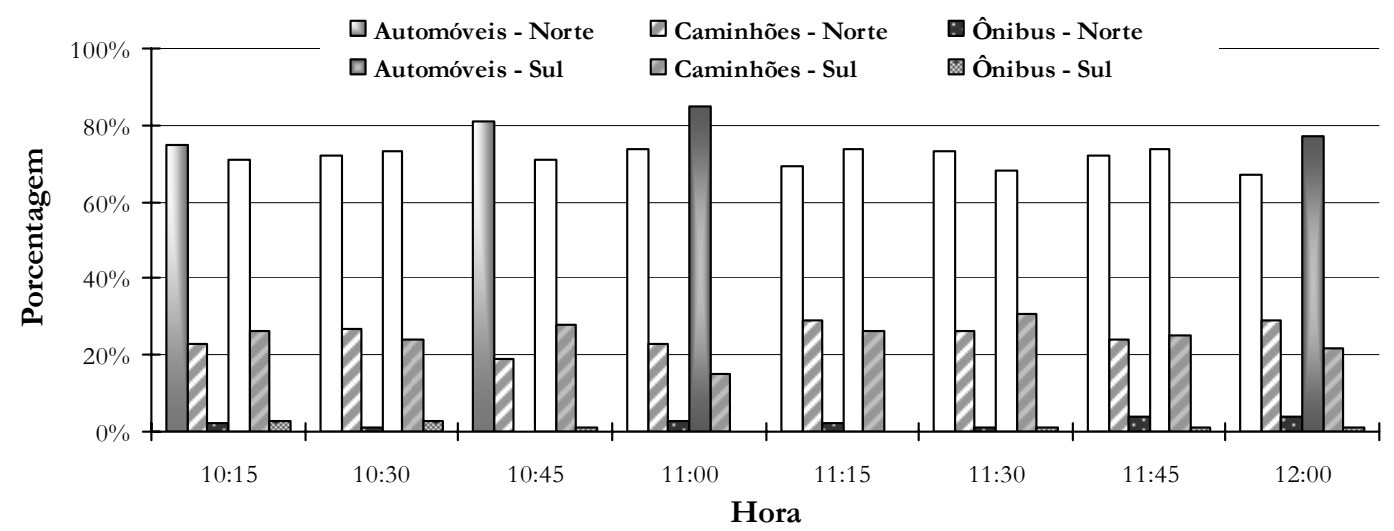

Figura 5.5 - Composição do tráfego na primeira coleta de dados (6/6/2005)

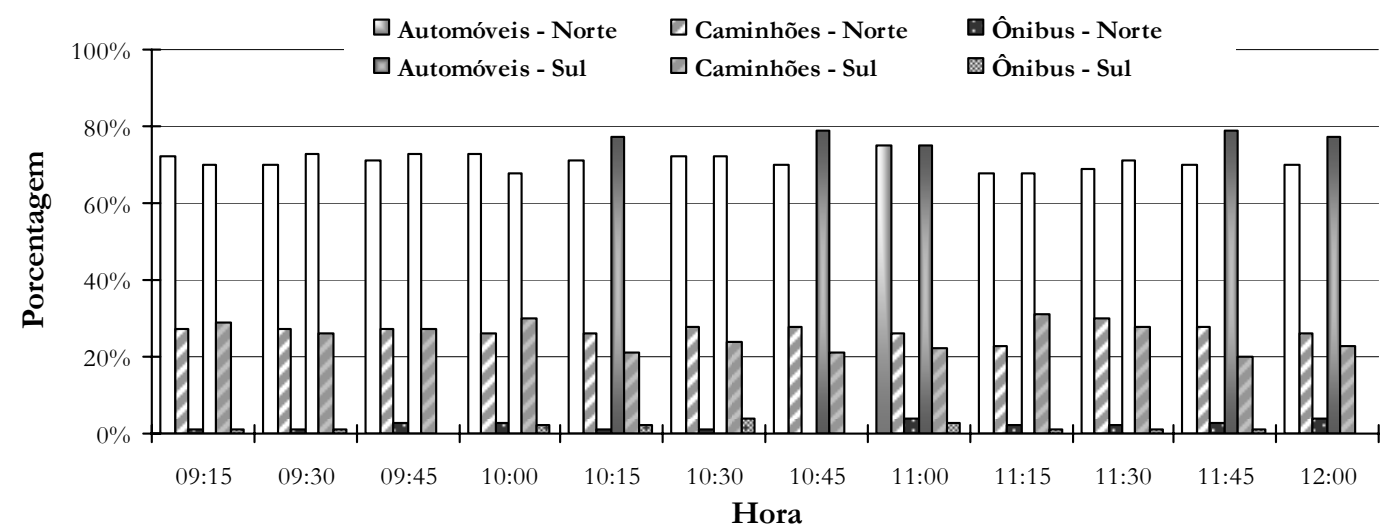

Figura 5.6 - Composição do tráfego na segunda coleta de dados (13/6/2005)

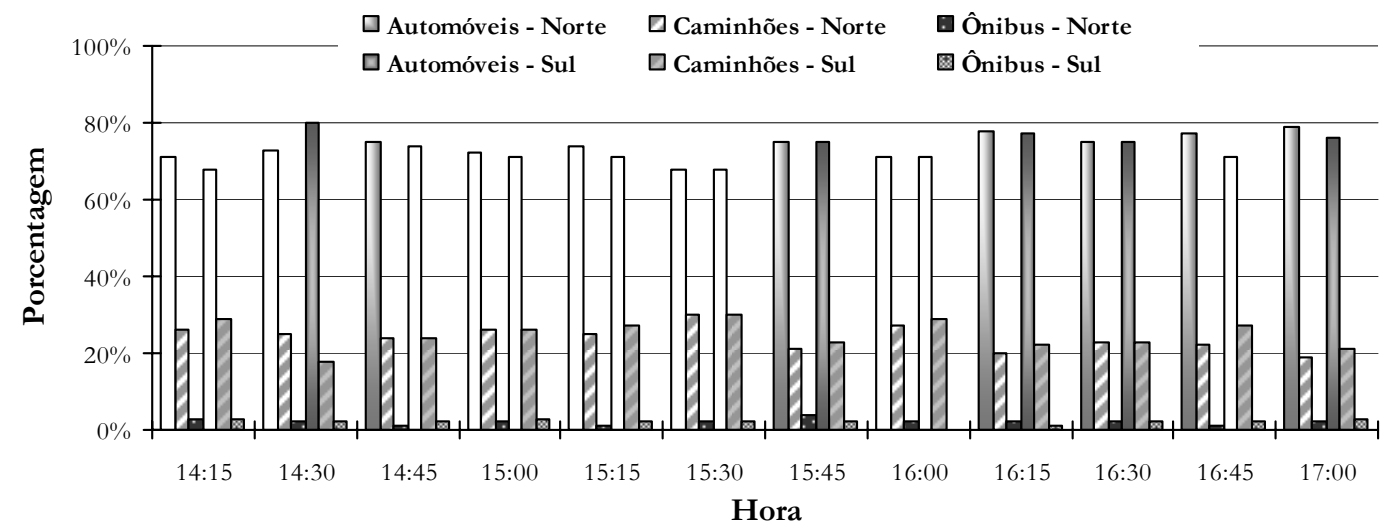

Figura 5.7 - Composição do tráfego na terceira coleta de dados (1/7/2005) 
Considerando-se todos os intervalos de 15 minutos, a participação dos automóveis na composição do tráfego do sentido Norte variou entre $67 \%$ e $81 \%$. Os caminhões apresentaram uma variação de $19 \%$ a $30 \%$ e os ônibus, de $0 \%$ a 4\%. No sentido Sul, a variação foi de $68 \%$ a $85 \%$ para os automóveis, $15 \%$ a $31 \%$ para os caminhões e $0 \%$ a $4 \%$ para os ônibus.

Tabela 5.3 - Composições horárias médias observadas nas coletas de dados (\%)

\begin{tabular}{ccccccc}
\hline \multirow{2}{*}{ Coleta de Dados } & \multicolumn{3}{c}{ Norte } & \multicolumn{3}{c}{ Sul } \\
\cline { 2 - 7 } & Automóveis & Caminhões & Ônibus & Automóveis & Caminhões & Onnibus \\
\hline $6 / 6 / 2005$ & 73 & 25 & 2 & 74 & 25 & 1 \\
$13 / 6 / 2005$ & 71 & 27 & 2 & 74 & 25 & 1 \\
$1 / 7 / 2005$ & 74 & 24 & 2 & 73 & 25 & 2 \\
\hline Média & $\mathbf{7 3}$ & $\mathbf{2 5}$ & $\mathbf{2}$ & $\mathbf{7 4}$ & $\mathbf{2 5}$ & $\mathbf{2}$ \\
\hline
\end{tabular}

Os dados apresentados na Tabela 5.3 indicam que não existe uma variação significativa nas composições médias do tráfego observadas entre as coletas de dados e também entre os sentidos de tráfego.

\subsubsection{Matriz origem/destino}

Através do "método das placas", foi possível obter as matrizes origem/destino do trecho estudado. Elas são matrizes dinâmicas, uma vez que o registro da hora de passagem do veículo pelos postos de controle associado à categoria e à placa desse veículo permite fazer a análise para cada período de 15 minutos.

O sentido Norte possui seis pontos de origem e sete pontos de destino, ou seja, 11 acessos intermediários além dos pontos de início e fim da SP-310. No sentido Sul, a rede simulada considera nove pontos de origem e nove pontos de destino, totalizando 16 acessos intermediários mais os dois pontos de início e fim da SP-310. A Figura 5.8 apresenta um desenho esquemático com os pontos de origem e destino da rede seguindo a numeração feita durante a codificação do CORSIM. 


\section{Norte}

6

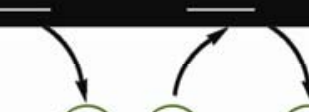

(15) 20
(60)

$60)$

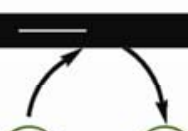

(27) 28

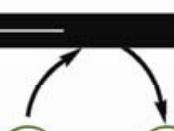

(32) 33

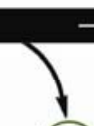

38

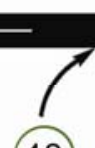

(42)

Sul

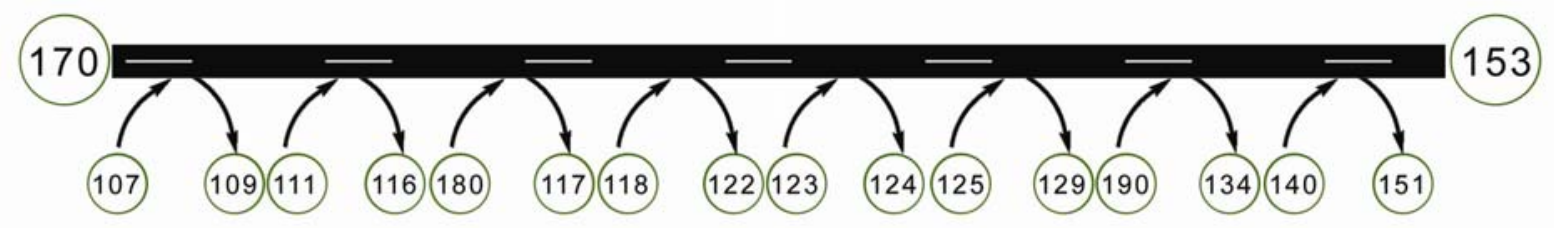

Figura 5.8 - Desenho esquemático com os pontos de origem e destino

As Tabelas 5.4 a 5.9 apresentam as matrizes médias de cada uma das coletas de dados e de cada sentido de tráfego. É importante ressaltar que, apesar de desejável, as matrizes não foram estratificadas por categoria de veículo, visto que o CORSIM não permite essa forma de inserção dos dados.

Tabela 5.4 - Matriz média da primeira coleta de dados (6/6/2005) - Sentido Norte

\begin{tabular}{cccccccc}
\hline $\mathbf{O} / \mathbf{D}$ & $\mathbf{1 5}$ & $\mathbf{6 0}$ & $\mathbf{2 7}$ & $\mathbf{3 2}$ & $\mathbf{3 8}$ & $\mathbf{4 4}$ & $\mathbf{4 6}$ \\
\hline $\mathbf{6}$ & $21 \%$ & $5 \%$ & $3 \%$ & $3 \%$ & $8 \%$ & $9 \%$ & $51 \%$ \\
$\mathbf{2 0}$ & - & $5 \%$ & $28 \%$ & $9 \%$ & $14 \%$ & $10 \%$ & $35 \%$ \\
$\mathbf{2 5}$ & - & - & $40 \%$ & $16 \%$ & $13 \%$ & $6 \%$ & $25 \%$ \\
$\mathbf{2 8}$ & - & - & - & $7 \%$ & $25 \%$ & $11 \%$ & $56 \%$ \\
$\mathbf{3 3}$ & - & - & - & - & $36 \%$ & $14 \%$ & $49 \%$ \\
$\mathbf{4 2}$ & - & - & - & - & - & $11 \%$ & $89 \%$ \\
\hline
\end{tabular}

Tabela 5.5 - Matriz média da primeira coleta de dados (6/6/2005) - Sentido Sul

\begin{tabular}{cccccccccc}
\hline $\mathbf{O} / \mathbf{D}$ & $\mathbf{1 0 9}$ & $\mathbf{1 1 6}$ & $\mathbf{1 1 7}$ & $\mathbf{1 2 2}$ & $\mathbf{1 2 4}$ & $\mathbf{1 2 9}$ & $\mathbf{1 3 4}$ & $\mathbf{1 5 1}$ & $\mathbf{1 5 3}$ \\
\hline $\mathbf{1 7 0}$ & $11 \%$ & $6 \%$ & $7 \%$ & $1 \%$ & $8 \%$ & $5 \%$ & $3 \%$ & $13 \%$ & $46 \%$ \\
$\mathbf{1 0 7}$ & $33 \%$ & $3 \%$ & $10 \%$ & $2 \%$ & $6 \%$ & $8 \%$ & $3 \%$ & $8 \%$ & $27 \%$ \\
$\mathbf{1 1 1}$ & - & $13 \%$ & $8 \%$ & $4 \%$ & $22 \%$ & $8 \%$ & $2 \%$ & $17 \%$ & $26 \%$ \\
$\mathbf{1 8 0}$ & - & - & $46 \%$ & $1 \%$ & $7 \%$ & $6 \%$ & $3 \%$ & $10 \%$ & $26 \%$ \\
$\mathbf{1 1 8}$ & - & - & - & $0 \%$ & $12 \%$ & $10 \%$ & $1 \%$ & $18 \%$ & $59 \%$ \\
$\mathbf{1 2 3}$ & - & - & - & - & $36 \%$ & $15 \%$ & $19 \%$ & $17 \%$ & $13 \%$ \\
$\mathbf{1 2 5}$ & - & - & - & - & - & $15 \%$ & $15 \%$ & $34 \%$ & $36 \%$ \\
$\mathbf{1 9 0}$ & - & - & - & - & - & - & $0 \%$ & $57 \%$ & $43 \%$ \\
$\mathbf{1 4 0}$ & - & - & - & - & - & - & - & $60 \%$ & $40 \%$ \\
\hline
\end{tabular}


Tabela 5.6 - Matriz média da segunda coleta de dados (13/6/2005) - Sentido Norte

\begin{tabular}{cccccccc}
\hline $\mathbf{O} / \mathbf{D}$ & $\mathbf{1 5}$ & $\mathbf{6 0}$ & $\mathbf{2 7}$ & $\mathbf{3 2}$ & $\mathbf{3 8}$ & $\mathbf{4 4}$ & $\mathbf{4 6}$ \\
\hline $\mathbf{6}$ & $23 \%$ & $4 \%$ & $2 \%$ & $3 \%$ & $9 \%$ & $8 \%$ & $51 \%$ \\
$\mathbf{2 0}$ & - & $4 \%$ & $15 \%$ & $8 \%$ & $15 \%$ & $8 \%$ & $50 \%$ \\
$\mathbf{2 5}$ & - & - & $23 \%$ & $14 \%$ & $11 \%$ & $7 \%$ & $46 \%$ \\
$\mathbf{2 8}$ & - & - & - & $5 \%$ & $24 \%$ & $10 \%$ & $61 \%$ \\
$\mathbf{3 3}$ & - & - & - & - & $38 \%$ & $15 \%$ & $46 \%$ \\
$\mathbf{4 2}$ & - & - & - & - & - & $12 \%$ & $88 \%$ \\
\hline
\end{tabular}

Tabela 5.7 - Matriz média da segunda coleta de dados (13/6/2005) - Sentido Sul

\begin{tabular}{cccccccccc}
\hline $\mathbf{O} / \mathbf{D}$ & $\mathbf{1 0 9}$ & $\mathbf{1 1 6}$ & $\mathbf{1 1 7}$ & $\mathbf{1 2 2}$ & $\mathbf{1 2 4}$ & $\mathbf{1 2 9}$ & $\mathbf{1 3 4}$ & $\mathbf{1 5 1}$ & $\mathbf{1 5 3}$ \\
\hline $\mathbf{1 7 0}$ & $10 \%$ & $7 \%$ & $7 \%$ & $1 \%$ & $7 \%$ & $4 \%$ & $2 \%$ & $12 \%$ & $49 \%$ \\
$\mathbf{1 0 7}$ & $33 \%$ & $2 \%$ & $10 \%$ & $2 \%$ & $6 \%$ & $7 \%$ & $3 \%$ & $8 \%$ & $29 \%$ \\
$\mathbf{1 1 1}$ & - & $15 \%$ & $9 \%$ & $3 \%$ & $21 \%$ & $7 \%$ & $1 \%$ & $16 \%$ & $28 \%$ \\
$\mathbf{1 8 0}$ & - & - & $45 \%$ & $1 \%$ & $5 \%$ & $7 \%$ & $5 \%$ & $10 \%$ & $28 \%$ \\
$\mathbf{1 1 8}$ & - & - & - & $0 \%$ & $10 \%$ & $10 \%$ & $3 \%$ & $17 \%$ & $61 \%$ \\
$\mathbf{1 2 3}$ & - & - & - & - & $33 \%$ & $14 \%$ & $15 \%$ & $16 \%$ & $22 \%$ \\
$\mathbf{1 2 5}$ & - & - & - & - & - & $13 \%$ & $13 \%$ & $30 \%$ & $43 \%$ \\
$\mathbf{1 9 0}$ & - & - & - & - & - & - & $1 \%$ & $54 \%$ & $46 \%$ \\
$\mathbf{1 4 0}$ & - & - & - & - & - & - & - & $59 \%$ & $41 \%$ \\
\hline
\end{tabular}

Tabela 5.8 - Matriz média da terceira coleta de dados (1/7/2005) - Sentido Norte

\begin{tabular}{cccccccc}
\hline $\mathbf{O} / \mathbf{D}$ & $\mathbf{1 5}$ & $\mathbf{6 0}$ & $\mathbf{2 7}$ & $\mathbf{3 2}$ & $\mathbf{3 8}$ & $\mathbf{4 4}$ & $\mathbf{4 6}$ \\
\hline $\mathbf{6}$ & $17 \%$ & $4 \%$ & $2 \%$ & $3 \%$ & $7 \%$ & $9 \%$ & $58 \%$ \\
$\mathbf{2 0}$ & - & $2 \%$ & $16 \%$ & $8 \%$ & $5 \%$ & $5 \%$ & $64 \%$ \\
$\mathbf{2 5}$ & - & - & $24 \%$ & $15 \%$ & $7 \%$ & $5 \%$ & $50 \%$ \\
$\mathbf{2 8}$ & - & - & - & $6 \%$ & $17 \%$ & $9 \%$ & $68 \%$ \\
$\mathbf{3 3}$ & - & - & - & - & $31 \%$ & $13 \%$ & $55 \%$ \\
$\mathbf{4 2}$ & - & - & - & - & - & $11 \%$ & $89 \%$ \\
\hline
\end{tabular}

Tabela 5.9 - Matriz média da terceira coleta de dados (1/7/2005) - Sentido Sul

\begin{tabular}{cccccccccc}
\hline $\mathbf{O} / \mathbf{D}$ & $\mathbf{1 0 9}$ & $\mathbf{1 1 6}$ & $\mathbf{1 1 7}$ & $\mathbf{1 2 2}$ & $\mathbf{1 2 4}$ & $\mathbf{1 2 9}$ & $\mathbf{1 3 4}$ & $\mathbf{1 5 1}$ & $\mathbf{1 5 3}$ \\
\hline $\mathbf{1 7 0}$ & $9 \%$ & $5 \%$ & $9 \%$ & $1 \%$ & $6 \%$ & $5 \%$ & $2 \%$ & $12 \%$ & $51 \%$ \\
$\mathbf{1 0 7}$ & $28 \%$ & $1 \%$ & $11 \%$ & $2 \%$ & $6 \%$ & $9 \%$ & $3 \%$ & $7 \%$ & $33 \%$ \\
$\mathbf{1 1 1}$ & - & $11 \%$ & $12 \%$ & $2 \%$ & $18 \%$ & $7 \%$ & $2 \%$ & $16 \%$ & $31 \%$ \\
$\mathbf{1 8 0}$ & - & - & $57 \%$ & $1 \%$ & $5 \%$ & $7 \%$ & $3 \%$ & $9 \%$ & $18 \%$ \\
$\mathbf{1 1 8}$ & - & - & - & $1 \%$ & $9 \%$ & $13 \%$ & $5 \%$ & $15 \%$ & $58 \%$ \\
$\mathbf{1 2 3}$ & - & - & - & - & $28 \%$ & $15 \%$ & $16 \%$ & $15 \%$ & $26 \%$ \\
$\mathbf{1 2 5}$ & - & - & - & - & - & $16 \%$ & $14 \%$ & $32 \%$ & $38 \%$ \\
$\mathbf{1 9 0}$ & - & - & - & - & - & - & $0 \%$ & $51 \%$ & $49 \%$ \\
$\mathbf{1 4 0}$ & - & - & - & - & - & - & - & $57 \%$ & $43 \%$ \\
\hline
\end{tabular}

As matrizes médias aqui apresentadas não mostram uma grande variabilidade entre as coletas de dados. Entretanto, as matrizes obtidas a cada 15 minutos (que serviram de dados de entra- 
da para o simulador CORSIM e que podem ser encontradas no Apêndice A) sofrem uma influência considerável do tráfego urbano e por isso apresentam uma variação notável.

\subsubsection{Velocidade média da corrente de tráfego}

A definição da velocidade média da corrente de tráfego adotada nesta pesquisa é a média aritmética das velocidades pontuais de todos os veículos que passam por um determinado ponto ou seção da via durante intervalos de tempo finitos, ainda que sejam muito pequenos. A velocidade pontual é a velocidade instantânea de um veículo quando passa por um determinado ponto ou seção da via.

Segundo o Departamento Nacional de Infra-estrutura de Transportes (DNIT), de maneira geral, os métodos de obtenção da velocidade pontual podem ser classificados em dois tipos: base curta e base longa. O termo "base" tem sentido de distância/comprimento e refere-se ao trecho ao longo do qual se observa o veículo e se obtém os instantes de entrada e saída da seção, que levarão à determinação da velocidade pontual.

Quando a base é curta, a probabilidade de que o veículo mude sensivelmente de velocidade é desprezível, permitindo que se considere que a velocidade de percurso é a velocidade pontual em qualquer ponto da base (DNIT, 2006).

O método das bases curtas precisa de instrumentos de alta precisão, que captem a passagem do veículo pelo trecho escolhido, enquanto que o das bases longas pode fazer uso de cronômetros. O DNIT (2006) sugere que distâncias entre 30 m e 100 m sejam usadas no método das bases longas.

Durante o período de planejamento das coletas de dados, foi estabelecido que as velocidades pontuais dos veículos seriam obtidas usando o método de base longa, através do conhecimento de uma distância pré-fixada em campo e do tempo gasto para percorrê-la. Essa distância foi escolhida em função das linhas de divisão de fluxos de mesmo sentido, na cor branca, que fazem parte da sinalização horizontal. No trecho estudado essas linhas são seccionadas, conforme 
mostra a Figura 5.9. A medição em campo indicou que o padrão adotado no trecho estabelece uma distância $\mathrm{A}+\mathrm{B}$ de $15,5 \mathrm{~m}$.

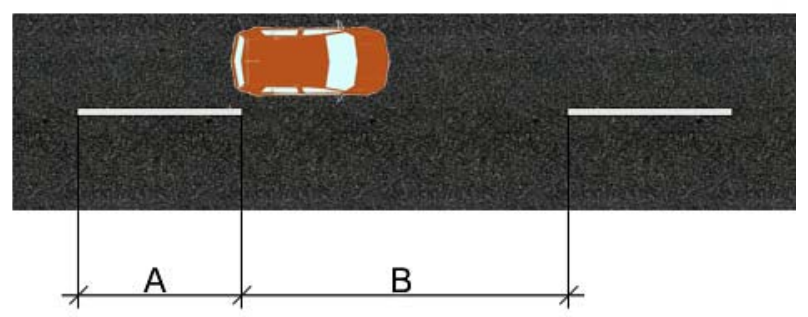

Figura 5.9 - Linhas de divisão seccionadas

Como as imagens captadas pelas câmeras de vídeo permitiam a visualização de sucessivas linhas seccionadas, foi fixada uma seção de $62 \mathrm{~m}$ em cada posto de controle ao longo da SP-310. Esse valor corresponde à distância de quatro linhas seccionadas e consiste na base do método para o cálculo da velocidade pontual.

Para a obtenção do tempo gasto por cada veículo para percorrer a seção de $62 \mathrm{~m}$ de rodovia fez-se uso de uma macro no Microsoft Excel, escrita na linguagem VBA (Visual Basic for Applications). A macro desenvolvida permitia a medição do tempo que um veículo demorava para transpor a seção, mediante a utilização do relógio do computador. Esse relógio era acionado através de teclas de atalho, relacionadas à entrada e à saída do veículo na seção. Dessa forma, com quatro teclas de atalhos ativadas era possível registrar a entrada e a saída de todos os veículos em cada uma das duas faixas de tráfego de cada seção. Então, o comprimento da seção dividido pelo tempo gasto para percorrê-la fornece a velocidade, que pode ser considerada a velocidade pontual. A principal desvantagem na utilização desse método consiste no erro que deriva da decisão do pesquisador acerca dos instantes de passagem do veículo pelos extremos da seção.

A Tabela 5.10 apresenta as velocidades médias obtidas por coleta de dados em cada um dos postos de controle da SP-310. Na terceira coleta de dados foram adicionados dois postos de controle intermediários, um em cada sentido de tráfego. 
À exemplo das matrizes origem/destino, os dados de velocidade não foram separados por categoria veicular porque o arquivo de resultados do CORSIM fornece apenas os dados de velocidade média dos veículos no tramo.

Tabela 5.10 - Velocidades médias $(\mathrm{km} / \mathrm{h})$

\begin{tabular}{|c|c|c|c|c|c|c|c|c|}
\hline \multirow{3}{*}{ Coleta de Dados } & \multicolumn{4}{|c|}{ Norte } & \multicolumn{4}{|c|}{ Sul } \\
\hline & \multirow{2}{*}{ Início } & \multicolumn{2}{|c|}{ Intermediário } & \multirow{2}{*}{ Fim } & \multirow{2}{*}{ Início } & \multicolumn{2}{|c|}{ Intermediário } & \multirow{2}{*}{ Fim } \\
\hline & & 1 & 2 & & & 1 & 2 & \\
\hline $6 / 6 / 2005$ & 79 & 83 & - & 82 & 78 & 71 & - & 73 \\
\hline $13 / 6 / 2005$ & 75 & 79 & - & 77 & 75 & 71 & - & 78 \\
\hline $1 / 7 / 2005$ & 75 & 77 & 83 & 82 & 75 & 67 & 74 & 76 \\
\hline Média & 76 & 80 & 83 & 80 & 76 & 70 & 74 & 76 \\
\hline
\end{tabular}

A observação da Tabela 5.10 indica que, para cada posto de controle, não há uma grande variação nas velocidades em função da coleta de dados. Além disso, verifica-se que as médias das velocidades do sentido Norte são superiores às médias das velocidades do sentido Sul, com exceção do posto de início do sentido Norte, que corresponde ao posto final do sentido Sul.

O fato de as velocidades do sentido Norte serem mais elevadas que no sentido Sul é justificado pela existência de rampas nos quatro postos de controle do sentido Norte, com declividades que variam de $2 \%$ a $4 \%$. Nos postos de controle do sentido Sul, a inclinação máxima das rampas é $5 \%$, sendo que não há rampas descendentes.

\subsection{Dados sobre as características dos veículos pesados}

Para a caracterização da frota de veículos pesados que trafega nas rodovias de pista dupla do estado de São Paulo, foram realizadas coletas de dados em balanças rodoviárias localizadas em diferentes rodovias. Essas balanças realizam uma pesagem dinâmica dos caminhões, com verificação não somente do peso de cada eixo isolado, como também do peso de grupos de eixos e do peso bruto total dos veículos. Essas pesagens têm por objetivo conhecer as cargas com as quais os veículos solicitam a infra-estrutura para efeito de fiscalização, controle, estatística, avaliação e dimensionamento de pavimentos e pontes. 
No Brasil, os limites máximos de peso relacionados aos veículos pesados são determinados através de resoluções do Conselho Nacional de Trânsito (CONTRAN). O Código de Trânsito Brasileiro, instituído pelo CONTRAN, estabeleceu, através da Resolução n. 210 de 13/11/2006, limites de peso e dimensões para veículos que transitam por vias terrestres. Em síntese, os limites de peso fixados são:

- Peso bruto total (PBT) até 45 t;

- Peso bruto por eixo isolado até 10 t (4 pneus) ou 6 t (2 pneus);

- Peso bruto por conjunto de dois eixos em tandem, com distância entre eixos superior a $1,20 \mathrm{~m}$ e inferior a $2,40 \mathrm{~m}$, até $17 \mathrm{t}$;

- Peso bruto por conjunto de três eixos em tandem, distanciados entre 1,20 m e 2,40 m, até $25,5 \mathrm{t}$.

No entanto, a circulação de Combinações de Veículos de Carga (CVCs) de até 74 t é permitida através de Autorização Especial de Trânsito (AET), de acordo com a Resolução n. ${ }^{\circ} 211$ de $13 / 11 / 2006$.

A localização das balanças, as datas das coletas de dados e os tamanhos das amostras obtidas estão listados na Tabela 5.11. Esse conjunto de balanças foi escolhido para que tornasse possível a obtenção de uma amostra que representasse a variabilidade das características dos veículos pesados, em uma tentativa de caracterizar a frota que circula no estado de São Paulo.

Tabela 5.11 - Balanças rodoviárias

\begin{tabular}{lccc}
\hline \multicolumn{1}{c}{ Localização } & Sentido & Data da Coleta & Amostra \\
\hline SP-225 $(\mathrm{km} \mathrm{224})$ & Oeste & $28 / 9 / 2004$ & 192 \\
SP-330 (km 207) & Norte & $7 / 10 / 2004$ & 209 \\
SP-330 (km 207) & Norte & $16 / 2 / 2005$ & 352 \\
SP-330 (km 53) & Sul & $1 / 3 / 2005$ & 968 \\
SP-330 (km 37) & Norte & $2 / 3 / 2005$ & 787 \\
SP-348 (km 58) & Sul & $8 / 3 / 2005$ & 1.901 \\
SP-348 (km 40) & Norte & $9 / 3 / 2005$ & 1.010 \\
SP-310 (km 200) & Norte & $12 / 8 / 2005$ & 834 \\
\hline
\end{tabular}


As coletas de dados nas balanças rodoviárias foram realizadas por dois pesquisadores, que registravam em planilha informações tais como marca, modelo, configuração de eixos dos veículos e existência de eixos erguidos. Essas informações foram posteriormente utilizadas no levantamento da potência nominal dos veículos, realizado através de consulta a dados contidos em catálogos, publicações especializadas em veículos pesados e websites dos fabricantes.

Duas câmeras de vídeo também foram utilizadas durante as coletas de dados, a fim de auxiliar na associação das informações obtidas em campo com os dados de pesagem contidos em relatórios emitidos pelas balanças.

\subsubsection{Nomenclatura adotada}

Em virtude da grande diversidade de veículos pesados existente na amostra obtida, foi necessário adotar uma nomenclatura, estabelecida em função da configuração básica dos veículos. Entende-se por configuração básica a quantidade de unidades que compõem o veículo, sua quantidade de eixos e de grupos de eixos, independentemente da rodagem. A adoção dessa nomenclatura visa uma melhor identificação e classificação dos veículos pesados.

Apesar de não haver um consenso com relação à nomenclatura que deve ser adotada no âmbito nacional, o DNIT sugere uma identificação representada por um código de até dois algarismos, intercalados por uma letra. O primeiro algarismo indica a quantidade de eixos da unidade tratora, enquanto o segundo algarismo, caso exista, indica a quantidade de eixos da(s) unidade(s) rebocada(s). As principais letras e seus respectivos significados são:

- C: caminhão-plataforma ou caminhão-plataforma + reboque;

- S: cavalo mecânico + semi-reboque;

- I: cavalo mecânico + semi-reboque com distância entre eixos $>2,40$ m (eixos isolados);

- J: cavalo mecânico + semi-reboque com um eixo isolado e um eixo em tandem; e

- T: cavalo mecânico + dois ou três semi-reboques.

Dessa forma, o código fica assim estabelecido: 
- $n$ Cm: caminhão-plataforma com $n$ eixos transporta um reboque acoplado de $m$ eixos. Se $m$ for omitido, o caminhão-plataforma não possui unidade rebocada.

- $n \mathrm{~S} m$ : cavalo mecânico com $n$ eixos transporta um semi-reboque (S) de $m$ eixos, sendo o total de eixos da composição dado por $n+m$.

- $n \mathrm{I} m$ : cavalo mecânico com $n$ eixos transporta um semi-reboque (I) de $m$ eixos, espaçados de pelo menos $2,40 \mathrm{~m}$, sendo o total de eixos da composição dado por $n+m$.

- $\quad n \mathrm{~J} m$ : cavalo mecânico com $n$ eixos transporta um semi-reboque $(\mathrm{J})$ de $m$ eixos, com um deles isolado e outro em tandem. O total de eixos da composição é dado por $n+m$.

- $\quad n$ T m: cavalo mecânico com $n$ eixos transporta duas ou três unidades rebocadas do tipo semi-reboque (T), que juntas totalizam $m$ eixos. O total de eixos da composição é dado por $n+m$.

Exemplificando a nomenclatura, tem-se que o veículo 2S3 é um cavalo mecânico com dois eixos tracionando um semi-reboque com três eixos e que o veículo 3T4 é um cavalo mecânico com três eixos tracionando dois semi-reboques com dois eixos cada.

\subsubsection{Dados coletados}

No total, foram coletados dados de 6.253 caminhões, distribuídos em 22 configurações de eixos. A Tabela 5.12 lista a nomenclatura das principais configurações observadas, com suas respectivas representações pictográficas. Essas representações pictográficas são as mesmas apresentadas por Widmer (2004). Ainda na Tabela 5.12, são apresentados o tamanho da amostra e a freqüência das principais configurações observadas.

A análise da Tabela 5.12 mostra que 59\% dos veículos pesados observados nas rodovias paulistas de pista dupla são do tipo caminhão-plataforma (rígidos) e 41\% são articulados. Dentre os articulados, o caminhão do tipo 2S3 é o mais comum da amostra (59,6\%). 
Tabela 5.12 - Configurações de eixos observadas nas balanças

\begin{tabular}{|c|c|c|c|c|}
\hline Eixos & Configuração & Nomenclatura & Amostra & Freqüência \\
\hline 2 & & $2 \mathrm{C}$ & 1.881 & $30,08 \%$ \\
\hline \multirow{2}{*}{3} & & $3 \mathrm{C}$ & 1.809 & $28,93 \%$ \\
\hline & & $2 \mathrm{~S} 1$ & 39 & $0,62 \%$ \\
\hline 4 & & $2 \mathrm{~S} 2$ & 206 & $3,29 \%$ \\
\hline \multirow{2}{*}{5} & & $2 \mathrm{~S} 3$ & 1.527 & $24,42 \%$ \\
\hline & & $2 \mathrm{I} 3$ & 71 & $1,14 \%$ \\
\hline 6 & & $3 \mathrm{~S} 3$ & 413 & $6,61 \%$ \\
\hline \multirow[t]{3}{*}{7} & & 3T4 & 243 & $3,89 \%$ \\
\hline & Outros & - & 64 & $1,02 \%$ \\
\hline & & Total & 6.253 & $100,00 \%$ \\
\hline
\end{tabular}

\subsubsection{Peso e relação peso/potência}

A Figura 5.10 apresenta as distribuições acumuladas dos pesos brutos totais e a Figura 5.11 mostra as distribuições acumuladas das relações peso/potência das oito configurações mais representativas da amostra de veículos pesados observada nas balanças.

Apesar de existirem oito configurações na amostra de pesagem com freqüência considerada significativa, o modelo de simulação de tráfego usado nesta pesquisa (CORSIM), dentro de suas limitações, permite ao usuário especificar no máximo quatro categorias de caminhões para serem utilizadas durante a simulação. Então, foi necessário adotar um critério de agrupamento das configurações observadas. À exemplo do trabalho desenvolvido por Cunha et al. (2005), o critério adotado foi a similaridade das distribuições acumuladas da relação peso/potência. A Tabela 5.13 apresenta o agrupamento das configurações em apenas quatro categorias, para fins de simulação. Esta tabela mostra também o veículo típico e a média e mediana da relação peso/potência de cada categoria. 


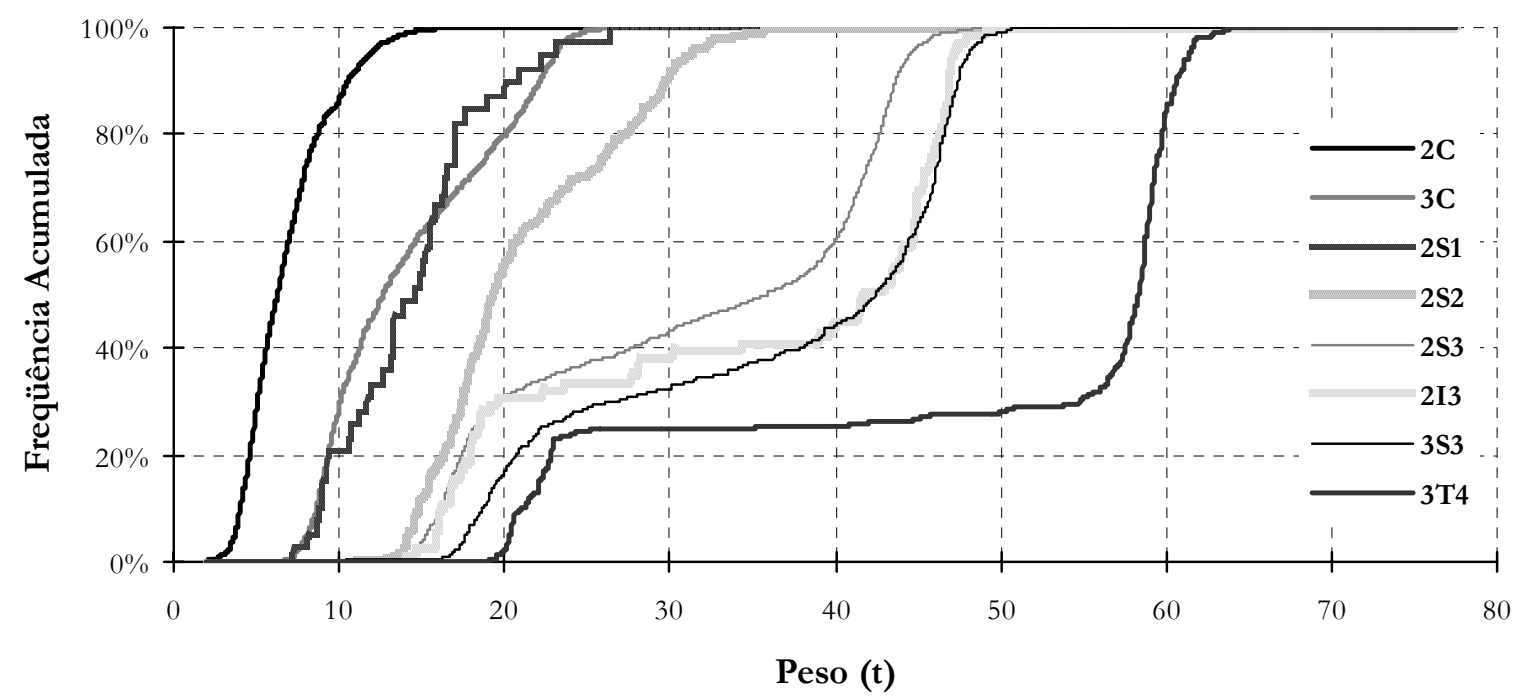

Figura 5.10 - Distribuição acumulada do PBT

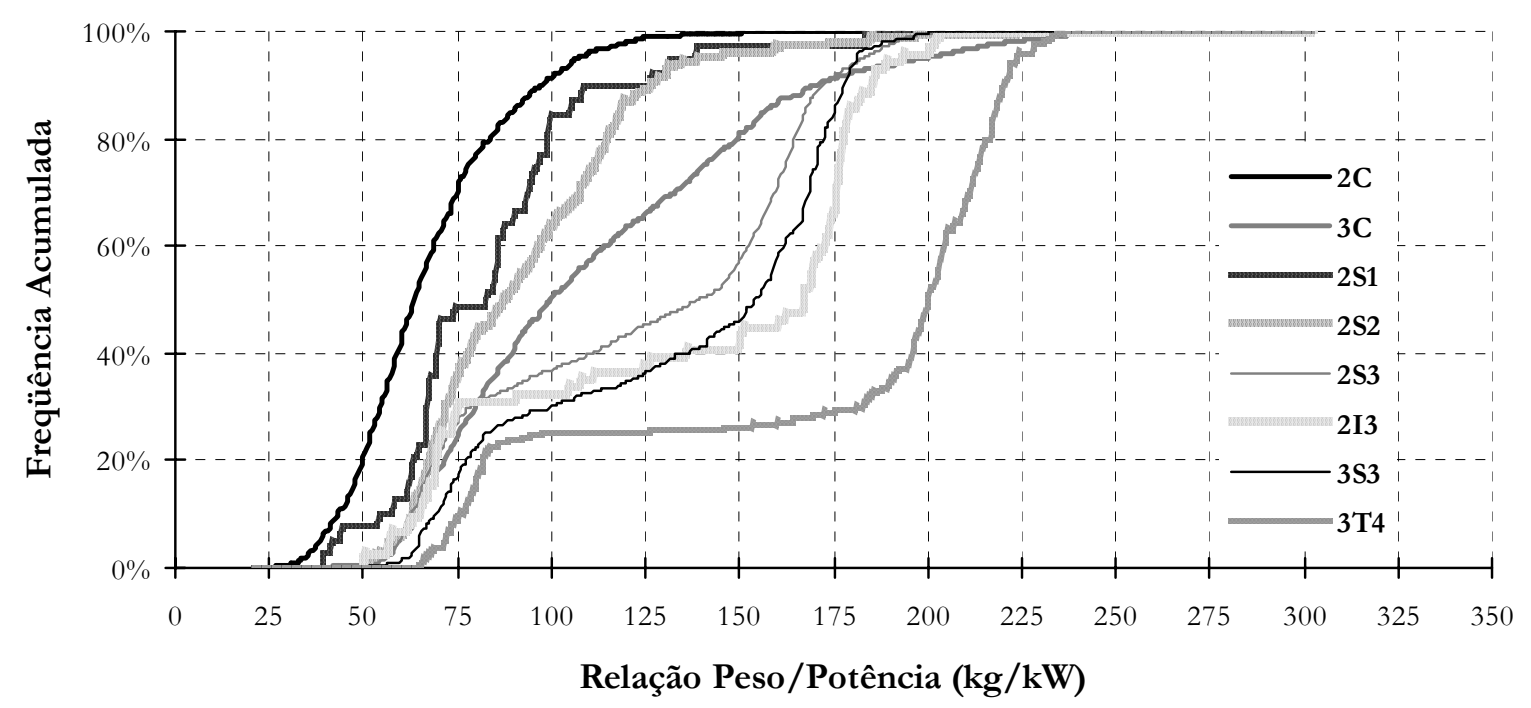

Figura 5.11 - Distribuição acumulada da relação peso/potência

Tabela 5.13 - Agrupamento das configurações e seus respectivos valores de peso/potência

\begin{tabular}{cccccc}
\hline Categoria & \multirow{2}{*}{ Eixos } & Configurações & Veículo Típico & \multicolumn{2}{c}{ Peso/Potência (kg/kW) } \\
\cline { 5 - 6 } & & 2C & Média & Mediana \\
\hline Leves & 2 & 3C, 2S1 e 2S2 & Mercedez-B000 & 67 & 64 \\
Médios & 3 e 4 & 3C 2 L 1620 & 110 & 98 \\
Pesados & 5 e 6 & 2S3, 2I3 e 3S3 & Scania 113H & 126 & 144 \\
Extra-pesados & $7+$ & 3T4 & Volvo FH12 & 173 & 200 \\
\hline
\end{tabular}

Uma vez definido o critério para agrupamento dos veículos pesados, optou-se por incluir nas categorias as demais configurações restantes na amostra, que juntas totalizaram apenas 64 pesagens. Dessa forma, o agrupamento geral das 22 configurações observadas em campo pode 
ser visualizado na Tabela 5.14. Nessa tabela, o PBT máximo leva em conta a atual legislação relativa às dimensões e pesos dos veículos e o PBT médio é aquele obtido nas pesagens.

Tabela 5.14 - Caracterização das categorias dos veículos pesados

\begin{tabular}{|c|c|c|c|c|c|c|}
\hline Categoria & Configuração & Amostra & Freqüência & Eixos & PBT Máximo (t) & PBT Médio (t) \\
\hline Leves & $2 \mathrm{C}$ & 1.881 & $30,08 \%$ & 2 & 16,0 & 6,8 \\
\hline \multirow{7}{*}{ Médios } & $3 \mathrm{C}$ & 1.809 & $28,93 \%$ & 3 & 23,0 & 14,2 \\
\hline & $2 \mathrm{~S} 2$ & 206 & $3,29 \%$ & 4 & 33,0 & 21,1 \\
\hline & $2 \mathrm{~S} 1$ & 39 & $0,62 \%$ & 3 & 26,0 & 14,4 \\
\hline & $2 \mathrm{I} 2$ & 6 & $0,10 \%$ & 4 & 36,0 & 19,4 \\
\hline & $2 \mathrm{C} 2$ & 1 & $0,02 \%$ & 4 & 36,0 & 21,0 \\
\hline & $4 \mathrm{CD}$ & 1 & $0,02 \%$ & 4 & 29,0 & 28,3 \\
\hline & $4 \mathrm{C}$ & 1 & $0,02 \%$ & 4 & 31,5 & 32,1 \\
\hline \multirow{11}{*}{ Pesados } & $2 \mathrm{~S} 3$ & 1.527 & $24,42 \%$ & 5 & 41,5 & 31,4 \\
\hline & $3 \mathrm{~S} 3$ & 413 & $6,61 \%$ & 6 & 48,5 & 36,3 \\
\hline & $2 \mathrm{I} 3$ & 71 & $1,14 \%$ & 5 & 46,0 & 34,5 \\
\hline & $3 \mathrm{~S} 2$ & 13 & $0,21 \%$ & 5 & 40,0 & 28,7 \\
\hline & $2 \mathrm{~J} 3$ & 11 & $0,18 \%$ & 5 & 43,0 & 34,2 \\
\hline & $3 \mathrm{C} 2$ & 9 & $0,14 \%$ & 5 & 43,0 & 33,7 \\
\hline & $3 \mathrm{I} 2$ & 4 & $0,06 \%$ & 5 & 43,0 & 30,0 \\
\hline & $2 \mathrm{~T} 4$ & 3 & $0,05 \%$ & 6 & 50,0 & 43,8 \\
\hline & $3 \mathrm{C} 3$ & 3 & $0,05 \%$ & 6 & 50,0 & 27,4 \\
\hline & $3 \mathrm{~J} 3$ & 3 & $0,05 \%$ & 6 & 50,0 & 42,8 \\
\hline & $3 \mathrm{I} 3$ & 1 & $0,02 \%$ & 6 & 53,0 & 18,0 \\
\hline \multirow{4}{*}{ Extra-pesados } & 3T4 & 243 & $3,89 \%$ & 7 & 57,0 & 49,1 \\
\hline & $3 \mathrm{~T} 6$ & 5 & $0,08 \%$ & 9 & 74,0 & 63,3 \\
\hline & $3 \mathrm{~S} 4$ & 3 & $0,05 \%$ & 7 & 57,0 & 54,5 \\
\hline & Total & 6.253 & $100,00 \%$ & & & \\
\hline
\end{tabular}

A Figura 5.12 apresenta as distribuições acumuladas da relação peso/potência para as categorias agrupadas. Observa-se que cada uma das distribuições possui um perfil bem definido, principalmente aquelas das categorias de caminhões leves e extra-pesados. Apesar de as demais distribuições mostrarem perfis semelhantes até aproximadamente o $30^{\circ}$ percentil, a partir desse ponto cada uma delas segue um perfil distinto, justificando a escolha de tais categorias. 


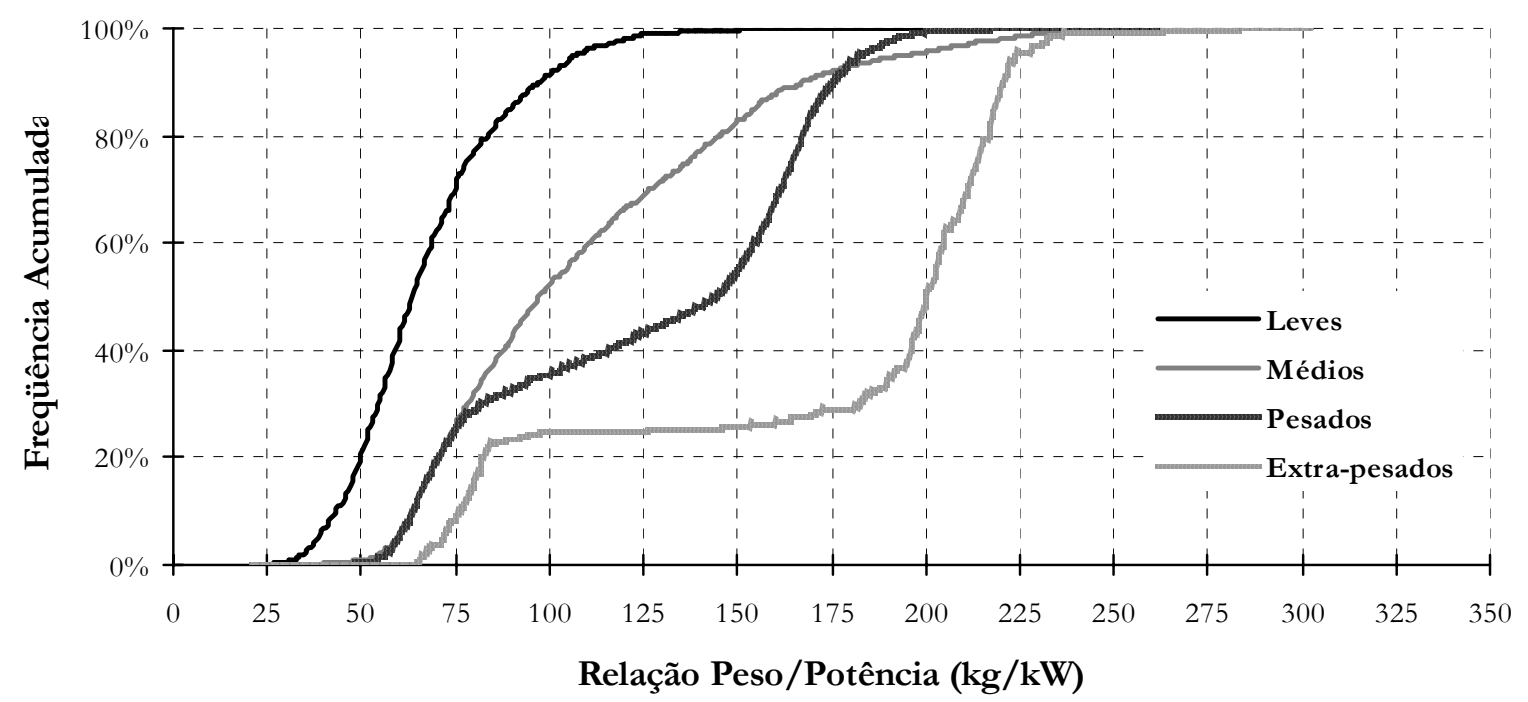

Figura 5.12 - Distribuição acumulada da relação peso/potência (categorias agrupadas)

\subsubsection{Distâncias entre eixos}

De posse da configuração de eixos, marca e modelo do caminhão, foi feito um levantamento detalhado de suas características. Esse levantamento visou não somente o conhecimento da potência nominal dos veículos (como citado anteriormente), como também o conhecimento de todas as distâncias entre eixos existentes. A obtenção das distâncias entre eixos é considerada fundamental para a realização do estudo de caso proposto nesta pesquisa.

A tarefa de obter a distância entre eixos dos 22 tipos de configurações observadas nas balanças consistiu em um trabalho minucioso, visto que existe uma grande variedade nos padrões estabelecidos por cada fabricante e mesmo entre modelos de um mesmo fabricante. Por exemplo, o modelo 1722 Cargo da Ford, com configuração 3C, pode apresentar distância entre os dois primeiros eixos de 4,34 $\mathrm{m}$ ou $4,80 \mathrm{~m}$.

Um outro fator importante é que os veículos articulados podem utilizar implementos rodoviários (carrocerias) de uma grande variedade de fabricantes, cada um adotando um padrão diferente de distâncias entre eixos, embora semelhantes entre si. Além disso, os implementos rodoviários são projetados em função da carga a ser transportada, ou seja, um semi-reboque de um determinado fabricante pode ser projetado para ser um caminhão tanque, graneleiro ou portacontêiner, entre outros. 
Dentre os principais fabricantes de implementos rodoviários pesquisados, aquele que apresentou dados mais completos das características técnicas de seus produtos foi a Randon S/A. Dessa forma, esta pesquisa considerou que toda a amostra de veículos articulados utilizava implementos desse fabricante.

É importante destacar que as imagens gravadas nas balanças foram usadas para que pudessem ser feitas considerações sobre o tipo de carga transportada por cada veículo e, assim, associar o modelo de implemento rodoviário que mais se aproximasse da realidade.

A Tabela 5.15 apresenta uma pequena amostra do banco de dados criado a partir das pesagens dos 6.253 veículos e do conhecimento de suas respectivas configurações, marcas e modelos. Essa tabela mostra apenas 10 combinações dessas três características. O total de combinações observadas nas balanças foi de 500, sendo que as configurações que apresentaram uma maior variedade de marcas e modelos foram a 3C e a 2C. As amostras dessas configurações possuem, respectivamente, 151 e 105 diferentes veículos.

Tabela 5.15 - Exemplo do banco de dados

\begin{tabular}{cccccccccccc}
\hline \multirow{2}{*}{ Configuração } & \multirow{2}{*}{ Marca/Modelo } & \multicolumn{4}{c}{ Distância entre Eixos (m) } & \multicolumn{5}{c}{ Peso por Eixo (kg) } \\
\cline { 3 - 10 } & & $\mathbf{1}$ & $\mathbf{2}$ & $\mathbf{3}$ & $\mathbf{4}$ & $\mathbf{1}^{\mathbf{0}}$ & $\mathbf{2}^{\mathbf{o}}$ & $\mathbf{3}^{\mathbf{o}}$ & $\mathbf{4}^{\mathbf{o}}$ & $\mathbf{5}^{\mathbf{0}}$ \\
\hline 2C & Ford 1415 Cargo & 4,80 & - & - & - & 4.090 & 4.720 & - & - & - \\
2C & Mercedes-Benz 1113 & 5,10 & - & - & - & 4.070 & 7.140 & - & - & - \\
2C & Volkswagen 13-180 & 3,56 & - & - & - & 4.170 & 4.760 & - & - & - \\
3C & Ford 4030 Cargo & 5,30 & 1,22 & - & - & 4.310 & 8.240 & 6.120 & - & - \\
3C & Ford 1722 Cargo & 4,80 & 1,22 & - & - & 6.030 & 10.020 & 8.160 & - & - \\
3C & Mercedes-Benz 1513 & 5,36 & 1,36 & - & - & 4.020 & 3.040 & 2.320 & - & - \\
3C & Volkswagen 17-210 & 4,56 & 1,37 & - & - & 2.960 & 6.780 & $0^{*}$ & - & - \\
2S2 & Mercedes-Benz 1630 & 4,50 & 7,05 & 1,25 & - & 4.390 & 5.820 & 3.120 & 3.700 & - \\
2S3 & Scania 113H & 3,55 & 4,55 & 1,25 & 1,25 & 4.640 & 8.140 & 2.680 & 7.670 & 6.640 \\
2S3 & Scania P310 & 3,55 & 8,57 & 1,25 & 1,25 & 4.190 & 4.250 & 1.700 & 2.750 & 3.820 \\
\hline
\end{tabular}

${ }^{*}$ Peso por eixo igual a zero significa que o eixo do veículo encontrava-se erguido

\subsection{Considerações finais}

Com base nos dados apresentados neste capítulo, o simulador CORSIM foi codificado de forma a representar adequadamente a rede de tráfego estudada. Essa representação permitiu que fossem executadas as etapas de calibração e validação do simulador, discutidas no Capítulo 6. 
Além disso, a realização de coletas de dados em balanças rodoviárias possibilitou a obtenção de dados importantes para a condução do estudo de caso, apresentado no Capítulo 7 deste texto. 


\section{Calibração e Validação do CORSIM}

Os modelos de simulação de tráfego são reconhecidos como uma das ferramentas mais poderosas para a análise e o planejamento de sistemas de tráfego. A maioria dos modelos conhecidos e usados no Brasil foi desenvolvida em outros países, com a inclusão de parâmetros ajustados para reproduzir as condições locais de tráfego. Como as características principais dos modelos de simulação estão relacionadas ao desempenho dos veículos e ao comportamento dos motoristas, os valores iniciais dos parâmetros do simulador podem não ser adequados para representar as condições de tráfego encontradas em outros locais. Portanto, esses parâmetros devem ser calibrados para melhor representar o funcionamento do sistema que está sendo modelado (Elefteriadou et al., 1999).

Este capítulo apresenta alguns conceitos referentes à calibração e validação de modelos de simulação de tráfego, o método utilizado para calibrar o CORSIM e os resultados obtidos em sua calibração e validação.

\subsection{Definição dos termos "calibração" e "validação"}

A calibração é o processo de ajuste dos parâmetros do modelo de simulação de tráfego para melhorar a sua habilidade de reproduzir o comportamento dos motoristas e o desempenho dos veículos para condições locais (Ben-Akiva et al., 2004). 
A calibração é necessária porque não se pode esperar que um modelo de simulação seja eficiente de forma que consiga representar com precisão suficiente todas as possíveis condições de tráfego. Até o mais detalhado modelo de simulação microscópica contém somente uma fração de todas as variáveis que afetam o tráfego real. Dessa forma, como nenhum modelo consegue incluir todo esse universo de variáveis, eles devem ser adaptados para condições locais (Dowling et al., 2004).

Todo simulador possui parâmetros de calibração que podem ser ajustados pelos usuários e que contém inicialmente valores default sugeridos pelos seus desenvolvedores. Entretanto, somente em raras circunstâncias esses modelos são capazes de produzir bons resultados para um caso específico usando os valores default. O usuário deve sempre realizar uma calibração para assegurar que o modelo codificado reproduz com fidelidade as condições de tráfego locais e o comportamento dos motoristas. Logo, o objetivo da calibração é procurar valores para os parâmetros do modelo que melhor reproduzam as condições locais. O principal desafio do processo consiste em conseguir os melhores valores para o grande número de parâmetros contido nos simuladores.

A calibração de um modelo de simulação pode ser considerada um problema de otimização em que se busca o conjunto de parâmetros que maximiza uma função objetivo (Kim e Rilett, 2001). A calibração é um processo iterativo em que os parâmetros do modelo são alterados até que os resultados produzidos pelo simulador fiquem o mais próximo possível dos dados de campo (Hourdakis et al., 2003). Esse processo iterativo envolve a escolha de valores para os parâmetros do modelo e a comparação entre os resultados do modelo e o comportamento observado no sistema real. A comparação é realizada através de medidas de desempenho do sistema, tais como fluxo, tempo de viagem, velocidade e atraso veicular.

A validação é uma etapa pós-calibração que tem como objetivo verificar a validade dos valores dos parâmetros encontrados na fase de calibração. A validação consiste no processo de determinar se o modelo pode representar de forma acurada as medidas de campo para diferentes 
cenários. Para isso, ela deve usar um conjunto de dados diferente daquele utilizado para a calibração do modelo (Zhang e Owen, 2004).

Em resumo, pode-se dizer que a validação é um processo que garante que o modelo é eficaz de uma forma global, enquanto que a calibração assegura a sua eficácia para condições específicas (Zhang et al., 2004).

\subsection{Calibração manual versus calibração automática}

O processo de calibração de um modelo de simulação de tráfego pode ser realizado de forma manual ou automática. No primeiro método, o próprio usuário do modelo altera os parâmetros, realiza simulações e analisa os resultados. Esse processo é repetido até que os resultados obtidos sejam considerados aceitáveis. No segundo método, todo o procedimento é realizado automaticamente através de um programa computacional.

A vantagem da calibração manual está relacionada à facilidade de realização do processo, que não requer conhecimento sobre programação de computador. Em contrapartida, pelo fato de ser realizado manualmente, esse método não permite a calibração simultânea de vários parâmetros, já que isso introduz um grau de complexidade maior no processo.

Alguns estudos foram conduzidos com o objetivo de calibrar manualmente simuladores de tráfego. Entre eles, pode-se citar o estudo realizado por Egami e Setti (2002), que fizeram a calibração do modelo TRARR, o estudo desenvolvido por Demarchi e Setti (2001), que calibraram o simulador INTEGRATION e os estudos realizados por Skabardonis (2002), Rakha e Crowther (2003) e Sousa e Ribeiro (2004), que realizaram a calibração manual do CORSIM.

A calibração automática tem como uma de suas principais vantagens permitir que vários parâmetros do modelo sejam calibrados simultaneamente (Bayarri et al., 2004). Além disso, as simulações e as análises dos resultados ao longo do processo são realizadas de forma automática, sem a intervenção do usuário. Neste caso, a etapa que demanda mais tempo e atenção por parte do usuário é a de desenvolvimento do programa computacional. Uma vez pronto, o programa deve ser submetido a testes que verifiquem o seu funcionamento correto. 


\subsection{Calibração automática usando algoritmo genético}

Devido ao grande número de parâmetros a ser ajustado nos simuladores de tráfego, o processo de calibração pode tornar-se bastante complexo. Por isso, técnicas de otimização vêm sendo empregadas visando a minimização desse esforço. Dentre elas, pode-se citar os algoritmos de busca, como os utilizados por Colella e Demarchi (2005) e Colella et al. (2005) para calibrar o simulador INTEGRATION, e os algoritmos genéticos, que realizam a calibração de vários parâmetros simultaneamente para diminuir a discrepância entre o sistema real e o modelo simulado (Ma e Abdulhai, 2002).

Os algoritmos genéticos são definidos como algoritmos que realizam buscas iterativas baseadas em mecanismos de seleção natural e na genética (Goldberg, 1989). Eles pertencem a um campo da computação evolutiva que é reconhecida como uma variedade de ferramentas flexíveis e adaptáveis para buscas globais e para solução de problemas de otimização difíceis.

Apesar de os algoritmos genéticos terem sido originalmente desenvolvidos para serem modelos genéricos de processos de adaptação, a otimização tem sido a sua única aplicação prática. $\mathrm{O}$ primeiro algoritmo genético foi desenvolvido por Holland (1975). Entretanto, quem popularizou o seu uso foi Goldberg (1989).

Os algoritmos genéticos têm sido usados como uma ferramenta de otimização devido à sua capacidade de fazer múltiplas buscas em espaços grandes, complexos e pouco conhecidos, como em geral são os casos de problemas da área de simulação de fluxos de tráfego (Kim e Rilett, 2001). Além disso, eles exploram de forma eficiente o histórico de informações para especular novos pontos em que o desempenho pode ser melhorado.

Os algoritmos genéticos são fundamentalmente técnicas de otimização mas, diferentemente das técnicas tradicionais, eles procuram uma solução ótima através de um processo que imita a evolução natural. Basicamente, os algoritmos genéticos diferem dos métodos tradicionais de otimização nos seguintes aspectos (Carvalho, 2003): 
- Eles trabalham com uma codificação do conjunto de parâmetros e não com os próprios parâmetros;

- Eles fazem buscas em uma população e não em um único ponto;

- Eles usam informações geradas por eles mesmos e não informações derivadas ou de outro conhecimento auxiliar; e

- Eles utilizam regras de transição probabilísticas e não regras determinísticas.

Os algoritmos genéticos já foram usados para calibrar alguns parâmetros dos simuladores FRESIM (Cheu et al., 1998), PARAMICS (Lee et al., 2001), TRANSIMS e CORSIM (Kim e Rilett, 2001; Kim e Rilett, 2004; Rilett e Kim, 2001) e TRARR (Egami, 2006).

\subsubsection{Método de calibração}

O método de calibração que tem como base algoritmos genéticos consiste na escolha de uma solução inicial que contenha valores para os parâmetros de interesse (no caso de modelos de simulação de tráfego, parâmetros típicos estão relacionados às características dos motoristas e dos veículos). Essa solução inicial é transformada num vetor binário, composto por subvetores que contêm os valores da solução inicial para cada parâmetro de interesse (Rilett e Kim, 2001). Esses vetores binários são chamados de cromossomos e são compostos por genes. Cada gene é a representação binária do valor de um único parâmetro de interesse para a calibração (Ma e Abdulhai, 2001). Um exemplo de cromossomo pode ser visto a seguir, onde cada seqüência binária (subvetor) desse cromossomo representa um parâmetro a ser calibrado:

$$
\text { (01101001 } 1011101000101010)
$$

Nesse exemplo, cada um dos três parâmetros tem um comprimento de oito bits, o que significa que a codificação do cromossomo tem 24 bits.

O objetivo dos algoritmos genéticos é repassar somente as características benéficas para as novas gerações, visando melhorar a habilidade do pseudo-organismo de alcançar metas predefi- 
nidas. No caso dos modelos de simulação de tráfego, a meta tipicamente desejada é a habilidade de replicar o comportamento da corrente de tráfego observada (Kim e Rilett, 2001).

A Figura 6.1 apresenta um fluxograma genérico contendo a estrutura básica de um algoritmo genético. Nos algoritmos genéticos, cada solução candidata é codificada como um cromossomo e o processo de busca começa a partir de um grupo desses cromossomos, chamado de população. Novas soluções são geradas através de recombinação (cruzamento) e alternância (mutação) desses cromossomos ao longo das iterações ou gerações. $\mathrm{O}$ algoritmo termina ao atingir um número previamente especificado de gerações ou até que a variação do fitness da população depois de várias gerações se torne muito pequeno.

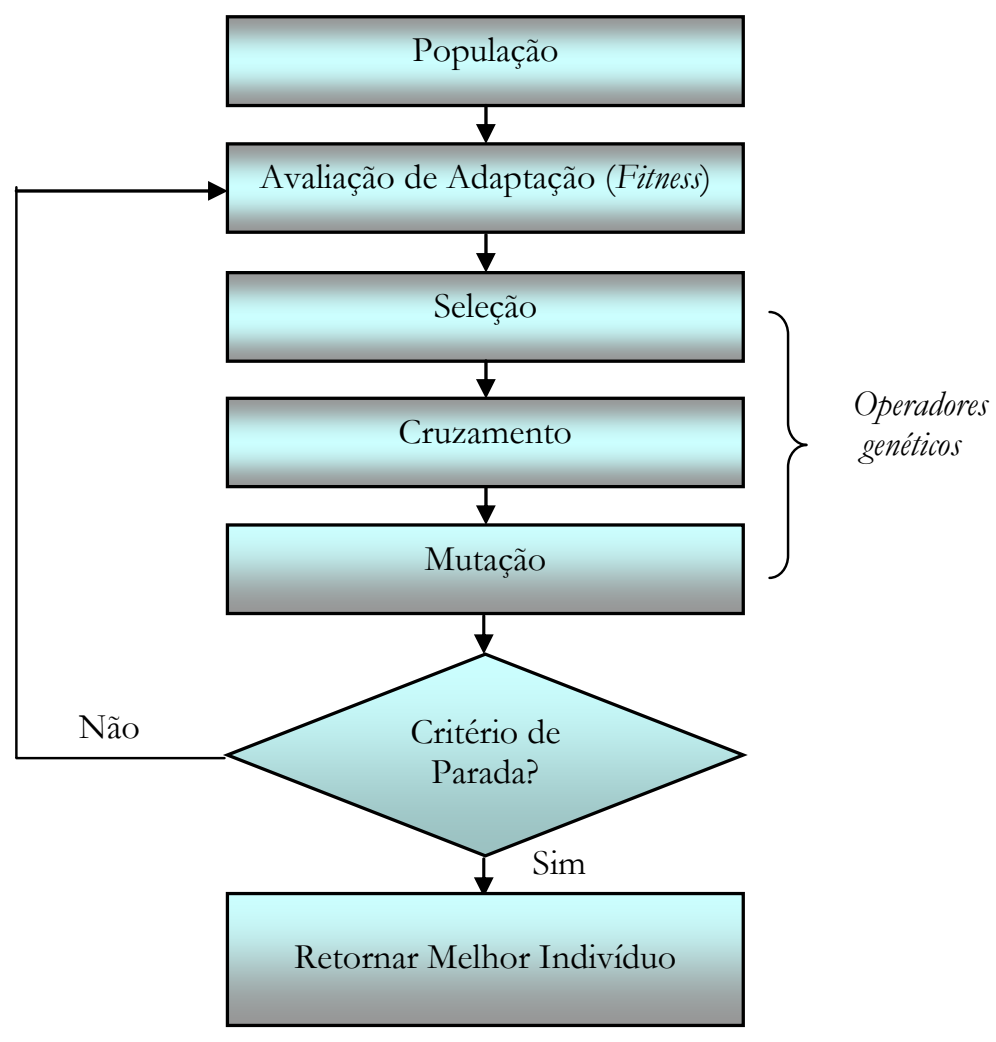

Figura 6.1 - Estrutura básica de um algoritmo genético

O pseudocódigo para o algoritmo genético consiste em (Wikipedia, 2006):

1. Criar uma população inicial

2. Determinar o grau de adaptação (fitness) de cada indivíduo na população 


\section{Repetir}

i. Selecionar os indivíduos mais bem adaptados para reprodução

ii. Criar descendentes através de cruzamento e mutação

iii. Avaliar o grau de adaptação da nova geração

iv. Substituir indivíduos menos adaptados na população pelos descendentes, criando uma nova geração

4. Até atingir um dos critérios de parada preestabelecidos

O tamanho da população afeta a eficácia do algoritmo genético. Populações grandes criam genes mais diversificados que ajudam a atingir a solução ótima, mas requerem um maior tempo computacional. Populações menores contêm genes menos diversificados e podem levar ao risco de uma convergência prematura para um ótimo local. Dessa forma, uma compensação deve ser feita entre populações grandes, com esforços computacionais substanciais, e populações pequenas, que podem convergir para um ótimo local mas requerem menos tempo de processamento. Não existem regras universais para determinação da população ideal para um problema ou aplicação específica; entretanto, uma regra disseminada indica que o tamanho da população deve ser pelo menos do tamanho da string que representa a codificação binária do cromossomo (Henderson e $\mathrm{Fu}, 2004)$.

\subsubsection{Operadores genéticos}

Um algoritmo genético simples, capaz de obter bons resultados em vários problemas práticos, deve ser composto por três operadores: (1) seleção, (2) cruzamento e (3) mutação (Goldberg, 1989). A seguir, cada um desses operadores será descrito de forma mais detalhada.

\subsubsection{Seleção}

A seleção é o processo no qual os cromossomos são reproduzidos de acordo com os valores de sua função objetivo, também chamada de função fitness. Selecionar cromossomos a partir dos valores de seu fitness significa fazer com que aqueles que possuem um valor maior tenham 
uma maior probabilidade de contribuir para a próxima geração. Esse operador é considerado uma versão artificial da seleção natural (Goldberg, 1989).

Muitos tipos de seleção são propostos para os algoritmos genéticos. Entretanto, a maioria deles pode ser classificada como variantes da seleção proporcional ao fitness (roleta) e da seleção elitista (Henderson e Fu, 2004).

A forma mais comum de implementar a seleção em um algoritmo genético é a que se utiliza da roleta. Para exemplificar o uso da roleta, na Tabela 6.1 é apresentada uma população de quatro cromossomos com seus respectivos valores de fitness. A roleta para a seleção desses cromossomos é a apresentada na Figura 6.2.

Tabela 6.1 - Exemplo de população de cromossomos e seus valores de fitness

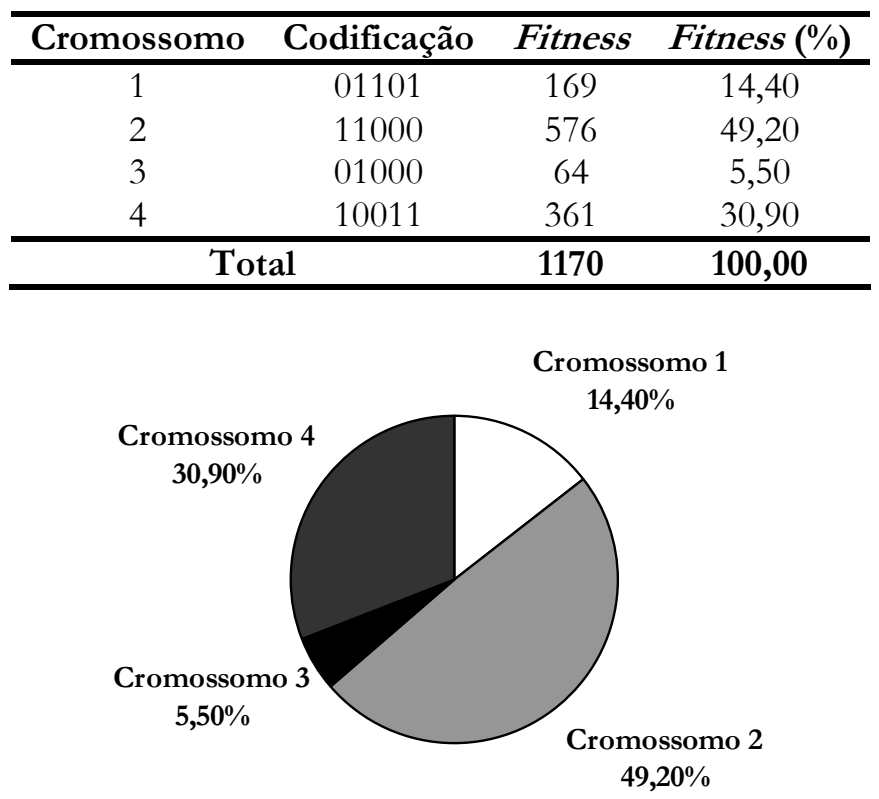

Figura 6.2 - Roleta para seleção de cromossomos a partir do fitness

A cada rotação da roleta um cromossomo é selecionado. Portanto, os cromossomos que têm fitness mais altos têm uma maior probabilidade de serem selecionados (nesse exemplo, os cromossomos 2 e 4). Uma vez selecionado, uma réplica do cromossomo é feita para que ele sofra a ação de outros operadores genéticos.

Um outro tipo de seleção muito utilizada é a que faz uso do elitismo. Nela, os melhores cromossomos da população sobrevivem até a próxima geração. Apesar de existir um risco de 
ficar preso a um ótimo local, esse método é útil para preservar os melhores indivíduos através das gerações (Henderson e Fu, 2004).

\subsubsection{Cruzamento}

Os cromossomos da população mantidos pela seleção podem sofrer modificações em suas características através de cruzamento (ou recombinação genética), gerando descendentes para a próxima geração.

Durante a operação de cruzamento, os cromossomos são agrupados dois a dois de forma aleatória e parte da seqüência binária é trocada entre eles. Para entender melhor esse processo, são apresentados dois cromossomos com as seguintes seqüências binárias:

Cromossomo 1: (01100101 1110100100011010$)$

Cromossomo 2: (00110100 0010001101011100$)$

A troca de material genético pode ocorrer em qualquer posição da seqüência, sendo a escolha tanto do ponto de início do cruzamento como do seu comprimento um processo aleatório. Supondo que o início do cruzamento se dê no sexto bit com um comprimento de seis bits, após a troca do material genético têm-se os cromossomos descendentes com as novas seqüências binárias:

$$
\begin{aligned}
& \text { Cromossomo 1': (01100100 } 0010100100011010) \\
& \text { Cromossomo 2': (00110101 } 1110001101011100)
\end{aligned}
$$

Holland (1975) percebeu que era o cruzamento que diferenciava os algoritmos genéticos dos outros métodos de computação evolutiva. Por causa da eficiência dessa operação, probabilidades altas são comumente usadas. A troca de material genético entre os indivíduos permite o surgimento de soluções melhores após sucessivas gerações. 


\subsubsection{Mutação}

Outro operador usado para a geração de novos indivíduos na população é a mutação, que possui um papel secundário na aplicação de um algoritmo genético. Em geral, considera-se que a mutação é principalmente uma técnica para recuperar material genético perdido e não uma técnica para buscar uma melhor solução. A mutação garante que cromossomos diferentes serão testados pelo algoritmo genético (Kim et al., 2005).

A mutação é uma pequena mudança feita na codificação de um cromossomo, usualmente realizada através da alteração de um ou mais bits de sua seqüência binária. Na mutação, os bits são alterados aleatoriamente. Para um melhor entendimento desse operador genético, apresenta-se um cromossomo com a seguinte seqüência binária:

$$
\text { Cromossomo 3: (01110111 } 10101001 \text { 10111010) }
$$

A mutação pode ocorrer em qualquer posição da seqüência, sendo a escolha dessa posição um processo aleatório. Supondo que a posição escolhida corresponda ao sétimo bit, após a alteração desse bit obtém-se o seguinte cromossomo descendente:

$$
\text { Cromossomo 3’: (01110101 } 10101001 \text { 10111010) }
$$

Alguns estudos sugerem que uma baixa probabilidade de mutação $\left(\mathrm{P}_{\mathrm{m}}\right)$ deve ser usada e

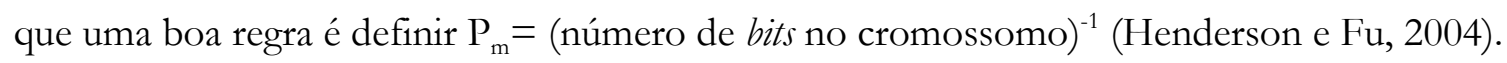

\subsubsection{Função fitness}

No algoritmo genético, o valor do fitness é calculado com base em uma função predeterminada e representa o grau de adaptação ao meio ambiente do cromossomo. O valor do fitness é usado pelo algoritmo durante o processo de seleção para determinar a probabilidade de o cromossomo ser selecionado para a próxima geração. Os cromossomos cujos valores do fitness são altos (ou seja, indivíduos mais bem adaptados ao meio ambiente) têm uma maior probabilidade de serem selecionados para serem submetidos ao cruzamento e à mutação. Em resumo, os algoritmos genéticos utilizam regras de seleção, cruzamento e mutação baseadas na genética para ge- 
rar populações de cromossomos que incluem os melhores parâmetros que atendem à função fitness (Rilett et al., 2000).

Várias funções objetivo podem ser usadas para avaliar o desempenho de um modelo de simulação. Dentre elas, pode-se citar: raiz quadrada do erro médio, raiz quadrada do erro médio percentual, erro médio absoluto e erro médio absoluto percentual. Essas estatísticas quantificam o erro global do simulador. A raiz quadrada do erro médio e a raiz quadrada do erro médio percentual penalizam os erros grandes a uma taxa maior que os erros pequenos. O erro médio absoluto e o erro médio absoluto percentual indicam se nos dados simulados ocorrem erros sistemáticos para mais ou para menos (Toledo e Koutsopoulos, 2004).

Apesar da variedade existente, a função objetivo comumente utilizada em análises de transportes é o erro médio absoluto percentual (MAER - Mean Absolute Error Ratio):

$$
\text { MAER }=\frac{1}{N} \sum_{i=1}^{N}\left(\frac{\left|O_{i}-S_{i}\right|}{O_{i}} \times 100\right)
$$

em que: $\quad$ MAER: $\quad$ erro médio absoluto percentual;

$$
\begin{array}{ll}
N: & \text { número de observações realizadas; } \\
O_{i}: & \text { valor observado; e } \\
S_{i:} & \text { valor simulado. }
\end{array}
$$

O MAER retorna um valor relativo à diferença entre os dados observados e simulados e, por isso, ele é uma função de minimização difícil de resolver matematicamente, mas que pode ser facilmente resolvida por uma técnica robusta tal como o algoritmo genético (Rilett e Kim, 2001).

Com base no estudo realizado por Rilett e Kim (2001), a função fitness utilizada para transformar a função objetivo da medida de desempenho desejada é uma função exponencial que converte o MAER em uma função de maximização exponencial. O propósito dessa conversão de uma função de minimização para uma maximização exponencial - é fornecer uma melhor me- 
dida da eficácia global de cada alternativa e produzir uma representação matemática dos resultados mais consistente. A função fitness usada por Rilett e Kim (2001) é:

$$
F=\alpha \cdot e^{(-\beta \cdot M A E R)}
$$

$$
\begin{array}{lll}
\text { em que: } & \text { fitness; } \\
\alpha, \beta: & \text { constantes; e } \\
\text { MAER: } & \text { erro médio absoluto percentual. }
\end{array}
$$

\subsubsection{Codificação do algoritmo genético}

O uso de um algoritmo genético requer a codificação dos parâmetros de calibração. Apesar de existirem vários esquemas de representação possíveis, a codificação dos genes dos cromossomos na forma binária (bits) ainda é a preferida pela maioria dos pesquisadores, uma vez que ela apresenta uma representação do problema de forma mais simplificada.

Se $x_{i j}$ representa o valor real de um parâmetro $j$ em um cromossomo $i$ com um domínio em $\left(\chi_{\min }, \chi_{\max }\right)$, o comprimento $B_{j}$ do vetor binário que fornece a precisão desejada pode ser calculado através da Equação 6.3, enquanto que o cálculo do valor de $\chi_{i j}$ a partir de uma string binária $A_{i j}$ de comprimento $B_{j}$ bits pode ser feito com o uso da Equação 6.4:

$$
B_{j} \geq \log _{2}\left(\frac{x_{j}^{\max }-x_{j}^{\min }}{D_{j}}+1\right) \quad \forall j=1, N P
$$

em que: $\quad B_{j}: \quad$ comprimento do vetor binário necessário para representar o parâmetro (inteiro);

$x_{j}^{\max }:$ valor máximo do parâmetro (inteiro ou real);

$x_{j}^{\min }:$ valor mínimo do parâmetro (inteiro ou real);

$D_{j}: \quad$ precisão desejada para o parâmetro (inteira ou real);

j: $\quad$ índice que representa o parâmetro de um cromossomo (inteiro ou real); e

NP: número de parâmetros. 


$$
x_{i j}=x_{j}^{\min }+A_{i j} \frac{x_{j}^{\max }-x_{j}^{\min }}{2^{B_{j}}-1} \quad \forall j=1, N
$$

em que: $\quad \chi_{i j}: \quad$ valor real do parâmetro $j$ de um cromossomo $i$;

$A_{i j}: \quad$ valor binário na base 2 de um parâmetro $j$ de um cromossomo $i$;

$i: \quad$ cromossomo (inteiro ou real); e

$N: \quad$ número de cromossomos.

O exemplo a seguir melhor ilustra a aplicação das equações acima.

Seja um parâmetro $x_{i j}$ (por exemplo, o tempo mínimo para geração de veículos no CORSIM), que pode variar entre 10 e 30. Se a precisão desejada é de um número inteiro, o comprimento do vetor binário é o mínimo inteiro que satisfaz a Equação 6.3:

$$
B_{j} \geq \log _{2}\left(\frac{30-10}{1}+1\right)=4,39
$$

Então, o número necessário de bits para codificar esse parâmetro é cinco. Supondo que a seqüência de bits desse parâmetro seja igual a (10111), o valor binário na base 2 correspondente a ela seria:

$$
1 \times 2^{4}+0 \times 2^{3}+1 \times 2^{2}+1 \times 2^{1}+1 \times 2^{0}=23
$$

Dessa forma, o valor do parâmetro pode ser calculado através da Equação 6.4:

$$
x_{i j}=10+23 \frac{30-10}{2^{5}-1}=25
$$

\subsection{Algoritmo genético para calibração do CORSIM}

Um programa computacional baseado em um algoritmo genético foi desenvolvido para calibrar o CORSIM no trecho de rodovia de pista dupla apresentado no Capítulo 4. O programa foi desenvolvido na linguagem Perl e, em muitos aspectos, é semelhante ao usado na calibração do CORSIM por Kim e Rilett (2001), uma vez que o desenvolvimento do algoritmo usado foi feito 
em colaboração com o Prof. Laurence Rilett, durante um estágio realizado na Texas A\&M University.

Perl (Practical Extraction and Report Language) é uma linguagem de programação de uso geral implementada nas principais plataformas computacionais e disponibilizada de forma gratuita (Wall et al., 2000). Originalmente projetada para o processamento de textos, a linguagem Perl tornou-se sofisticada, com um conjunto completo de depuradores, referências cruzadas, compiladores, interpretadores e bibliotecas.

A seguir, são descritas as etapas percorridas para a execução da calibração.

\subsubsection{Escolha das medidas de desempenho}

As medidas de desempenho são estatísticas calculadas a partir dos dados de saída do modelo de simulação, que podem ser comparadas com dados obtidos em campo para determinar o grau de qualidade dos resultados da simulação. A escolha de medidas de desempenho apropriadas é o primeiro passo para a calibração de um modelo de simulação (Toledo e Koutsopoulos, 2004).

A calibração de um modelo de simulação em função de uma única medida de desempenho pode levar a uma superestimação do realismo do modelo. Por isso, em geral são escolhidas duas ou mais medidas de desempenho.

As medidas de desempenho e o nível de agregação temporal em que elas são calculadas (por exemplo, $15 \mathrm{~min}, 30 \mathrm{~min}$ ) devem ser escolhidos de tal forma que tornem fácil verificar se o modelo captura corretamente a dinâmica do tráfego (Toledo e Koutsopoulos, 2004).

Nesta pesquisa, as medidas de desempenho utilizadas para avaliar a eficiência do modelo de simulação foram o fluxo de tráfego e a velocidade média em alguns tramos da rede. Esses dados foram medidos em campo juntamente com a composição do tráfego e a matriz origem/destino e estão apresentados no Capítulo 5. Os estudos realizados por Rakha et al. (1996) e Cheu et al. (1998) também usaram o fluxo e a velocidade como medidas de desempenho. A razão principal para a escolha destas variáveis como medidas de desempenho baseia-se na facilidade de obtenção desses dados no campo e da sua relação direta com a aplicação do simulador. A composição do 
tráfego não foi escolhida como medida de desempenho porque o mínimo que se espera de um simulador é que ele seja capaz de gerar veículos de acordo com a distribuição veicular observada - ou seja, que o erro observado na composição de tráfego seja nulo. Apesar disso, durante a calibração teve-se sempre o cuidado de verificar se o tráfego gerado pelo CORSIM estava de acordo com a composição observada.

Para a realização de uma comparação apropriada entre as velocidades simuladas e observadas, a rede foi codificada de tal forma que a extensão dos tramos em que foram obtidas as velocidades simuladas fosse igual ao comprimento das seções em que elas foram coletadas em campo (62 m). Assim, a velocidade média no tramo fornecida pelo arquivo OUT corresponde à velocidade média na seção.

\subsubsection{Escolha dos parâmetros do modelo a serem calibrados}

No CORSIM, foram identificados vários parâmetros de entrada que podem ser modificados para melhor reproduzir as condições de tráfego locais, conforme apresentados no Capítulo 4. Esses parâmetros compõem os seguintes Record Types: RT68, RT69, RT70, RT71 e RT173.

A fim de evitar um gasto desnecessário de tempo na calibração de parâmetros que produzem pequeno impacto nos resultados da simulação, é mais conveniente que se faça ajuste apenas nos parâmetros mais significativos. Além disso, em um algoritmo genético o tamanho da seqüência binária é proporcional ao número de parâmetros codificados em cada cromossomo e, quanto maiores as seqüências binárias que formam os cromossomos, maiores são as necessidades computacionais. Portanto, apenas os parâmetros mais significativos devem ser usados, com o intuito de permitir que a calibração seja alcançada dentro do mínimo de gerações possível (Ma e Abdulhai, 2001).

Nesta pesquisa, os parâmetros de calibração de distribuição da frota (RT71) são considerados dados de entrada do modelo, uma vez que as coletas dados permitiram a obtenção da composição do tráfego. Como discutido no Capítulo 5, os veículos pesados foram agrupados nas 
quatro categorias permitidas pelo CORSIM, com base nas suas distribuições acumuladas da relação peso/potência.

Adicionalmente, um estudo desenvolvido por Cunha e Setti (2006) calibrou o modelo de locomoção dos veículos pesados no CORSIM através do uso de um algoritmo genético codificado em VBA. Esse modelo de locomoção é representado pelos parâmetros de calibração do RT173, apresentados anteriormente na Tabela 4.5. Nesse estudo, as curvas de desempenho analíticas para as quatro categorias de veículos pesados do CORSIM foram comparadas com curvas empíricas obtidas com aparelhos de GPS (Global Position System) em rodovias de pista dupla do estado de São Paulo. As curvas de desempenho obtidas com a versão calibrada do CORSIM apresentam erros médios da ordem de 5\% para as quatro categorias. As acelerações resultantes dessa calibração são apresentadas na Tabela 6.2.

Tabela 6.2 - Aceleração máxima calibrada para os veículos pesados (pé/s²)

\begin{tabular}{|c|c|c|c|c|c|}
\hline & & \multicolumn{4}{|c|}{ Índice de Desempenho } \\
\hline & & 3 & 4 & 5 & 6 \\
\hline \multirow{12}{*}{$\begin{array}{l}0 \\
0 \\
0 \\
0 \\
0 \\
\frac{\pi}{0} \\
\frac{0}{0} \\
0 \\
0 \\
0\end{array}$} & 0 & 8,99 & 14,26 & 9,54 & 13,11 \\
\hline & 10 & 8,90 & 3,39 & 8,04 & 2,00 \\
\hline & 20 & 3,60 & 1,72 & 5,81 & 1,53 \\
\hline & 30 & 3,02 & 0,65 & 2,20 & 0,52 \\
\hline & 40 & 2,03 & 0,51 & 1,01 & 0,43 \\
\hline & 50 & 1,76 & 0,30 & 0,71 & 0,40 \\
\hline & 60 & 1,09 & 0,30 & 0,60 & 0,37 \\
\hline & 70 & 1,00 & 0,36 & 0,41 & 0,16 \\
\hline & 80 & 0,49 & 0,36 & 0,50 & 0,07 \\
\hline & 90 & 0,19 & 0,07 & 0,07 & 0,05 \\
\hline & 100 & $-0,91$ & 0,04 & $-0,10$ & $-0,55$ \\
\hline & 110 & $-0,98$ & $-0,20$ & $-0,13$ & $-0,66$ \\
\hline
\end{tabular}

Por se considerar que a calibração desses valores levou em conta a frota típica de veículos pesados que trafega nas rodovias de pista dupla paulistas e que o método de calibração mostrouse eficiente, esta pesquisa substituiu os valores default do CORSIM pelos obtidos por Cunha e Setti (2006). Entretanto, os valores das acelerações máximas que representam os índices de desempenho 1, 2 e 7 do CORSIM (relacionados aos automóveis e ônibus) permaneceram aqueles originalmente contidos no RT173, já que esses veículos não são tratados em Cunha e Setti (2006). 
Dessa forma, nesta pesquisa optou-se inicialmente pela calibração de todos os parâmetros contidos no RT68, RT69 e RT70 do CORSIM, com exceção daqueles relativos à desaceleração máxima não emergencial por tipo de veículo $\left(\mathrm{P}_{21}\right.$ a $\left.\mathrm{P}_{29}\right)$. Esses parâmetros foram excluídos do processo por se considerar que os valores default eram aceitáveis e não teriam influência significativa nos resultados da simulação da rede. Além disso, um estudo anterior verificou que a inclusão desses parâmetros na calibração piorou o desempenho do simulador (Schultz, 2003).

Em função disso, uma calibração preliminar do modelo foi feita com a inclusão de 20 parâmetros. Para um melhor entendimento, a Tabela 6.3 lista os parâmetros selecionados para a calibração do CORSIM, que são os parâmetros gerais de calibração apresentados no Capítulo 4.

Tabela 6.3 - Parâmetros selecionados para a calibração do CORSIM

\begin{tabular}{cl}
\hline Parâmetro & \multicolumn{1}{c}{ Descrição } \\
\hline $\mathrm{P}_{1}-\mathrm{P}_{10}$ & Fator de sensibilidade para o car-following (motoristas do tipo 1 ao 10) \\
$\mathrm{P}_{11}$ & Constante de Pitt para o car-following \\
$\mathrm{P}_{12}$ & Tempo de reação para acelerar \\
$\mathrm{P}_{13}$ & Tempo de reação para desacelerar \\
$\mathrm{P}_{14}$ & Tempo para completar uma mudança de faixa \\
$\mathrm{P}_{15}$ & Tempo mínimo para geração de veículos \\
$\mathrm{P}_{16}$ & Aceitação de gap para mudança de faixa obrigatória \\
$\mathrm{P}_{17}$ & Porcentagem de motoristas que cedem o direito de passagem para veículos mudando de faixa \\
$\mathrm{P}_{18}$ & Multiplicador para o desejo de realizar uma mudança de faixa arbitrária \\
$\mathrm{P}_{19}$ & Valor limite do benefício para realizar uma mudança de faixa arbitrária \\
$\mathrm{P}_{20}$ & Desaceleração máxima do veículo líder percebida pelo seu seguidor \\
\hline
\end{tabular}

Apesar de considerados satisfatórios com base no MAER, os parâmetros resultantes dessa calibração preliminar revelaram um comportamento errático do modelo. $\mathrm{O}$ valor calibrado de $\mathrm{P}_{19}$, que atingiu o valor máximo permitido pelo CORSIM, reduziu drasticamente o número de mudanças de faixas realizadas em toda a rede. Então, como a análise detalhada desse fenômeno indicou uma distorção entre o comportamento real e o simulado, optou-se por excluir da calibração o parâmetro $\mathrm{P}_{19}$.

Dentre os 19 parâmetros selecionados para calibração, os fatores de sensibilidade para o car-following $\left(\mathrm{P}_{1}\right.$ a $\left.\mathrm{P}_{10}\right)$ representam a mesma variável para diferentes tipos de motoristas e, de acordo com Cohen (2004), são os principais parâmetros de calibração do CORSIM. 
Segundo Schultz e Rilett (2004), duas alternativas podem ser consideradas para representar a distribuição desses fatores. A primeira delas é tratar cada fator como um parâmetro independente e modelar esses parâmetros individualmente (por exemplo, distribuídos aleatoriamente). A segunda alternativa é gerar os parâmetros a partir de distribuições de tendência e dispersão (por exemplo, média e variância).

Nesta pesquisa, os fatores de sensibilidade para o car-following foram considerados de forma independente e distribuídos aleatoriamente. Isso significa que, embora os valores default desses fatores sejam distribuídos de forma uniforme (partindo do motorista mais tímido para o mais agressivo), os valores resultantes da calibração não necessariamente seguirão essa distribuição. Os limites mínimos e máximos definidos nesta pesquisa para os fatores de sensibilidade para o carfollowing são apresentados na Figura 6.3. Como se pode perceber, há uma sobreposição nos limites de alguns parâmetros.

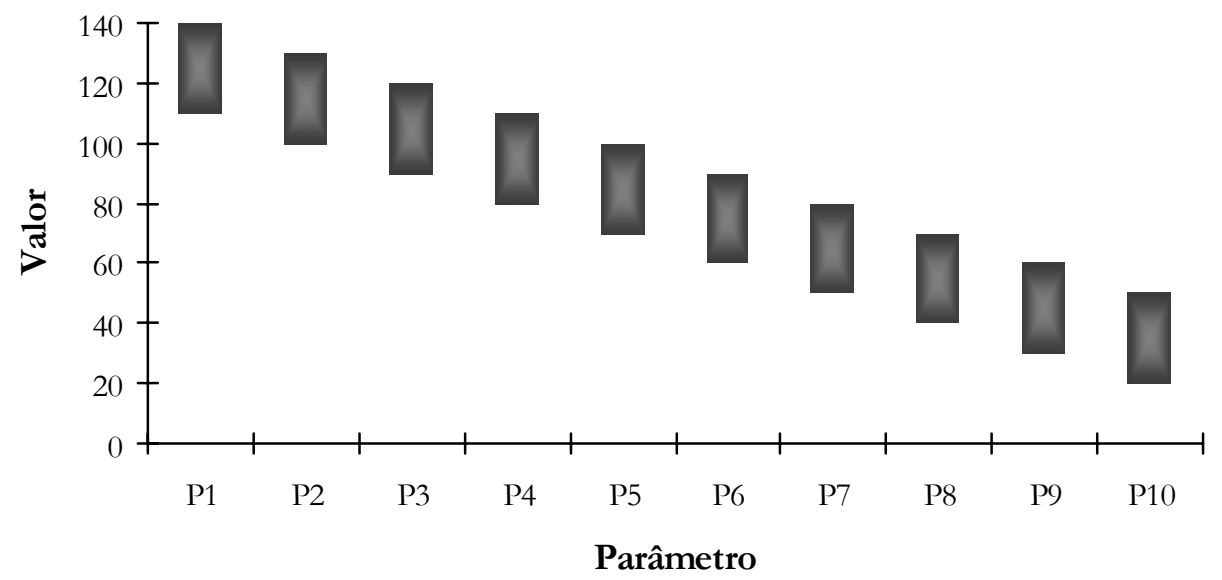

Figura 6.3 - Limites estabelecidos no algoritmo genético para os parâmetros $\mathrm{P}_{1}$ a $\mathrm{P}_{10}$, os fatores de sensibilidade para o modelo de car-following

Os demais parâmetros calibrados são independentes e seus limites mínimo e máximo são os mesmos estabelecidos pelo CORSIM, que estão apresentados na Tabela 4.1. 


\subsubsection{Escolha dos parâmetros do algoritmo genético}

Para executar uma calibração fazendo uso de um algoritmo genético, devem ser especificados o número de cromossomos (tamanho da população), o número máximo de gerações e as probabilidades de cruzamento e de mutação.

O tempo de processamento pode restringir a utilização de combinações grandes de número de cromossomos versus número máximo de gerações. Portanto, vários testes foram realizados com o objetivo de obter uma combinação que fornecesse uma boa convergência do MAER. A combinação escolhida para a calibração foi a de 100 cromossomos e 200 gerações, que no caso específico da rede simulada e do computador utilizado, requer um tempo de processamento de aproximadamente 49 horas. Apesar de a população inicial de cada geração ser constante, não é possível saber a priori o número total de simulações para cada geração porque o número de cromossomos varia de acordo com os resultados das etapas de cruzamento e mutação.

As probabilidades de cruzamento $\left(\mathrm{P}_{\mathrm{c}}\right)$ e de mutação $\left(\mathrm{P}_{\mathrm{m}}\right)$ adotadas foram de $50 \%$ e $20 \%$, respectivamente. Esses valores foram determinados a partir de uma análise de sensibilidade, que testou diversas combinações em que $\mathrm{P}_{c}$ e $\mathrm{P}_{\mathrm{m}}$ variavam de $10 \%$ a $50 \%$, com incrementos de $10 \%$. Os intervalos de variação dessas probabilidades foram fundamentados nos experimentos realizados por Kim e Rilett (2001) e Schultz e Rilett (2005).

O tamanho total da string que representa os 19 parâmetros escolhidos para calibração é de 89 bits e o critério de parada do algoritmo genético é o número máximo de gerações (200).

A função fitness utilizada nesta pesquisa é a apresentada na Equação 6.5. As constantes dessa equação são as mesmas adotadas por Egami et al. (2004) e Schultz e Rilett (2005).

$$
F=100 e^{(-5 \text { MAER })}
$$




\subsection{Resultado da calibração}

Na calibração, o MAER foi calculado em função das duas medidas de desempenho escolhidas (fluxo e velocidade média) em seis pontos de controle ao longo da rede de tráfego, três em cada sentido. Os dados utilizados na calibração foram os observados na primeira e segunda coleta de dados (realizadas nos dias 6 e 13/6/2005), perfazendo um total de cinco horas. Entretanto, como foram definidos intervalos de simulação de 15 minutos e o CORSIM só permite que no máximo 19 intervalos de tempo sejam simulados, os dados dos 15 minutos finais da segunda coleta de dados foram descartados.

O MAER é calculado através da Equação 6.1. A Figura 6.4 mostra a evolução do MAER do melhor cromossomo de cada geração ao longo do tempo. A observação da figura permite verificar que uma boa convergência do MAER foi obtida após 56 gerações, com a ocorrência de

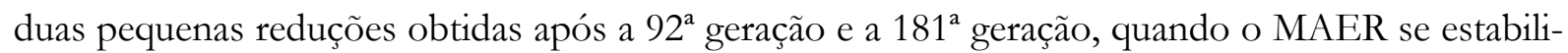
zou em 6,32\%. A Figura 6.4 apresenta também o MAER calculado antes da calibração do simulador, ou seja, com os parâmetros default do CORSIM. O MAER defaulté 9,11\%.

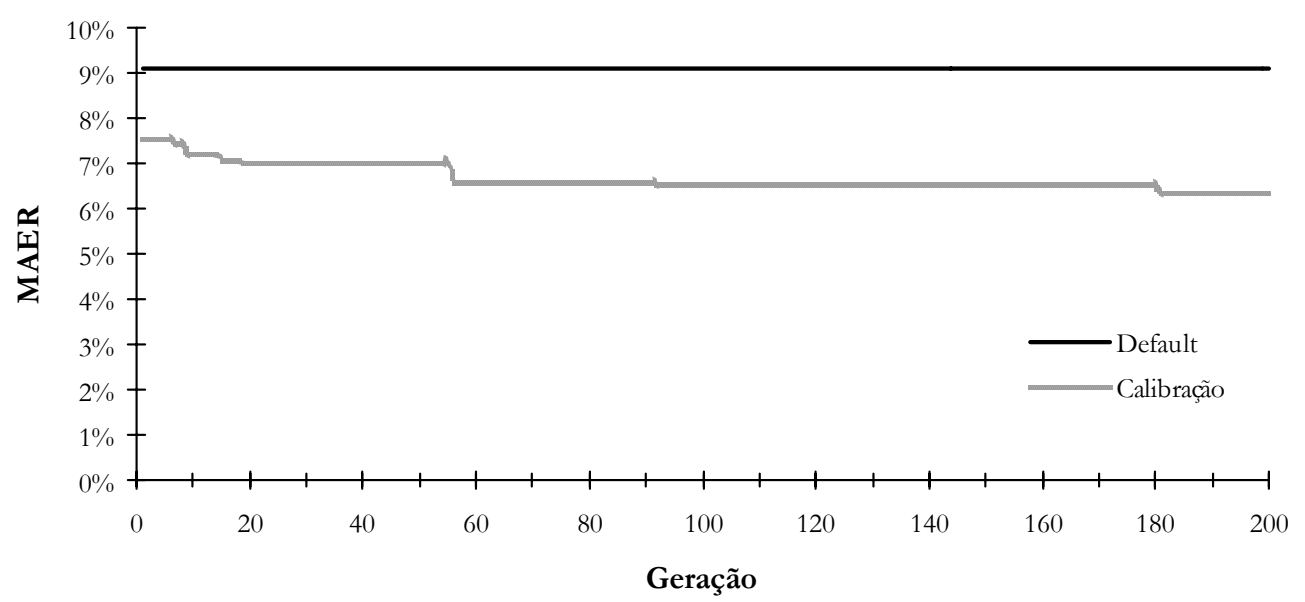

Figura 6.4 - Evolução do MAER

A Figura 6.5 apresenta a evolução do fitness do melhor cromossomo, calculado através da Equação 6.5. O valor do fitness calculado com os parâmetros default do CORSIM é 63,41. Ao final da calibração, esse valor chegou a 72,89, sendo que o valor máximo é 100. 


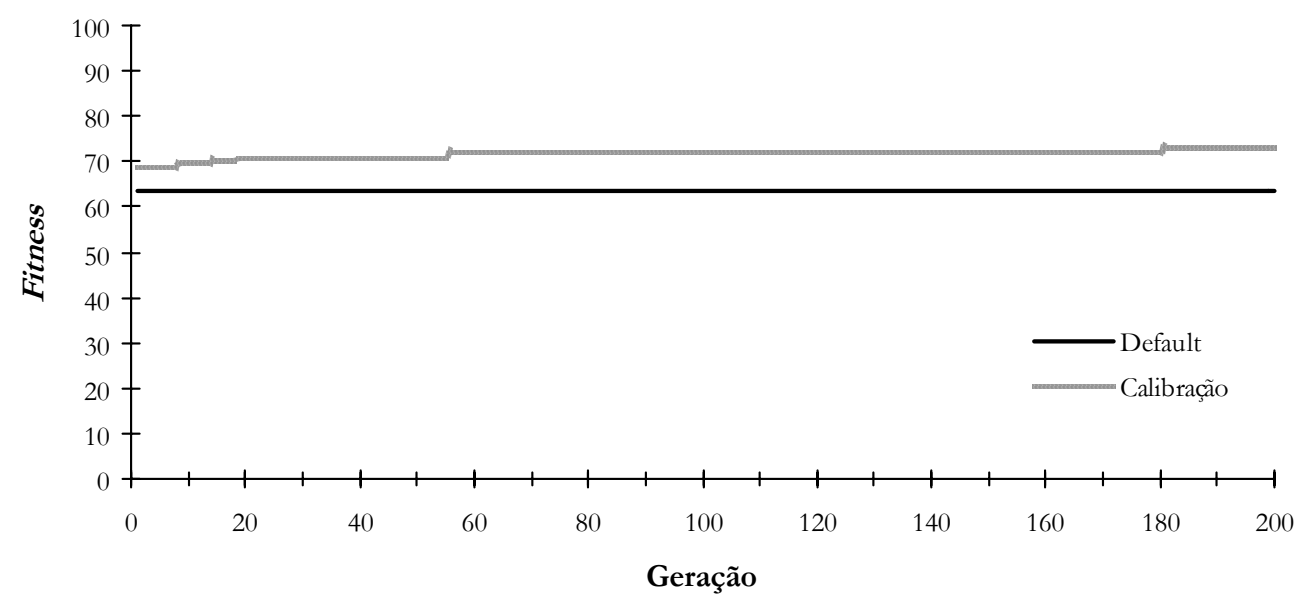

Figura 6.5 - Evolução do fitness

Os dados apresentados indicam que a calibração reduziu o MAER em 2,79\%, o que representa uma redução relativa do erro médio de aproximadamente 30\%. Paralelamente, o fitness aumentou em 9,48.

A Figura 6.6 apresenta a comparação das medidas de desempenho obtidas após a calibração do modelo no sentido Norte da rede simulada. A Figura 6.7 apresenta os mesmos dados para o sentido Sul.

A observação das figuras permite constatar que os dados simulados e observados de fluxo se aproximam mais que os dados de velocidade, nos dois sentidos de tráfego. Esse mesmo comportamento foi observado por Rakha et al. (1996) no simulador INTEGRATION. Adicionalmente, os fluxos simulados nos tramos próximos às entradas da rede são os que mais se aproximam dos fluxos observados, como era de se esperar.

Pode-se perceber também que no sentido Norte as velocidades observadas são sistematicamente menores que as simuladas. Já no sentido Sul, ocorre o inverso: somente no posto de controle que representa a saída da rede a velocidade observada é menor que a simulada.

As Tabelas 6.4 e 6.5 apresentam os valores médios observados e simulados das medidas de desempenho em cada posto de controle para os sentidos Norte e Sul, respectivamente. A diferença entre as médias também é apresentada, sendo o seu cálculo feito pela Equação 6.6. 


$$
\Delta(\%)=100 \frac{(\text { Observado }- \text { Simulado })}{\text { Observado }}
$$
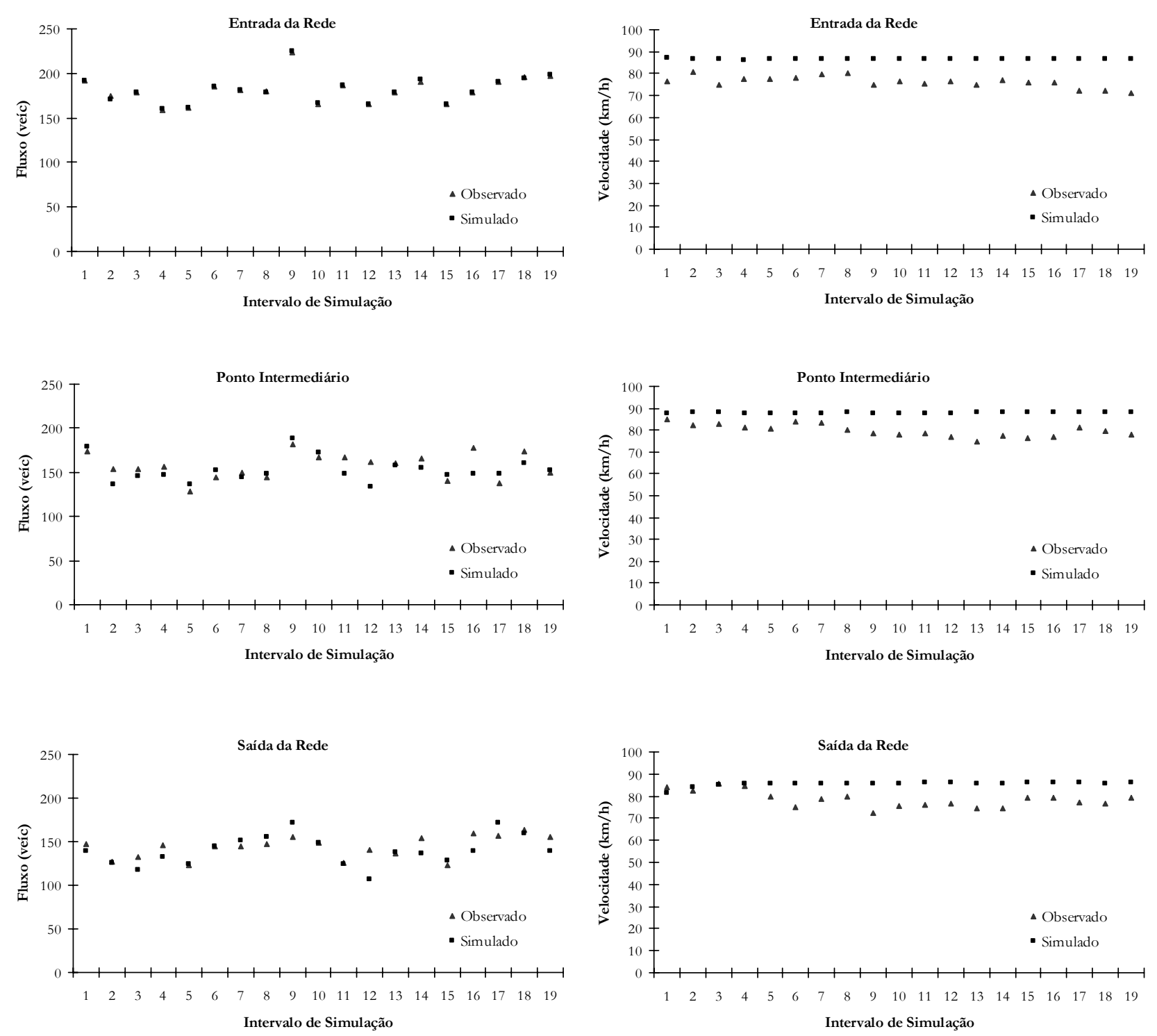

Figura 6.6 - Comparação das medidas de desempenho para o modelo calibrado (Sentido Norte)

Tabela 6.4 - Valores médios das medidas de desempenho na calibração (Sentido Norte)

\begin{tabular}{ccccccc}
\hline \multirow{2}{*}{ Posto de Controle } & \multicolumn{3}{c}{ Fluxo Médio (veíc) } & \multicolumn{3}{c}{ Velocidade Média $(\mathbf{k m} / \mathbf{h})$} \\
\cline { 2 - 7 } & Observado & Simulado & $\boldsymbol{\Delta ( \mathbf { ~ } \% )}$ & Observado & Simulado & $\boldsymbol{\Delta} \mathbf{( \% )}$ \\
\hline Entrada & 182 & 182 & 0,00 & 76 & 87 & $-14,47$ \\
Intermediário & 158 & 153 & 3,16 & 80 & 88 & $-10,00$ \\
Saída & 144 & 140 & 2,78 & 79 & 85 & $-7,59$ \\
\hline
\end{tabular}



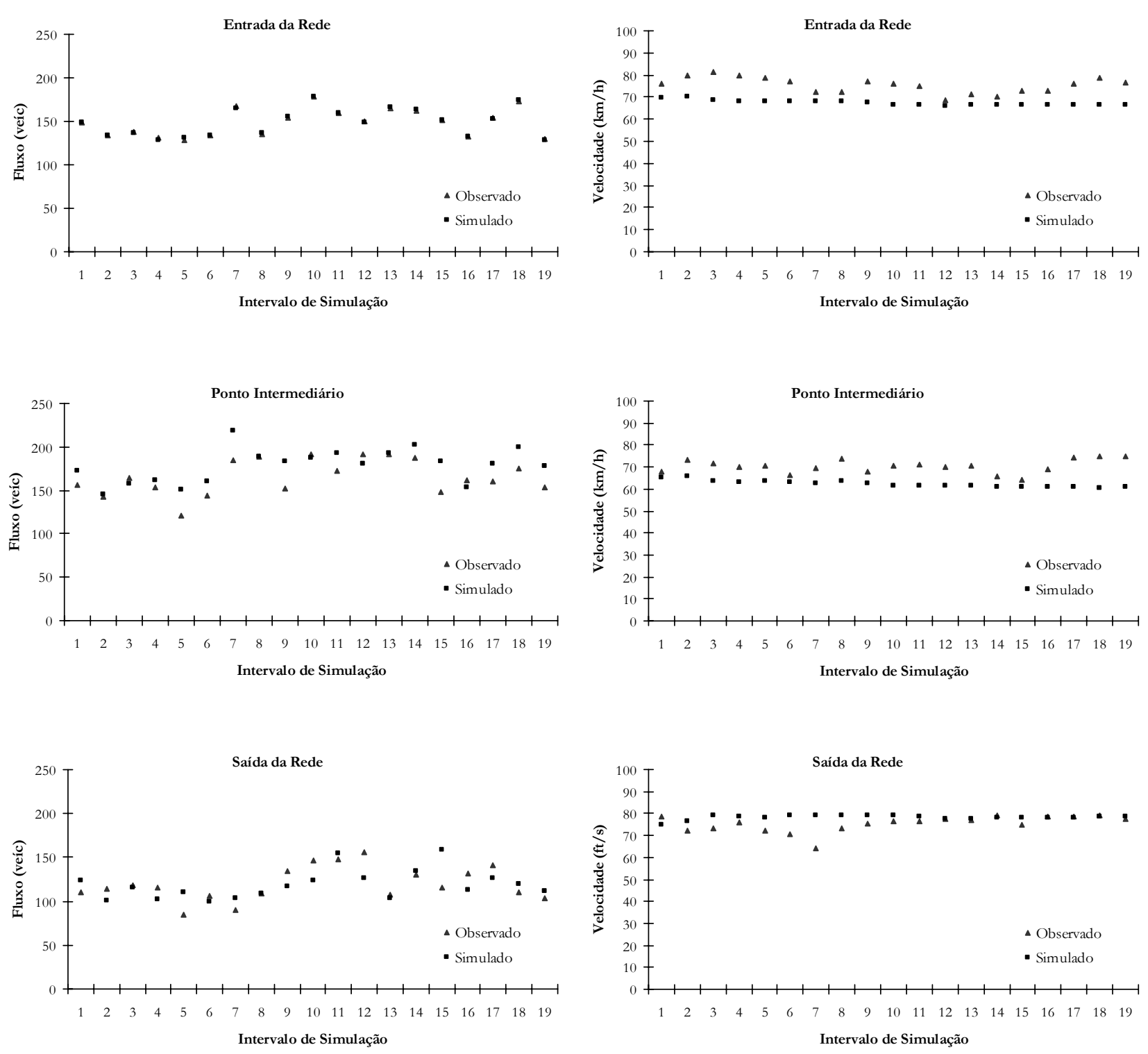

Figura 6.7 - Comparação das medidas de desempenho para o modelo calibrado (Sentido Sul)

Tabela 6.5 - Valores médios das medidas de desempenho na calibração (Sentido Sul)

\begin{tabular}{ccccccc}
\hline \multirow{2}{*}{ Posto de Controle } & \multicolumn{3}{c}{ Fluxo Médio (veíc) } & \multicolumn{3}{c}{ Velocidade Média $(\mathrm{km} / \mathbf{h})$} \\
\cline { 2 - 7 } & Observado & Simulado & $\boldsymbol{\Delta} \mathbf{( \% )}$ & Observado & Simulado & $\boldsymbol{\Delta} \mathbf{( \% )}$ \\
\hline Entrada & 149 & 149 & 0,00 & 75 & 67 & 10,67 \\
Intermediário & 165 & 179 & $-8,48$ & 70 & 62 & 11,43 \\
Saída & 120 & 119 & 0,83 & 75 & 78 & $-4,00$ \\
\hline
\end{tabular}

Alguns pesquisadores sugerem que um aspecto que deve ser analisado durante o cálculo do MAER é a parcela de contribuição de cada uma das duas medidas de desempenho sobre o valor resultante. De acordo com Dowling et al. (2004), um critério amplamente aceito para que a cali- 
bração seja considerada eficiente é que o MAER gerado pelos fluxos isoladamente não ultrapasse 5\%. Por outro lado, não foi encontrado na literatura um critério bem estabelecido para a aceitação da calibração quanto à velocidade.

A Figura 6.8 mostra a contribuição das duas medidas de desempenho utilizadas no valor final do MAER antes e depois da calibração. Como era de se esperar, a parcela de erro da velocidade é superior à do fluxo e representa, em média, 74\% do MAER. Além disso, verifica-se que o MAER calculado isoladamente para o fluxo apresenta valor inferior a 5\%. Antes da calibração, o MAER devido ao volume representava 31\% do total. Após a calibração, essa porcentagem foi reduzida para $20 \%$, o que significa que a calibração afetou mais os dados de fluxo que os de velocidade. Uma das explicações para isso são as limitações do modelo de desempenho veicular usado pelo CORSIM, que, ao invés de usar a resultante das forças que atuam sobre os veículos pesados, baseia-se em acelerações médias que são admitidas constantes ao longo de uma faixa relativamente ampla de velocidades (10 pés/s ou quase $11 \mathrm{~km} / \mathrm{h}$ ).

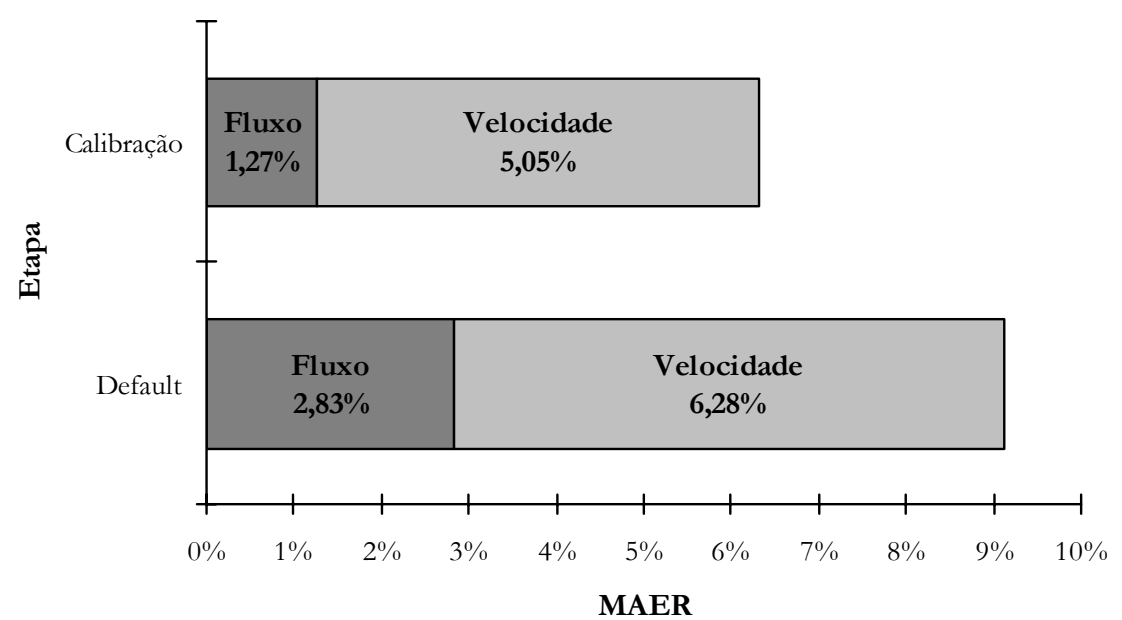

Figura 6.8 - Contribuição das medidas de desempenho no MAER

\subsubsection{Apresentação dos parâmetros calibrados}

A Figura 6.9 apresenta a comparação dos valores default dos parâmetros $\mathrm{P}_{1}$ a $\mathrm{P}_{10}$ do CORSIM com os valores calibrados. Observa-se que esses valores seguiram uma distribuição diferente daquela estabelecida originalmente no CORSIM. Outros estudos que fizeram uso da calibração para os parâmetros relacionados à lógica do car-following do CORSIM verificaram esse 
mesmo comportamento (Payne et al., 1997; Prevedouros e Wang, 1999; Schultz, 2003). Pode-se verificar também que, enquanto os valores default desses parâmetros variam entre $0,35 \mathrm{~s}$ e 1,25 s, no modelo calibrado eles variam entre $0,42 \mathrm{~s}$ e 1,21 s, indicando um menor intervalo de variação para o grau de agressividade dos motoristas.

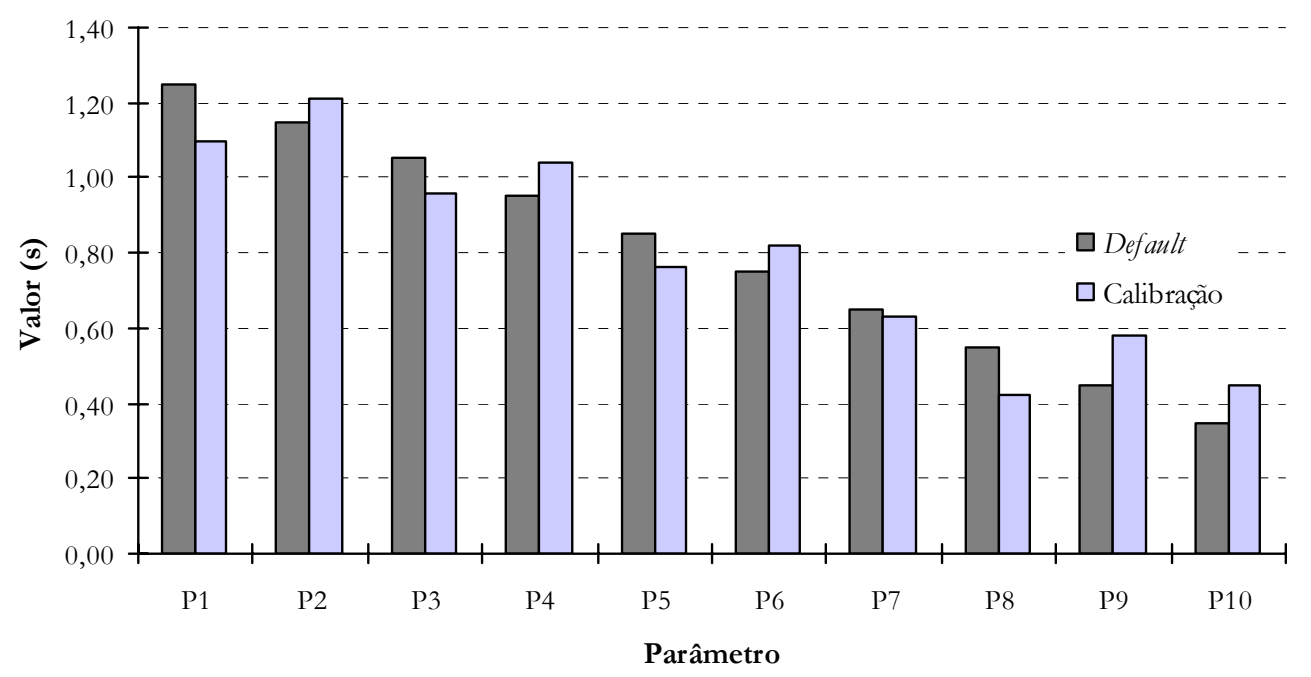

Figura 6.9 - Comparação dos valores default e calibrados dos parâmetros $\mathrm{P}_{1}$ a $\mathrm{P}_{10}$

A Tabela 6.6 mostra a comparação entre os valores default e calibrados dos demais parâmetros. O parâmetro $\mathrm{P}_{11}$, que caracteriza a distância absoluta mínima entre dois veículos, assumiu o menor valor permitido pelo CORSIM, que é 3 pés. O parâmetro $\mathrm{P}_{12}$ (tempo de reação para acelerar) aumentou de $0,3 \mathrm{~s}$ para $0,8 \mathrm{~s}$, enquanto o parâmetro $\mathrm{P}_{13}$ (tempo de reação para desacelerar) aumentou de $0,3 \mathrm{~s}$ para $0,5 \mathrm{~s}$.

Tabela 6.6 - Comparação entre os valores default e calibrados dos parâmetros $\mathrm{P}_{11}$ a $\mathrm{P}_{20}$

\begin{tabular}{cccc}
\hline Parâmetro & Unidade & Valor Default & Valor Calibrado \\
\hline $\mathrm{P}_{11}$ & pé & 10 & 3 \\
$\mathrm{P}_{12}$ & $\mathrm{~s}$ & 0,3 & 0,8 \\
$\mathrm{P}_{13}$ & $\mathrm{~s}$ & 0,3 & 0,5 \\
$\mathrm{P}_{14}$ & $\mathrm{~s}$ & 2,0 & 5,3 \\
$\mathrm{P}_{15}$ & $\mathrm{~s}$ & 1,6 & 1,5 \\
$\mathrm{P}_{16}$ & - & 3 & 3 \\
$\mathrm{P}_{17}$ & $\%$ & 20 & 15 \\
$\mathrm{P}_{18}$ & - & 0,5 & 0,1 \\
$\mathrm{P}_{20}$ & pé/s & 15 & 12 \\
\hline
\end{tabular}


O tempo para completar uma mudança de faixa, $\mathrm{P}_{14}$, saltou de $2,0 \mathrm{~s}$ para $5,3 \mathrm{~s}$, valor muito próximo do máximo permitido pelo simulador (6,0 s). Já o tempo mínimo para geração de veículos $\left(\mathrm{P}_{15}\right)$, que define a capacidade de uma faixa de tráfego, permaneceu praticamente inalterado, saindo de 1,6 s para 1,5 s.

$\mathrm{O}$ valor default do $\mathrm{P}_{16}$, que representa a aceitação de gap para mudança de faixa obrigatória, mostrou-se adequado para a rede simulada e não sofreu alteração.

A porcentagem de motoristas que cedem o direito de passagem para veículos mudando de faixa $\left(\mathrm{P}_{17}\right)$ sofreu uma redução de $20 \%$ para $15 \%$ e o multiplicador para o desejo de realizar uma mudança de faixa arbitrária, $\mathrm{P}_{18}$, atingiu o menor valor possível $(0,1)$. Este valor demonstra um alto desejo de mudar de faixa.

A desaceleração máxima do veículo líder percebida pelo seu seguidor $\left(\mathrm{P}_{20}\right)$ sofreu uma redução de 15 pés $/ \mathrm{s}^{2}$ para 12 pés/s².

\subsection{Validação do modelo calibrado para a rede estudada}

A validação foi realizada usando um conjunto de dados diferente daquele utilizado na calibração do CORSIM. A adoção do critério utilizado para separar os dados para calibração e validação de um modelo é arbitrária (Ni et al. 2004). O conjunto de dados usado na validação foi o observado na terceira coleta de dados, que compreendeu três horas e foi realizada em 1/7/2005. Estes dados apresentaram características operacionais diferentes dos observados nas outras coletas, com fluxos de tráfego superiores. Nessa coleta de dados, foi adicionado um posto de controle em cada sentido de tráfego, ou seja, o total de postos de controle passou a ser oito, sendo quatro em cada sentido.

A validação envolve a aplicação do modelo de simulação com o uso dos parâmetros encontrados na fase de calibração (Merritt, 2004). Ela serve para verificar se os resultados da representação de diferentes condições de tráfego são confiáveis (Sacks et al., 2002).

Na validação, executa-se uma simulação empregando a mesma seqüência de número aleatórios utilizadas na calibração. A importância de simular com a mesma seqüência reside no fato de 
que se deseja reproduzir as mesmas condições de tráfego encontradas na calibração, já que a seqüência de números aleatórios está relacionada aos processos estocásticos de tomada de decisão envolvidos na simulação.

O MAER foi calculado na validação com as mesmas medidas de desempenho da calibração. $\mathrm{O}$ valor calculado para a validação foi de $6,58 \%$, ligeiramente superior ao valor obtido na calibração (6,32\%), apesar da inclusão de mais dois postos de controle na rede de tráfego. Esse resultado comprova que os parâmetros calibrados são válidos para uso em um conjunto de dados com características diferentes. A diferença entre o MAER da validação e da calibração é considerada inexpressiva.

A Figura 6.10 apresenta a comparação das medidas de desempenho obtidas na validação do modelo para o sentido Norte da rede simulada. A Figura 6.11 apresenta os mesmos dados para o sentido Sul. As Tabelas 6.7 e 6.8 apresentam os valores médios observados e simulados das medidas de desempenho em cada posto de controle para os sentidos Norte e Sul, respectivamente.

Tabela 6.7 - Valores médios das medidas de desempenho na validação (Sentido Norte)

\begin{tabular}{ccccccc}
\hline \multirow{2}{*}{ Posto de Controle } & \multicolumn{3}{c}{ Fluxo Médio (veíc) } & \multicolumn{3}{c}{ Velocidade Média $(\mathrm{km} / \mathbf{h})$} \\
\cline { 2 - 7 } & Observado & Simulado & $\boldsymbol{\Delta} \mathbf{( \% )}$ & Observado & Simulado & $\boldsymbol{\Delta} \mathbf{( \% )}$ \\
\hline Entrada & 244 & 244 & 0,00 & 75 & 87 & $-16,00$ \\
Intermediário 1 & 217 & 210 & 3,23 & 82 & 88 & $-7,32$ \\
Intermediário 2 & 228 & 223 & 2,19 & 76 & 88 & $-15,79$ \\
Saída & 225 & 213 & 5,33 & 81 & 85 & $-4,94$ \\
\hline
\end{tabular}

Tabela 6.8 - Valores médios das medidas de desempenho na validação (Sentido Sul)

\begin{tabular}{ccccccc}
\hline \multirow{2}{*}{ Posto de Controle } & \multicolumn{3}{c}{ Fluxo Médio (veíc) } & \multicolumn{3}{c}{ Velocidade Média $(\mathrm{km} / \mathbf{h})$} \\
\cline { 2 - 8 } & Observado & Simulado & $\boldsymbol{\Delta} \mathbf{( \% )}$ & Observado & Simulado & $\boldsymbol{\Delta} \mathbf{( \% )}$ \\
\hline Entrada & 193 & 193 & 0,00 & 74 & 66 & 10,81 \\
Intermediário 1 & 222 & 240 & $-8,11$ & 67 & 59 & 11,94 \\
Intermediário 2 & 216 & 222 & $-2,78$ & 73 & 70 & 4,11 \\
Saída & 169 & 162 & 4,14 & 76 & 77 & $-1,32$ \\
\hline
\end{tabular}

Seguindo o comportamento verificado na calibração, a observação das Figuras 6.10 e 6.11 mostra que os dados de fluxo se aproximam mais que os dados de velocidade, para os dois sentidos de tráfego. As velocidades também seguem a mesma tendência notada na calibração, com 
valores observados menores em todos os postos de controle do sentido Norte e apenas no posto de controle da saída da rede no sentido Sul.
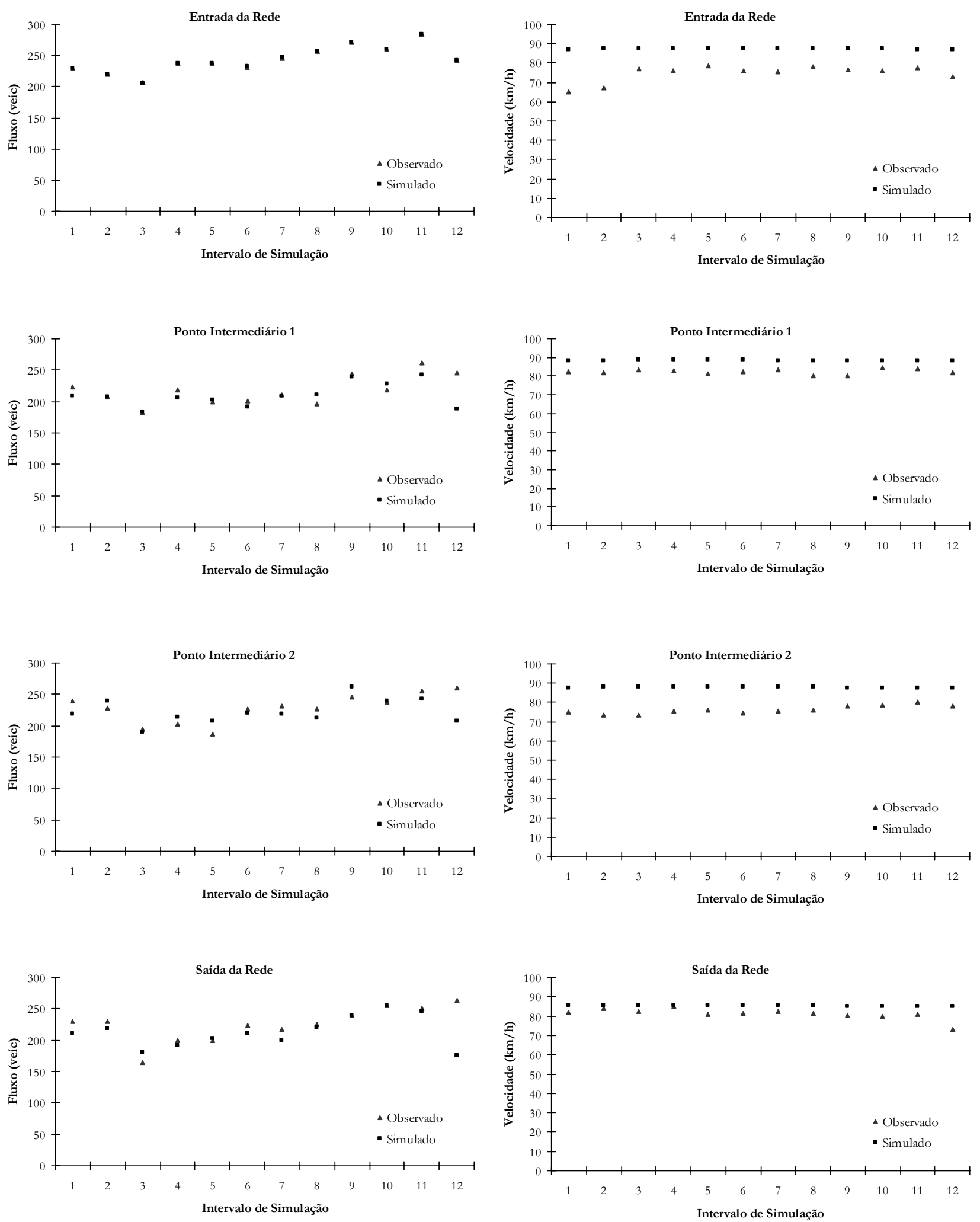

Figura 6.10 - Comparação das medidas de desempenho obtidas na validação (Sentido Norte) 

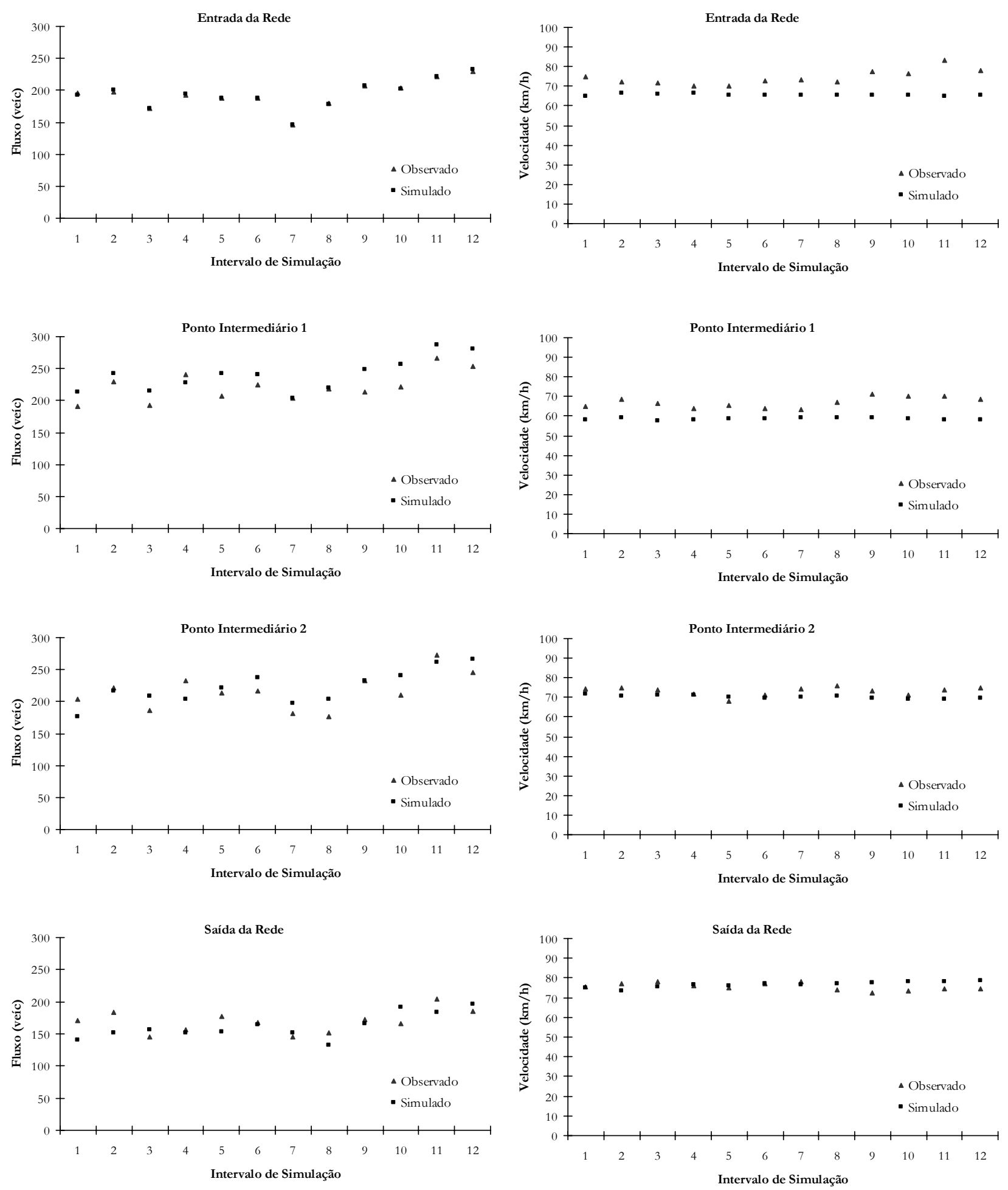

Figura 6.11 - Comparação das medidas de desempenho obtidas na validação (Sentido Sul) 
A Figura 6.12 mostra a contribuição das duas medidas de desempenho utilizadas no valor final do MAER para cada uma das etapas realizadas nesta pesquisa. Na validação, o MAER devido ao volume representa $27 \%$ do total. Esse valor indica que a contribuição de cada um das medidas de desempenho na validação se assemelha àquela obtida com os parâmetros default.

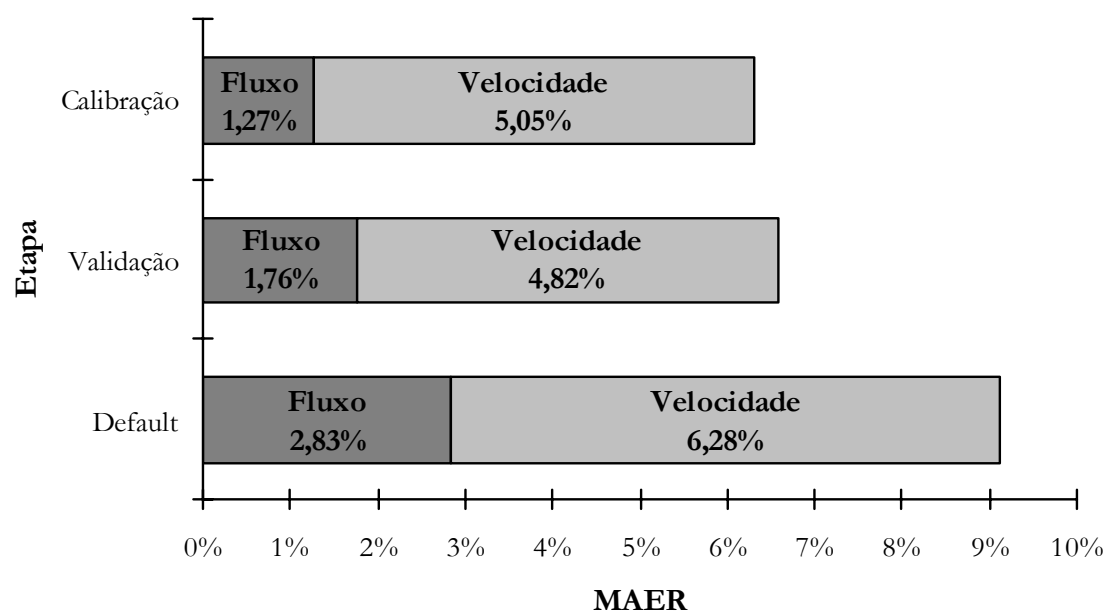

Figura 6.12 - Contribuição das medidas de desempenho no MAER em todas as etapas

\subsection{Considerações finais}

Os resultados apresentados neste capítulo indicam que a calibração do simulador de tráfego CORSIM foi adequada. A simulação com os parâmetros default do simulador forneceu um MAER de 9,11\%, correspondente a um fitness de 63,41. O MAER obtido com o CORSIM calibrado através do uso de um algoritmo genético foi de 6,32\%, com um fitness de 72,89. Essa redução de 2,79\% no MAER é significativa e demonstra a eficiência do algoritmo genético na calibração do modelo de simulação. Na validação do CORSIM, o MAER obtido foi de 6,58\% (fitness de $78,10)$, o que representa um aumento de $0,26 \%$ no MAER.

Dessa forma, pode-se considerar que a calibração do CORSIM foi realizada com êxito e que o modelo calibrado (e devidamente validado) é capaz de reproduzir com a fidelidade desejada o comportamento do tráfego na rede estudada para os propósitos desejados nesta pesquisa. 


\section{Estudo de Caso}

Uma vez obtida uma versão calibrada do simulador CORSIM, capaz de reproduzir as condições de tráfego observadas em campo, procedeu-se a um estudo de caso em que se buscou estabelecer o efeito do tráfego dos veículos pesados sobre um componente da infra-estrutura rodoviária. Este capítulo descreve as etapas percorridas para a execução do estudo de caso, cujo propósito foi demonstrar como os dados sobre o carregamento móvel obtidos a partir da simulação microscópica de uma rede de tráfego podem ser usados no processo de dimensionamento de pontes. No estudo de caso, foram considerados dois cenários de tráfego e o efeito analisado foi o momento fletor máximo positivo ocasionado pela presença simultânea de veículos pesados na ponte, a fim de fazer uma comparação com aquele provocado pelo veículo-tipo e a carga uniformemente distribuída estabelecidos na NBR-7188. Essa ponte é hipotética e está localizada em um dos tramos da rede simulada.

\subsection{Definição dos cenários simulados}

A escolha dos cenários simulados no estudo de caso deu-se em função da vida útil de projeto das pontes, que, em geral, é de 50 anos para pontes de concreto (Ferreira, 2006). Eles foram definidos com o intuito de demonstrar a metodologia proposta nesta pesquisa e não têm a pretensão de prever as alterações das características da corrente de tráfego ao longo do tempo. Os cenários foram assim estabelecidos: 
- Cenário 1: crescimento do fluxo de tráfego atual a uma taxa de 2\% ao ano para um período de 50 anos, mantendo a composição do tráfego obtida nas coletas de dados; e

- Cenário 2: crescimento do fluxo de tráfego atual a uma taxa de $2 \%$ ao ano para um período de 50 anos, modificando a composição do tráfego obtida nas coletas de dados para contemplar uma participação de $50 \%$ da frota de veículos pesados.

O cálculo do crescimento do tráfego foi feito admitindo uma progressão geométrica, através da Equação 7.1:

$$
V_{n}=V+(1+i)^{n}
$$

em que: $\quad V_{n}: \quad$ fluxo diário de tráfego calculado para o ano $n$, em veículos;

V: $\quad$ fluxo diário de tráfego atual, em veículos;

$i: \quad$ taxa de crescimento anual; e

n: $\quad$ horizonte de projeto, em anos.

O fluxo diário de tráfego atual foi definido como o observado em um dia usual na rede simulada, cuja obtenção é detalhada a seguir.

\subsubsection{Fluxo diário de tráfego}

As coletas de dados perfizeram um total de oito horas e foram realizadas em três dias, conforme discutido no Capítulo 5. Esse período não é suficiente para caracterizar a flutuação da demanda de tráfego ao longo de um dia. Dessa forma, com o objetivo de obter um fluxo diário de tráfego no trecho da SP-310 estudado, foi feita uma comparação entre os fluxos horários coletados e os fluxos horários medidos por sensores automáticos instalados no pavimento pela concessionária que o administra. A partir dessa comparação (e o conseqüente ajuste), foi obtida a variação do fluxo para um período de 24 horas.

Dentre os sensores automáticos de contagem permanente de tráfego que a concessionária possui ao longo de sua área de concessão, um está localizado a uma distância aproximada de $400 \mathrm{~m}$ do posto de controle que representa o início da rede simulada, no sentido Norte. Apesar 
de essa distância ser relativamente pequena, considerou-se que a existência de um acesso de saída da rodovia para a cidade de São Carlos - SP poderia gerar uma diferença significativa entre os fluxos horários observados nas coletas e os fluxos horários medidos pelos sensores. Dessa forma, optou-se por fazer uma comparação entre os dados de contagem cedidos pela concessionária e os dados coletados em campo. Essa comparação foi feita para cada uma das oito horas em que foram realizadas as coletas de dados e é apresentada na Figura 7.1. Os fluxos das horas 1 e 2 são os obtidos na primeira coleta de dados (6/6/2005), os fluxos das horas 3 a 5 são os obtidos na segunda coleta de dados (13/6/2005) e os fluxos das horas 6 a 8 são os obtidos na terceira coleta de dados $(1 / 7 / 2005)$.

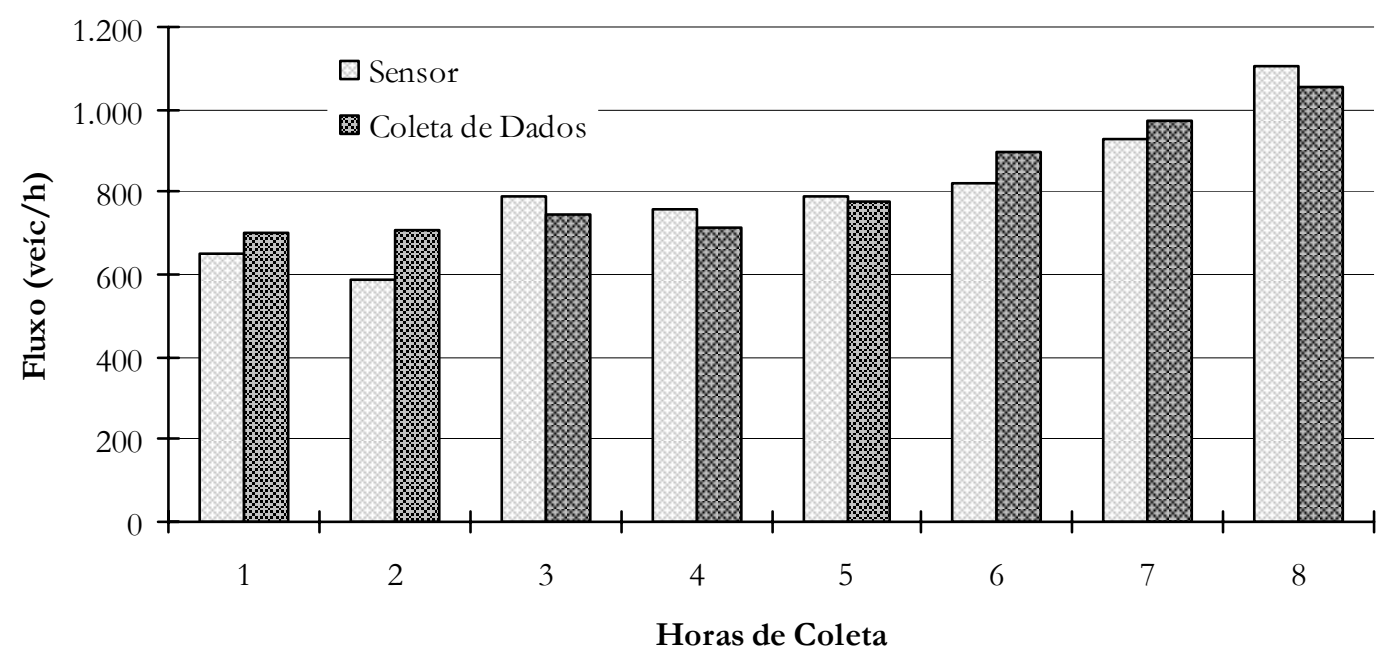

Figura 7.1 - Comparação entre os fluxos horários coletados e medidos pelo sensor (sentido Norte)

Como pode ser observado, as diferenças encontradas não são sistemáticas, ou seja, em quatro horas os fluxos coletados são maiores que os medidos pelo sensor e nas quatros horas restantes ocorre o inverso. Além da influência do acesso de saída da rodovia, essas diferenças podem ser justificadas pelo fato de que a hora da câmera de vídeo não estava sincronizada com a hora do sensor. A diferença média calculada entre os dados coletados e os medidos pelo sensor para as oito horas foi de 2,28\%. Entretanto, uma diferença de 16,83\% foi calculada para a segunda hora da primeira coleta de dados. 
A observação da Figura 7.1 permite verificar que os dados que representam a segunda coleta de dados (horas 3 a 5) são os que apresentam uma maior uniformidade nas diferenças encontradas entre os dois fluxos. Essas diferenças são mostradas na Tabela 7.1.

Tabela 7.1 - Diferenças entre os fluxos no sentido Norte (13/6/2005)

\begin{tabular}{cccc}
\hline \multirow{2}{*}{ Hora } & \multicolumn{2}{c}{ Fluxo (veíc) } & \multirow{2}{*}{$\boldsymbol{\Delta}(\mathbf{\%})$} \\
\cline { 2 - 3 } & Sensor & Coleta de Dados & \\
\hline $09: 00$ & 789 & 743 & $-6,19$ \\
10:00 & 756 & 714 & $-5,88$ \\
11:00 & 790 & 775 & $-1,94$ \\
\hline \multicolumn{4}{c}{ Média } \\
\hline
\end{tabular}

Assim, foi definido que o ajuste para a obtenção de um tráfego diário seria feito com os dados da segunda coleta de dados. Esse ajuste aplicou um fator de correção aos fluxos das 21 horas do dia 13/6/2005 em que não foram feitas coletas de dados e corresponde à média calculada para as três horas em que foram feitas as coletas $(-4,67 \%)$.

A variação dos fluxos horários ao longo do dia está apresentada na Figura 7.2. Essa figura mostra também a variação dos fluxos previstos para o horizonte de projeto, calculado pela Equação 7.1. O fluxo previsto foi usado na codificação do CORSIM para a simulação dos cenários de tráfego definidos para o estudo de caso. A matriz origem/destino usada foi a matriz média do sentido Norte obtida para a segunda coleta de dados, apresentada anteriormente na Tabela 5.6.

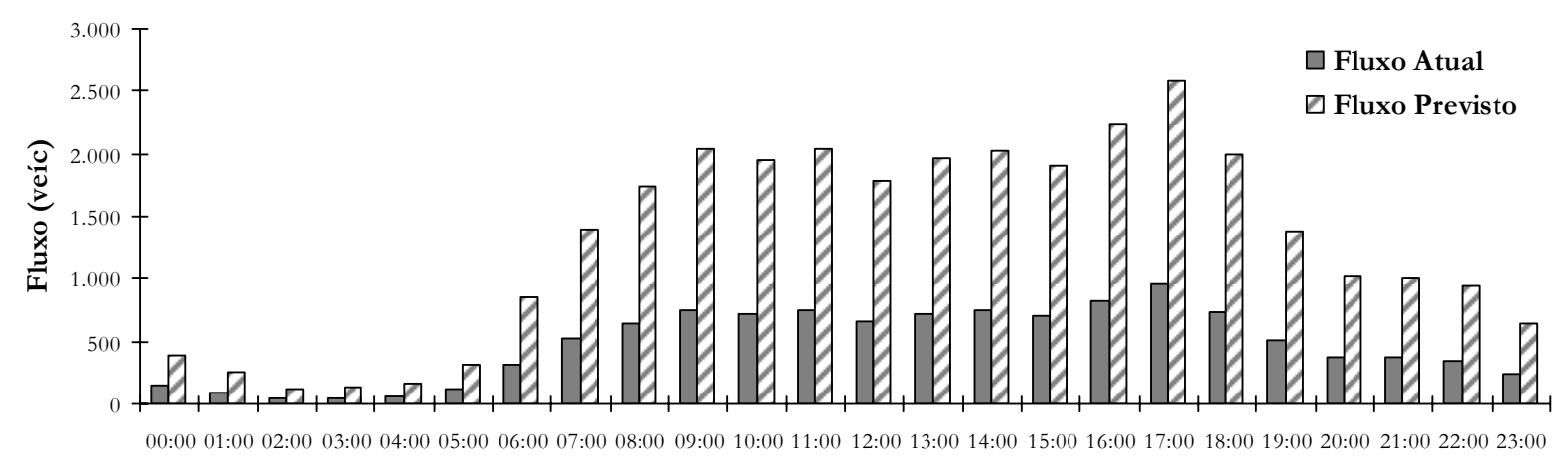

Hora

Figura 7.2 - Variação dos fluxos atual e previsto ao longo do dia (sentido Norte) 


\subsubsection{Localização da ponte na rede de tráfego}

O tramo escolhido para representar a ponte está localizado no sentido Norte da rede, uma vez que a variação do fluxo foi obtida para esse sentido. Durante a escolha do tramo, o único aspecto considerado foi a sua posição em relação ao ponto de início da rede, pois um tramo localizado muito próximo da entrada da rede sofreria uma grande influência do processo de geração de veículos do simulador de tráfego e pouca influência do car-following e da mudança de faixa, o que não seria desejável. Dessa forma, o tramo escolhido está situado a uma distância aproximada de $2 \mathrm{~km}$ do início da rede.

O tramo que representa a ponte possui extensão de $100 \mathrm{~m}$. Para fins desta pesquisa, considera-se que a ponte é simplesmente apoiada, apesar de, na prática, vãos maiores que $50 \mathrm{~m}$ dificilmente serem empregados em pontes com esse sistema estrutural. A razão para isso é que vigas simplesmente apoiadas sem balanço se constituem em um tipo estrutural relativamente pobre, pois, uma vez imposto um determinado vão, existem poucas possibilidades de melhorar a distribuição dos esforços (El Debs e Takeya, 1995).

\subsection{Extração de dados do CORSIM}

Diante da necessidade de obter dados microscópicos da simulação, verificou-se que o arquivo OUT do CORSIM não poderia ser utilizado, já que ele contém apenas relatórios globais e esse tipo de informação não atende aos propósitos desta pesquisa. Nesse caso, a fim de obter dados individuais de cada veículo simulado, foi usado o TSD, um arquivo de resultados binário gerado pelo CORSIM em que são escritas a cada segundo de simulação diversas informações sobre cada um dos veículos. Apesar de esse arquivo conter dados variados tais como velocidade, aceleração, tipo de motorista, entre outros, os dados que foram usados nesta pesquisa foram basicamente:

- Número de identificação do veículo (ID);

- Tipo do veículo;

- Faixa de tráfego em que o veículo se encontra; e 
- Posição do veículo na faixa de tráfego.

Para ler o arquivo TSD, foi desenvolvida uma macro escrita na linguagem VBA. Essa macro se baseou no programa de extração de dados do arquivo TSD criado por Dhulipala (2002) e codificado em $\mathrm{C}++$.

Em síntese, a macro busca em um determinado tramo da rede os segundos em que ocorrem a presença dos veículos do tipo 3 a 6 (que representam os caminhões no CORSIM). Aqui, o tramo de interesse é o que representa a ponte. Para os instantes em que se verifica a existência de caminhões no tramo, são extraídos os números de identificação dos veículos (ID), os tipos de veículos $(3,4,5$ e 6$)$, as faixas de tráfego em que eles se encontram naquele instante (faixa 1 ou 2) e suas posições nessas faixas, medidas em relação ao início do tramo. A Tabela 7.2 exemplifica a extração de um instante em que ocorre a presença de seis caminhões na ponte, estando quatro em uma mesma faixa de tráfego. Apesar da possibilidade de existência de automóveis ou ônibus juntamente com os caminhões, eles não são levados em conta neste trabalho porque não chegam a produzir solicitações suficientes para causar danos às pontes (Loriggio,1993).

Tabela 7.2 - Exemplo dos dados extraídos pela macro

\begin{tabular}{ccccc}
\hline Segundo & ID & Tipo do Veículo & Faixa de Tráfego & Posição (pé) \\
\hline 34092 & 9155 & 4 & 2 & 362 \\
34092 & 9158 & 3 & 1 & 345 \\
34092 & 9160 & 4 & 1 & 313 \\
34092 & 9159 & 4 & 1 & 285 \\
34092 & 9161 & 5 & 2 & 255 \\
34092 & 9162 & 5 & 1 & 226 \\
\hline
\end{tabular}

Um fluxograma geral da macro desenvolvida é apresentado na Figura 7.3, enquanto a Figura 7.4 detalha o funcionamento de algumas de suas etapas. A Equação 7.2 apresenta o cálculo da probabilidade. O evento A se refere à presença de uma quantidade $\mathrm{N}$ de caminhões sobre a ponte, o número de eventos é o total de segundos em que essa quantidade $\mathrm{N}$ ocorre e o espaço amostral é o total de segundos da simulação.

$$
P(A)=\frac{n_{A}}{n}
$$


em que: $\quad P(A)$ : probabilidade de ocorrência do evento A;

$$
\begin{aligned}
& n_{A}: \quad \text { número de eventos; e } \\
& n: \quad \text { espaço amostral. }
\end{aligned}
$$

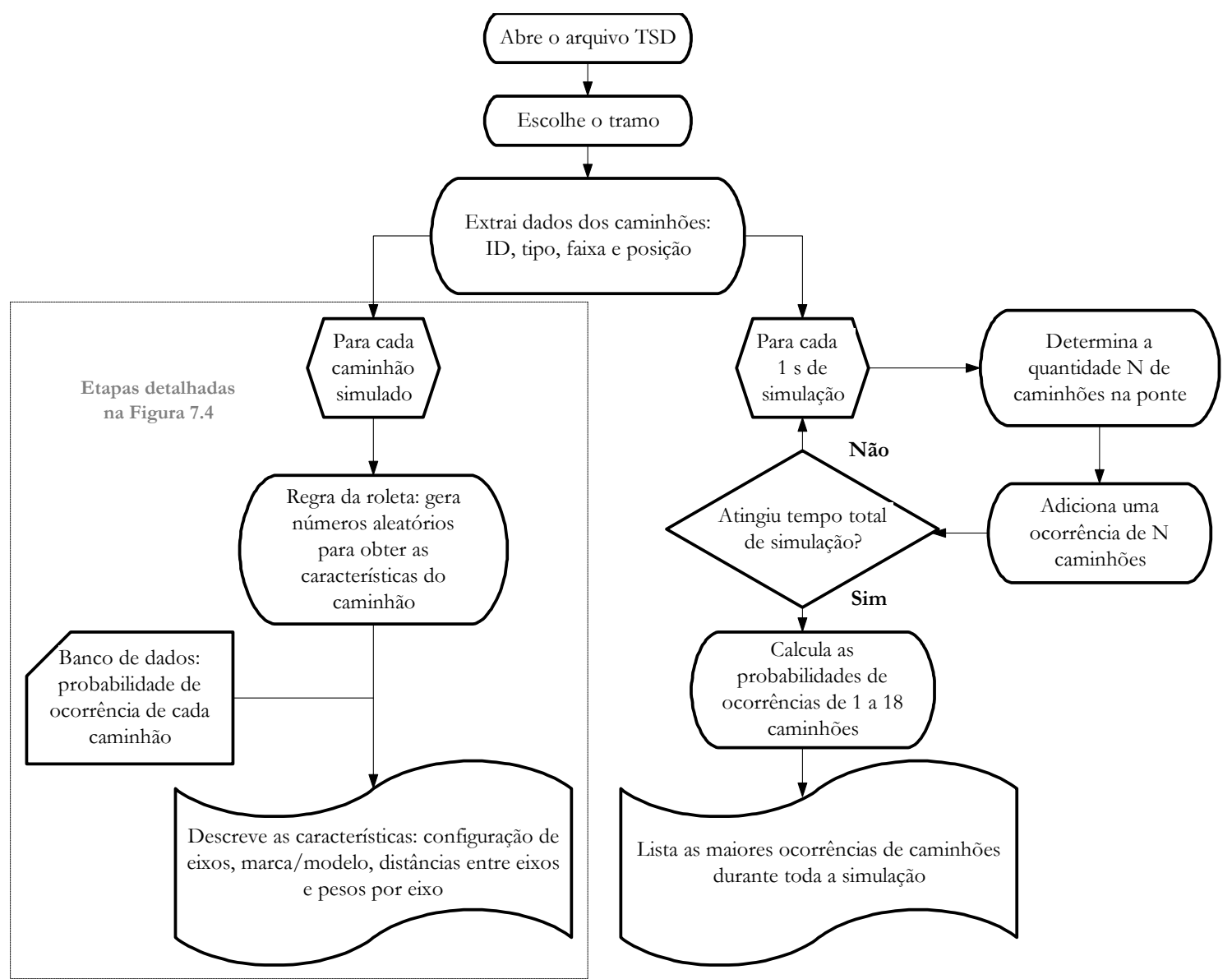

Figura 7.3 - Fluxograma da macro escrita em VBA
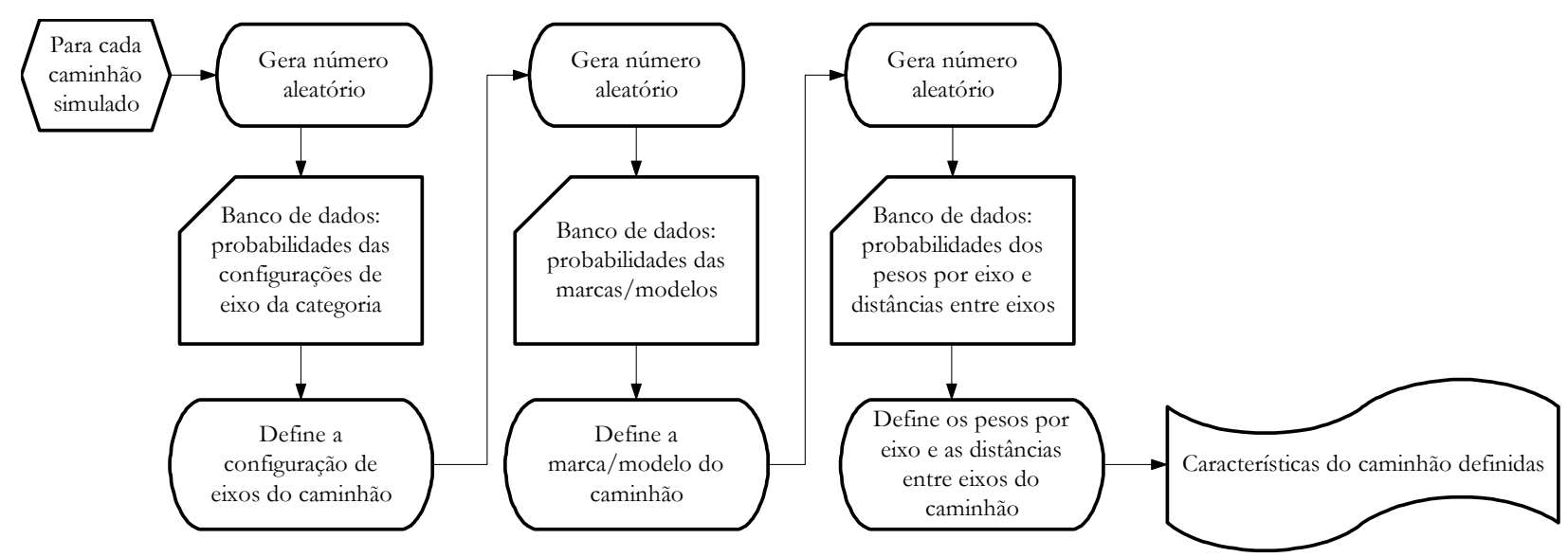

Figura 7.4 - Fluxograma detalhado de algumas etapas da macro 
Como mostrado na Figura 7.4, o banco de dados utilizado pela macro possui três subdivisões. Todas as informações contidas nesse banco de dados têm como base os dados coletados em balanças rodoviárias, discutidos no Capítulo 5 .

$\mathrm{Na}$ primeira subdivisão do banco de dados são definidas as probabilidades de ocorrência das diversas configurações de eixo em cada categoria, mostradas na Tabela 7.3.

Tabela 7.3 - Probabilidades das configurações na categoria

\begin{tabular}{|c|c|c|c|c|}
\hline Categoria & Tipo do Veículo & Configuração & Amostra & Probabilidade \\
\hline Leves & 3 & $2 \mathrm{C}$ & 1.881 & $100,00 \%$ \\
\hline \multirow{7}{*}{ Médios } & \multirow{7}{*}{4} & $3 \mathrm{C}$ & 1.809 & $87,69 \%$ \\
\hline & & $2 \mathrm{~S} 2$ & 206 & $9,99 \%$ \\
\hline & & $2 \mathrm{~S} 1$ & 39 & $1,89 \%$ \\
\hline & & $2 \mathrm{I} 2$ & 6 & $0,29 \%$ \\
\hline & & $2 \mathrm{C} 2$ & 1 & $0,05 \%$ \\
\hline & & $4 \mathrm{CD}$ & 1 & $0,05 \%$ \\
\hline & & $4 \mathrm{C}$ & 1 & $0,05 \%$ \\
\hline \multirow{11}{*}{ Pesados } & \multirow{11}{*}{5} & $2 \mathrm{~S} 3$ & 1.527 & $74,20 \%$ \\
\hline & & $3 \mathrm{~S} 3$ & 413 & $20,07 \%$ \\
\hline & & $2 \mathrm{I} 3$ & 71 & $3,45 \%$ \\
\hline & & $3 \mathrm{~S} 2$ & 13 & $0,63 \%$ \\
\hline & & $2 \mathrm{~J} 3$ & 11 & $0,53 \%$ \\
\hline & & $3 \mathrm{C} 2$ & 9 & $0,44 \%$ \\
\hline & & $3 \mathrm{I} 2$ & 4 & $0,19 \%$ \\
\hline & & $2 \mathrm{~T} 4$ & 3 & $0,15 \%$ \\
\hline & & $3 \mathrm{C} 3$ & 3 & $0,15 \%$ \\
\hline & & $3 \mathrm{~J} 3$ & 3 & $0,15 \%$ \\
\hline & & $3 \mathrm{I} 3$ & 1 & $0,05 \%$ \\
\hline \multirow{3}{*}{ Extra-pesados } & \multirow{3}{*}{6} & $3 \mathrm{~T} 4$ & 243 & $96,81 \%$ \\
\hline & & 3T6 & 5 & $1,99 \%$ \\
\hline & & $3 \mathrm{~S} 4$ & 3 & $1,20 \%$ \\
\hline
\end{tabular}

A segunda subdivisão do banco de dados diz respeito às probabilidades de ocorrência das marcas/modelos em cada uma das configurações de eixo. Um exemplo dessas probabilidades, referente à configuração 3S2, pode ser visto na Tabela 7.4.

Tabela 7.4 - Probabilidades das marcas/modelos (configuração 3S2)

\begin{tabular}{cc}
\hline Marca/Modelo & Probabilidade \\
\hline Scania 124G & $46,16 \%$ \\
Scania 113H & $23,08 \%$ \\
Scania 142H & $15,38 \%$ \\
Mercedes-Benz 1944S & $15,38 \%$ \\
\hline
\end{tabular}


Por fim, a terceira subdivisão do banco de dados contém as probabilidades dos pesos por eixo de cada caminhão de um determinado modelo e suas respectivas distâncias entre eixos. A Tabela 7.5 mostra esses dados para os caminhões da configuração 3S2. O método da roleta, descrito no Capítulo 6 e utilizado no algoritmo genético que calibrou o simulador CORSIM, foi usado na definição das características dos caminhões a partir do banco de dados.

Tabela 7.5 - Probabilidades dos pesos por eixo e distâncias entre eixos (configuração 3S2)

\begin{tabular}{ccccccccccc}
\hline \multirow{2}{*}{ Marca/Modelo } & \multirow{2}{*}{ Probabilidade } & \multicolumn{4}{c}{ Peso por Eixo $\mathbf{( k g})$} & \multicolumn{4}{c}{ Distância entre Eixos (m) } \\
\cline { 3 - 10 } & & $\mathbf{1}^{\mathbf{o}}$ & $\mathbf{2}^{\mathbf{o}}$ & $\mathbf{3}^{\mathbf{o}}$ & $\mathbf{4}^{\mathbf{0}}$ & $\mathbf{5}^{\mathbf{0}}$ & $\mathbf{1}$ & $\mathbf{2}$ & $\mathbf{3}$ & $\mathbf{4}$ \\
\hline Scania 124G & $16,66 \%$ & 4.420 & 8.150 & 0 & 4.730 & 5.350 & 3,55 & 1,31 & 7,57 & 1,25 \\
Scania 124G & $16,66 \%$ & 5.850 & 9.350 & 7.730 & 8.730 & 7.770 & 3,55 & 1,31 & 7,57 & 1,25 \\
Scania 124G & $16,66 \%$ & 5.790 & 9.430 & 7.290 & 9.430 & 8.190 & 3,55 & 1,31 & 7,57 & 1,25 \\
Scania 124G & $16,66 \%$ & 6.230 & 9.250 & 6.940 & 9.000 & 8.000 & 3,55 & 1,31 & 7,57 & 1,25 \\
Scania 124G & $16,66 \%$ & 4.500 & 6.150 & 0 & 5.500 & 4.950 & 3,55 & 1,31 & 7,57 & 1,25 \\
Scania 124G & $16,66 \%$ & 4.650 & 7.200 & 4.450 & 6.800 & 7.400 & 3,55 & 1,31 & 7,57 & 1,25 \\
Scania 113H & $33,33 \%$ & 4.240 & 6.930 & 0 & 4.330 & 0 & 3,55 & 1,31 & 7,57 & 1,25 \\
Scania 113H & $33,33 \%$ & 4.400 & 6.640 & 0 & 1.810 & 2.560 & 3,55 & 1,31 & 7,57 & 1,25 \\
Scania 113H & $33,33 \%$ & 5.450 & 8.290 & 6.050 & 5.650 & 5.700 & 3,55 & 1,31 & 7,57 & 1,25 \\
Scania 142H & $50,00 \%$ & 4.660 & 8.940 & 2.980 & 6.760 & 5.640 & 3,55 & 1,31 & 7,57 & 1,25 \\
Scania 142H & $50,00 \%$ & 5.200 & 9.100 & 4.600 & 4.950 & 4.800 & 3,55 & 1,31 & 7,57 & 1,25 \\
Mercedes-Benz 1944S & $50,00 \%$ & 5.390 & 5.120 & 3.600 & 7.540 & 4.140 & 4,20 & 1,36 & 7,57 & 1,25 \\
Mercedes-Benz 1944S & $50,00 \%$ & 5.290 & 9.150 & 7.500 & 6.200 & 5.970 & 4,20 & 1,36 & 7,57 & 1,25 \\
\hline
\end{tabular}

Um aspecto que foi observado durante o uso da macro é que o CORSIM considera que um veículo se encontra no tramo a partir do instante de passagem do seu pára-choque dianteiro pelo nó à montante do tramo. Da mesma forma, ele só identifica a saída do veículo do tramo após a passagem do seu pára-choque traseiro pelo nó à jusante. Assim, mesmo que apenas uma pequena porção do veículo esteja no tramo (por exemplo, o seu primeiro ou último eixo), a sua presença é detectada.

A posição do veículo que consta no arquivo TSD é a do seu pára-choque dianteiro. Logo, para efeito de posicionamento das cargas por eixo, foi feita a suposição de que o balanço dianteiro de todos os caminhões era igual a 1,35 m. Essa suposição deu-se em virtude da grande variedade de modelos de caminhões existentes na amostra e o valor adotado corresponde à média encontrada para os balanços dos modelos cujas especificações técnicas disponibilizadas pelos fabricantes eram mais completas. 


\subsection{Definição do número de dias simulados}

A definição da quantidade de dias que seriam simulados para cada um dos cenários teve como base a estabilização da diferença de probabilidade de ocorrência de caminhões sobre a ponte, obtida com o uso da macro. Para isso, foram feitas replicações da simulação. Cada replicação usa uma seqüência diferente de números aleatórios e assim se introduz uma variabilidade aos processos estocásticos envolvidos na simulação (Cohen, 2004).

Os arquivos do CORSIM foram codificados para reproduzir 48 horas, ou seja, as simulações realizadas descrevem a variação do tráfego ao longo de dois dias. Esse valor foi determinado em função de uma limitação existente no simulador quanto ao número máximo de segundos que pode ser simulado.

É importante ressaltar que, enquanto cada replicação da simulação de 48 horas leva, em média, 15 minutos para ser concluída, a macro despende outros 20 minutos para ler o arquivo TSD gerado por essa replicação. Isso ocorre devido à grande quantidade de dados a ser extraída para um período de 172.800 segundos.

Inicialmente, o número de replicações escolhido para verificar o comportamento da diferença de probabilidade foi 15, o que significa 30 dias de simulação. Contudo, os resultados obtidos com esse número de replicações não foram satisfatórios, ou seja, as diferenças entre as probabilidades não se estabilizaram. Dessa forma, foi definido que um número de 45 replicações (ou 90 dias) seria testado.

A simulação de 90 dias verificou a ocorrência de até dez caminhões sobre a ponte para o Cenário 1. Entretanto, como esse evento aconteceu apenas uma vez (um segundo), não foi possível analisar o comportamento da probabilidade. Sendo assim, a análise foi feita com base na ocorrência de nove caminhões. A Figura 7.5 apresenta o comportamento da diferença de probabilidade ao longo dos 90 dias simulados.

Para o Cenário 2, foi verificada a ocorrência de até 12 caminhões na ponte, mas, à exemplo do Cenário 1, esse evento ocorreu poucas vezes (nove segundos em 90 dias de simulação). Dessa 
forma, analisou-se a probabilidade de ocorrência de 11 caminhões, conforme apresentado na Figura 7.6.

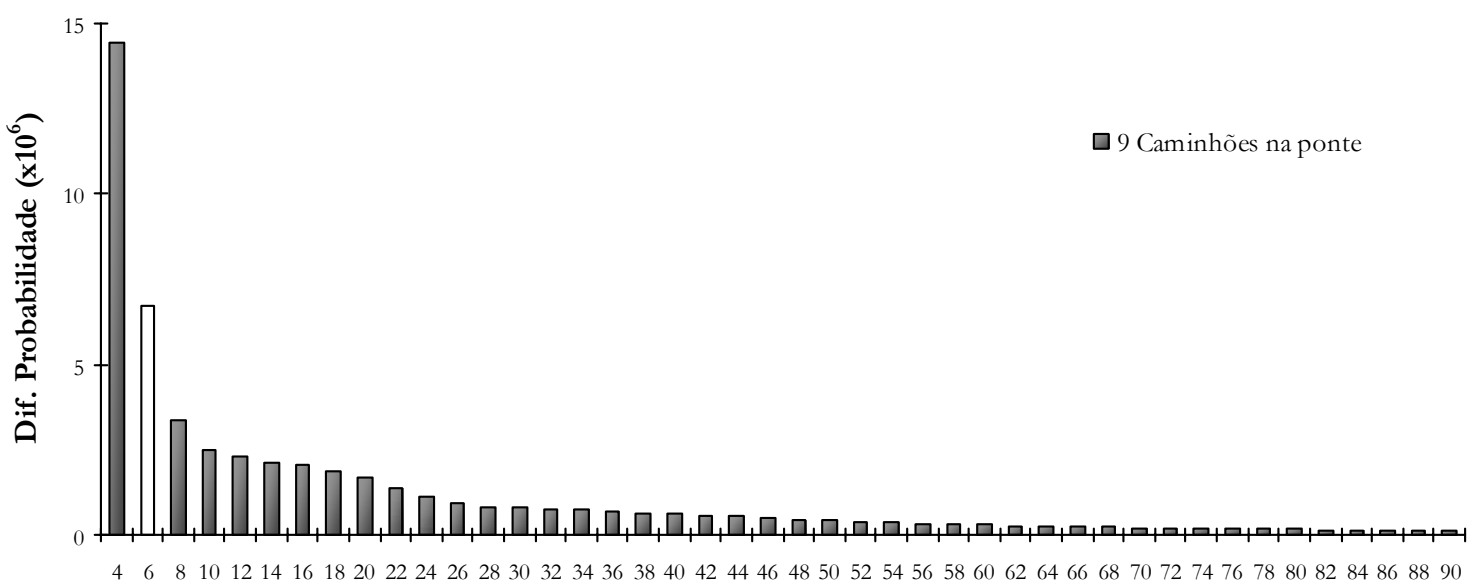

Dias Simulados

Figura 7.5 - Diferença de probabilidade (Cenário 1)

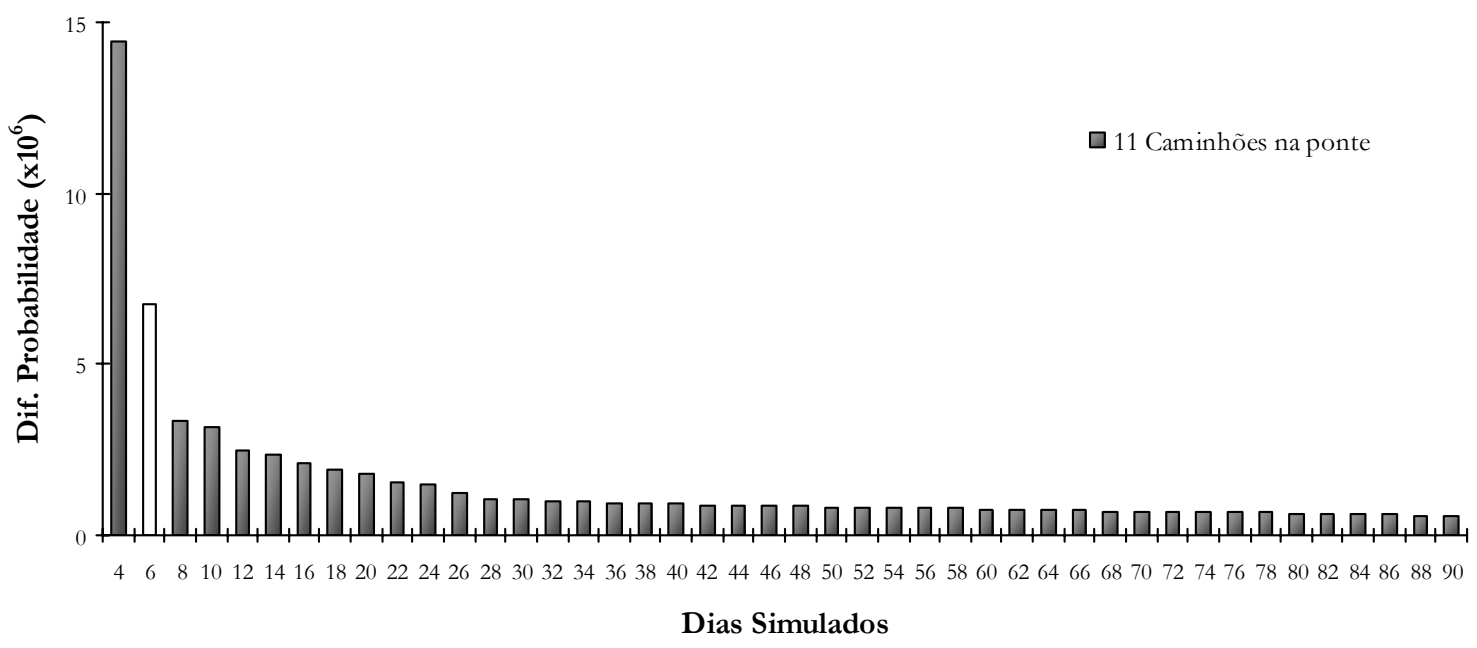

Figura 7.6 - Diferença de probabilidade (Cenário 2)

A Figura 7.5 demonstra que, a partir do $70^{\circ}$ dia simulado, a diferença nas probabilidades sofre uma alteração muito pequena. O mesmo ocorre com os dados mostrados na Figura 7.6, com as diferenças permanecendo praticamente estáveis a partir do $80^{\circ}$ dia simulado. Portanto, considera-se que o período de 90 dias é suficiente para representar o comportamento da probabilidade de ocorrências de caminhões sobre a ponte para os dois cenários. 


\subsection{Probabilidades de ocorrência}

Com um tempo total de 7.776 .000 segundos, que corresponde a 90 dias de simulação do tráfego para cada cenário, foram obtidas as probabilidades de ocorrência de caminhões sobre a ponte. Essas probabilidades são mostradas na Tabela 7.6.

Tabela 7.6 - Probabilidades de ocorrência

\begin{tabular}{ccccc}
\hline \multirow{2}{*}{$\begin{array}{c}\text { Quantidade de } \\
\text { Caminhões na Ponte }\end{array}$} & \multicolumn{2}{c}{ Cenário 1 } & \multicolumn{2}{c}{ Cenário 2 } \\
\cline { 2 - 5 } & $\begin{array}{c}\text { Número de } \\
\text { Segundos }\end{array}$ & Probabilidade & $\begin{array}{c}\text { Número de } \\
\text { Segundos }\end{array}$ & Probabilidade \\
\hline 12 & - & - & 9 & $1 / 864.000$ \\
11 & - & - & 194 & $1 / 40.082$ \\
10 & 1 & $1 / 7.776 .000$ & 1.458 & $1 / 5.333$ \\
9 & 43 & $1 / 180.837$ & 7.608 & $1 / 1.022$ \\
8 & 233 & $1 / 33.373$ & 31.771 & $1 / 245$ \\
7 & 1.950 & $1 / 3.988$ & 98.821 & $1 / 79$ \\
6 & 10.984 & $1 / 708$ & 227.730 & $1 / 34$ \\
5 & 48.620 & $1 / 160$ & 406.220 & $1 / 19$ \\
4 & 161.009 & $1 / 48$ & 611.143 & $1 / 13$ \\
3 & 437.294 & $1 / 18$ & 831.925 & $1 / 9$ \\
2 & 1.008 .948 & $1 / 8$ & 1.147 .965 & $1 / 7$ \\
1 & 2.057 .484 & $1 / 4$ & 1.701 .233 & $1 / 5$ \\
\hline
\end{tabular}

Como se pode perceber, o aumento da participação de caminhões na corrente de tráfego, que era de 27\% no Cenário 1 e passou a 50\% no Cenário 2, fez com que a ocorrência de todas as quantidades de caminhões sobre a ponte se tornasse mais freqüente, a menos da ocorrência de um único caminhão, que sofreu uma pequena redução. A alteração na composição do tráfego permitiu também que fossem verificadas as ocorrências de 11 e 12 caminhões na ponte, o que não ocorreu no Cenário 1.

Um aspecto a ser mencionado é que entre os nove instantes em que existem 12 caminhões na ponte, apenas quatro deles apresentam uma divisão equilibrada por faixa (ou seja, seis caminhões em cada faixa de tráfego). Nos cinco segundos restantes, foram observados até sete caminhões em uma mesma faixa de tráfego, como mostrado na Figura 7.7. Esse fato leva a crer que, apesar de se constituir em um evento raro e não ter sido observado nesse experimento, a possibilidade de ocorrência de até 14 caminhões em uma ponte de 100 m não pode ser descartada. 


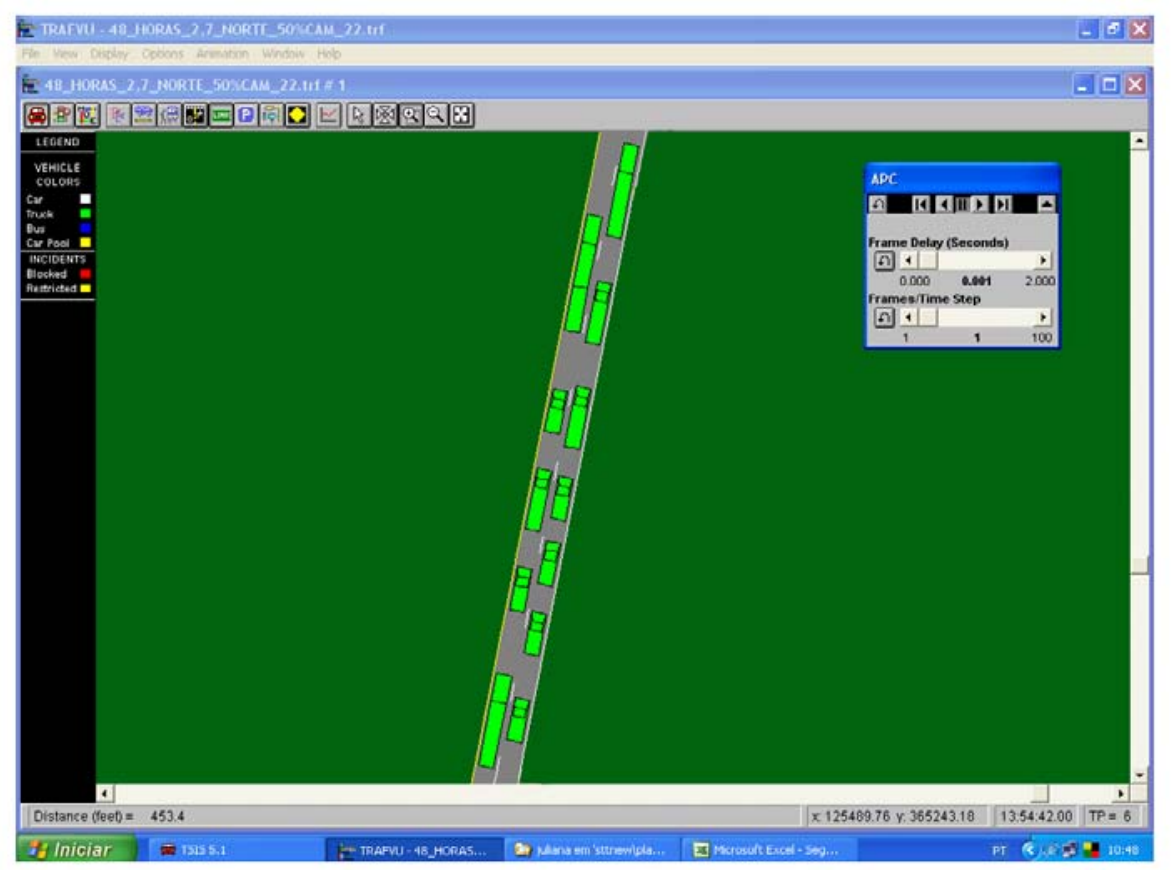

Figura 7.7 - Visualização de 12 caminhões na ponte

\subsection{Efeito do tráfego de veículos pesados sobre a ponte}

Para a análise do efeito do tráfego dos veículos pesados sobre a ponte (nesse caso, o momento fletor máximo positivo), fez-se uso da versão 2.11 do FTOOL, que é um programa que se destina à análise do comportamento estrutural de pórticos planos (Martha, 2002). Ele é uma ferramenta simples, que combina em uma única interface recursos para uma eficiente criação e manipulação do modelo (pré-processamento) aliados a uma análise da estrutura rápida e a uma visualização de resultados efetiva (pós-processamento).

A seguir, demonstra-se como são obtidas as cargas móveis estabelecidas na norma atualmente em vigência e aquelas derivadas da simulação. O efeito que esses carregamentos provocam na estrutura também é apresentado.

\subsubsection{Carga móvel da NBR-7188}

Segundo a NBR-7188, em pontes rodoviárias, a carga móvel é constituída por um veículotipo e por cargas $q$ e q' uniformemente distribuídas. Enquanto a carga $q$ procura levar em consideração a existência de outros veículos na ponte, a carga q' tenta reproduzir a ação de multidão (ABNT, 1984). 
Nesse estudo de caso, considera-se que a ponte é da classe 45 , o que implica que a carga $q$ tem valor de $5 \mathrm{kN} / \mathrm{m}^{2}$. Essa carga deve ser aplicada nas faixas de tráfego e nos acostamentos, deduzindo-se apenas a área ocupada pelo veículo, conforme mostrado na Figura 7.8.

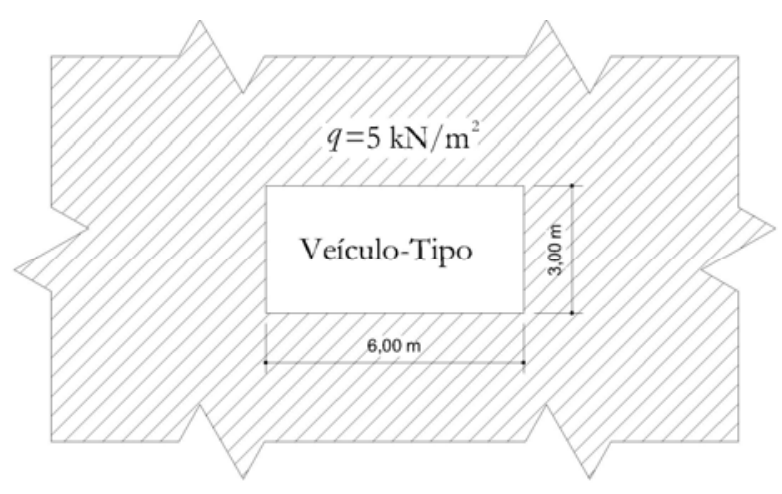

Figura 7.8 - Aplicação da carga $q$

A carga q', que possui valor de $3 \mathrm{kN} / \mathrm{m}^{2}$ para todas as classes de ponte e é aplicada nos passeios, não foi considerada nesta pesquisa. A razão para tal reside no fato de que o efeito provocado por ela seria o mesmo para as situações de carregamento móvel da norma e carregamento móvel das simulações.

A Figura 7.9 apresenta o veículo-tipo normativo para classe de ponte 45. O tabuleiro considerado para a ponte foi de 8,20 m, ou seja, duas faixas de tráfego com 3,60 m cada e um acostamento com $1 \mathrm{~m}$ (Figura 7.10). A largura do tabuleiro é levada em conta no cálculo da carga q.
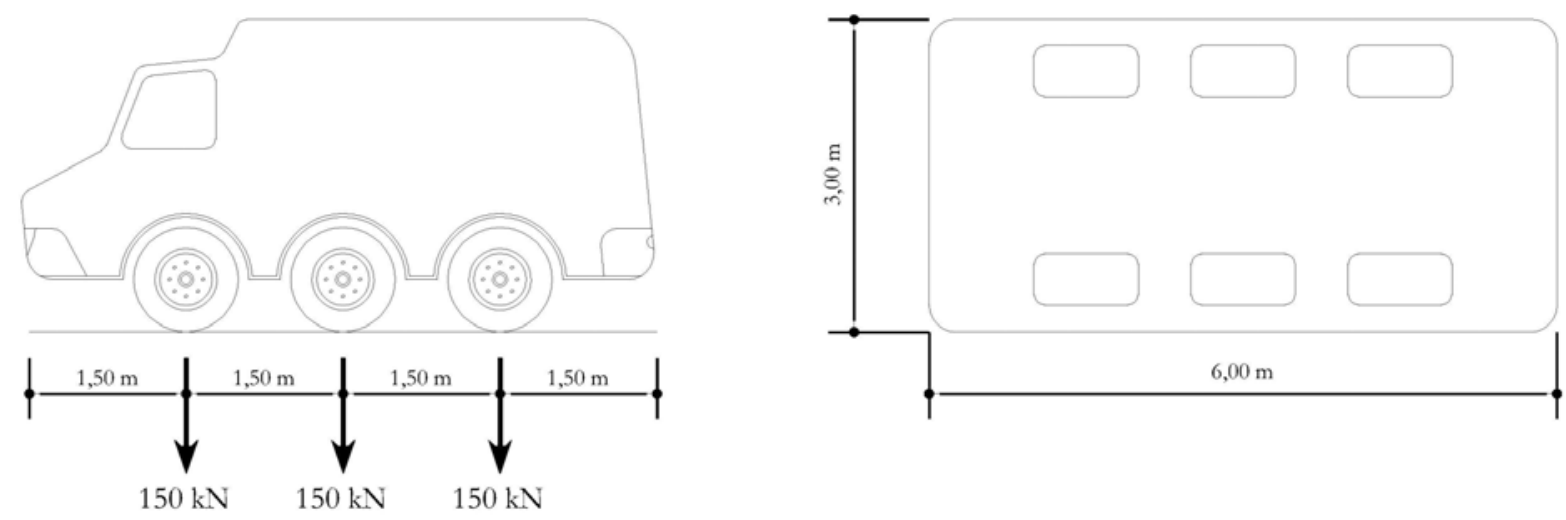

Figura 7.9 - Veículo-tipo da NBR-7188 (classe 45) 


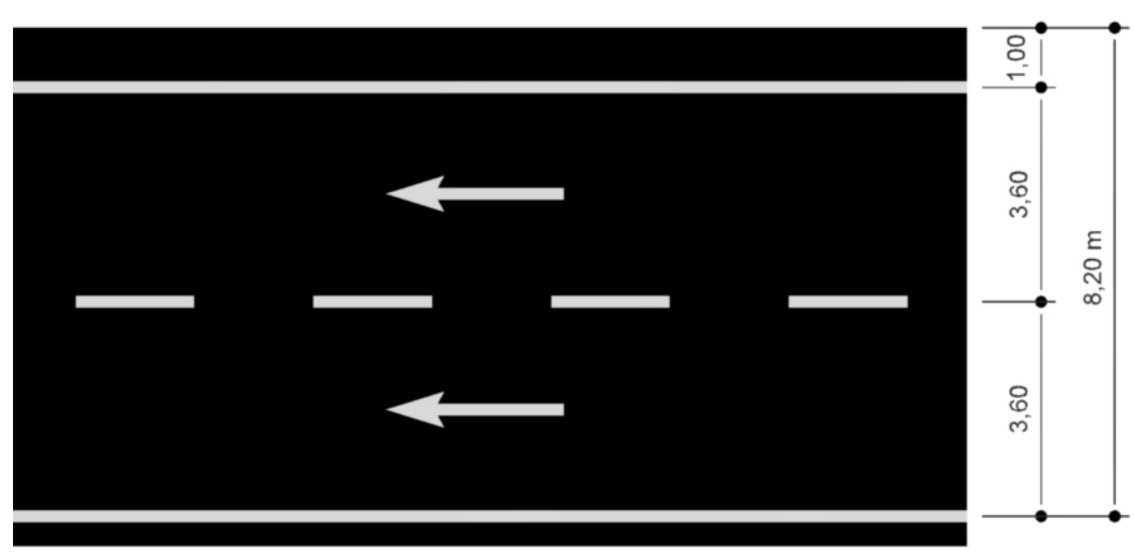

Figura 7.10 - Tabuleiro da ponte

Para a ponte simplesmente apoiada, o veículo-tipo, com suas três cargas concentradas de 150 kN cada uma, é posicionado no meio do vão. Essa localização representa o caso mais crítico para o cálculo do momento fletor. Os valores de $26 \mathrm{kN} / \mathrm{m}$ e $41 \mathrm{kN} / \mathrm{m}$ correspondem às cargas $q$ calculadas para o local em que o veículo-tipo está posicionado e para o restante da ponte, respectivamente. A Figura 7.11 apresenta o carregamento móvel da NBR-7188 resultante sobre a ponte fictícia de $100 \mathrm{~m}$, chamado de trem-tipo.

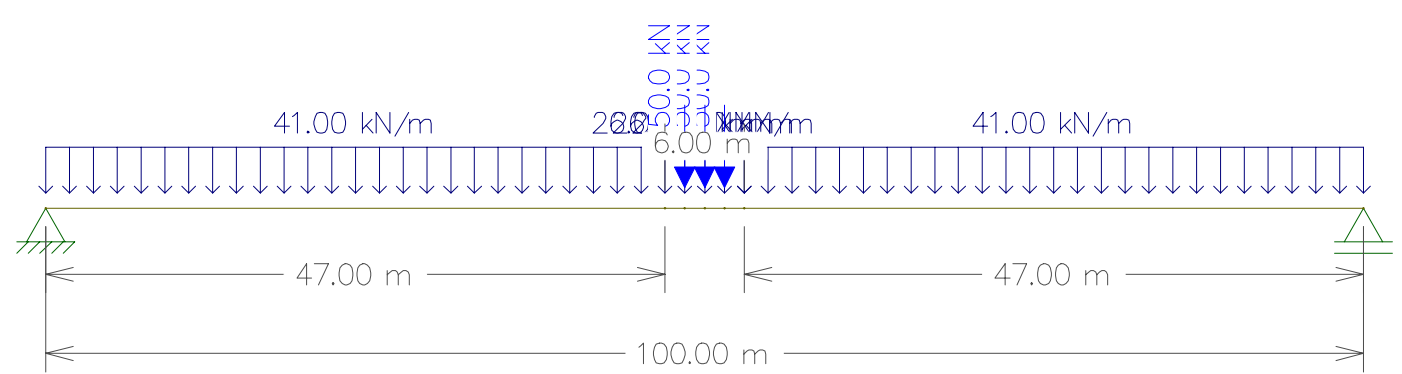

Figura 7.11 - Trem-tipo segundo a NBR-7188

\subsubsection{Momento fletor máximo causado pelo trem-tipo}

O momento fletor máximo provocado pelo carregamento móvel da NBR-7188 ocorre no meio do vão e tem valor de 6.009 kNm. O diagrama desse momento é mostrado na Figura 7.12. O peso total do trem-tipo para esse vão é de $4.460 \mathrm{kN}$. 


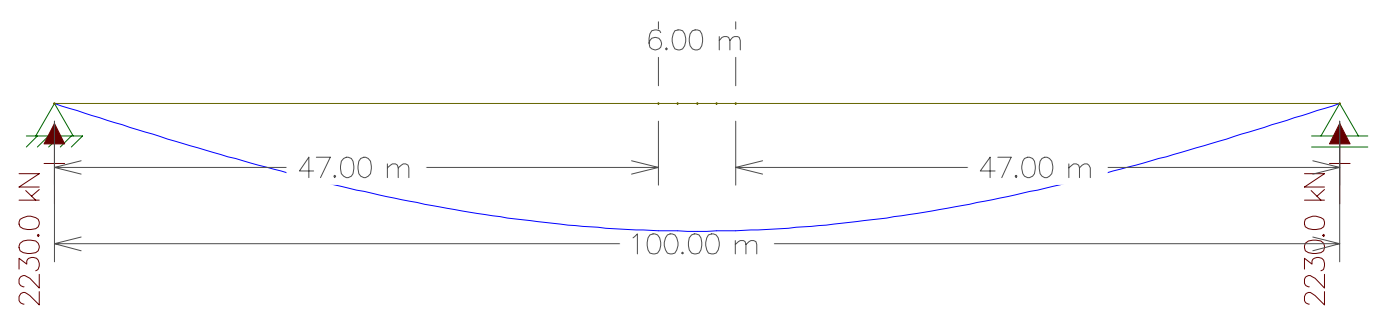

Figura 7.12 - Diagrama do momento fletor para o carregamento da NBR-7188

\subsubsection{Carga móvel gerada pelas simulações}

O carregamento móvel gerado pelos veículos simulados corresponde às cargas por eixo dos caminhões e suas respectivas localizações na ponte. Essas cargas e locais foram obtidos com o uso da macro descrita neste capítulo, que permitiu definir o conjunto de características dos caminhões com base em análises probabilísticas a partir da geração de números aleatórios. As solicitações na estrutura dependem bastante do posicionamento das cargas móveis sobre ela (Loriggio,1993).

Destaca-se que no caso em que se obtém toda a distribuição de cargas sobre a ponte, que poderia ser chamada de um trem-tipo representativo, não é necessária a consideração da carga de multidão (q), uma vez que ela é admitida na norma para reproduzir as solicitações provocadas por outros veículos na ponte além do veículo-tipo.

Devido à alta freqüência das probabilidades de ocorrência de algumas quantidades de caminhões sobre a ponte de $100 \mathrm{~m}$, optou-se por fazer a análise do efeito provocado pela presença de múltiplos caminhões apenas para as três maiores quantidades verificadas para cada cenário simulado. Entende-se que, de forma geral, maiores quantidades de caminhões implicam em maiores carregamentos, levando à análise dos casos mais críticos.

Dessa forma, para o Cenário 1 foram analisados os efeitos provocados em alguns segundos em que ocorre a presença de 8, 9 e 10 caminhões sobre a ponte, enquanto que para o Cenário 2, alguns segundos em que ocorre a presença de 10, 11 e 12 caminhões. A escolha dos segundos analisados é detalhada no item a seguir. 


\subsubsection{Escolha dos segundos analisados}

A Tabela 7.6 apresentada anteriormente indicou a ocorrência de apenas um segundo para a presença de 10 caminhões sobre a ponte para o Cenário 1. Para o Cenário 2, a presença de 12 caminhões foi verificada nove vezes. Essas são as maiores quantidades de caminhões observadas em cada cenário e foram usadas para estabelecer um critério para a escolha dos segundos que seriam analisados. Esse critério baseou-se na verificação do comportamento dos valores obtidos para o momento fletor máximo em função do peso total na ponte decorrente da presença dos 12 caminhões (Cenário 2), já que a presença de 10 caminhões aconteceu uma única vez (Cenário 1).

O peso total engloba apenas os pesos dos eixos efetivamente sobre a ponte, obtidos a partir da posição fornecida pelo arquivo TSD e das distâncias entre eixos geradas pela macro. A Figura 7.13 mostra a relação momento fletor máximo versus peso total na ponte para os segundos em que 12 caminhões foram verificados sobre a ponte.

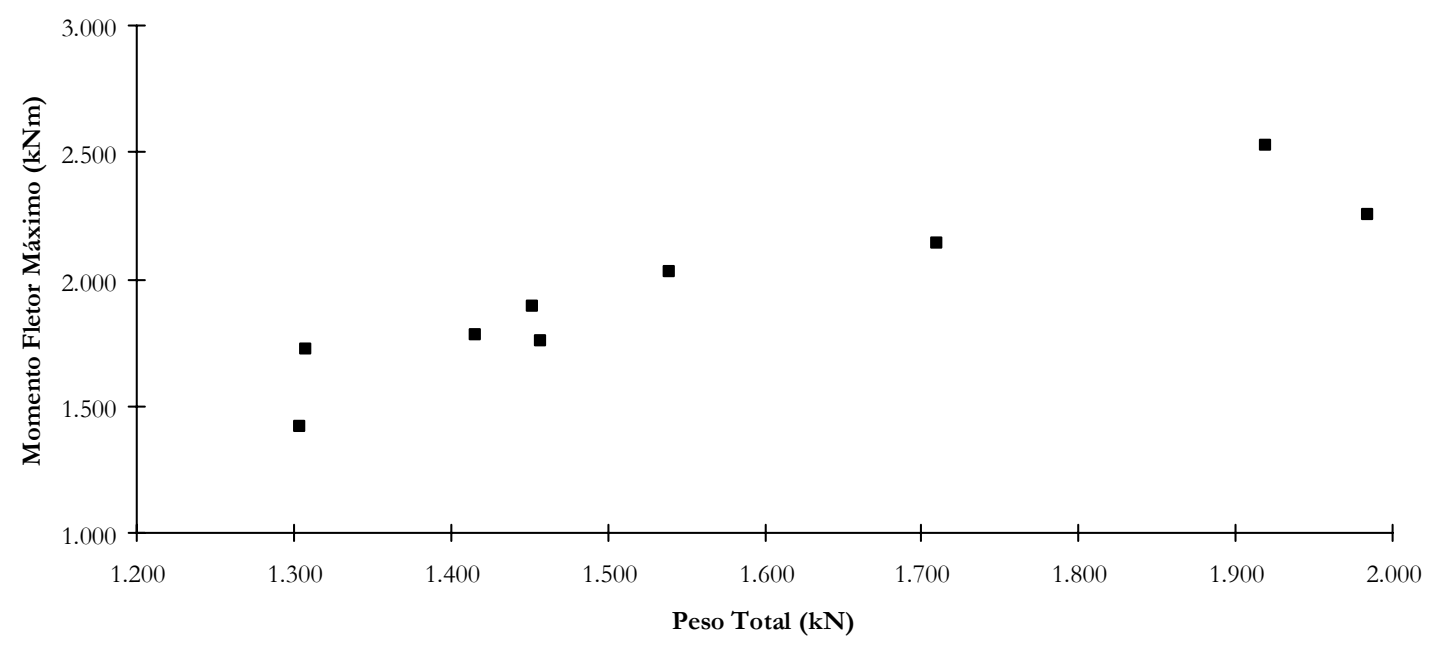

Figura 7.13 - Momentos fletores versus peso total (12 caminhões)

A observação da figura indica que, mesmo para uma amostra pequena, a variação do peso total na ponte é grande, com limites entre $1.304 \mathrm{kN}$ e $1.984 \mathrm{kN}$. Além disso, percebe-se que o maior momento fletor foi obtido com o segundo maior peso total na ponte, uma conseqüência da influência do posicionamento das cargas no cálculo do momento.

A Figura 7.14 mostra as distribuições dos pesos totais na ponte para as situações que possuem amostras maiores. Como se pode perceber, para uma mesma quantidade de caminhões 
sobre a ponte, a diferença entres os pesos totais máximo e mínimo é grande. Por exemplo, para o caso de 10 caminhões, o valor mínimo $(704 \mathrm{kN})$ consiste em apenas $25 \%$ do valor máximo $(2.843 \mathrm{kN})$.

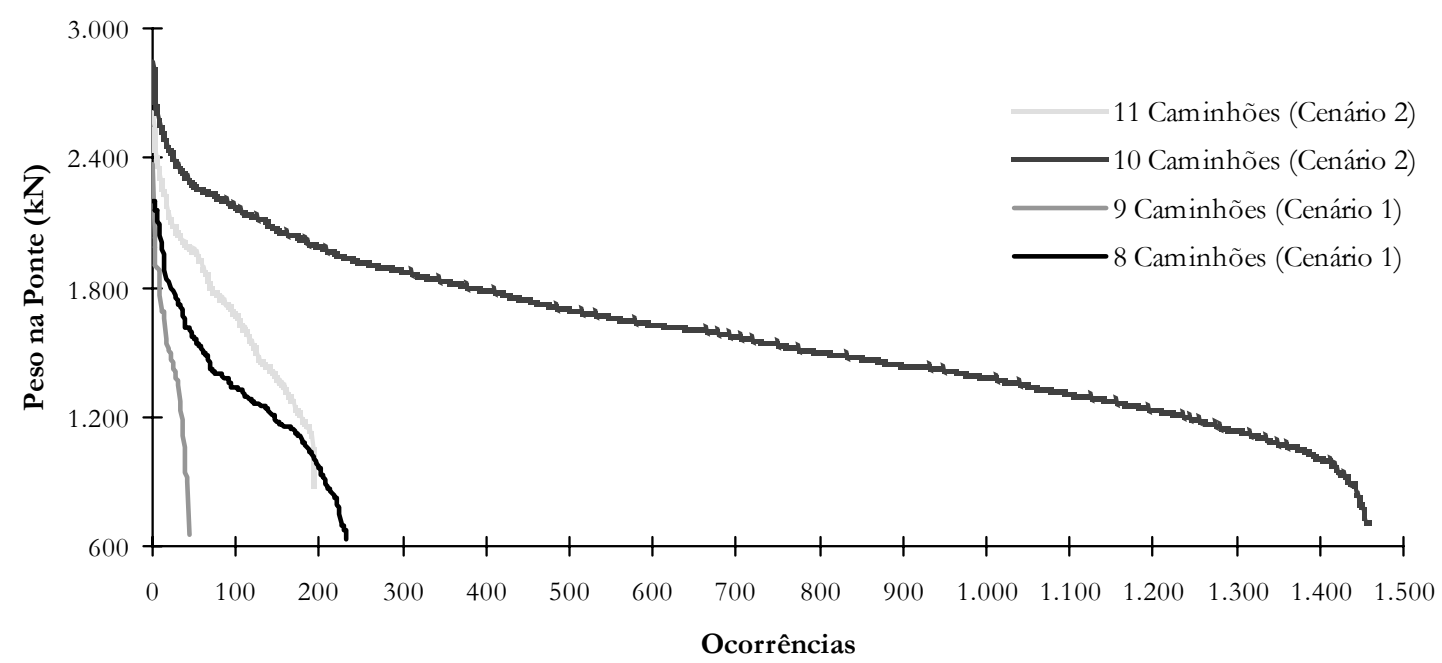

Figura 7.14 - Distribuições dos pesos totais na ponte

Face aos dados apresentados e à necessidade de restringir o número de situações analisadas, esta pesquisa limitou-se a verificar o efeito da carga móvel gerado pelas simulações apenas para os três maiores pesos de cada uma das situações.

\subsubsection{Carregamentos analisados}

As Figuras 7.15 a 7.30 apresentam os carregamentos originados pelos três maiores pesos de cada situação, à exceção da ocorrência de 10 caminhões no Cenário 1, que só aconteceu uma vez.

A Tabela 7.7 mostra uma comparação do peso total máximo dos veículos simulados com o peso do trem-tipo da NBR-7188. Os dados indicam que o carregamento máximo obtido $(2.843 \mathrm{kN})$ representa apenas $63,74 \%$ do peso do trem-tipo normativo.

Tabela 7.7 - Comparação entre o peso total das simulações e do trem-tipo

\begin{tabular}{cccc}
\hline Quantidade de Caminhões & Cenário & Peso Total Máximo (kN) & \% do Peso do Trem-Tipo \\
\hline 12 & 2 & 1.984 & 44,48 \\
11 & 2 & 2.602 & 58,34 \\
10 & 2 & 2.843 & 63,74 \\
10 & 1 & 1.712 & 38,39 \\
9 & 1 & 2.373 & 53,21 \\
8 & 1 & 2.198 & 49,28 \\
\hline
\end{tabular}




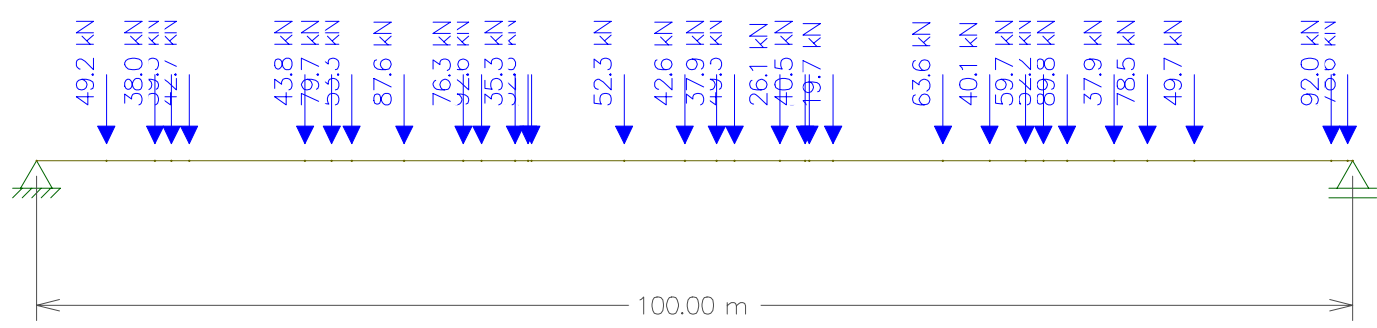

Figura 7.15 - Carregamento gerado por 10 caminhões (Cenário 1)

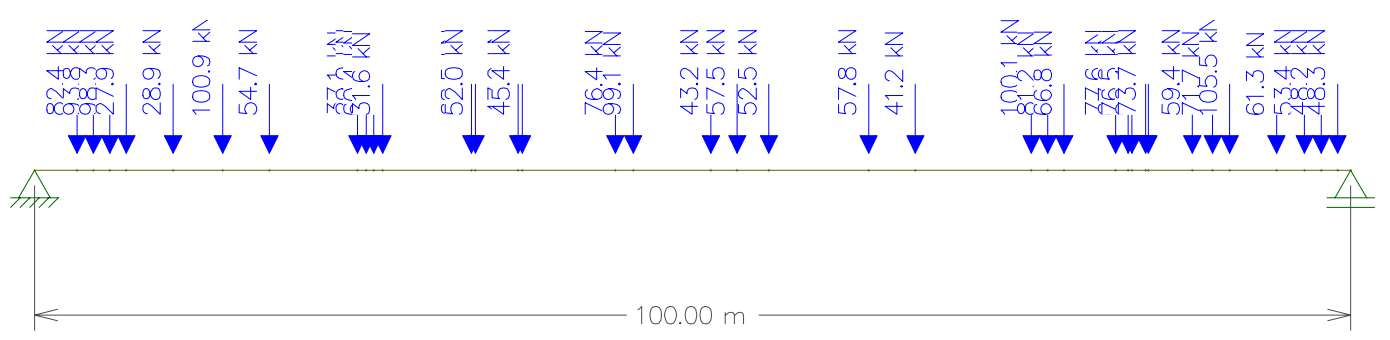

Figura 7.16 - Carregamento gerado por 9 caminhões (Cenário 1), maior peso

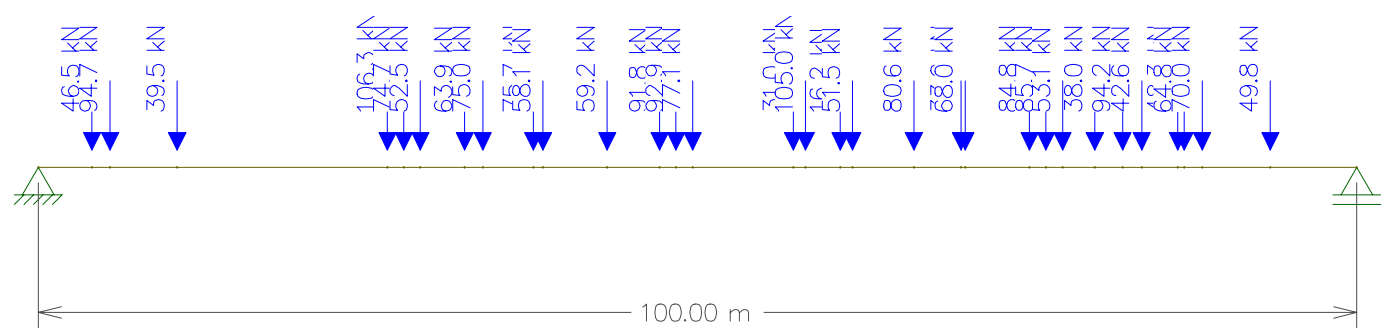

Figura 7.17 - Carregamento gerado por 9 caminhões (Cenário 1), segundo maior peso

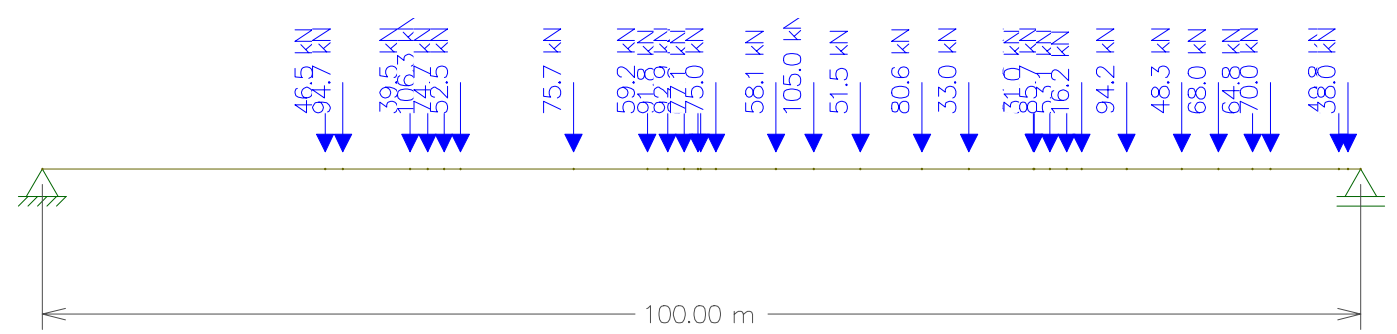

Figura 7.18 - Carregamento gerado por 9 caminhões (Cenário 1), terceiro maior peso 


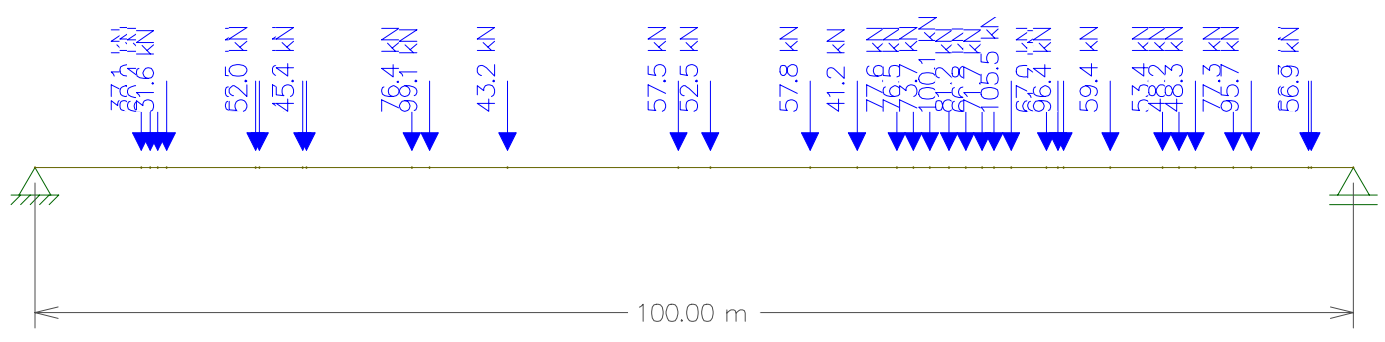

Figura 7.19 - Carregamento gerado por 8 caminhões (Cenário 1), maior peso

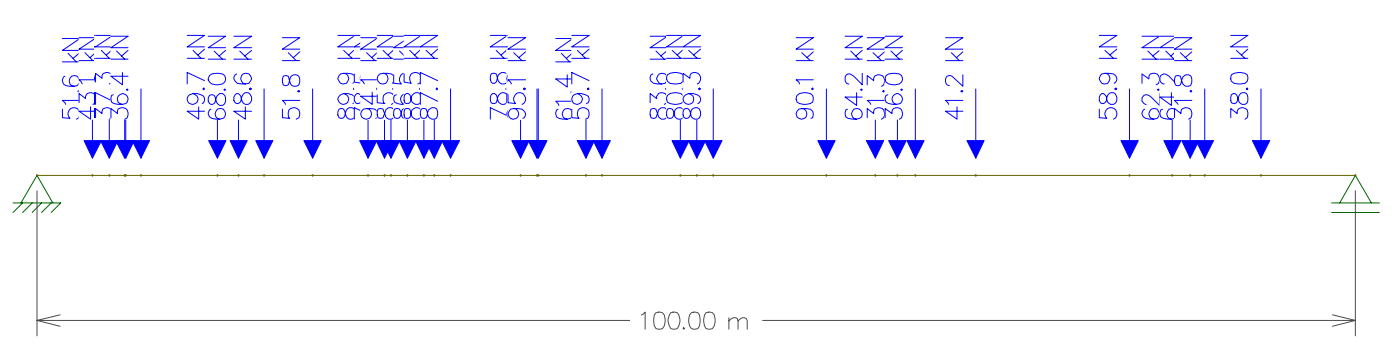

Figura 7.20 - Carregamento gerado por 8 caminhões (Cenário 1), segundo maior peso

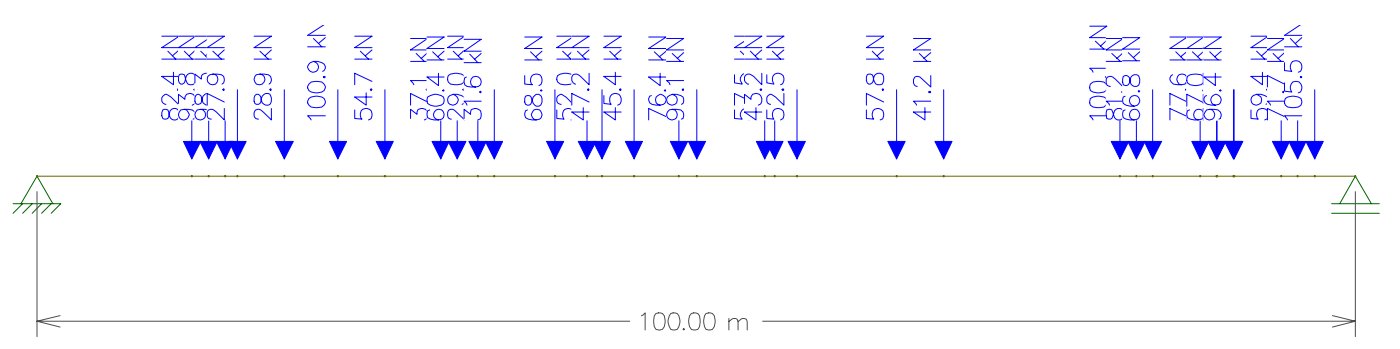

Figura 7.21 - Carregamento gerado por 8 caminhões (Cenário 1), terceiro maior peso

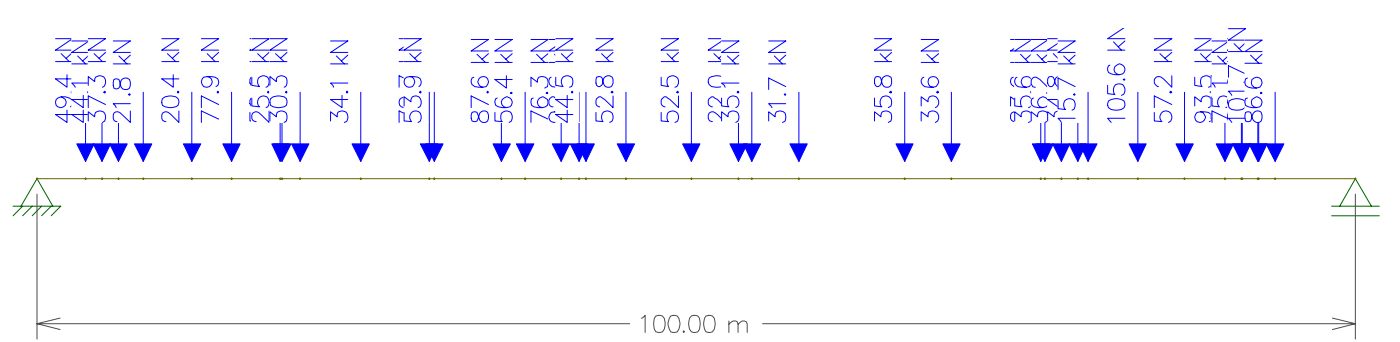

Figura 7.22 - Carregamento gerado por 12 caminhões (Cenário 2), maior peso 


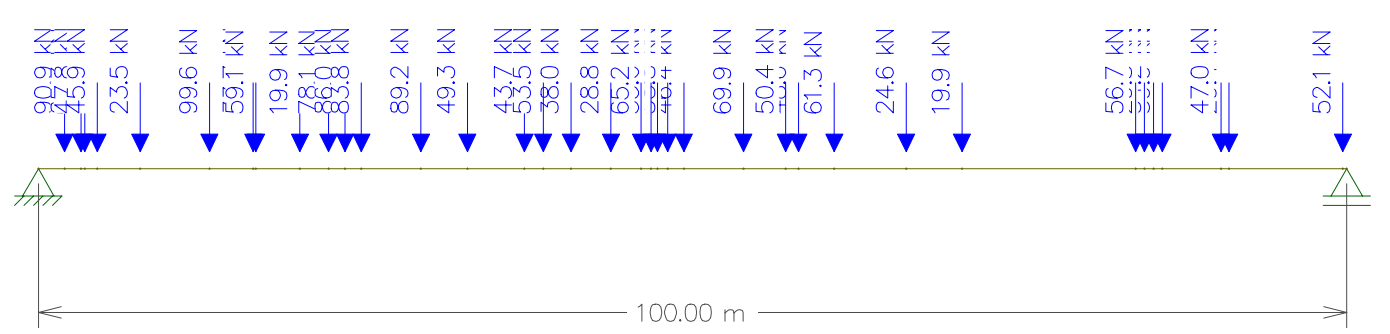

Figura 7.23 - Carregamento gerado por 12 caminhões (Cenário 2), segundo maior peso

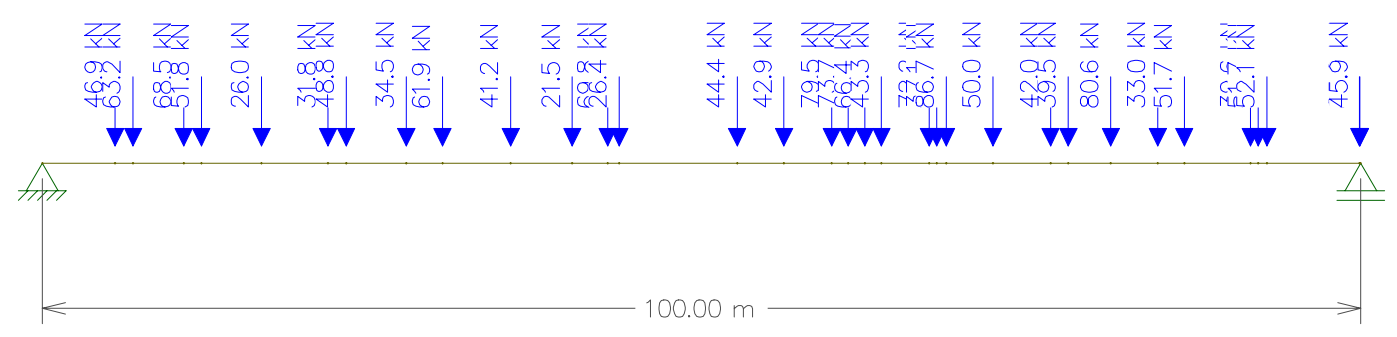

Figura 7.24 - Carregamento gerado por 12 caminhões (Cenário 2), terceiro maior peso

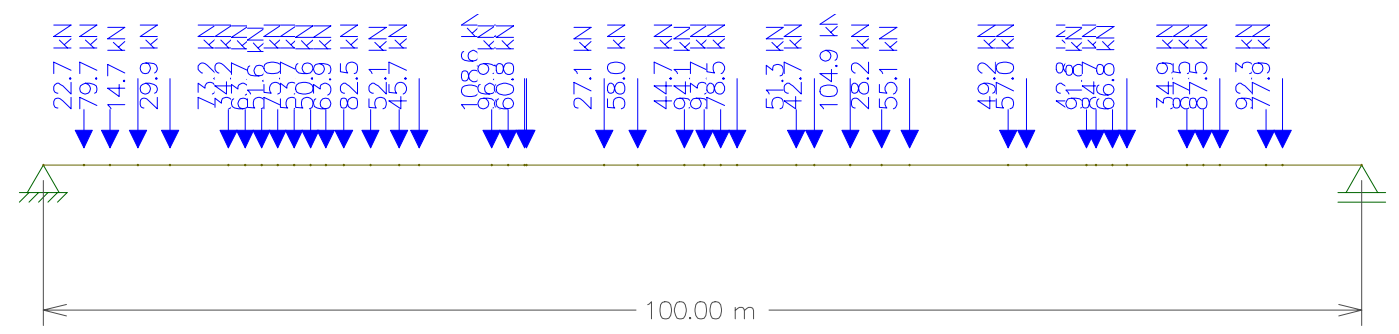

Figura 7.25 - Carregamento gerado por 11 caminhões (Cenário 2), maior peso

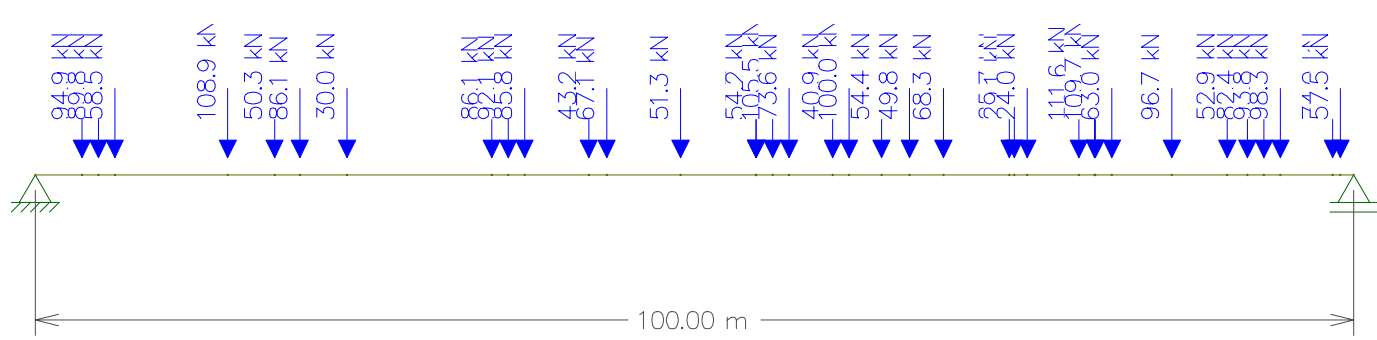

Figura 7.26 - Carregamento gerado por 11 caminhões (Cenário 2), segundo maior peso 


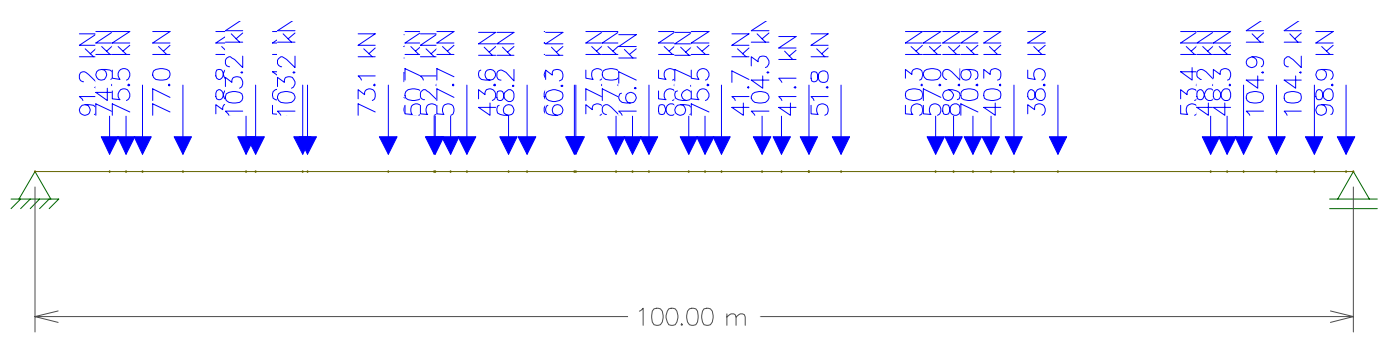

Figura 7.27 - Carregamento gerado por 11 caminhões (Cenário 2), terceiro maior peso

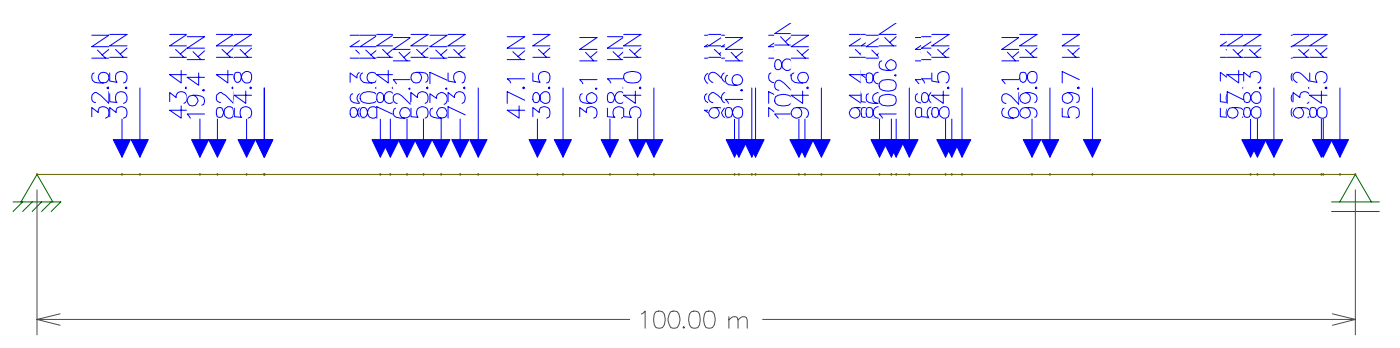

Figura 7.28 - Carregamento gerado por 10 caminhões (Cenário 2), maior peso

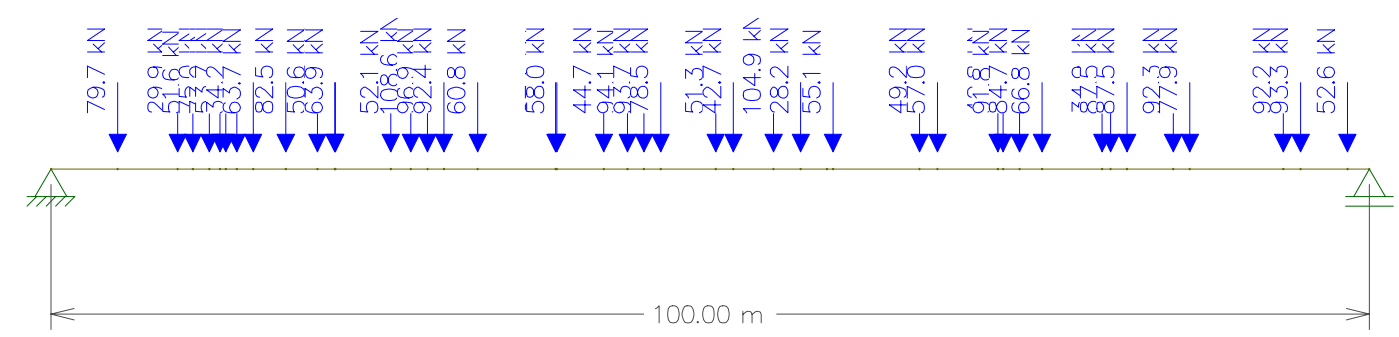

Figura 7.29 - Carregamento gerado por 10 caminhões (Cenário 2), segundo maior peso

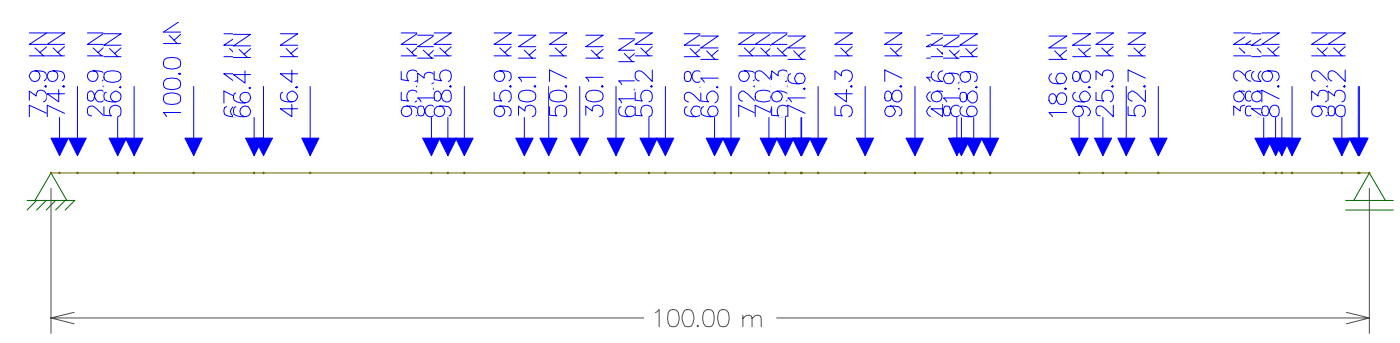

Figura 7.30 - Carregamento gerado por 10 caminhões (Cenário 2), terceiro maior peso 


\subsubsection{Momento fletor máximo causado pelos veículos simulados}

O momento fletor máximo positivo decorrente de cada um dos carregamentos apresentados nas Figuras 7.15 a 7.30 foi calculado com o uso do programa FTOOL. O valor do momento para cada uma das 16 situações analisadas está apresentado na Tabela 7.8. Essa tabela mostra também uma comparação entre os momentos máximos gerados pelos veículos simulados e aquele gerado pelo trem-tipo $(6.009 \mathrm{kNm})$.

Tabela 7.8 - Momentos fletores máximos (veículos simulados)

\begin{tabular}{ccccc}
\hline $\begin{array}{c}\text { Quantidade } \\
\text { de Caminhões }\end{array}$ & Cenário & Peso Total $(\mathbf{k N})$ & $\begin{array}{c}\text { Momento Fletor } \\
\text { Máximo }(\mathbf{k N m})\end{array}$ & $\begin{array}{c}\text { \% do Momento Fletor } \\
\text { Máximo do Trem-Tipo }\end{array}$ \\
\hline 12 & 2 & 1.984 & 2.250 & 37,44 \\
12 & 2 & 1.919 & 2.523 & 41,99 \\
12 & 2 & 1.709 & 2.144 & 35,68 \\
11 & 2 & 2.602 & 3.434 & 57,15 \\
11 & 2 & 2.533 & 3.097 & 51,54 \\
11 & 2 & 2.492 & 3.161 & 52,60 \\
10 & 2 & 2.843 & 4.082 & 67,93 \\
10 & 2 & 2.803 & 3.561 & 59,26 \\
10 & 2 & 2.712 & 3.417 & 56,86 \\
10 & 1 & 1.712 & 2.193 & 36,50 \\
9 & 1 & 2.373 & 2.473 & 41,15 \\
9 & 1 & 2.025 & 2.878 & 49,78 \\
9 & 1 & 1.982 & 2.991 & 45,86 \\
8 & 1 & 2.198 & 2.756 & 53,69 \\
8 & 1 & 2.195 & 3.226 & 41,80 \\
8 & 1 & 2.162 & 2.512 & \\
\hline
\end{tabular}

Os dados da Tabela 7.8 apontam que o momento mais crítico é o gerado pela presença de 10 caminhões na ponte (Cenário 2), com um valor de $4.082 \mathrm{kNm}$. Esse momento corresponde a $67,93 \%$ do causado pelo trem-tipo normativo.

A relação momento fletor máximo versus peso total na ponte para as 16 situações analisadas está apresentada na Figura 7.31. Como se pode perceber, o momento fletor máximo é produzido pelo maior peso na ponte $(2.843 \mathrm{kN})$ e o menor momento, que tem valor de $2.144 \mathrm{kNm}$, é produzido pelo menor peso $(1.709 \mathrm{kN})$. Esse menor momento é ocasionado pela presença de 12 caminhões. 


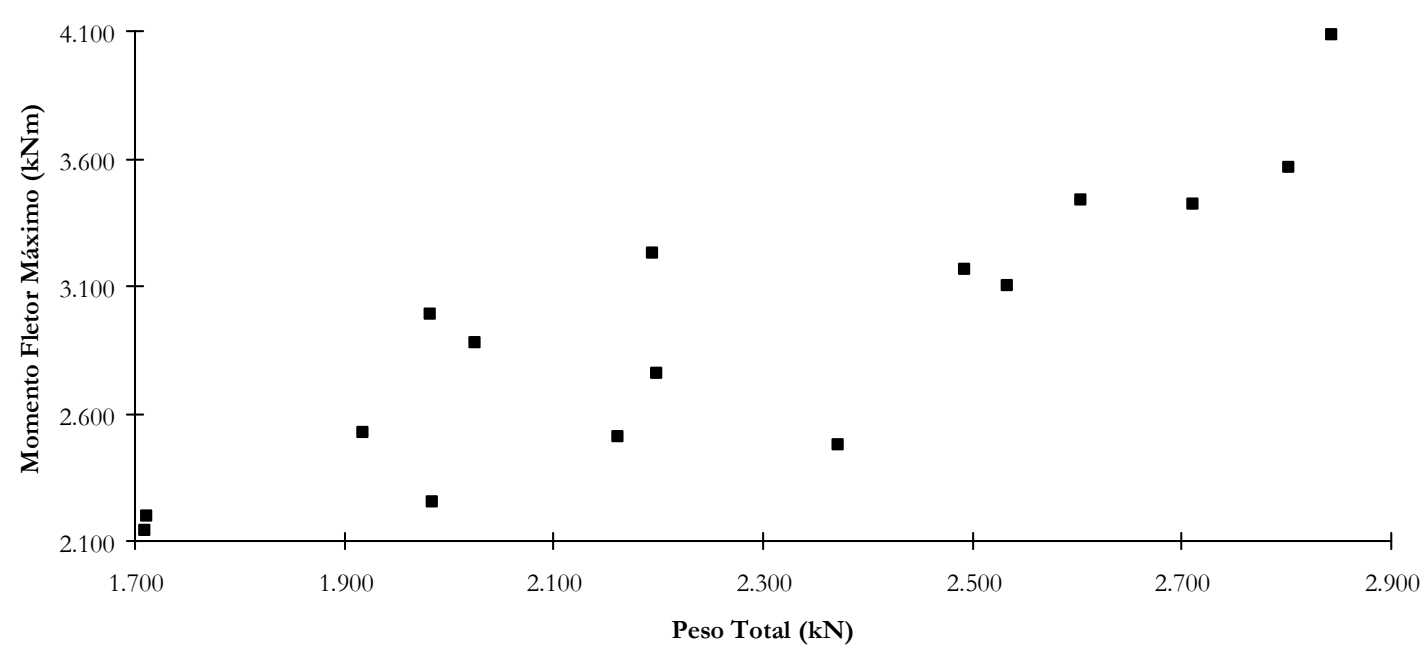

Figura 7.31 - Momentos fletores versus peso total das situações analisadas

Os resultados aqui apresentados indicam que o número de caminhões na ponte, que a princípio pode ser visto como um fator crítico, não é predominante no cálculo do momento fletor. A razão para isso decorre do fato de que quanto maior o número de caminhões, menores ele tendem a ser, implicando em menores quantidades de eixos e carregamentos totais.

Outro aspecto relevante é o conservadorismo que se verifica quanto ao carregamento móvel estabelecido pela NBR-7188. Para o estudo de caso realizado, enquanto o peso total na ponte causado pelos veículos simulados chegou a um máximo de $2.843 \mathrm{kN}$, o peso total do trem-tipo para essa ponte é de $4.460 \mathrm{kN}$.

O conservadorismo da norma reside principalmente no valor da carga $q\left(5 \mathrm{kN} / \mathrm{m}^{2}\right)$ que, nesse caso específico, demonstrou ser muito elevado para representar as cargas de outros veículos sobre a ponte além do veículo-tipo. Observando que a ponte hipotética considerada tem $100 \mathrm{~m}$ de extensão e 8,2 m de largura e descontando a carga referente ao veículo-tipo considerado $(450 \mathrm{kN})$ e a área ocupada por ele $\left(18 \mathrm{~m}^{2}\right)$, obtém-se um valor correspondente para a carga $q$ de aproximadamente $3 \mathrm{kN} / \mathrm{m}^{2}$ para a situação mais crítica simulada (peso total de $2.843 \mathrm{kN}$ ).

\subsection{Considerações finais}

Esse estudo de caso serviu para demonstrar que um modelo de simulação de tráfego detalhado pode ser uma ferramenta de análise muito útil durante o processo de dimensionamento de 
pontes ou viadutos. Através do uso da simulação, as variáveis aleatórias envolvidas no carregamento móvel da ponte podem ser incluídas no cálculo do máximo efeito sobre a estrutura. Essas variáveis são o número de caminhões, suas posições relativas, seus pesos dos eixos e seus espaçamentos entre eixos. A importância na consideração de todas essas variáveis é justificada pelo fato de que o máximo efeito da carga móvel em uma ponte ocorre devido à presença simultânea de vários caminhões (Ghosn, 2000).

Um outro tipo de análise que poderia ser realizada através da simulação do tráfego é a que diz respeito à fadiga, que é a diminuição gradual da resistência de um material por efeito de solicitações repetidas. Para a análise da fadiga, é necessário que seja estabelecido um trem-tipo representativo e o número de ocorrências correspondentes (Galgoul e Chamon, 1990).

A análise da fadiga a partir da NBR-7187 - Projeto e Execução de Pontes de Concreto Armado e Protendido é considerada muito rigorosa, uma vez que se baseia na premissa de que todas as oscilações de tensões são iguais à máxima provocada pelo trem-tipo (Galgoul e Chamon, 1990). Assim, com a simulação do tráfego, pode-se verificar a probabilidade de ocorrência dos carregamentos e os seus valores, investigando com que freqüência os carregamentos muito pesados ocorrem. 



\section{Conclusões e Recomendações}

Com base nos resultados e análises apresentados no decorrer deste texto, pode-se considerar que foi alcançado o objetivo principal da tese: desenvolver uma metodologia que permita determinar o efeito do tráfego real de veículos pesados sobre a infra-estrutura rodoviária com auxílio de um modelo de simulação microscópica de tráfego. A metodologia desenvolvida foi demonstrada a partir da geração de um carregamento móvel para uma ponte rodoviária. A modelagem das cargas móveis de forma acurada se constitui na base para um projeto mais racional e econômico dos componentes da infra-estrutura rodoviária (Nowak, 1995).

Para alcançar o objetivo principal, foram estabelecidos dois objetivos secundários. O primeiro deles era obter uma amostra de dados sobre as características dos veículos pesados, que foi conseguida através de coletas de dados em balanças rodoviárias. A escolha do conjunto de balanças foi feita de forma a possibilitar a caracterização da frota de veículos pesados que trafega nas rodovias de pista dupla do estado de São Paulo. No total, foram coletados dados de 6.253 veículos em sete diferentes balanças. Esses veículos estavam distribuídos em 22 configurações de eixos, que produziram um total de 500 combinações de marcas e modelos de caminhões e de semireboques, cada qual correspondendo a um arranjo de eixos e de distâncias entre eixos.

O segundo objetivo secundário consistia na calibração e validação do simulador de tráfego CORSIM. Esse objetivo foi atingido com o uso de um algoritmo genético codificado em Perl, 
que realizou a calibração a partir de dados coletados em um trecho de rodovia de pista dupla paulista. A calibração tornou o simulador capaz de reproduzir adequadamente as características e o comportamento do tráfego observado.

Para demonstrar como a metodologia desenvolvida pode ser utilizada, efetuou-se um estudo de caso que calculou o momento fletor ocasionado pela presença simultânea de veículos pesados sobre uma ponte, a fim de compará-lo com o provocado pelo trem-tipo normativo.

\subsection{Conclusões}

As conclusões deste trabalho estão relacionadas ao processo de calibração do CORSIM, à forma de obtenção de um carregamento móvel a partir do uso de um simulador de tráfego e à condução do estudo de caso.

\subsubsection{Calibração do modelo de simulação}

A calibração do CORSIM foi realizada com o auxílio de um algoritmo genético, uma técnica sofisticada de otimização que permitiu o ajuste simultâneo de 19 parâmetros do simulador, de forma a minimizar as diferenças entre os resultados do fluxo de tráfego simulado e o observado no trecho escolhido para a calibração. As medidas de desempenho usadas para medir essas diferenças na calibração do CORSIM foram o fluxo de tráfego em alguns tramos da rede e a velocidade da corrente de tráfego nesses mesmos tramos.

A calibração fez com que o erro médio do simulador fosse reduzido de 9,11\% para 6,32\%. Essa redução relativa de aproximadamente $30 \%$ é considerada significativa e demonstra a eficiência do uso de um algoritmo genético para a calibração de um modelo de simulação. O processo de validação comprovou que os parâmetros obtidos na calibração poderiam ser usados para um outro conjunto de dados com características distintas.

\subsubsection{Obtenção de um carregamento móvel}

A extração de dados do simulador de forma microscópica permite ao usuário obter um carregamento móvel representativo do tráfego real de veículos pesados. O método de obtenção de um carregamento móvel através de um simulador de tráfego se mostra mais completo que os 
métodos atualmente usados na Engenharia de Estruturas, que se baseiam na teoria dos processos estocásticos, na consideração de configurações estáticas do tráfego ou na simulação de Monte Carlo, uma vez que incorpora um modelo de car-following para representar o posicionamento dos veículos sobre as pontes.

Apesar da necessidade de agregar veículos com características similares para fins de simulação (devido a uma limitação do CORSIM), a análise probabilística a partir da geração de números aleatórios torna possível a desagregação dos dados de uma maneira que não compromete os resultados obtidos.

O carregamento móvel obtido a partir da extração dos dados do simulador juntamente com as informações contidas em um banco de dados é composto não somente pelas cargas dos eixos dos veículos como também pelo posicionamento dessas cargas. A importância da aquisição de um banco de dados detalhado sobre a frota de veículos pesados (com informações de configuração de eixos, marca/modelo, pesos por eixos e espaçamento entre eixos dos caminhões e dos implementos rodoviários) reside no fato de que a consideração de uma variável global, tal como o peso bruto, se revela incapaz de fornecer subsídios para o cálculo do efeito do tráfego desses veículos sobre a infra-estrutura rodoviária. Mais importante do que o carregamento total sobre a estrutura é a distribuição desse carregamento, uma vez que são as concentrações de cargas dos veículos que podem produzir esforços nocivos.

Apesar de o estudo de caso ter sido realizado para a análise estrutural de uma ponte, o método de obtenção do carregamento móvel desenvolvido nesta tese pode ser adaptado para aplicação no dimensionamento de pavimento, um outro componente da infra-estrutura rodoviária.

\subsubsection{Estudo de caso}

A partir das análises feitas no estudo de caso, que verificou o efeito do tráfego de veículos pesados sobre uma ponte hipotética de $100 \mathrm{~m}$ simplesmente apoiada, pode-se concluir que:

- As presenças simultâneas de veículos pesados nas pontes podem ser muito freqüentes e estão diretamente relacionadas às características do fluxo de tráfego; 
- O carregamento máximo obtido a partir dos veículos simulados representa apenas 63,74\% do peso do trem-tipo da NBR-7188 para a classe de ponte 45;

- A quantidade de veículos pesados sobre a ponte não indica a situação mais crítica para o cálculo dos esforços. A distribuição das cargas e seus respectivos valores são fatores determinantes;

- O maior momento fletor gerado pelo tráfego simulado foi ocasionado pela presença simultânea de 10 caminhões sobre a ponte. Esse momento corresponde a 67,93\% do causado pelo trem-tipo normativo; e

- A carga uniformemente distribuída $q$ (estabelecida pela NBR-7188) se mostra conservadora para representar as solicitações provocadas por outros veículos na ponte além do veículo-tipo.

Cabe lembrar que essas conclusões estão limitadas ao estudo de caso específico que foi realizado, ou seja, elas são válidas apenas para as condições de tráfego e características da frota simuladas.

É importante ressaltar também que, embora o estudo de caso tenha feito a análise de um único vão em um sistema estrutural específico, a metodologia desenvolvida pode ser aplicada para vãos de quaisquer magnitude e sistema estrutural.

\subsection{Recomendações}

A escolha do modelo de simulação de tráfego usado nesta pesquisa deu-se em função da sua ampla utilização no meio técnico e científico. Ainda que o CORSIM seja considerado eficaz na representação das mais variadas situações dos fluxos de tráfego, um outro modelo de simulação microscópica poderia se mostrar mais adequado para as análises realizadas. Por exemplo, poderia ter sido utilizado algum modelo cujas lógicas de car-following e de locomoção veicular fossem mais refinadas, que possuísse menos limitação quanto ao número de veículos simulados ou que usasse uma resolução menor que um segundo para descrever a operação do tráfego. 
Outras medidas de desempenho poderiam ter sido usadas no processo de calibração e validação do CORSIM e, talvez, produzido melhores resultados na calibração do modelo. O principal aspecto que deve ser levado em conta na escolha das medidas de desempenho utilizadas é a possibilidade de aquisição dos dados em campo da mesma forma que eles estejam disponíveis no arquivo de resultados do simulador.

Quanto à macro criada para desagregar os veículos pesados simulados, nela poderia ter sido introduzido um mecanismo capaz de selecionar, a partir do banco de dados, um conjunto de veículos para cada tipo simulado e não um veículo único. Esse procedimento permitiria a criação de intervalos de confiança para as configurações de eixos dentro de um mesmo tipo de veículo considerado pelo CORSIM e também entre os pesos dos eixos desses veículos, enriquecendo as análises realizadas.

No estudo de caso realizado não foi previsto aumento nos pesos dos eixos dos veículos, ou seja, admite-se que não ocorrerão mudanças na legislação ao longo da vida útil da ponte. Variações deste tipo poderiam ser introduzidas na análise, mas envolveriam, necessariamente, suposições sobre o desempenho dos veículos futuros que não poderiam ser verificadas durante o processo de calibração do CORSIM. O efeito dinâmico das cargas móveis, traduzido em termos de um coeficiente dinâmico, também não foi considerado no estudo de caso realizado. Apesar de o CORSIM gerar informações tais como velocidade e aceleração dos veículos a cada segundo, somente o componente estático das cargas móveis foi analisado nesta pesquisa.

Um dos temas que podem ser explorados em novas pesquisas é a fadiga de pontes a partir de dados de simulação microscópica, já que ela depende substancialmente das características do tráfego. Uma outra aplicação da metodologia aqui desenvolvida é o cálculo do número $N$ para dimensionamento de pavimentos. 



\section{Referências Bibliográficas}

ABNT (1960). NB-6: Cargas móveis em pontes rodoviárias. Rio de Janeiro.

(1984). NBR-7188: Carga móvel em ponte rodoviária e passarela de pedestres. Rio de Janeiro.

(1986). NBR-7187: Projeto e execução de pontes de concreto armado e protendido. Rio de Janeiro.

AYCIN, M. F.; BENEKOHAL, R. F. (1999). Comparison of car-Following models for simulation. Transportation Research Record 1678, Transportation Research Board, National Research Council, Washington, p.116-127.

BAYARRI, M. J.; BERGER, J. O.; MOLINA, G.; ROUPHAIL, N. M., SACKS, J. (2004). Assessing uncertainties in traffic simulation: A key component in model calibration and validation. In: $83^{\text {rd }}$ ANNUAL MEETING OF THE TRANSPORTATION RESEARCH BOARD, 2004, Washington. Proceedings... 1 CD-ROM.

BEN-AKIVA, M. E.; DARDA, D.; JHA, M.; KOUTSOPOULOS, H. N.; TOLEDO, T. (2004). Calibration of microscopic traffic simulation models with aggregate data. In: $83^{\text {rd }}$ ANNUAL MEETING OF THE TRANSPORTATION RESEARCH BOARD, 2004, Washington. Proceedings... 1 CD-ROM.

BLOOMBERG, L.; DALE, J. (2000). Comparison of VISSIM and CORSIM traffic simulation models on a congested network. Transportation Research Record 1727, Transportation Research Board, National Research Council, Washington, p.52-60. 
BOTZOW, H. (1974). Level-of-service concept for evaluating public transport. Transportation Research Record 519, Transportation Research Board, National Research Council, Washington, p.73-84.

BROCKFELD, E.; KÜHNE, R. D.; WAGNER, P. (2004). Calibration and validation of microscopic traffic flow models. In: $83^{\text {rd }}$ ANNUAL MEETING OF THE TRANSPORTATION RESEARCH BOARD, 2004, Washington. Proceedings... 1 CD-ROM.

CARVAlHO, A. P. L. F. (2003). Algoritmos genéticos. Disponível em: <http://www.icmsc.sc.usp.br/ andre/gene1.html>. Acesso em: 30 jun. 2003.

CHEU, R.; JIN, X.; NG, K.; NG, Y.; SRINIVASAN, D. (1998). Calibration of FRESIM for Singapore expressway using genetic algorithm. ASCE Journal of Transportation Engineering, p.526-535, dez.

COHEN, S. L. (2004). An approach to calibration and validation of traffic simulation models. In: $83^{\text {rd }}$ ANNUAL MEETING OF THE TRANSPORTATION RESEARCH BOARD, 2004, Washington. Proceedings... 1 CD-ROM.

COLELLA, D. A. T; DEMARCHI, S. H. (2005). Calibração do modelo fluxo-velocidade do simulador INTEGRATION a partir de tempos de percurso em vias urbanas. In: CONGRESSO DE PESQUISA E ENSINO EM TRANSPORTES, 19., 2005, Recife. Anais... Recife: Associação Nacional de Pesquisa e Ensino em Transportes. v.2, p.1058-1069.

COLELLA, D. A. T; LIMA, E. P.; DEMARCHI, S. H. (2005). Calibração e validação do modelo fluxo-velocidade do INTEGRATION para vias urbanas semaforizadas. Transporte em Transformação IX - Trabalhos Vencedores do Prêmio CNT Produção Acadêmica 2004, Brasília, p.101-121.

CONFEDERAÇÃO NACIONAL DO TRANSPORTE (2006). Boletim estatístico da CNT. Disponível em: <http://www.cnt.org.br>. Acesso em: 30 dez. 2006.

CRESPO-MINGUILLÓN, C.; CASAS, J. R. (1997). A comprehensive traffic load model for bridge safety checking. Structural Safety, v.19, n.4, p.339-359.

CUNHA, A. L. B. N.; MON-MA, M. L.; ARAÚJO, J. J.; EGAMI, C. Y.; SETTI, J. R. A. (2005). Caracterização da frota de caminhões no sistema Anhanguera-Bandeirantes. In: XIX CONGRESSO DE PESQUISA E ENSINO EM TRANSPORTES, 2005, Recife. Anais... 1 CD-ROM. 
CUNHA, A. L. B. N.; SETTI, J. R. A. (2006). Calibração do modelo de desempenho de caminhões do CORSIM através de um algoritmo genético. In: XX CONGRESSO DE PESQUISA E ENSINO EM TRANSPORTES, 2006, Brasília. Anais... 1 CD-ROM.

DEMARCHI, S. H.; SETTI, J. R. A. (2001). Recalibração do simulador INTEGRATION para uma rodovia de pista dupla brasileira. Transportes: Experiências em Rede. Rio de Janeiro, p.87102.

DENATRAN (2006). Frota de veículos. Disponível em: <http://www.denatran.gov.br/frota_UF_fabr.htm>. Acesso em: 30 dez. 2006.

DHULIPALA, S. (2002). A system for travel time estimation on urban freeways. 115p. Dissertação (Mestrado) - Virginia Polytechnic Institute and State University, Blacksburg, 2002.

DNIT (2006). Manual de estudos de tráfego. Versão preliminar. Departamento Nacional de Infra-Estrutura de Transportes, Ministério dos Transportes, Brasil.

DOWLING, R.; SKABARDONIS, A.; HALKIAS, J.; MCHALE, G.; ZAMMIT, G. (2004). Guidelines for calibration of microsimulation models: framework and applications. In: $83^{\text {rd }}$ ANNUAL MEETING OF THE TRANSPORTATION RESEARCH BOARD, 2004, Washington. Proceedings... 1 CD-ROM.

EGAMI, C. Y. (2000). Recalibração de um modelo de simulação do tráfego em rodovias de pista simples. 137p. Dissertação (Mestrado) - Escola de Engenharia de São Carlos, Universidade de São Paulo, São Carlos, 2000.

(2006). Adaptação do HCM-2000 para determinação do nível de serviço em rodovias de pista simples sem faixas adicionais no Brasil. 233p. Tese (Doutorado) - Escola de Engenharia de São Carlos, Universidade de São Paulo, São Carlos, 2006.

EGAMI, C. Y.; SETTI, J. R. A (2002). Recalibração do modelo TRARR para simulação de rodovias de pista simples no Brasil. Transporte em Transformação V - Trabalhos Vencedores do Prêmio CNT Produção Acadêmica 2000, São Paulo, p.31-46.

EGAMI, C. Y.; SETTI, J. R. A; RILETTT, L. R. (2004). Algoritmo genético para calibração automática de um simulador de tráfego em rodovias de pista simples. Transportes, Rio de Janeiro, v.12, n.2, p.5-14.

EL DEBS, M. K.; TAKEYA, T. (1995). Pontes de concreto: Fascículo 2 - Ações nas pontes. 29p. (Notas de Aula) - Departamento de Engenharia de Estruturas, Escola de Engenharia de São Carlos, Universidade de São Paulo, São Carlos, 1995. 
. (1995). Pontes de concreto: Fascículo 3 - Sistemas estruturais. 15p. (Notas de Aula) - Departamento de Engenharia de Estruturas, Escola de Engenharia de São Carlos, Universidade de São Paulo, São Carlos, 1995.

ELEFTERIADOU, L.; LEONARD II, J. D.; LIST, G.; LIEU, H; THOMAS, M.; GIGUERE, R.; JOHNSON, G.; BREWISH, R. (1999). Beyond the Highway Capacity Manual: Framework for selecting simulation models in traffic operational analyses. Transportation Research Record 1678, Transportation Research Board, National Research Council, Washington, p.96-106.

FERREIRA, L. M. (2006). Aplicação da teoria da confiabilidade na obtenção de limites para o peso de veículos de carga em pontes de concreto. 273p. Tese (Doutorado) - Escola de Engenharia de São Carlos, Universidade de São Paulo, São Carlos, 2006.

FHWA (2001). TSIS: Traffic software integrated system. Version 5.0. Colorado Springs: ITT Industries.

FRANKEL, J.; ALVAREZ, L.; HOROWITZ, R.; LI, P. (1996). Safety oriented maneuvers for IVHS. Vehicle System Dynamics, v.26, n.4, p.271-299, out.

GALGOUL, N. S.; CHAMON, R. (1990). Avaliação do trem-tipo de norma para o dimensionamento à fadiga de vigas de pontes rodoviárias de concreto armado. II Simpósio EPUSP sobre Estruturas de Concreto, Universidade de São Paulo, São Paulo, p. 103-131.

GHOSN, M.; MOSES, F. (1985). Markov renewal model for maximum bridge loading. ASCE Journal of Engineering Mechanics, v.111, n.9, p.1093-1104.

GHOSN, M. (2000). Development of truck weight regulations using bridge reliability model. Journal of Bridge Engineering, p.293-303, nov.

GOLDBERG, D. E. (1989). Genetic algorithms in search, optimization, and machine learning. Reading: Addison-Wesley.

HALATI, A.; LIEU, H.; WALKER, S. (1997). CORSIM - Corridor traffic simulation model. In: TRAFFIC CONGESTION AND TRAFFIC SAFETY IN THE 21ST CENTURY : Challenges, Innovations and Opportunities, 1997, Chicago. Proceedings... Chicago: American Society of Civil Engineers, p.570-576. 
HELLINGA, B. R. (1998). Requirements for the calibration of traffic simulation models. In: PROCEEDINGS OF ANNUAL CONFERENCE, 1998, Halifax. Proceedings... Halifax: Canadian Society for Civil Engineering, v.4b, p.211-222.

HENDERSON, J.; FU, L. (2004). Applications of genetic algorithms in transportation engineering. In: $83^{\text {rd }}$ ANNUAL MEETING OF THE TRANSPORTATION RESEARCH BOARD, 2004, Washington. Proceedings... 1 CD-ROM.

HOLLAND, J. H. (1975). Adaptation in natural and artificial systems. Ann Arbor: University of Michigan Press.

HOURDAKIS, J.; MICHALOPOULOS, P. G.; KOTTOMMANNIL, J. (2003). Practical procedure for calibrating microscopic traffic simulation models. Transportation Research Record 1852, Transportation Research Board, National Research Council, Washington, p.130-139.

HUFF, T. S.; SCRIVNER, F. H. (1955). Simplified climbing-lane design theory and road test results. Bulletin 104, Highway Research Board, National Research Council, Washington, p.1-11.

HWANG, E. S.; KOH, H. M. (2000). Simulation of bridge live load effects. In: $16^{\mathrm{TH}}$ CONGRESS OF IABSE, 2000, Lucerne. Proceedings... 1 CD-ROM.

ITE (1965). Traffic Engineering Handbook. 3thed. Englewood Cliffs: Prentice-Hall.

KHAN, S; MAINI, P.; THANASUPSIN, K. (2000). Car-following and collision constraint models for uninterrupted traffic. Transportation Research Record 1710, Transportation Research Board, National Research Council, Washington, p.37-46.

KIM, K.; RILETT, L. R. (2001). Genetic-algorithm-based approach for calibrating microscopic simulation models. In: IEEE INTELLIGENT TRANSPORTATION SYSTEMS CONFERENCE, 2001, Oakland. Proceedings... 1 CD-ROM.

(2004). A genetic algorithm based approach to traffic micro-simulation calibration using ITS data. In: $83^{\text {rd }}$ ANNUAL MEETING OF THE TRANSPORTATION RESEARCH BOARD, 2004, Washington. Proceedings... 1 CD-ROM.

KIM, S.; KIM, K.; RILETTT, L. R. (2005). Calibrating of microsimulation models using nonparametric statistical techniques. Journal of the Transportation Research Board 1935, Transportation Research Board of the National Academies, Washington, p.111-119. 
LEE, D.; YANG, X.; CHANDRASEKAR, P. (2001). Parameter calibration for PARAMICS using genetic algorithm. In: $80^{\text {th }}$ ANNUAL MEETING OF THE TRANSPORTATION RESEARCH BOARD, 2001, Washington. Proceedings... 1 CD-ROM.

LORIGGIO, D. D. (1993). Contribuições para a normalização da fadiga na revisão da norma NB1/93. III Simpósio EPUSP sobre Estruturas de Concreto, Universidade de São Paulo, São Paulo, p. 293-322.

LUCHI, L. A. R. (2006). Reavaliação do trem-tipo à luz das cargas reais nas rodovias brasileiras. 257p. Tese (Doutorado) - Escola Politécnica, Universidade de São Paulo, São Paulo, 2006.

MA, T.; ABDULHAI, B. (2001). Genetic algorithm-based combinatorial parametric optimization for the calibration of microscopic traffic simulation models. In: IEEE INTELLIGENT TRANSPORTATION SYSTEMS CONFERENCE, 2001, Oakland. Proceedings... 1 CDROM.

(2002). Genetic algorithm-based optimization approach and generic tool for calibrating traffic microscopic simulation parameters. Transportation Research Record 1800, Transportation Research Board, National Research Council, Washington, p.6-15.

MARTHA, L. F. (2002). FTOOL - Versão 2.11. Disponível em: < http://www.tecgraf.pucrio.br/ftool/manual/>. Acesso em: 30 out. 2006.

MERRITT, E. (2004). Calibration and validation of CORSIM for Swedish road traffic conditions. In: $83^{\text {rd }}$ ANNUAL MEETING OF THE TRANSPORTATION RESEARCH BOARD, 2004, Washington. Proceedings... 1 CD-ROM.

MILAM, R. T.; CHOA, F. (2002). Recommended guidelines for the calibration and validation of traffic simulation models. Disponível em: $<$ http://www.fehrandpeers.com/publications/papers/traff_simulation.pdf $>$. Acesso em: 18 mar. 2003.

MOSES, F.; GHOSN, M. (1985). A comprehensive study of bridge loads and reliability. Columbus: Ohio Department of Transportation. Report n. FHWA/OH-85/005.

NI, D.; LEONARD II, J. D.; GUIN, A.; WILLIAMS, B. M. (2004). A systematic approach for validating traffic simulation models. In: $83^{\text {rd }}$ ANNUAL MEETING OF THE TRANSPORTATION RESEARCH BOARD, 2004, Washington. Proceedings... 1 CD-ROM. 
NOWAK, A. S.; LIND, N. C. (1979). Practical bridge code calibration. Journal of the Structural Division, v.105, n.ST12, p.2497-2510, dez.

NOWAK, A. S.; HONG, Y. K. (1991). Bridge live-load models. Journal of Structural Engineering, v.117, n.9, p.2757-2767, set.

NOWAK, A. S. (1993). Live load model for highway bridges. Journal of Structural Safety, v.13, p.53-66.

NOWAK, A. S. (1995). Calibration of LRFD bridge code. Journal of Structural Engineering, v.121, n.8, p.1245-1251, ago.

NOWAK, A. S. (1999). Calibration of LRFD bridge design code. NCHRP Report 368. Transportation Research Board, National Research Council, Washington.

OWEN, L. E. ; ZHANG, Y.; RAO, L. ; MCHALE, G. (2000). Traffic flow simulation using CORSIM. In: WINTER SIMULATION CONFERENCE, 2000, Orlando. Proceedings... Orlando: INFORMS Simulation Society, p.1143-1147.

PAYNE, H. J.; THOMPSON, S.; CHANG, G. (1997). Calibration of FRESIM to achieve desired capabilities. Transportation Research Record 1591, Transportation Research Board, National Research Council, Washington, p.23-30.

PREVEDOUROS, P. D.; WANG, Y. (1999). Simulation of large freeway and arterial network with CORSIM, INTEGRATION and WATSim. Transportation Research Record 1678, Transportation Research Board, National Research Council, Washington, p.197-207.

RAKHA, H.; HELLINGA, B.; VAN AERDE, M.; PEREZ, W. (1996). Systematic verification, validation and calibration of traffic simulation models. In: $75^{\text {th }}$ ANNUAL MEETING OF THE TRANSPORTATION RESEARCH BOARD, 1996, Washington. Proceedings... 1 CD-ROM.

RAKHA, H.; CROWTHER, B. (2002). Comparison of Greenshields, Pipes, and Van Aerde carfollowing and traffic streams models. Transportation Research Record 1802, Transportation Research Board, National Research Council, Washington, p.248-262.

(2003). Comparison and calibration of FRESIM and INTEGRATION steady-state carfollowing behavior. Transportation Research Part A, v.37, n.1, p.1-27, jan. 
RILETT, L. R.; KIM, K. (2001). Automatic calibration of surface transportation demand and supply modes using ITS data. In: $9^{\text {th }}$ WORLD CONGRESS ON TRANSPORT RESEARCH, 2001, Seoul. Proceedings... 1 CD-ROM.

RILETT, L. R.; KIM, K. K.; RANEY, B. (2000). Comparison of low-fidelity TRANSIMS and high-fidelity CORSIM highway simulation models with intelligent transportation system data. Transportation Research Record 1739, Transportation Research Board, National Research Council, Washington, p.1-8.

ROBERTSON, H. D.; HUMMER, J. E.; NELSON, D. C. (1994). Manual of transportation engineering studies. Englewood Cliffs: Prentice-Hall.

SACKS, J.; ROUPHAIL, N. M.; PARK, B.; THAKURIAH, P. (2002). Statistically-based validation of computer simulation models in traffic operations and management. Journal of Transportation and Statistics, v.5, n.1, p.1-15.

SANTOS, M. F. (2003). Contribuição ao estudo do efeito de combinação de veículos de carga sobre pontes rodoviárias de concreto. 152p. Dissertação (Mestrado) - Escola de Engenharia de São Carlos, Universidade de São Paulo, São Carlos, 2003.

SCHULTZ, G. G. (2003). Developing a methodology to account for commercial motor vehicles using microscopic traffic simulation models. 332p. Tese (Doutorado) - Texas A\&M University, College Station, 2003.

SCHULTZ, G. G.; RILETT, L. R. (2004). An analysis of the distribution and calibration of carfollowing sensitivity parameters in microscopic traffic simulation models. In: $83^{\text {rd }}$ ANNUAL MEETING OF THE TRANSPORTATION RESEARCH BOARD, 2004, Washington. Proceedings... 1 CD-ROM.

(2005). Calibration of distributions of commercial motor vehicles in CORSIM. Journal

of the Transportation Research Board 1934, Transportation Research Board of the National Academies, Washington, p.246-255.

SKABARDONIS, A. (2002). Simulation of freeway weaving areas. Transportation Research Record 1802, Transportation Research Board, National Research Council, Washington, p.115124.

SOUSA, D. L. M; RIBEIRO, P. C. M. (2004). Análise dos impactos causados no tráfego por alterações na rede viária utilizando micro-simulação. In: CONGRESSO DE PESQUISA E ENSINO EM TRANSPORTES, 18., 2004, Florianópolis. Anais... Florianópolis: Associação Nacional de Pesquisa e Ensino em Transportes. v.1, p.441-452. 
ST. JOHN, A. D.; KOBETT, D. R. (1978). Grade effects on traffic flow stability and capacity. NCHRP Report 185. Transportation Research Board, National Research Council, Washington.

TOLEDO, T.; KOUTSOPOULOS, H. (2004). Statistical validation of traffic simulation models. In: $83^{\text {rd }}$ ANNUAL MEETING OF THE TRANSPORTATION RESEARCH BOARD, 2004, Washington. Proceedings... 1 CD-ROM.

TRB (2002). Regulation of weights, lengths, and widths of commercial motor vehicle. TRB Special Report 267. Transportation Research Board, National Research Council, Washington.

WALL, L.; CHRISTIANSEN, T.; ORWANT, J. (2000). Programming Perl. 3thed. Sebastopol: O’Reilly.

WICKS, D. A.; LIEBERMAN, E. B. (1980). Development and testing of INTRAS, a microscopic freeway simulation model. Vol. 1 - Program design, parameter calibration and freeway dynamics component development. Washington: U.S. Department of Transportation. Report FHWA/RD-80/106.

WIDMER, J. A. (2004). Proposta de nomenclatura de caminhões. In: CONGRESSO DE PESQUISA E ENSINO EM TRANSPORTES, 18., 2004, Florianópolis. Anais... Florianópolis: Associação Nacional de Pesquisa e Ensino em Transportes. v.1, p.624-635.

WIKIPEDIA (2006). Genetic Algorithm. Disponível em: <http://en.wikipedia.org/wiki/Genetic_algorithm >. Acesso em: 27 dez. 2006.

ZHANG, Y.; OWEN, L. E. (2004). Systematic validation of a microscopic traffic simulation program. In: $83^{\text {rd }}$ ANNUAL MEETING OF THE TRANSPORTATION RESEARCH BOARD, 2004, Washington. Proceedings... 1 CD-ROM.

ZHANG, L.; COLYAR, J.; HALKIAS, J.; ZHANG, Y. (2004). CORSIM sensitivity analysis and its application in model validation and calibration at signalized intersections. In: $83^{\text {rd }}$ ANNUAL MEETING OF THE TRANSPORTATION RESEARCH BOARD, 2004, Washington. Proceedings... 1 CD-ROM.

* De acordo com:

ASSOCIAÇÃO BRASILEIRA DE NORMAS TÉCNICAS. NBR-6023: informação e documentação: referências: elaboração. Rio de Janeiro, 2002. 

Apêndice A 

APÊNDICE A - Matrizes origem/destino por intervalo de 15 minutos

Tabela A.1 - Matriz da primeira coleta de dados (6/6/2005) - 10:15 hs - Sentido Norte

\begin{tabular}{cccccccc}
\hline $\mathbf{O} / \mathbf{D}$ & $\mathbf{1 5}$ & $\mathbf{6 0}$ & $\mathbf{2 7}$ & $\mathbf{3 2}$ & $\mathbf{3 8}$ & $\mathbf{4 4}$ & $\mathbf{4 6}$ \\
\hline $\mathbf{6}$ & $18 \%$ & $3 \%$ & $4 \%$ & $3 \%$ & $10 \%$ & $11 \%$ & $51 \%$ \\
$\mathbf{2 0}$ & - & $0 \%$ & $29 \%$ & $0 \%$ & $14 \%$ & $14 \%$ & $43 \%$ \\
$\mathbf{2 5}$ & - & - & $33 \%$ & $13 \%$ & $13 \%$ & $7 \%$ & $33 \%$ \\
$\mathbf{2 8}$ & - & - & - & $7 \%$ & $27 \%$ & $13 \%$ & $53 \%$ \\
$\mathbf{3 3}$ & - & - & - & - & $44 \%$ & $22 \%$ & $33 \%$ \\
$\mathbf{4 2}$ & - & - & - & - & - & $22 \%$ & $78 \%$ \\
\hline
\end{tabular}

Tabela A.2 - Matriz da primeira coleta de dados (6/6/2005) - 10:15 hs - Sentido Sul

\begin{tabular}{cccccccccc}
\hline $\mathbf{O} / \mathbf{D}$ & $\mathbf{1 0 9}$ & $\mathbf{1 1 6}$ & $\mathbf{1 1 7}$ & $\mathbf{1 2 2}$ & $\mathbf{1 2 4}$ & $\mathbf{1 2 9}$ & $\mathbf{1 3 4}$ & $\mathbf{1 5 1}$ & $\mathbf{1 5 3}$ \\
\hline $\mathbf{1 7 0}$ & $12 \%$ & $5 \%$ & $5 \%$ & $1 \%$ & $5 \%$ & $6 \%$ & $3 \%$ & $14 \%$ & $49 \%$ \\
$\mathbf{1 0 7}$ & $38 \%$ & $3 \%$ & $8 \%$ & $0 \%$ & $5 \%$ & $13 \%$ & $3 \%$ & $8 \%$ & $23 \%$ \\
$\mathbf{1 1 1}$ & - & $13 \%$ & $5 \%$ & $3 \%$ & $13 \%$ & $11 \%$ & $3 \%$ & $18 \%$ & $34 \%$ \\
$\mathbf{1 8 0}$ & - & - & $32 \%$ & $0 \%$ & $9 \%$ & $9 \%$ & $5 \%$ & $9 \%$ & $36 \%$ \\
$\mathbf{1 1 8}$ & - & - & - & $0 \%$ & $9 \%$ & $9 \%$ & $0 \%$ & $18 \%$ & $64 \%$ \\
$\mathbf{1 2 3}$ & - & - & - & - & $25 \%$ & $17 \%$ & $8 \%$ & $17 \%$ & $33 \%$ \\
$\mathbf{1 2 5}$ & - & - & - & - & - & $11 \%$ & $11 \%$ & $33 \%$ & $44 \%$ \\
$\mathbf{1 9 0}$ & - & - & - & - & - & - & $0 \%$ & $62 \%$ & $38 \%$ \\
$\mathbf{1 4 0}$ & - & - & - & - & - & - & - & $65 \%$ & $35 \%$ \\
\hline
\end{tabular}

Tabela A.3 - Matriz da primeira coleta de dados (6/6/2005) - 10:30 hs - Sentido Norte

\begin{tabular}{cccccccc}
\hline $\mathbf{O} / \mathbf{D}$ & $\mathbf{1 5}$ & $\mathbf{6 0}$ & $\mathbf{2 7}$ & $\mathbf{3 2}$ & $\mathbf{3 8}$ & $\mathbf{4 4}$ & $\mathbf{4 6}$ \\
\hline $\mathbf{6}$ & $24 \%$ & $5 \%$ & $3 \%$ & $3 \%$ & $9 \%$ & $11 \%$ & $45 \%$ \\
$\mathbf{2 0}$ & - & $0 \%$ & $33 \%$ & $22 \%$ & $11 \%$ & $11 \%$ & $22 \%$ \\
$\mathbf{2 5}$ & - & - & $56 \%$ & $13 \%$ & $13 \%$ & $6 \%$ & $13 \%$ \\
$\mathbf{2 8}$ & - & - & - & $6 \%$ & $28 \%$ & $11 \%$ & $56 \%$ \\
$\mathbf{3 3}$ & - & - & - & - & $43 \%$ & $17 \%$ & $40 \%$ \\
$\mathbf{4 2}$ & - & - & - & - & - & $18 \%$ & $82 \%$ \\
\hline
\end{tabular}

Tabela A.4 - Matriz da primeira coleta de dados (6/6/2005) - 10:30 hs - Sentido Sul

\begin{tabular}{cccccccccc}
\hline $\mathbf{O} / \mathbf{D}$ & $\mathbf{1 0 9}$ & $\mathbf{1 1 6}$ & $\mathbf{1 1 7}$ & $\mathbf{1 2 2}$ & $\mathbf{1 2 4}$ & $\mathbf{1 2 9}$ & $\mathbf{1 3 4}$ & $\mathbf{1 5 1}$ & $\mathbf{1 5 3}$ \\
\hline $\mathbf{1 7 0}$ & $16 \%$ & $3 \%$ & $10 \%$ & $1 \%$ & $5 \%$ & $2 \%$ & $4 \%$ & $13 \%$ & $46 \%$ \\
$\mathbf{1 0 7}$ & $48 \%$ & $0 \%$ & $14 \%$ & $3 \%$ & $7 \%$ & $3 \%$ & $3 \%$ & $7 \%$ & $14 \%$ \\
$\mathbf{1 1 1}$ & - & $4 \%$ & $4 \%$ & $4 \%$ & $13 \%$ & $4 \%$ & $4 \%$ & $17 \%$ & $50 \%$ \\
$\mathbf{1 8 0}$ & - & - & $59 \%$ & $5 \%$ & $5 \%$ & $5 \%$ & $5 \%$ & $9 \%$ & $14 \%$ \\
$\mathbf{1 1 8}$ & - & - & - & $0 \%$ & $0 \%$ & $0 \%$ & $0 \%$ & $0 \%$ & $100 \%$ \\
$\mathbf{1 2 3}$ & - & - & - & - & $17 \%$ & $8 \%$ & $25 \%$ & $17 \%$ & $33 \%$ \\
$\mathbf{1 2 5}$ & - & - & - & - & - & $13 \%$ & $13 \%$ & $38 \%$ & $38 \%$ \\
$\mathbf{1 9 0}$ & - & - & - & - & - & - & $0 \%$ & $54 \%$ & $46 \%$ \\
$\mathbf{1 4 0}$ & - & - & - & - & - & - & - & $62 \%$ & $38 \%$ \\
\hline
\end{tabular}


Tabela A.5 - Matriz da primeira coleta de dados (6/6/2005) - 10:45 hs - Sentido Norte

\begin{tabular}{cccccccc}
\hline $\mathbf{O} / \mathbf{D}$ & $\mathbf{1 5}$ & $\mathbf{6 0}$ & $\mathbf{2 7}$ & $\mathbf{3 2}$ & $\mathbf{3 8}$ & $\mathbf{4 4}$ & $\mathbf{4 6}$ \\
\hline $\mathbf{6}$ & $22 \%$ & $4 \%$ & $4 \%$ & $1 \%$ & $10 \%$ & $10 \%$ & $48 \%$ \\
$\mathbf{2 0}$ & - & $0 \%$ & $40 \%$ & $0 \%$ & $20 \%$ & $10 \%$ & $30 \%$ \\
$\mathbf{2 5}$ & - & - & $45 \%$ & $9 \%$ & $18 \%$ & $9 \%$ & $18 \%$ \\
$\mathbf{2 8}$ & - & - & - & $6 \%$ & $29 \%$ & $12 \%$ & $53 \%$ \\
$\mathbf{3 3}$ & - & - & - & - & $47 \%$ & $16 \%$ & $37 \%$ \\
$\mathbf{4 2}$ & - & - & - & - & - & $12 \%$ & $88 \%$ \\
\hline
\end{tabular}

Tabela A.6 - Matriz da primeira coleta de dados (6/6/2005) - 10:45 hs - Sentido Sul

\begin{tabular}{cccccccccc}
\hline $\mathbf{O} / \mathbf{D}$ & $\mathbf{1 0 9}$ & $\mathbf{1 1 6}$ & $\mathbf{1 1 7}$ & $\mathbf{1 2 2}$ & $\mathbf{1 2 4}$ & $\mathbf{1 2 9}$ & $\mathbf{1 3 4}$ & $\mathbf{1 5 1}$ & $\mathbf{1 5 3}$ \\
\hline $\mathbf{1 7 0}$ & $10 \%$ & $5 \%$ & $7 \%$ & $1 \%$ & $4 \%$ & $4 \%$ & $2 \%$ & $14 \%$ & $54 \%$ \\
$\mathbf{1 0 7}$ & $31 \%$ & $3 \%$ & $10 \%$ & $0 \%$ & $5 \%$ & $8 \%$ & $3 \%$ & $8 \%$ & $33 \%$ \\
$\mathbf{1 1 1}$ & - & $13 \%$ & $10 \%$ & $3 \%$ & $17 \%$ & $7 \%$ & $3 \%$ & $17 \%$ & $30 \%$ \\
$\mathbf{1 8 0}$ & - & - & $40 \%$ & $0 \%$ & $0 \%$ & $7 \%$ & $0 \%$ & $13 \%$ & $40 \%$ \\
$\mathbf{1 1 8}$ & - & - & - & $0 \%$ & $0 \%$ & $20 \%$ & $0 \%$ & $20 \%$ & $60 \%$ \\
$\mathbf{1 2 3}$ & - & - & - & - & $27 \%$ & $18 \%$ & $9 \%$ & $18 \%$ & $27 \%$ \\
$\mathbf{1 2 5}$ & - & - & - & - & - & $11 \%$ & $11 \%$ & $33 \%$ & $44 \%$ \\
$\mathbf{1 9 0}$ & - & - & - & - & - & - & $0 \%$ & $59 \%$ & $41 \%$ \\
$\mathbf{1 4 0}$ & - & - & - & - & - & - & - & $65 \%$ & $35 \%$ \\
\hline
\end{tabular}

Tabela A.7 - Matriz da primeira coleta de dados (6/6/2005) - 11:00 hs - Sentido Norte

\begin{tabular}{cccccccc}
\hline $\mathbf{O} / \mathbf{D}$ & $\mathbf{1 5}$ & $\mathbf{6 0}$ & $\mathbf{2 7}$ & $\mathbf{3 2}$ & $\mathbf{3 8}$ & $\mathbf{4 4}$ & $\mathbf{4 6}$ \\
\hline $\mathbf{6}$ & $16 \%$ & $3 \%$ & $3 \%$ & $3 \%$ & $8 \%$ & $9 \%$ & $58 \%$ \\
$\mathbf{2 0}$ & - & $8 \%$ & $23 \%$ & $8 \%$ & $15 \%$ & $8 \%$ & $38 \%$ \\
$\mathbf{2 5}$ & - & - & $29 \%$ & $18 \%$ & $12 \%$ & $6 \%$ & $35 \%$ \\
$\mathbf{2 8}$ & - & - & - & $8 \%$ & $25 \%$ & $8 \%$ & $58 \%$ \\
$\mathbf{3 3}$ & - & - & - & - & $33 \%$ & $14 \%$ & $52 \%$ \\
$\mathbf{4 2}$ & - & - & - & - & - & $15 \%$ & $85 \%$ \\
\hline
\end{tabular}

Tabela A.8 - Matriz da primeira coleta de dados (6/6/2005) - 11:00 hs - Sentido Sul

\begin{tabular}{cccccccccc}
\hline $\mathbf{O} / \mathbf{D}$ & $\mathbf{1 0 9}$ & $\mathbf{1 1 6}$ & $\mathbf{1 1 7}$ & $\mathbf{1 2 2}$ & $\mathbf{1 2 4}$ & $\mathbf{1 2 9}$ & $\mathbf{1 3 4}$ & $\mathbf{1 5 1}$ & $\mathbf{1 5 3}$ \\
\hline $\mathbf{1 7 0}$ & $9 \%$ & $7 \%$ & $8 \%$ & $2 \%$ & $5 \%$ & $5 \%$ & $2 \%$ & $18 \%$ & $45 \%$ \\
$\mathbf{1 0 7}$ & $29 \%$ & $3 \%$ & $9 \%$ & $3 \%$ & $6 \%$ & $9 \%$ & $3 \%$ & $9 \%$ & $29 \%$ \\
$\mathbf{1 1 1}$ & - & $14 \%$ & $11 \%$ & $4 \%$ & $11 \%$ & $7 \%$ & $0 \%$ & $18 \%$ & $36 \%$ \\
$\mathbf{1 8 0}$ & - & - & $55 \%$ & $0 \%$ & $9 \%$ & $9 \%$ & $0 \%$ & $18 \%$ & $9 \%$ \\
$\mathbf{1 1 8}$ & - & - & - & $0 \%$ & $10 \%$ & $10 \%$ & $0 \%$ & $30 \%$ & $50 \%$ \\
$\mathbf{1 2 3}$ & - & - & - & - & $40 \%$ & $13 \%$ & $13 \%$ & $27 \%$ & $7 \%$ \\
$\mathbf{1 2 5}$ & - & - & - & - & - & $14 \%$ & $14 \%$ & $29 \%$ & $43 \%$ \\
$\mathbf{1 9 0}$ & - & - & - & - & - & - & $0 \%$ & $67 \%$ & $33 \%$ \\
$\mathbf{1 4 0}$ & - & - & - & - & - & - & - & $80 \%$ & $20 \%$ \\
\hline
\end{tabular}


Tabela A.9 - Matriz da primeira coleta de dados (6/6/2005) - 11:15 hs - Sentido Norte

\begin{tabular}{cccccccc}
\hline $\mathbf{O} / \mathbf{D}$ & $\mathbf{1 5}$ & $\mathbf{6 0}$ & $\mathbf{2 7}$ & $\mathbf{3 2}$ & $\mathbf{3 8}$ & $\mathbf{4 4}$ & $\mathbf{4 6}$ \\
\hline $\mathbf{6}$ & $20 \%$ & $5 \%$ & $5 \%$ & $5 \%$ & $7 \%$ & $9 \%$ & $50 \%$ \\
$\mathbf{2 0}$ & - & $25 \%$ & $25 \%$ & $25 \%$ & $25 \%$ & $0 \%$ & $0 \%$ \\
$\mathbf{2 5}$ & - & - & $62 \%$ & $15 \%$ & $15 \%$ & $8 \%$ & $0 \%$ \\
$\mathbf{2 8}$ & - & - & - & $6 \%$ & $24 \%$ & $12 \%$ & $59 \%$ \\
$\mathbf{3 3}$ & - & - & - & - & $29 \%$ & $18 \%$ & $53 \%$ \\
$\mathbf{4 2}$ & - & - & - & - & - & $15 \%$ & $85 \%$ \\
\hline
\end{tabular}

Tabela A.10 - Matriz da primeira coleta de dados (6/6/2005) - 11:15 hs - Sentido Sul

\begin{tabular}{cccccccccc}
\hline $\mathbf{O} / \mathbf{D}$ & $\mathbf{1 0 9}$ & $\mathbf{1 1 6}$ & $\mathbf{1 1 7}$ & $\mathbf{1 2 2}$ & $\mathbf{1 2 4}$ & $\mathbf{1 2 9}$ & $\mathbf{1 3 4}$ & $\mathbf{1 5 1}$ & $\mathbf{1 5 3}$ \\
\hline $\mathbf{1 7 0}$ & $9 \%$ & $9 \%$ & $7 \%$ & $2 \%$ & $11 \%$ & $3 \%$ & $4 \%$ & $13 \%$ & $42 \%$ \\
$\mathbf{1 0 7}$ & $29 \%$ & $6 \%$ & $13 \%$ & $3 \%$ & $6 \%$ & $6 \%$ & $3 \%$ & $10 \%$ & $23 \%$ \\
$\mathbf{1 1 1}$ & - & $20 \%$ & $11 \%$ & $3 \%$ & $29 \%$ & $6 \%$ & $3 \%$ & $17 \%$ & $11 \%$ \\
$\mathbf{1 8 0}$ & - & - & $54 \%$ & $0 \%$ & $8 \%$ & $0 \%$ & $8 \%$ & $0 \%$ & $31 \%$ \\
$\mathbf{1 1 8}$ & - & - & - & $0 \%$ & $15 \%$ & $8 \%$ & $8 \%$ & $15 \%$ & $54 \%$ \\
$\mathbf{1 2 3}$ & - & - & - & - & $44 \%$ & $13 \%$ & $19 \%$ & $13 \%$ & $13 \%$ \\
$\mathbf{1 2 5}$ & - & - & - & - & - & $18 \%$ & $18 \%$ & $36 \%$ & $27 \%$ \\
$\mathbf{1 9 0}$ & - & - & - & - & - & - & $0 \%$ & $44 \%$ & $56 \%$ \\
$\mathbf{1 4 0}$ & - & - & - & - & - & - & - & $53 \%$ & $47 \%$ \\
\hline
\end{tabular}

Tabela A.11 - Matriz da primeira coleta de dados (6/6/2005) - 11:30 hs - Sentido Norte

\begin{tabular}{cccccccc}
\hline $\mathbf{O} / \mathbf{D}$ & $\mathbf{1 5}$ & $\mathbf{6 0}$ & $\mathbf{2 7}$ & $\mathbf{3 2}$ & $\mathbf{3 8}$ & $\mathbf{4 4}$ & $\mathbf{4 6}$ \\
\hline $\mathbf{6}$ & $19 \%$ & $4 \%$ & $2 \%$ & $3 \%$ & $7 \%$ & $8 \%$ & $57 \%$ \\
$\mathbf{2 0}$ & - & $0 \%$ & $25 \%$ & $13 \%$ & $13 \%$ & $13 \%$ & $38 \%$ \\
$\mathbf{2 5}$ & - & - & $29 \%$ & $14 \%$ & $14 \%$ & $7 \%$ & $36 \%$ \\
$\mathbf{2 8}$ & - & - & - & $10 \%$ & $20 \%$ & $10 \%$ & $60 \%$ \\
$\mathbf{3 3}$ & - & - & - & - & $24 \%$ & $10 \%$ & $67 \%$ \\
$\mathbf{4 2}$ & - & - & - & - & - & $10 \%$ & $90 \%$ \\
\hline
\end{tabular}

Tabela A.12 - Matriz da primeira coleta de dados (6/6/2005) - 11:30 hs - Sentido Sul

\begin{tabular}{cccccccccc}
\hline $\mathbf{O} / \mathbf{D}$ & $\mathbf{1 0 9}$ & $\mathbf{1 1 6}$ & $\mathbf{1 1 7}$ & $\mathbf{1 2 2}$ & $\mathbf{1 2 4}$ & $\mathbf{1 2 9}$ & $\mathbf{1 3 4}$ & $\mathbf{1 5 1}$ & $\mathbf{1 5 3}$ \\
\hline $\mathbf{1 7 0}$ & $9 \%$ & $7 \%$ & $7 \%$ & $1 \%$ & $9 \%$ & $5 \%$ & $4 \%$ & $11 \%$ & $46 \%$ \\
$\mathbf{1 0 7}$ & $26 \%$ & $3 \%$ & $9 \%$ & $0 \%$ & $6 \%$ & $9 \%$ & $3 \%$ & $6 \%$ & $40 \%$ \\
$\mathbf{1 1 1}$ & - & $19 \%$ & $7 \%$ & $4 \%$ & $22 \%$ & $7 \%$ & $0 \%$ & $15 \%$ & $26 \%$ \\
$\mathbf{1 8 0}$ & - & - & $50 \%$ & $0 \%$ & $6 \%$ & $6 \%$ & $6 \%$ & $11 \%$ & $22 \%$ \\
$\mathbf{1 1 8}$ & - & - & - & $0 \%$ & $13 \%$ & $13 \%$ & $0 \%$ & $13 \%$ & $63 \%$ \\
$\mathbf{1 2 3}$ & - & - & - & - & $40 \%$ & $15 \%$ & $30 \%$ & $10 \%$ & $5 \%$ \\
$\mathbf{1 2 5}$ & - & - & - & - & - & $14 \%$ & $14 \%$ & $29 \%$ & $43 \%$ \\
$\mathbf{1 9 0}$ & - & - & - & - & - & - & $0 \%$ & $50 \%$ & $50 \%$ \\
$\mathbf{1 4 0}$ & - & - & - & - & - & - & - & $56 \%$ & $44 \%$ \\
\hline
\end{tabular}


Tabela A.13 - Matriz da primeira coleta de dados (6/6/2005) - 11:45 hs - Sentido Norte

\begin{tabular}{cccccccc}
\hline $\mathbf{O} / \mathbf{D}$ & $\mathbf{1 5}$ & $\mathbf{6 0}$ & $\mathbf{2 7}$ & $\mathbf{3 2}$ & $\mathbf{3 8}$ & $\mathbf{4 4}$ & $\mathbf{4 6}$ \\
\hline $\mathbf{6}$ & $18 \%$ & $9 \%$ & $3 \%$ & $2 \%$ & $9 \%$ & $7 \%$ & $52 \%$ \\
$\mathbf{2 0}$ & - & $13 \%$ & $38 \%$ & $13 \%$ & $13 \%$ & $13 \%$ & $13 \%$ \\
$\mathbf{2 5}$ & - & - & $50 \%$ & $20 \%$ & $10 \%$ & $10 \%$ & $10 \%$ \\
$\mathbf{2 8}$ & - & - & - & $7 \%$ & $29 \%$ & $14 \%$ & $50 \%$ \\
$\mathbf{3 3}$ & - & - & - & - & $40 \%$ & $15 \%$ & $45 \%$ \\
$\mathbf{4 2}$ & - & - & - & - & - & $8 \%$ & $92 \%$ \\
\hline
\end{tabular}

Tabela A.14 - Matriz da primeira coleta de dados (6/6/2005) - 11:45 hs - Sentido Sul

\begin{tabular}{cccccccccc}
\hline $\mathbf{O} / \mathbf{D}$ & $\mathbf{1 0 9}$ & $\mathbf{1 1 6}$ & $\mathbf{1 1 7}$ & $\mathbf{1 2 2}$ & $\mathbf{1 2 4}$ & $\mathbf{1 2 9}$ & $\mathbf{1 3 4}$ & $\mathbf{1 5 1}$ & $\mathbf{1 5 3}$ \\
\hline $\mathbf{1 7 0}$ & $8 \%$ & $5 \%$ & $7 \%$ & $2 \%$ & $10 \%$ & $6 \%$ & $4 \%$ & $11 \%$ & $46 \%$ \\
$\mathbf{1 0 7}$ & $28 \%$ & $3 \%$ & $10 \%$ & $3 \%$ & $8 \%$ & $8 \%$ & $3 \%$ & $8 \%$ & $33 \%$ \\
$\mathbf{1 1 1}$ & - & $13 \%$ & $9 \%$ & $7 \%$ & $26 \%$ & $11 \%$ & $2 \%$ & $17 \%$ & $15 \%$ \\
$\mathbf{1 8 0}$ & - & - & $43 \%$ & $0 \%$ & $14 \%$ & $7 \%$ & $0 \%$ & $7 \%$ & $29 \%$ \\
$\mathbf{1 1 8}$ & - & - & - & $0 \%$ & $18 \%$ & $9 \%$ & $0 \%$ & $18 \%$ & $55 \%$ \\
$\mathbf{1 2 3}$ & - & - & - & - & $35 \%$ & $24 \%$ & $24 \%$ & $18 \%$ & $0 \%$ \\
$\mathbf{1 2 5}$ & - & - & - & - & - & $18 \%$ & $18 \%$ & $36 \%$ & $27 \%$ \\
$\mathbf{1 9 0}$ & - & - & - & - & - & - & $0 \%$ & $55 \%$ & $45 \%$ \\
$\mathbf{1 4 0}$ & - & - & - & - & - & - & - & $50 \%$ & $50 \%$ \\
\hline
\end{tabular}

Tabela A.15 - Matriz da primeira coleta de dados (6/6/2005) - 12:00 hs - Sentido Norte

\begin{tabular}{cccccccc}
\hline $\mathbf{O} / \mathbf{D}$ & $\mathbf{1 5}$ & $\mathbf{6 0}$ & $\mathbf{2 7}$ & $\mathbf{3 2}$ & $\mathbf{3 8}$ & $\mathbf{4 4}$ & $\mathbf{4 6}$ \\
\hline $\mathbf{6}$ & $30 \%$ & $4 \%$ & $2 \%$ & $3 \%$ & $7 \%$ & $6 \%$ & $48 \%$ \\
$\mathbf{2 0}$ & - & $5 \%$ & $19 \%$ & $5 \%$ & $10 \%$ & $10 \%$ & $52 \%$ \\
$\mathbf{2 5}$ & - & - & $24 \%$ & $24 \%$ & $12 \%$ & $0 \%$ & $41 \%$ \\
$\mathbf{2 8}$ & - & - & - & $9 \%$ & $18 \%$ & $9 \%$ & $64 \%$ \\
$\mathbf{3 3}$ & - & - & - & - & $25 \%$ & $5 \%$ & $70 \%$ \\
$\mathbf{4 2}$ & - & - & - & - & - & $3 \%$ & $97 \%$ \\
\hline
\end{tabular}

Tabela A.16 - Matriz da primeira coleta de dados (6/6/2005) - 12:00 hs - Sentido Sul

\begin{tabular}{cccccccccc}
\hline $\mathbf{O} / \mathbf{D}$ & $\mathbf{1 0 9}$ & $\mathbf{1 1 6}$ & $\mathbf{1 1 7}$ & $\mathbf{1 2 2}$ & $\mathbf{1 2 4}$ & $\mathbf{1 2 9}$ & $\mathbf{1 3 4}$ & $\mathbf{1 5 1}$ & $\mathbf{1 5 3}$ \\
\hline $\mathbf{1 7 0}$ & $13 \%$ & $5 \%$ & $5 \%$ & $1 \%$ & $11 \%$ & $5 \%$ & $4 \%$ & $12 \%$ & $44 \%$ \\
$\mathbf{1 0 7}$ & $39 \%$ & $4 \%$ & $11 \%$ & $4 \%$ & $7 \%$ & $7 \%$ & $4 \%$ & $7 \%$ & $18 \%$ \\
$\mathbf{1 1 1}$ & - & $11 \%$ & $8 \%$ & $3 \%$ & $30 \%$ & $8 \%$ & $1 \%$ & $16 \%$ & $23 \%$ \\
$\mathbf{1 8 0}$ & - & - & $40 \%$ & $0 \%$ & $10 \%$ & $10 \%$ & $0 \%$ & $10 \%$ & $30 \%$ \\
$\mathbf{1 1 8}$ & - & - & - & $0 \%$ & $17 \%$ & $8 \%$ & $0 \%$ & $17 \%$ & $58 \%$ \\
$\mathbf{1 2 3}$ & - & - & - & - & $47 \%$ & $13 \%$ & $20 \%$ & $20 \%$ & $0 \%$ \\
$\mathbf{1 2 5}$ & - & - & - & - & - & $18 \%$ & $18 \%$ & $36 \%$ & $27 \%$ \\
$\mathbf{1 9 0}$ & - & - & - & - & - & - & $0 \%$ & $60 \%$ & $40 \%$ \\
$\mathbf{1 4 0}$ & - & - & - & - & - & - & - & $55 \%$ & $45 \%$ \\
\hline
\end{tabular}


Tabela A.17 - Matriz da segunda coleta de dados (13/6/2005) - 9:15 hs - Sentido Norte

\begin{tabular}{cccccccc}
\hline $\mathbf{O} / \mathbf{D}$ & $\mathbf{1 5}$ & $\mathbf{6 0}$ & $\mathbf{2 7}$ & $\mathbf{3 2}$ & $\mathbf{3 8}$ & $\mathbf{4 4}$ & $\mathbf{4 6}$ \\
\hline $\mathbf{6}$ & $22 \%$ & $3 \%$ & $2 \%$ & $2 \%$ & $8 \%$ & $10 \%$ & $53 \%$ \\
$\mathbf{2 0}$ & - & $0 \%$ & $10 \%$ & $0 \%$ & $20 \%$ & $10 \%$ & $60 \%$ \\
$\mathbf{2 5}$ & - & - & $24 \%$ & $6 \%$ & $12 \%$ & $6 \%$ & $53 \%$ \\
$\mathbf{2 8}$ & - & - & - & $0 \%$ & $16 \%$ & $11 \%$ & $74 \%$ \\
$\mathbf{3 3}$ & - & - & - & - & $37 \%$ & $17 \%$ & $47 \%$ \\
$\mathbf{4 2}$ & - & - & - & - & - & $12 \%$ & $88 \%$ \\
\hline
\end{tabular}

Tabela A.18 - Matriz da segunda coleta de dados (13/6/2005) - 9:15 hs - Sentido Sul

\begin{tabular}{cccccccccc}
\hline $\mathbf{O} / \mathbf{D}$ & $\mathbf{1 0 9}$ & $\mathbf{1 1 6}$ & $\mathbf{1 1 7}$ & $\mathbf{1 2 2}$ & $\mathbf{1 2 4}$ & $\mathbf{1 2 9}$ & $\mathbf{1 3 4}$ & $\mathbf{1 5 1}$ & $\mathbf{1 5 3}$ \\
\hline $\mathbf{1 7 0}$ & $12 \%$ & $11 \%$ & $8 \%$ & $1 \%$ & $7 \%$ & $3 \%$ & $3 \%$ & $12 \%$ & $42 \%$ \\
$\mathbf{1 0 7}$ & $37 \%$ & $2 \%$ & $11 \%$ & $0 \%$ & $7 \%$ & $4 \%$ & $0 \%$ & $9 \%$ & $30 \%$ \\
$\mathbf{1 1 1}$ & - & $20 \%$ & $10 \%$ & $0 \%$ & $20 \%$ & $3 \%$ & $0 \%$ & $17 \%$ & $30 \%$ \\
$\mathbf{1 8 0}$ & - & - & $52 \%$ & $0 \%$ & $8 \%$ & $4 \%$ & $4 \%$ & $12 \%$ & $20 \%$ \\
$\mathbf{1 1 8}$ & - & - & - & $0 \%$ & $14 \%$ & $14 \%$ & $0 \%$ & $14 \%$ & $57 \%$ \\
$\mathbf{1 2 3}$ & - & - & - & - & $31 \%$ & $8 \%$ & $8 \%$ & $15 \%$ & $38 \%$ \\
$\mathbf{1 2 5}$ & - & - & - & - & - & $13 \%$ & $0 \%$ & $38 \%$ & $50 \%$ \\
$\mathbf{1 9 0}$ & - & - & - & - & - & - & $0 \%$ & $56 \%$ & $44 \%$ \\
$\mathbf{1 4 0}$ & - & - & - & - & - & - & - & $57 \%$ & $43 \%$ \\
\hline
\end{tabular}

Tabela A.19 - Matriz da segunda coleta de dados (13/6/2005) - 9:30 hs - Sentido Norte

\begin{tabular}{cccccccc}
\hline $\mathbf{O} / \mathbf{D}$ & $\mathbf{1 5}$ & $\mathbf{6 0}$ & $\mathbf{2 7}$ & $\mathbf{3 2}$ & $\mathbf{3 8}$ & $\mathbf{4 4}$ & $\mathbf{4 6}$ \\
\hline $\mathbf{6}$ & $18 \%$ & $4 \%$ & $2 \%$ & $2 \%$ & $10 \%$ & $9 \%$ & $55 \%$ \\
$\mathbf{2 0}$ & - & $0 \%$ & $29 \%$ & $0 \%$ & $14 \%$ & $14 \%$ & $43 \%$ \\
$\mathbf{2 5}$ & - & - & $18 \%$ & $6 \%$ & $12 \%$ & $6 \%$ & $59 \%$ \\
$\mathbf{2 8}$ & - & - & - & $0 \%$ & $25 \%$ & $13 \%$ & $63 \%$ \\
$\mathbf{3 3}$ & - & - & - & - & $45 \%$ & $10 \%$ & $45 \%$ \\
$\mathbf{4 2}$ & - & - & - & - & - & $14 \%$ & $86 \%$ \\
\hline
\end{tabular}

Tabela A.20 - Matriz da segunda coleta de dados (13/6/2005) - 9:30 hs - Sentido Sul

\begin{tabular}{cccccccccc}
\hline $\mathbf{O} / \mathbf{D}$ & $\mathbf{1 0 9}$ & $\mathbf{1 1 6}$ & $\mathbf{1 1 7}$ & $\mathbf{1 2 2}$ & $\mathbf{1 2 4}$ & $\mathbf{1 2 9}$ & $\mathbf{1 3 4}$ & $\mathbf{1 5 1}$ & $\mathbf{1 5 3}$ \\
\hline $\mathbf{1 7 0}$ & $11 \%$ & $4 \%$ & $6 \%$ & $2 \%$ & $6 \%$ & $3 \%$ & $2 \%$ & $11 \%$ & $55 \%$ \\
$\mathbf{1 0 7}$ & $37 \%$ & $2 \%$ & $8 \%$ & $2 \%$ & $3 \%$ & $7 \%$ & $3 \%$ & $7 \%$ & $31 \%$ \\
$\mathbf{1 1 1}$ & - & $11 \%$ & $6 \%$ & $6 \%$ & $11 \%$ & $6 \%$ & $0 \%$ & $17 \%$ & $44 \%$ \\
$\mathbf{1 8 0}$ & - & - & $33 \%$ & $0 \%$ & $6 \%$ & $6 \%$ & $6 \%$ & $11 \%$ & $39 \%$ \\
$\mathbf{1 1 8}$ & - & - & - & $0 \%$ & $25 \%$ & $0 \%$ & $0 \%$ & $25 \%$ & $50 \%$ \\
$\mathbf{1 2 3}$ & - & - & - & - & $38 \%$ & $8 \%$ & $15 \%$ & $15 \%$ & $23 \%$ \\
$\mathbf{1 2 5}$ & - & - & - & - & - & $14 \%$ & $14 \%$ & $29 \%$ & $43 \%$ \\
$\mathbf{1 9 0}$ & - & - & - & - & - & - & $0 \%$ & $44 \%$ & $56 \%$ \\
$\mathbf{1 4 0}$ & - & - & - & - & - & - & - & $48 \%$ & $52 \%$ \\
\hline
\end{tabular}


Tabela A.21 - Matriz da segunda coleta de dados (13/6/2005) - 9:45 hs - Sentido Norte

\begin{tabular}{cccccccc}
\hline $\mathbf{O} / \mathbf{D}$ & $\mathbf{1 5}$ & $\mathbf{6 0}$ & $\mathbf{2 7}$ & $\mathbf{3 2}$ & $\mathbf{3 8}$ & $\mathbf{4 4}$ & $\mathbf{4 6}$ \\
\hline $\mathbf{6}$ & $21 \%$ & $2 \%$ & $2 \%$ & $4 \%$ & $11 \%$ & $9 \%$ & $50 \%$ \\
$\mathbf{2 0}$ & - & $0 \%$ & $17 \%$ & $17 \%$ & $17 \%$ & $8 \%$ & $42 \%$ \\
$\mathbf{2 5}$ & - & - & $21 \%$ & $21 \%$ & $14 \%$ & $7 \%$ & $36 \%$ \\
$\mathbf{2 8}$ & - & - & - & $12 \%$ & $29 \%$ & $12 \%$ & $47 \%$ \\
$\mathbf{3 3}$ & - & - & - & - & $47 \%$ & $18 \%$ & $35 \%$ \\
$\mathbf{4 2}$ & - & - & - & - & - & $18 \%$ & $82 \%$ \\
\hline
\end{tabular}

Tabela A.22 - Matriz da segunda coleta de dados (13/6/2005) - 9:45 hs - Sentido Sul

\begin{tabular}{cccccccccc}
\hline $\mathbf{O} / \mathbf{D}$ & $\mathbf{1 0 9}$ & $\mathbf{1 1 6}$ & $\mathbf{1 1 7}$ & $\mathbf{1 2 2}$ & $\mathbf{1 2 4}$ & $\mathbf{1 2 9}$ & $\mathbf{1 3 4}$ & $\mathbf{1 5 1}$ & $\mathbf{1 5 3}$ \\
\hline $\mathbf{1 7 0}$ & $11 \%$ & $8 \%$ & $6 \%$ & $1 \%$ & $6 \%$ & $4 \%$ & $3 \%$ & $12 \%$ & $51 \%$ \\
$\mathbf{1 0 7}$ & $33 \%$ & $4 \%$ & $10 \%$ & $2 \%$ & $4 \%$ & $6 \%$ & $4 \%$ & $6 \%$ & $29 \%$ \\
$\mathbf{1 1 1}$ & - & $17 \%$ & $9 \%$ & $4 \%$ & $17 \%$ & $9 \%$ & $0 \%$ & $13 \%$ & $30 \%$ \\
$\mathbf{1 8 0}$ & - & - & $42 \%$ & $0 \%$ & $0 \%$ & $11 \%$ & $5 \%$ & $5 \%$ & $37 \%$ \\
$\mathbf{1 1 8}$ & - & - & - & $0 \%$ & $7 \%$ & $13 \%$ & $7 \%$ & $7 \%$ & $67 \%$ \\
$\mathbf{1 2 3}$ & - & - & - & - & $25 \%$ & $13 \%$ & $13 \%$ & $0 \%$ & $50 \%$ \\
$\mathbf{1 2 5}$ & - & - & - & - & - & $13 \%$ & $13 \%$ & $25 \%$ & $50 \%$ \\
190 & - & - & - & - & - & - & $0 \%$ & $47 \%$ & $53 \%$ \\
140 & - & - & - & - & - & - & - & $59 \%$ & $41 \%$ \\
\hline
\end{tabular}

Tabela A.23 - Matriz da segunda coleta de dados (13/6/2005) - 10:00 hs - Sentido Norte

\begin{tabular}{cccccccc}
\hline $\mathbf{O} / \mathbf{D}$ & $\mathbf{1 5}$ & $\mathbf{6 0}$ & $\mathbf{2 7}$ & $\mathbf{3 2}$ & $\mathbf{3 8}$ & $\mathbf{4 4}$ & $\mathbf{4 6}$ \\
\hline $\mathbf{6}$ & $27 \%$ & $5 \%$ & $2 \%$ & $2 \%$ & $14 \%$ & $11 \%$ & $39 \%$ \\
$\mathbf{2 0}$ & - & $13 \%$ & $25 \%$ & $0 \%$ & $13 \%$ & $13 \%$ & $38 \%$ \\
$\mathbf{2 5}$ & - & - & $25 \%$ & $8 \%$ & $17 \%$ & $8 \%$ & $42 \%$ \\
$\mathbf{2 8}$ & - & - & - & $5 \%$ & $26 \%$ & $11 \%$ & $58 \%$ \\
$\mathbf{3 3}$ & - & - & - & - & $55 \%$ & $21 \%$ & $24 \%$ \\
$\mathbf{4 2}$ & - & - & - & - & - & $13 \%$ & $87 \%$ \\
\hline
\end{tabular}

Tabela A.24 - Matriz da segunda coleta de dados (13/6/2005) - 10:00 hs - Sentido Sul

\begin{tabular}{cccccccccc}
\hline $\mathbf{O} / \mathbf{D}$ & $\mathbf{1 0 9}$ & $\mathbf{1 1 6}$ & $\mathbf{1 1 7}$ & $\mathbf{1 2 2}$ & $\mathbf{1 2 4}$ & $\mathbf{1 2 9}$ & $\mathbf{1 3 4}$ & $\mathbf{1 5 1}$ & $\mathbf{1 5 3}$ \\
\hline $\mathbf{1 7 0}$ & $11 \%$ & $7 \%$ & $9 \%$ & $2 \%$ & $7 \%$ & $3 \%$ & $1 \%$ & $14 \%$ & $45 \%$ \\
$\mathbf{1 0 7}$ & $35 \%$ & $2 \%$ & $13 \%$ & $2 \%$ & $5 \%$ & $6 \%$ & $2 \%$ & $8 \%$ & $27 \%$ \\
$\mathbf{1 1 1}$ & - & $15 \%$ & $12 \%$ & $4 \%$ & $15 \%$ & $8 \%$ & $0 \%$ & $19 \%$ & $27 \%$ \\
$\mathbf{1 8 0}$ & - & - & $57 \%$ & $0 \%$ & $5 \%$ & $10 \%$ & $5 \%$ & $10 \%$ & $14 \%$ \\
$\mathbf{1 1 8}$ & - & - & - & $0 \%$ & $0 \%$ & $17 \%$ & $0 \%$ & $17 \%$ & $67 \%$ \\
$\mathbf{1 2 3}$ & - & - & - & - & $25 \%$ & $13 \%$ & $13 \%$ & $19 \%$ & $31 \%$ \\
$\mathbf{1 2 5}$ & - & - & - & - & - & $14 \%$ & $14 \%$ & $29 \%$ & $43 \%$ \\
$\mathbf{1 9 0}$ & - & - & - & - & - & - & $0 \%$ & $59 \%$ & $41 \%$ \\
$\mathbf{1 4 0}$ & - & - & - & - & - & - & - & $68 \%$ & $32 \%$ \\
\hline
\end{tabular}


Tabela A.25 - Matriz da segunda coleta de dados (13/6/2005) - 10:15 hs - Sentido Norte

\begin{tabular}{cccccccc}
\hline $\mathbf{O} / \mathbf{D}$ & $\mathbf{1 5}$ & $\mathbf{6 0}$ & $\mathbf{2 7}$ & $\mathbf{3 2}$ & $\mathbf{3 8}$ & $\mathbf{4 4}$ & $\mathbf{4 6}$ \\
\hline $\mathbf{6}$ & $20 \%$ & $4 \%$ & $1 \%$ & $3 \%$ & $9 \%$ & $6 \%$ & $57 \%$ \\
$\mathbf{2 0}$ & - & $0 \%$ & $0 \%$ & $0 \%$ & $25 \%$ & $0 \%$ & $75 \%$ \\
$\mathbf{2 5}$ & - & - & $13 \%$ & $13 \%$ & $13 \%$ & $7 \%$ & $53 \%$ \\
$\mathbf{2 8}$ & - & - & - & $5 \%$ & $27 \%$ & $5 \%$ & $64 \%$ \\
$\mathbf{3 3}$ & - & - & - & - & $39 \%$ & $16 \%$ & $45 \%$ \\
$\mathbf{4 2}$ & - & - & - & - & - & $10 \%$ & $90 \%$ \\
\hline
\end{tabular}

Tabela A.26 - Matriz da segunda coleta de dados (13/6/2005) - 10:15 hs - Sentido Sul

\begin{tabular}{cccccccccc}
\hline $\mathbf{O} / \mathbf{D}$ & $\mathbf{1 0 9}$ & $\mathbf{1 1 6}$ & $\mathbf{1 1 7}$ & $\mathbf{1 2 2}$ & $\mathbf{1 2 4}$ & $\mathbf{1 2 9}$ & $\mathbf{1 3 4}$ & $\mathbf{1 5 1}$ & $\mathbf{1 5 3}$ \\
\hline $\mathbf{1 7 0}$ & $14 \%$ & $8 \%$ & $8 \%$ & $2 \%$ & $7 \%$ & $5 \%$ & $2 \%$ & $13 \%$ & $41 \%$ \\
$\mathbf{1 0 7}$ & $44 \%$ & $2 \%$ & $12 \%$ & $2 \%$ & $7 \%$ & $10 \%$ & $2 \%$ & $8 \%$ & $14 \%$ \\
$\mathbf{1 1 1}$ & - & $19 \%$ & $7 \%$ & $4 \%$ & $15 \%$ & $11 \%$ & $0 \%$ & $19 \%$ & $26 \%$ \\
$\mathbf{1 8 0}$ & - & - & $56 \%$ & $6 \%$ & $6 \%$ & $6 \%$ & $6 \%$ & $11 \%$ & $11 \%$ \\
$\mathbf{1 1 8}$ & - & - & - & $0 \%$ & $13 \%$ & $13 \%$ & $0 \%$ & $13 \%$ & $63 \%$ \\
$\mathbf{1 2 3}$ & - & - & - & - & $36 \%$ & $18 \%$ & $9 \%$ & $18 \%$ & $18 \%$ \\
$\mathbf{1 2 5}$ & - & - & - & - & - & $11 \%$ & $11 \%$ & $33 \%$ & $44 \%$ \\
$\mathbf{1 9 0}$ & - & - & - & - & - & - & $0 \%$ & $62 \%$ & $38 \%$ \\
$\mathbf{1 4 0}$ & - & - & - & - & - & - & - & $63 \%$ & $38 \%$ \\
\hline
\end{tabular}

Tabela A.27 - Matriz da segunda coleta de dados (13/6/2005) - 10:30 hs - Sentido Norte

\begin{tabular}{cccccccc}
\hline $\mathbf{O} / \mathbf{D}$ & $\mathbf{1 5}$ & $\mathbf{6 0}$ & $\mathbf{2 7}$ & $\mathbf{3 2}$ & $\mathbf{3 8}$ & $\mathbf{4 4}$ & $\mathbf{4 6}$ \\
\hline $\mathbf{6}$ & $21 \%$ & $4 \%$ & $2 \%$ & $3 \%$ & $9 \%$ & $9 \%$ & $52 \%$ \\
$\mathbf{2 0}$ & - & $0 \%$ & $19 \%$ & $6 \%$ & $19 \%$ & $13 \%$ & $44 \%$ \\
$\mathbf{2 5}$ & - & - & $27 \%$ & $18 \%$ & $18 \%$ & $9 \%$ & $27 \%$ \\
$\mathbf{2 8}$ & - & - & - & $6 \%$ & $29 \%$ & $12 \%$ & $53 \%$ \\
$\mathbf{3 3}$ & - & - & - & - & $40 \%$ & $20 \%$ & $40 \%$ \\
$\mathbf{4 2}$ & - & - & - & - & - & $12 \%$ & $88 \%$ \\
\hline
\end{tabular}

Tabela A.28 - Matriz da segunda coleta de dados (13/6/2005) - 10:30 hs - Sentido Sul

\begin{tabular}{cccccccccc}
\hline $\mathbf{O} / \mathbf{D}$ & $\mathbf{1 0 9}$ & $\mathbf{1 1 6}$ & $\mathbf{1 1 7}$ & $\mathbf{1 2 2}$ & $\mathbf{1 2 4}$ & $\mathbf{1 2 9}$ & $\mathbf{1 3 4}$ & $\mathbf{1 5 1}$ & $\mathbf{1 5 3}$ \\
\hline $\mathbf{1 7 0}$ & $10 \%$ & $3 \%$ & $8 \%$ & $2 \%$ & $6 \%$ & $4 \%$ & $2 \%$ & $10 \%$ & $55 \%$ \\
$\mathbf{1 0 7}$ & $33 \%$ & $2 \%$ & $9 \%$ & $2 \%$ & $4 \%$ & $7 \%$ & $4 \%$ & $9 \%$ & $30 \%$ \\
$\mathbf{1 1 1}$ & - & $9 \%$ & $9 \%$ & $3 \%$ & $18 \%$ & $6 \%$ & $3 \%$ & $15 \%$ & $36 \%$ \\
$\mathbf{1 8 0}$ & - & - & $50 \%$ & $0 \%$ & $0 \%$ & $6 \%$ & $6 \%$ & $11 \%$ & $28 \%$ \\
$\mathbf{1 1 8}$ & - & - & - & $0 \%$ & $0 \%$ & $9 \%$ & $0 \%$ & $18 \%$ & $73 \%$ \\
$\mathbf{1 2 3}$ & - & - & - & - & $25 \%$ & $19 \%$ & $13 \%$ & $19 \%$ & $25 \%$ \\
$\mathbf{1 2 5}$ & - & - & - & - & - & $11 \%$ & $11 \%$ & $33 \%$ & $44 \%$ \\
$\mathbf{1 9 0}$ & - & - & - & - & - & - & $0 \%$ & $54 \%$ & $46 \%$ \\
$\mathbf{1 4 0}$ & - & - & - & - & - & - & - & $50 \%$ & $50 \%$ \\
\hline
\end{tabular}


Tabela A.29 - Matriz da segunda coleta de dados (13/6/2005) - 10:45 hs - Sentido Norte

\begin{tabular}{cccccccc}
\hline $\mathbf{O} / \mathbf{D}$ & $\mathbf{1 5}$ & $\mathbf{6 0}$ & $\mathbf{2 7}$ & $\mathbf{3 2}$ & $\mathbf{3 8}$ & $\mathbf{4 4}$ & $\mathbf{4 6}$ \\
\hline $\mathbf{6}$ & $25 \%$ & $5 \%$ & $2 \%$ & $4 \%$ & $9 \%$ & $10 \%$ & $46 \%$ \\
$\mathbf{2 0}$ & - & $8 \%$ & $0 \%$ & $8 \%$ & $17 \%$ & $8 \%$ & $58 \%$ \\
$\mathbf{2 5}$ & - & - & $20 \%$ & $20 \%$ & $15 \%$ & $10 \%$ & $35 \%$ \\
$\mathbf{2 8}$ & - & - & - & $10 \%$ & $30 \%$ & $10 \%$ & $50 \%$ \\
$\mathbf{3 3}$ & - & - & - & - & $42 \%$ & $17 \%$ & $42 \%$ \\
$\mathbf{4 2}$ & - & - & - & - & - & $13 \%$ & $88 \%$ \\
\hline
\end{tabular}

Tabela A.30 - Matriz da segunda coleta de dados (13/6/2005) - 10:45 hs - Sentido Sul

\begin{tabular}{cccccccccc}
\hline $\mathbf{O} / \mathbf{D}$ & $\mathbf{1 0 9}$ & $\mathbf{1 1 6}$ & $\mathbf{1 1 7}$ & $\mathbf{1 2 2}$ & $\mathbf{1 2 4}$ & $\mathbf{1 2 9}$ & $\mathbf{1 3 4}$ & $\mathbf{1 5 1}$ & $\mathbf{1 5 3}$ \\
\hline $\mathbf{1 7 0}$ & $9 \%$ & $8 \%$ & $8 \%$ & $2 \%$ & $5 \%$ & $3 \%$ & $1 \%$ & $13 \%$ & $51 \%$ \\
$\mathbf{1 0 7}$ & $32 \%$ & $2 \%$ & $11 \%$ & $2 \%$ & $5 \%$ & $7 \%$ & $2 \%$ & $9 \%$ & $30 \%$ \\
$\mathbf{1 1 1}$ & - & $22 \%$ & $7 \%$ & $4 \%$ & $15 \%$ & $7 \%$ & $0 \%$ & $19 \%$ & $26 \%$ \\
$\mathbf{1 8 0}$ & - & - & $50 \%$ & $0 \%$ & $0 \%$ & $6 \%$ & $6 \%$ & $11 \%$ & $28 \%$ \\
$\mathbf{1 1 8}$ & - & - & - & $0 \%$ & $0 \%$ & $9 \%$ & $0 \%$ & $18 \%$ & $73 \%$ \\
$\mathbf{1 2 3}$ & - & - & - & - & $25 \%$ & $13 \%$ & $13 \%$ & $19 \%$ & $31 \%$ \\
$\mathbf{1 2 5}$ & - & - & - & - & - & $17 \%$ & $0 \%$ & $33 \%$ & $50 \%$ \\
$\mathbf{1 9 0}$ & - & - & - & - & - & - & $0 \%$ & $53 \%$ & $47 \%$ \\
$\mathbf{1 4 0}$ & - & - & - & - & - & - & - & $65 \%$ & $35 \%$ \\
\hline
\end{tabular}

Tabela A.31 - Matriz da segunda coleta de dados (13/6/2005) - 11:00 hs - Sentido Norte

\begin{tabular}{cccccccc}
\hline $\mathbf{O} / \mathbf{D}$ & $\mathbf{1 5}$ & $\mathbf{6 0}$ & $\mathbf{2 7}$ & $\mathbf{3 2}$ & $\mathbf{3 8}$ & $\mathbf{4 4}$ & $\mathbf{4 6}$ \\
\hline $\mathbf{6}$ & $18 \%$ & $3 \%$ & $2 \%$ & $3 \%$ & $8 \%$ & $11 \%$ & $54 \%$ \\
$\mathbf{2 0}$ & - & $7 \%$ & $21 \%$ & $7 \%$ & $14 \%$ & $7 \%$ & $43 \%$ \\
$\mathbf{2 5}$ & - & - & $29 \%$ & $18 \%$ & $6 \%$ & $6 \%$ & $41 \%$ \\
$\mathbf{2 8}$ & - & - & - & $5 \%$ & $24 \%$ & $10 \%$ & $62 \%$ \\
$\mathbf{3 3}$ & - & - & - & - & $37 \%$ & $16 \%$ & $47 \%$ \\
$\mathbf{4 2}$ & - & - & - & - & - & $18 \%$ & $82 \%$ \\
\hline
\end{tabular}

Tabela A.32 - Matriz da segunda coleta de dados (13/6/2005) - 11:00 hs - Sentido Sul

\begin{tabular}{cccccccccc}
\hline $\mathbf{O} / \mathbf{D}$ & $\mathbf{1 0 9}$ & $\mathbf{1 1 6}$ & $\mathbf{1 1 7}$ & $\mathbf{1 2 2}$ & $\mathbf{1 2 4}$ & $\mathbf{1 2 9}$ & $\mathbf{1 3 4}$ & $\mathbf{1 5 1}$ & $\mathbf{1 5 3}$ \\
\hline $\mathbf{1 7 0}$ & $8 \%$ & $8 \%$ & $8 \%$ & $1 \%$ & $7 \%$ & $4 \%$ & $4 \%$ & $14 \%$ & $47 \%$ \\
$\mathbf{1 0 7}$ & $21 \%$ & $3 \%$ & $10 \%$ & $3 \%$ & $8 \%$ & $5 \%$ & $3 \%$ & $8 \%$ & $41 \%$ \\
$\mathbf{1 1 1}$ & - & $17 \%$ & $14 \%$ & $3 \%$ & $17 \%$ & $3 \%$ & $3 \%$ & $17 \%$ & $24 \%$ \\
$\mathbf{1 8 0}$ & - & - & $57 \%$ & $0 \%$ & $7 \%$ & $0 \%$ & $0 \%$ & $7 \%$ & $29 \%$ \\
$\mathbf{1 1 8}$ & - & - & - & $0 \%$ & $15 \%$ & $8 \%$ & $8 \%$ & $15 \%$ & $54 \%$ \\
$\mathbf{1 2 3}$ & - & - & - & - & $25 \%$ & $13 \%$ & $25 \%$ & $19 \%$ & $19 \%$ \\
$\mathbf{1 2 5}$ & - & - & - & - & - & $10 \%$ & $20 \%$ & $30 \%$ & $40 \%$ \\
$\mathbf{1 9 0}$ & - & - & - & - & - & - & $0 \%$ & $56 \%$ & $44 \%$ \\
$\mathbf{1 4 0}$ & - & - & - & - & - & - & - & $67 \%$ & $33 \%$ \\
\hline
\end{tabular}


Tabela A. - Matriz da segunda coleta de dados (13/6/2005) - 11:15 hs - Sentido Norte

\begin{tabular}{cccccccc}
\hline $\mathbf{O} / \mathbf{D}$ & $\mathbf{1 5}$ & $\mathbf{6 0}$ & $\mathbf{2 7}$ & $\mathbf{3 2}$ & $\mathbf{3 8}$ & $\mathbf{4 4}$ & $\mathbf{4 6}$ \\
\hline $\mathbf{6}$ & $21 \%$ & $5 \%$ & $2 \%$ & $4 \%$ & $6 \%$ & $4 \%$ & $58 \%$ \\
$\mathbf{2 0}$ & - & $0 \%$ & $13 \%$ & $13 \%$ & $0 \%$ & $0 \%$ & $75 \%$ \\
$\mathbf{2 5}$ & - & - & $31 \%$ & $23 \%$ & $8 \%$ & $0 \%$ & $38 \%$ \\
$\mathbf{2 8}$ & - & - & - & $9 \%$ & $18 \%$ & $0 \%$ & $73 \%$ \\
$\mathbf{3 3}$ & - & - & - & - & $23 \%$ & $9 \%$ & $68 \%$ \\
$\mathbf{4 2}$ & - & - & - & - & - & $9 \%$ & $91 \%$ \\
\hline
\end{tabular}

Tabela A.34 - Matriz da segunda coleta de dados (13/6/2005) - 11:15 hs - Sentido Sul

\begin{tabular}{cccccccccc}
\hline $\mathbf{O} / \mathbf{D}$ & $\mathbf{1 0 9}$ & $\mathbf{1 1 6}$ & $\mathbf{1 1 7}$ & $\mathbf{1 2 2}$ & $\mathbf{1 2 4}$ & $\mathbf{1 2 9}$ & $\mathbf{1 3 4}$ & $\mathbf{1 5 1}$ & $\mathbf{1 5 3}$ \\
\hline $\mathbf{1 7 0}$ & $8 \%$ & $8 \%$ & $5 \%$ & $1 \%$ & $10 \%$ & $3 \%$ & $3 \%$ & $10 \%$ & $53 \%$ \\
$\mathbf{1 0 7}$ & $23 \%$ & $3 \%$ & $9 \%$ & $0 \%$ & $6 \%$ & $6 \%$ & $3 \%$ & $9 \%$ & $43 \%$ \\
$\mathbf{1 1 1}$ & - & $16 \%$ & $9 \%$ & $3 \%$ & $25 \%$ & $3 \%$ & $3 \%$ & $19 \%$ & $22 \%$ \\
$\mathbf{1 8 0}$ & - & - & $35 \%$ & $0 \%$ & $5 \%$ & $10 \%$ & $5 \%$ & $10 \%$ & $35 \%$ \\
$\mathbf{1 1 8}$ & - & - & - & $0 \%$ & $10 \%$ & $10 \%$ & $0 \%$ & $20 \%$ & $60 \%$ \\
$\mathbf{1 2 3}$ & - & - & - & - & $46 \%$ & $15 \%$ & $15 \%$ & $15 \%$ & $8 \%$ \\
$\mathbf{1 2 5}$ & - & - & - & - & - & $14 \%$ & $14 \%$ & $29 \%$ & $43 \%$ \\
$\mathbf{1 9 0}$ & - & - & - & - & - & - & $0 \%$ & $58 \%$ & $42 \%$ \\
$\mathbf{1 4 0}$ & - & - & - & - & - & - & - & $52 \%$ & $48 \%$ \\
\hline
\end{tabular}

Tabela A.35 - Matriz da segunda coleta de dados (13/6/2005) - 11:30 hs - Sentido Norte

\begin{tabular}{cccccccc}
\hline $\mathbf{O} / \mathbf{D}$ & $\mathbf{1 5}$ & $\mathbf{6 0}$ & $\mathbf{2 7}$ & $\mathbf{3 2}$ & $\mathbf{3 8}$ & $\mathbf{4 4}$ & $\mathbf{4 6}$ \\
\hline $\mathbf{6}$ & $26 \%$ & $4 \%$ & $2 \%$ & $2 \%$ & $8 \%$ & $6 \%$ & $54 \%$ \\
$\mathbf{2 0}$ & - & $7 \%$ & $0 \%$ & $7 \%$ & $14 \%$ & $7 \%$ & $64 \%$ \\
$\mathbf{2 5}$ & - & - & $16 \%$ & $5 \%$ & $5 \%$ & $11 \%$ & $63 \%$ \\
$\mathbf{2 8}$ & - & - & - & $7 \%$ & $14 \%$ & $14 \%$ & $64 \%$ \\
$\mathbf{3 3}$ & - & - & - & - & $24 \%$ & $18 \%$ & $59 \%$ \\
$\mathbf{4 2}$ & - & - & - & - & - & $7 \%$ & $93 \%$ \\
\hline
\end{tabular}

Tabela A.36 - Matriz da segunda coleta de dados (13/6/2005) - 11:30 hs - Sentido Sul

\begin{tabular}{cccccccccc}
\hline $\mathbf{O} / \mathbf{D}$ & $\mathbf{1 0 9}$ & $\mathbf{1 1 6}$ & $\mathbf{1 1 7}$ & $\mathbf{1 2 2}$ & $\mathbf{1 2 4}$ & $\mathbf{1 2 9}$ & $\mathbf{1 3 4}$ & $\mathbf{1 5 1}$ & $\mathbf{1 5 3}$ \\
\hline $\mathbf{1 7 0}$ & $9 \%$ & $8 \%$ & $5 \%$ & $2 \%$ & $8 \%$ & $4 \%$ & $2 \%$ & $13 \%$ & $50 \%$ \\
$\mathbf{1 0 7}$ & $29 \%$ & $2 \%$ & $7 \%$ & $2 \%$ & $7 \%$ & $10 \%$ & $2 \%$ & $7 \%$ & $33 \%$ \\
$\mathbf{1 1 1}$ & - & $19 \%$ & $7 \%$ & $4 \%$ & $19 \%$ & $7 \%$ & $0 \%$ & $19 \%$ & $26 \%$ \\
$\mathbf{1 8 0}$ & - & - & $33 \%$ & $0 \%$ & $6 \%$ & $6 \%$ & $6 \%$ & $11 \%$ & $39 \%$ \\
$\mathbf{1 1 8}$ & - & - & - & $0 \%$ & $25 \%$ & $0 \%$ & $0 \%$ & $25 \%$ & $50 \%$ \\
$\mathbf{1 2 3}$ & - & - & - & - & $33 \%$ & $17 \%$ & $11 \%$ & $17 \%$ & $22 \%$ \\
$\mathbf{1 2 5}$ & - & - & - & - & - & $11 \%$ & $11 \%$ & $33 \%$ & $44 \%$ \\
$\mathbf{1 9 0}$ & - & - & - & - & - & - & $0 \%$ & $56 \%$ & $44 \%$ \\
$\mathbf{1 4 0}$ & - & - & - & - & - & - & - & $69 \%$ & $31 \%$ \\
\hline
\end{tabular}


Tabela A.37 - Matriz da segunda coleta de dados (13/6/2005) - 11:45 hs - Sentido Norte

\begin{tabular}{cccccccc}
\hline $\mathbf{O} / \mathbf{D}$ & $\mathbf{1 5}$ & $\mathbf{6 0}$ & $\mathbf{2 7}$ & $\mathbf{3 2}$ & $\mathbf{3 8}$ & $\mathbf{4 4}$ & $\mathbf{4 6}$ \\
\hline $\mathbf{6}$ & $28 \%$ & $4 \%$ & $3 \%$ & $4 \%$ & $8 \%$ & $7 \%$ & $48 \%$ \\
$\mathbf{2 0}$ & - & $5 \%$ & $16 \%$ & $11 \%$ & $21 \%$ & $11 \%$ & $37 \%$ \\
$\mathbf{2 5}$ & - & - & $30 \%$ & $20 \%$ & $10 \%$ & $0 \%$ & $40 \%$ \\
$\mathbf{2 8}$ & - & - & - & $5 \%$ & $19 \%$ & $10 \%$ & $67 \%$ \\
$\mathbf{3 3}$ & - & - & - & - & $29 \%$ & $12 \%$ & $59 \%$ \\
$\mathbf{4 2}$ & - & - & - & - & - & $10 \%$ & $90 \%$ \\
\hline
\end{tabular}

Tabela A.38 - Matriz da segunda coleta de dados (13/6/2005) - 11:45 hs - Sentido Sul

\begin{tabular}{cccccccccc}
\hline $\mathbf{O} / \mathbf{D}$ & $\mathbf{1 0 9}$ & $\mathbf{1 1 6}$ & $\mathbf{1 1 7}$ & $\mathbf{1 2 2}$ & $\mathbf{1 2 4}$ & $\mathbf{1 2 9}$ & $\mathbf{1 3 4}$ & $\mathbf{1 5 1}$ & $\mathbf{1 5 3}$ \\
\hline $\mathbf{1 7 0}$ & $13 \%$ & $7 \%$ & $5 \%$ & $2 \%$ & $12 \%$ & $5 \%$ & $5 \%$ & $10 \%$ & $43 \%$ \\
$\mathbf{1 0 7}$ & $43 \%$ & $3 \%$ & $10 \%$ & $3 \%$ & $8 \%$ & $8 \%$ & $3 \%$ & $5 \%$ & $20 \%$ \\
$\mathbf{1 1 1}$ & - & $13 \%$ & $9 \%$ & $4 \%$ & $30 \%$ & $9 \%$ & $2 \%$ & $4 \%$ & $28 \%$ \\
$\mathbf{1 8 0}$ & - & - & $37 \%$ & $5 \%$ & $5 \%$ & $11 \%$ & $5 \%$ & $11 \%$ & $26 \%$ \\
$\mathbf{1 1 8}$ & - & - & - & $0 \%$ & $10 \%$ & $10 \%$ & $10 \%$ & $20 \%$ & $50 \%$ \\
$\mathbf{1 2 3}$ & - & - & - & - & $41 \%$ & $18 \%$ & $24 \%$ & $12 \%$ & $6 \%$ \\
$\mathbf{1 2 5}$ & - & - & - & - & - & $15 \%$ & $23 \%$ & $23 \%$ & $38 \%$ \\
$\mathbf{1 9 0}$ & - & - & - & - & - & - & $14 \%$ & $43 \%$ & $43 \%$ \\
$\mathbf{1 4 0}$ & - & - & - & - & - & - & - & $51 \%$ & $49 \%$ \\
\hline
\end{tabular}

Tabela A.39 - Matriz da segunda coleta de dados (13/6/2005) - 12:00 hs - Sentido Norte

\begin{tabular}{cccccccc}
\hline $\mathbf{O} / \mathbf{D}$ & $\mathbf{1 5}$ & $\mathbf{6 0}$ & $\mathbf{2 7}$ & $\mathbf{3 2}$ & $\mathbf{3 8}$ & $\mathbf{4 4}$ & $\mathbf{4 6}$ \\
\hline $\mathbf{6}$ & $24 \%$ & $4 \%$ & $2 \%$ & $3 \%$ & $7 \%$ & $9 \%$ & $51 \%$ \\
$\mathbf{2 0}$ & - & $0 \%$ & $29 \%$ & $14 \%$ & $0 \%$ & $0 \%$ & $57 \%$ \\
$\mathbf{2 5}$ & - & - & $25 \%$ & $13 \%$ & $6 \%$ & $6 \%$ & $50 \%$ \\
$\mathbf{2 8}$ & - & - & - & $6 \%$ & $24 \%$ & $12 \%$ & $59 \%$ \\
$\mathbf{3 3}$ & - & - & - & - & $33 \%$ & $14 \%$ & $52 \%$ \\
$\mathbf{4 2}$ & - & - & - & - & - & $11 \%$ & $89 \%$ \\
\hline
\end{tabular}

Tabela A.40 - Matriz da segunda coleta de dados (13/6/2005) - 12:00 hs - Sentido Sul

\begin{tabular}{cccccccccc}
\hline $\mathbf{O} / \mathbf{D}$ & $\mathbf{1 0 9}$ & $\mathbf{1 1 6}$ & $\mathbf{1 1 7}$ & $\mathbf{1 2 2}$ & $\mathbf{1 2 4}$ & $\mathbf{1 2 9}$ & $\mathbf{1 3 4}$ & $\mathbf{1 5 1}$ & $\mathbf{1 5 3}$ \\
\hline $\mathbf{1 7 0}$ & $9 \%$ & $6 \%$ & $5 \%$ & $1 \%$ & $10 \%$ & $4 \%$ & $2 \%$ & $12 \%$ & $49 \%$ \\
$\mathbf{1 0 7}$ & $25 \%$ & $2 \%$ & $8 \%$ & $2 \%$ & $8 \%$ & $8 \%$ & $4 \%$ & $8 \%$ & $33 \%$ \\
$\mathbf{1 1 1}$ & - & $12 \%$ & $8 \%$ & $3 \%$ & $26 \%$ & $7 \%$ & $1 \%$ & $16 \%$ & $26 \%$ \\
$\mathbf{1 8 0}$ & - & - & $36 \%$ & $0 \%$ & $7 \%$ & $7 \%$ & $0 \%$ & $7 \%$ & $43 \%$ \\
$\mathbf{1 1 8}$ & - & - & - & $0 \%$ & $20 \%$ & $10 \%$ & $0 \%$ & $20 \%$ & $50 \%$ \\
$\mathbf{1 2 3}$ & - & - & - & - & $47 \%$ & $13 \%$ & $20 \%$ & $20 \%$ & $0 \%$ \\
$\mathbf{1 2 5}$ & - & - & - & - & - & $17 \%$ & $17 \%$ & $33 \%$ & $33 \%$ \\
$\mathbf{1 9 0}$ & - & - & - & - & - & - & $0 \%$ & $50 \%$ & $50 \%$ \\
$\mathbf{1 4 0}$ & - & - & - & - & - & - & - & $59 \%$ & $41 \%$ \\
\hline
\end{tabular}


Tabela A.41 - Matriz da terceira coleta de dados (1/7/2005) - 14:15 hs - Sentido Norte

\begin{tabular}{cccccccc}
\hline $\mathbf{O} / \mathbf{D}$ & $\mathbf{1 5}$ & $\mathbf{6 0}$ & $\mathbf{2 7}$ & $\mathbf{3 2}$ & $\mathbf{3 8}$ & $\mathbf{4 4}$ & $\mathbf{4 6}$ \\
\hline $\mathbf{6}$ & $17 \%$ & $4 \%$ & $1 \%$ & $2 \%$ & $8 \%$ & $8 \%$ & $60 \%$ \\
$\mathbf{2 0}$ & - & $0 \%$ & $5 \%$ & $5 \%$ & $10 \%$ & $0 \%$ & $80 \%$ \\
$\mathbf{2 5}$ & - & - & $15 \%$ & $12 \%$ & $12 \%$ & $4 \%$ & $58 \%$ \\
$\mathbf{2 8}$ & - & - & - & $4 \%$ & $16 \%$ & $8 \%$ & $72 \%$ \\
$\mathbf{3 3}$ & - & - & - & - & $36 \%$ & $12 \%$ & $52 \%$ \\
$\mathbf{4 2}$ & - & - & - & - & - & $10 \%$ & $90 \%$ \\
\hline
\end{tabular}

Tabela A.42 - Matriz da terceira coleta de dados (1/7/2005) - 14:15 hs - Sentido Sul

\begin{tabular}{cccccccccc}
\hline $\mathbf{O} / \mathbf{D}$ & $\mathbf{1 0 9}$ & $\mathbf{1 1 6}$ & $\mathbf{1 1 7}$ & $\mathbf{1 2 2}$ & $\mathbf{1 2 4}$ & $\mathbf{1 2 9}$ & $\mathbf{1 3 4}$ & $\mathbf{1 5 1}$ & $\mathbf{1 5 3}$ \\
\hline $\mathbf{1 7 0}$ & $11 \%$ & $9 \%$ & $10 \%$ & $2 \%$ & $4 \%$ & $3 \%$ & $2 \%$ & $12 \%$ & $49 \%$ \\
$\mathbf{1 0 7}$ & $33 \%$ & $4 \%$ & $13 \%$ & $2 \%$ & $6 \%$ & $7 \%$ & $2 \%$ & $7 \%$ & $26 \%$ \\
$\mathbf{1 1 1}$ & - & $17 \%$ & $17 \%$ & $4 \%$ & $13 \%$ & $9 \%$ & $0 \%$ & $17 \%$ & $22 \%$ \\
$\mathbf{1 8 0}$ & - & - & $59 \%$ & $2 \%$ & $2 \%$ & $5 \%$ & $0 \%$ & $10 \%$ & $22 \%$ \\
$\mathbf{1 1 8}$ & - & - & - & $0 \%$ & $7 \%$ & $7 \%$ & $7 \%$ & $13 \%$ & $67 \%$ \\
$\mathbf{1 2 3}$ & - & - & - & - & $21 \%$ & $7 \%$ & $14 \%$ & $14 \%$ & $43 \%$ \\
$\mathbf{1 2 5}$ & - & - & - & - & - & $0 \%$ & $0 \%$ & $40 \%$ & $60 \%$ \\
$\mathbf{1 9 0}$ & - & - & - & - & - & - & $0 \%$ & $58 \%$ & $42 \%$ \\
$\mathbf{1 4 0}$ & - & - & - & - & - & - & - & $60 \%$ & $40 \%$ \\
\hline
\end{tabular}

Tabela A.43 - Matriz da terceira coleta de dados (1/7/2005) - 14:30 hs - Sentido Norte

\begin{tabular}{cccccccc}
\hline $\mathbf{O} / \mathbf{D}$ & $\mathbf{1 5}$ & $\mathbf{6 0}$ & $\mathbf{2 7}$ & $\mathbf{3 2}$ & $\mathbf{3 8}$ & $\mathbf{4 4}$ & $\mathbf{4 6}$ \\
\hline $\mathbf{6}$ & $17 \%$ & $4 \%$ & $2 \%$ & $2 \%$ & $7 \%$ & $9 \%$ & $60 \%$ \\
$\mathbf{2 0}$ & - & $0 \%$ & $13 \%$ & $0 \%$ & $0 \%$ & $13 \%$ & $73 \%$ \\
$\mathbf{2 5}$ & - & - & $20 \%$ & $7 \%$ & $7 \%$ & $7 \%$ & $60 \%$ \\
$\mathbf{2 8}$ & - & - & - & $3 \%$ & $21 \%$ & $12 \%$ & $64 \%$ \\
$\mathbf{3 3}$ & - & - & - & - & $33 \%$ & $17 \%$ & $50 \%$ \\
$\mathbf{4 2}$ & - & - & - & - & - & $14 \%$ & $86 \%$ \\
\hline
\end{tabular}

Tabela A.44 - Matriz da terceira coleta de dados (1/7/2005) - 14:30 hs - Sentido Sul

\begin{tabular}{cccccccccc}
\hline $\mathbf{O} / \mathbf{D}$ & $\mathbf{1 0 9}$ & $\mathbf{1 1 6}$ & $\mathbf{1 1 7}$ & $\mathbf{1 2 2}$ & $\mathbf{1 2 4}$ & $\mathbf{1 2 9}$ & $\mathbf{1 3 4}$ & $\mathbf{1 5 1}$ & $\mathbf{1 5 3}$ \\
\hline $\mathbf{1 7 0}$ & $11 \%$ & $5 \%$ & $7 \%$ & $1 \%$ & $5 \%$ & $4 \%$ & $3 \%$ & $13 \%$ & $53 \%$ \\
$\mathbf{1 0 7}$ & $36 \%$ & $1 \%$ & $10 \%$ & $1 \%$ & $6 \%$ & $7 \%$ & $2 \%$ & $7 \%$ & $28 \%$ \\
$\mathbf{1 1 1}$ & - & $12 \%$ & $8 \%$ & $0 \%$ & $19 \%$ & $4 \%$ & $0 \%$ & $19 \%$ & $38 \%$ \\
$\mathbf{1 8 0}$ & - & - & $44 \%$ & $0 \%$ & $7 \%$ & $4 \%$ & $4 \%$ & $11 \%$ & $30 \%$ \\
$\mathbf{1 1 8}$ & - & - & - & $0 \%$ & $0 \%$ & $13 \%$ & $0 \%$ & $13 \%$ & $75 \%$ \\
$\mathbf{1 2 3}$ & - & - & - & - & $32 \%$ & $11 \%$ & $16 \%$ & $16 \%$ & $26 \%$ \\
$\mathbf{1 2 5}$ & - & - & - & - & - & $20 \%$ & $20 \%$ & $40 \%$ & $20 \%$ \\
$\mathbf{1 9 0}$ & - & - & - & - & - & - & $0 \%$ & $58 \%$ & $42 \%$ \\
$\mathbf{1 4 0}$ & - & - & - & - & - & - & - & $63 \%$ & $38 \%$ \\
\hline
\end{tabular}


Tabela A.45 - Matriz da terceira coleta de dados (1/7/2005) - 14:45 hs - Sentido Norte

\begin{tabular}{cccccccc}
\hline $\mathbf{O} / \mathbf{D}$ & $\mathbf{1 5}$ & $\mathbf{6 0}$ & $\mathbf{2 7}$ & $\mathbf{3 2}$ & $\mathbf{3 8}$ & $\mathbf{4 4}$ & $\mathbf{4 6}$ \\
\hline $\mathbf{6}$ & $18 \%$ & $4 \%$ & $2 \%$ & $3 \%$ & $9 \%$ & $11 \%$ & $52 \%$ \\
$\mathbf{2 0}$ & - & $0 \%$ & $0 \%$ & $14 \%$ & $14 \%$ & $14 \%$ & $57 \%$ \\
$\mathbf{2 5}$ & - & - & $22 \%$ & $13 \%$ & $13 \%$ & $13 \%$ & $39 \%$ \\
$\mathbf{2 8}$ & - & - & - & $5 \%$ & $26 \%$ & $11 \%$ & $58 \%$ \\
$\mathbf{3 3}$ & - & - & - & - & $38 \%$ & $21 \%$ & $41 \%$ \\
$\mathbf{4 2}$ & - & - & - & - & - & $13 \%$ & $88 \%$ \\
\hline
\end{tabular}

Tabela A.46 - Matriz da terceira coleta de dados (1/7/2005) - 14:45 hs - Sentido Sul

\begin{tabular}{cccccccccc}
\hline $\mathbf{O} / \mathbf{D}$ & $\mathbf{1 0 9}$ & $\mathbf{1 1 6}$ & $\mathbf{1 1 7}$ & $\mathbf{1 2 2}$ & $\mathbf{1 2 4}$ & $\mathbf{1 2 9}$ & $\mathbf{1 3 4}$ & $\mathbf{1 5 1}$ & $\mathbf{1 5 3}$ \\
\hline $\mathbf{1 7 0}$ & $11 \%$ & $7 \%$ & $9 \%$ & $1 \%$ & $6 \%$ & $5 \%$ & $2 \%$ & $10 \%$ & $48 \%$ \\
$\mathbf{1 0 7}$ & $35 \%$ & $2 \%$ & $11 \%$ & $3 \%$ & $5 \%$ & $8 \%$ & $2 \%$ & $6 \%$ & $29 \%$ \\
$\mathbf{1 1 1}$ & - & $17 \%$ & $14 \%$ & $3 \%$ & $21 \%$ & $7 \%$ & $0 \%$ & $14 \%$ & $24 \%$ \\
$\mathbf{1 8 0}$ & - & - & $55 \%$ & $0 \%$ & $5 \%$ & $10 \%$ & $0 \%$ & $10 \%$ & $20 \%$ \\
$\mathbf{1 1 8}$ & - & - & - & $0 \%$ & $11 \%$ & $11 \%$ & $5 \%$ & $16 \%$ & $58 \%$ \\
$\mathbf{1 2 3}$ & - & - & - & - & $27 \%$ & $18 \%$ & $9 \%$ & $18 \%$ & $27 \%$ \\
$\mathbf{1 2 5}$ & - & - & - & - & - & $13 \%$ & $0 \%$ & $38 \%$ & $50 \%$ \\
$\mathbf{1 9 0}$ & - & - & - & - & - & - & $0 \%$ & $50 \%$ & $50 \%$ \\
$\mathbf{1 4 0}$ & - & - & - & - & - & - & - & $43 \%$ & $57 \%$ \\
\hline
\end{tabular}

Tabela A.47 - Matriz da terceira coleta de dados (1/7/2005) - 15:00 hs - Sentido Norte

\begin{tabular}{cccccccc}
\hline $\mathbf{O} / \mathbf{D}$ & $\mathbf{1 5}$ & $\mathbf{6 0}$ & $\mathbf{2 7}$ & $\mathbf{3 2}$ & $\mathbf{3 8}$ & $\mathbf{4 4}$ & $\mathbf{4 6}$ \\
\hline $\mathbf{6}$ & $14 \%$ & $5 \%$ & $2 \%$ & $2 \%$ & $9 \%$ & $8 \%$ & $61 \%$ \\
$\mathbf{2 0}$ & - & $0 \%$ & $10 \%$ & $10 \%$ & $10 \%$ & $0 \%$ & $70 \%$ \\
$\mathbf{2 5}$ & - & - & $13 \%$ & $13 \%$ & $7 \%$ & $0 \%$ & $67 \%$ \\
$\mathbf{2 8}$ & - & - & - & $5 \%$ & $18 \%$ & $9 \%$ & $68 \%$ \\
$\mathbf{3 3}$ & - & - & - & - & $39 \%$ & $10 \%$ & $52 \%$ \\
$\mathbf{4 2}$ & - & - & - & - & - & $5 \%$ & $95 \%$ \\
\hline
\end{tabular}

Tabela A.48 - Matriz da terceira coleta de dados (1/7/2005) - 15:00 hs - Sentido Sul

\begin{tabular}{cccccccccc}
\hline $\mathbf{O} / \mathbf{D}$ & $\mathbf{1 0 9}$ & $\mathbf{1 1 6}$ & $\mathbf{1 1 7}$ & $\mathbf{1 2 2}$ & $\mathbf{1 2 4}$ & $\mathbf{1 2 9}$ & $\mathbf{1 3 4}$ & $\mathbf{1 5 1}$ & $\mathbf{1 5 3}$ \\
\hline $\mathbf{1 7 0}$ & $8 \%$ & $5 \%$ & $11 \%$ & $1 \%$ & $5 \%$ & $4 \%$ & $2 \%$ & $16 \%$ & $49 \%$ \\
$\mathbf{1 0 7}$ & $26 \%$ & $2 \%$ & $11 \%$ & $0 \%$ & $5 \%$ & $8 \%$ & $3 \%$ & $8 \%$ & $37 \%$ \\
$\mathbf{1 1 1}$ & - & $8 \%$ & $12 \%$ & $4 \%$ & $16 \%$ & $8 \%$ & $0 \%$ & $16 \%$ & $36 \%$ \\
$\mathbf{1 8 0}$ & - & - & $70 \%$ & $0 \%$ & $4 \%$ & $9 \%$ & $4 \%$ & $9 \%$ & $4 \%$ \\
$\mathbf{1 1 8}$ & - & - & - & $0 \%$ & $7 \%$ & $13 \%$ & $7 \%$ & $13 \%$ & $60 \%$ \\
$\mathbf{1 2 3}$ & - & - & - & - & $24 \%$ & $18 \%$ & $18 \%$ & $18 \%$ & $24 \%$ \\
$\mathbf{1 2 5}$ & - & - & - & - & - & $14 \%$ & $14 \%$ & $36 \%$ & $36 \%$ \\
$\mathbf{1 9 0}$ & - & - & - & - & - & - & $0 \%$ & $57 \%$ & $43 \%$ \\
$\mathbf{1 4 0}$ & - & - & - & - & - & - & - & $74 \%$ & $26 \%$ \\
\hline
\end{tabular}


Tabela A.49 - Matriz da terceira coleta de dados (1/7/2005) - 15:15 hs - Sentido Norte

\begin{tabular}{cccccccc}
\hline $\mathbf{O} / \mathbf{D}$ & $\mathbf{1 5}$ & $\mathbf{6 0}$ & $\mathbf{2 7}$ & $\mathbf{3 2}$ & $\mathbf{3 8}$ & $\mathbf{4 4}$ & $\mathbf{4 6}$ \\
\hline $\mathbf{6}$ & $14 \%$ & $4 \%$ & $3 \%$ & $3 \%$ & $6 \%$ & $10 \%$ & $60 \%$ \\
$\mathbf{2 0}$ & - & $0 \%$ & $27 \%$ & $9 \%$ & $0 \%$ & $9 \%$ & $55 \%$ \\
$\mathbf{2 5}$ & - & - & $36 \%$ & $18 \%$ & $0 \%$ & $9 \%$ & $36 \%$ \\
$\mathbf{2 8}$ & - & - & - & $6 \%$ & $6 \%$ & $12 \%$ & $76 \%$ \\
$\mathbf{3 3}$ & - & - & - & - & $21 \%$ & $17 \%$ & $62 \%$ \\
$\mathbf{4 2}$ & - & - & - & - & - & $13 \%$ & $87 \%$ \\
\hline
\end{tabular}

Tabela A.50 - Matriz da terceira coleta de dados (1/7/2005) - 15:15 hs - Sentido Sul

\begin{tabular}{cccccccccc}
\hline $\mathbf{O} / \mathbf{D}$ & $\mathbf{1 0 9}$ & $\mathbf{1 1 6}$ & $\mathbf{1 1 7}$ & $\mathbf{1 2 2}$ & $\mathbf{1 2 4}$ & $\mathbf{1 2 9}$ & $\mathbf{1 3 4}$ & $\mathbf{1 5 1}$ & $\mathbf{1 5 3}$ \\
\hline $\mathbf{1 7 0}$ & $9 \%$ & $4 \%$ & $9 \%$ & $1 \%$ & $5 \%$ & $4 \%$ & $3 \%$ & $11 \%$ & $55 \%$ \\
$\mathbf{1 0 7}$ & $25 \%$ & $0 \%$ & $11 \%$ & $1 \%$ & $6 \%$ & $7 \%$ & $3 \%$ & $8 \%$ & $39 \%$ \\
$\mathbf{1 1 1}$ & - & $5 \%$ & $14 \%$ & $0 \%$ & $18 \%$ & $9 \%$ & $0 \%$ & $18 \%$ & $36 \%$ \\
$\mathbf{1 8 0}$ & - & - & $47 \%$ & $0 \%$ & $0 \%$ & $6 \%$ & $6 \%$ & $12 \%$ & $29 \%$ \\
$\mathbf{1 1 8}$ & - & - & - & $0 \%$ & $8 \%$ & $15 \%$ & $8 \%$ & $15 \%$ & $54 \%$ \\
$\mathbf{1 2 3}$ & - & - & - & - & $30 \%$ & $20 \%$ & $20 \%$ & $20 \%$ & $10 \%$ \\
$\mathbf{1 2 5}$ & - & - & - & - & - & $18 \%$ & $18 \%$ & $36 \%$ & $27 \%$ \\
$\mathbf{1 9 0}$ & - & - & - & - & - & - & $0 \%$ & $56 \%$ & $44 \%$ \\
$\mathbf{1 4 0}$ & - & - & - & - & - & - & - & $57 \%$ & $43 \%$ \\
\hline
\end{tabular}

Tabela A.51 - Matriz da terceira coleta de dados (1/7/2005) - 15:30 hs - Sentido Norte

\begin{tabular}{cccccccc}
\hline $\mathbf{O} / \mathbf{D}$ & $\mathbf{1 5}$ & $\mathbf{6 0}$ & $\mathbf{2 7}$ & $\mathbf{3 2}$ & $\mathbf{3 8}$ & $\mathbf{4 4}$ & $\mathbf{4 6}$ \\
\hline $\mathbf{6}$ & $19 \%$ & $3 \%$ & $2 \%$ & $3 \%$ & $6 \%$ & $8 \%$ & $58 \%$ \\
$\mathbf{2 0}$ & - & $0 \%$ & $8 \%$ & $8 \%$ & $0 \%$ & $0 \%$ & $85 \%$ \\
$\mathbf{2 5}$ & - & - & $21 \%$ & $17 \%$ & $4 \%$ & $8 \%$ & $50 \%$ \\
$\mathbf{2 8}$ & - & - & - & $5 \%$ & $13 \%$ & $8 \%$ & $74 \%$ \\
$\mathbf{3 3}$ & - & - & - & - & $28 \%$ & $11 \%$ & $61 \%$ \\
$\mathbf{4 2}$ & - & - & - & - & - & $5 \%$ & $95 \%$ \\
\hline
\end{tabular}

Tabela A.52 - Matriz da terceira coleta de dados (1/7/2005) - 15:30 hs - Sentido Sul

\begin{tabular}{cccccccccc}
\hline $\mathbf{O} / \mathbf{D}$ & $\mathbf{1 0 9}$ & $\mathbf{1 1 6}$ & $\mathbf{1 1 7}$ & $\mathbf{1 2 2}$ & $\mathbf{1 2 4}$ & $\mathbf{1 2 9}$ & $\mathbf{1 3 4}$ & $\mathbf{1 5 1}$ & $\mathbf{1 5 3}$ \\
\hline $\mathbf{1 7 0}$ & $9 \%$ & $3 \%$ & $7 \%$ & $1 \%$ & $7 \%$ & $4 \%$ & $3 \%$ & $12 \%$ & $53 \%$ \\
$\mathbf{1 0 7}$ & $31 \%$ & $0 \%$ & $12 \%$ & $2 \%$ & $5 \%$ & $8 \%$ & $3 \%$ & $7 \%$ & $32 \%$ \\
$\mathbf{1 1 1}$ & - & $10 \%$ & $10 \%$ & $3 \%$ & $20 \%$ & $7 \%$ & $3 \%$ & $17 \%$ & $30 \%$ \\
$\mathbf{1 8 0}$ & - & - & $48 \%$ & $0 \%$ & $8 \%$ & $8 \%$ & $4 \%$ & $12 \%$ & $20 \%$ \\
$\mathbf{1 1 8}$ & - & - & - & $0 \%$ & $15 \%$ & $15 \%$ & $8 \%$ & $15 \%$ & $46 \%$ \\
$\mathbf{1 2 3}$ & - & - & - & - & $25 \%$ & $17 \%$ & $17 \%$ & $17 \%$ & $25 \%$ \\
$\mathbf{1 2 5}$ & - & - & - & - & - & $11 \%$ & $11 \%$ & $33 \%$ & $44 \%$ \\
$\mathbf{1 9 0}$ & - & - & - & - & - & - & $0 \%$ & $50 \%$ & $50 \%$ \\
$\mathbf{1 4 0}$ & - & - & - & - & - & - & - & $58 \%$ & $42 \%$ \\
\hline
\end{tabular}


Tabela A.53 - Matriz da terceira coleta de dados (1/7/2005) - 15:45 hs - Sentido Norte

\begin{tabular}{cccccccc}
\hline $\mathbf{O} / \mathbf{D}$ & $\mathbf{1 5}$ & $\mathbf{6 0}$ & $\mathbf{2 7}$ & $\mathbf{3 2}$ & $\mathbf{3 8}$ & $\mathbf{4 4}$ & $\mathbf{4 6}$ \\
\hline $\mathbf{6}$ & $17 \%$ & $4 \%$ & $2 \%$ & $2 \%$ & $8 \%$ & $7 \%$ & $59 \%$ \\
$\mathbf{2 0}$ & - & $0 \%$ & $20 \%$ & $7 \%$ & $0 \%$ & $7 \%$ & $67 \%$ \\
$\mathbf{2 5}$ & - & - & $25 \%$ & $15 \%$ & $5 \%$ & $5 \%$ & $50 \%$ \\
$\mathbf{2 8}$ & - & - & - & $4 \%$ & $21 \%$ & $8 \%$ & $67 \%$ \\
$\mathbf{3 3}$ & - & - & - & - & $33 \%$ & $6 \%$ & $61 \%$ \\
$\mathbf{4 2}$ & - & - & - & - & - & $0 \%$ & $100 \%$ \\
\hline
\end{tabular}

Tabela A.54 - Matriz da terceira coleta de dados (1/7/2005) - 15:45 hs - Sentido Sul

\begin{tabular}{cccccccccc}
\hline $\mathbf{O} / \mathbf{D}$ & $\mathbf{1 0 9}$ & $\mathbf{1 1 6}$ & $\mathbf{1 1 7}$ & $\mathbf{1 2 2}$ & $\mathbf{1 2 4}$ & $\mathbf{1 2 9}$ & $\mathbf{1 3 4}$ & $\mathbf{1 5 1}$ & $\mathbf{1 5 3}$ \\
\hline $\mathbf{1 7 0}$ & $10 \%$ & $6 \%$ & $13 \%$ & $2 \%$ & $10 \%$ & $6 \%$ & $1 \%$ & $12 \%$ & $40 \%$ \\
$\mathbf{1 0 7}$ & $28 \%$ & $1 \%$ & $12 \%$ & $4 \%$ & $7 \%$ & $10 \%$ & $1 \%$ & $9 \%$ & $25 \%$ \\
$\mathbf{1 1 1}$ & - & $15 \%$ & $12 \%$ & $3 \%$ & $27 \%$ & $9 \%$ & $0 \%$ & $18 \%$ & $15 \%$ \\
$\mathbf{1 8 0}$ & - & - & $67 \%$ & $5 \%$ & $5 \%$ & $10 \%$ & $0 \%$ & $10 \%$ & $5 \%$ \\
$\mathbf{1 1 8}$ & - & - & - & $0 \%$ & $10 \%$ & $10 \%$ & $0 \%$ & $20 \%$ & $60 \%$ \\
$\mathbf{1 2 3}$ & - & - & - & - & $33 \%$ & $11 \%$ & $11 \%$ & $22 \%$ & $22 \%$ \\
$\mathbf{1 2 5}$ & - & - & - & - & - & $18 \%$ & $9 \%$ & $36 \%$ & $36 \%$ \\
$\mathbf{1 9 0}$ & - & - & - & - & - & - & $0 \%$ & $60 \%$ & $40 \%$ \\
$\mathbf{1 4 0}$ & - & - & - & - & - & - & - & $59 \%$ & $41 \%$ \\
\hline
\end{tabular}

Tabela A.55 - Matriz da terceira coleta de dados (1/7/2005) - 16:00 hs - Sentido Norte

\begin{tabular}{cccccccc}
\hline $\mathbf{O} / \mathbf{D}$ & $\mathbf{1 5}$ & $\mathbf{6 0}$ & $\mathbf{2 7}$ & $\mathbf{3 2}$ & $\mathbf{3 8}$ & $\mathbf{4 4}$ & $\mathbf{4 6}$ \\
\hline $\mathbf{6}$ & $16 \%$ & $4 \%$ & $3 \%$ & $4 \%$ & $5 \%$ & $9 \%$ & $59 \%$ \\
$\mathbf{2 0}$ & - & $0 \%$ & $20 \%$ & $20 \%$ & $0 \%$ & $10 \%$ & $50 \%$ \\
$\mathbf{2 5}$ & - & - & $38 \%$ & $19 \%$ & $0 \%$ & $6 \%$ & $38 \%$ \\
$\mathbf{2 8}$ & - & - & - & $13 \%$ & $13 \%$ & $13 \%$ & $63 \%$ \\
$\mathbf{3 3}$ & - & - & - & - & $16 \%$ & $16 \%$ & $69 \%$ \\
$\mathbf{4 2}$ & - & - & - & - & - & $14 \%$ & $86 \%$ \\
\hline
\end{tabular}

Tabela A.56 - Matriz da terceira coleta de dados (1/7/2005) - 16:00 hs - Sentido Sul

\begin{tabular}{cccccccccc}
\hline $\mathbf{O} / \mathbf{D}$ & $\mathbf{1 0 9}$ & $\mathbf{1 1 6}$ & $\mathbf{1 1 7}$ & $\mathbf{1 2 2}$ & $\mathbf{1 2 4}$ & $\mathbf{1 2 9}$ & $\mathbf{1 3 4}$ & $\mathbf{1 5 1}$ & $\mathbf{1 5 3}$ \\
\hline $\mathbf{1 7 0}$ & $8 \%$ & $3 \%$ & $8 \%$ & $1 \%$ & $7 \%$ & $4 \%$ & $4 \%$ & $12 \%$ & $53 \%$ \\
$\mathbf{1 0 7}$ & $25 \%$ & $2 \%$ & $11 \%$ & $0 \%$ & $6 \%$ & $8 \%$ & $6 \%$ & $8 \%$ & $36 \%$ \\
$\mathbf{1 1 1}$ & - & $8 \%$ & $11 \%$ & $0 \%$ & $19 \%$ & $5 \%$ & $3 \%$ & $14 \%$ & $41 \%$ \\
$\mathbf{1 8 0}$ & - & - & $54 \%$ & $0 \%$ & $8 \%$ & $4 \%$ & $4 \%$ & $12 \%$ & $19 \%$ \\
$\mathbf{1 1 8}$ & - & - & - & $0 \%$ & $12 \%$ & $12 \%$ & $6 \%$ & $18 \%$ & $53 \%$ \\
$\mathbf{1 2 3}$ & - & - & - & - & $25 \%$ & $17 \%$ & $17 \%$ & $8 \%$ & $33 \%$ \\
$\mathbf{1 2 5}$ & - & - & - & - & - & $17 \%$ & $17 \%$ & $33 \%$ & $33 \%$ \\
$\mathbf{1 9 0}$ & - & - & - & - & - & - & $0 \%$ & $42 \%$ & $58 \%$ \\
$\mathbf{1 4 0}$ & - & - & - & - & - & - & - & $59 \%$ & $41 \%$ \\
\hline
\end{tabular}


Tabela A.57 - Matriz da terceira coleta de dados (1/7/2005) - 16:15 hs - Sentido Norte

\begin{tabular}{cccccccc}
\hline $\mathbf{O} / \mathbf{D}$ & $\mathbf{1 5}$ & $\mathbf{6 0}$ & $\mathbf{2 7}$ & $\mathbf{3 2}$ & $\mathbf{3 8}$ & $\mathbf{4 4}$ & $\mathbf{4 6}$ \\
\hline $\mathbf{6}$ & $14 \%$ & $5 \%$ & $2 \%$ & $2 \%$ & $7 \%$ & $8 \%$ & $62 \%$ \\
$\mathbf{2 0}$ & - & $0 \%$ & $8 \%$ & $8 \%$ & $0 \%$ & $0 \%$ & $83 \%$ \\
$\mathbf{2 5}$ & - & - & $24 \%$ & $14 \%$ & $5 \%$ & $5 \%$ & $52 \%$ \\
$\mathbf{2 8}$ & - & - & - & $7 \%$ & $17 \%$ & $7 \%$ & $70 \%$ \\
$\mathbf{3 3}$ & - & - & - & - & $32 \%$ & $14 \%$ & $54 \%$ \\
$\mathbf{4 2}$ & - & - & - & - & - & $10 \%$ & $90 \%$ \\
\hline
\end{tabular}

Tabela A.58 - Matriz da terceira coleta de dados (1/7/2005) - 16:15 hs - Sentido Sul

\begin{tabular}{cccccccccc}
\hline $\mathbf{O} / \mathbf{D}$ & $\mathbf{1 0 9}$ & $\mathbf{1 1 6}$ & $\mathbf{1 1 7}$ & $\mathbf{1 2 2}$ & $\mathbf{1 2 4}$ & $\mathbf{1 2 9}$ & $\mathbf{1 3 4}$ & $\mathbf{1 5 1}$ & $\mathbf{1 5 3}$ \\
\hline $\mathbf{1 7 0}$ & $10 \%$ & $5 \%$ & $8 \%$ & $2 \%$ & $6 \%$ & $7 \%$ & $3 \%$ & $10 \%$ & $48 \%$ \\
$\mathbf{1 0 7}$ & $30 \%$ & $2 \%$ & $11 \%$ & $2 \%$ & $3 \%$ & $11 \%$ & $3 \%$ & $7 \%$ & $31 \%$ \\
$\mathbf{1 1 1}$ & - & $9 \%$ & $13 \%$ & $3 \%$ & $16 \%$ & $9 \%$ & $3 \%$ & $19 \%$ & $28 \%$ \\
$\mathbf{1 8 0}$ & - & - & $54 \%$ & $4 \%$ & $4 \%$ & $8 \%$ & $4 \%$ & $0 \%$ & $25 \%$ \\
$\mathbf{1 1 8}$ & - & - & - & $6 \%$ & $6 \%$ & $19 \%$ & $6 \%$ & $6 \%$ & $56 \%$ \\
$\mathbf{1 2 3}$ & - & - & - & - & $21 \%$ & $14 \%$ & $21 \%$ & $14 \%$ & $29 \%$ \\
$\mathbf{1 2 5}$ & - & - & - & - & - & $18 \%$ & $18 \%$ & $27 \%$ & $36 \%$ \\
$\mathbf{1 9 0}$ & - & - & - & - & - & - & $0 \%$ & $33 \%$ & $67 \%$ \\
$\mathbf{1 4 0}$ & - & - & - & - & - & - & - & $48 \%$ & $53 \%$ \\
\hline
\end{tabular}

Tabela A.59 - Matriz da terceira coleta de dados (1/7/2005) - 16:30 hs - Sentido Norte

\begin{tabular}{cccccccc}
\hline $\mathbf{O} / \mathbf{D}$ & $\mathbf{1 5}$ & $\mathbf{6 0}$ & $\mathbf{2 7}$ & $\mathbf{3 2}$ & $\mathbf{3 8}$ & $\mathbf{4 4}$ & $\mathbf{4 6}$ \\
\hline $\mathbf{6}$ & $12 \%$ & $3 \%$ & $3 \%$ & $2 \%$ & $6 \%$ & $9 \%$ & $65 \%$ \\
$\mathbf{2 0}$ & - & $0 \%$ & $15 \%$ & $5 \%$ & $5 \%$ & $5 \%$ & $70 \%$ \\
$\mathbf{2 5}$ & - & - & $8 \%$ & $17 \%$ & $8 \%$ & $0 \%$ & $67 \%$ \\
$\mathbf{2 8}$ & - & - & - & $5 \%$ & $14 \%$ & $5 \%$ & $77 \%$ \\
$\mathbf{3 3}$ & - & - & - & - & $30 \%$ & $15 \%$ & $56 \%$ \\
$\mathbf{4 2}$ & - & - & - & - & - & $13 \%$ & $87 \%$ \\
\hline
\end{tabular}

Tabela A.60 - Matriz da terceira coleta de dados (1/7/2005) - 16:30 hs - Sentido Sul

\begin{tabular}{cccccccccc}
\hline $\mathbf{O} / \mathbf{D}$ & $\mathbf{1 0 9}$ & $\mathbf{1 1 6}$ & $\mathbf{1 1 7}$ & $\mathbf{1 2 2}$ & $\mathbf{1 2 4}$ & $\mathbf{1 2 9}$ & $\mathbf{1 3 4}$ & $\mathbf{1 5 1}$ & $\mathbf{1 5 3}$ \\
\hline $\mathbf{1 7 0}$ & $7 \%$ & $5 \%$ & $7 \%$ & $3 \%$ & $6 \%$ & $3 \%$ & $1 \%$ & $10 \%$ & $57 \%$ \\
$\mathbf{1 0 7}$ & $20 \%$ & $0 \%$ & $9 \%$ & $4 \%$ & $7 \%$ & $7 \%$ & $2 \%$ & $7 \%$ & $44 \%$ \\
$\mathbf{1 1 1}$ & - & $8 \%$ & $8 \%$ & $3 \%$ & $19 \%$ & $3 \%$ & $3 \%$ & $14 \%$ & $43 \%$ \\
$\mathbf{1 8 0}$ & - & - & $50 \%$ & $5 \%$ & $9 \%$ & $9 \%$ & $0 \%$ & $9 \%$ & $18 \%$ \\
$\mathbf{1 1 8}$ & - & - & - & $6 \%$ & $12 \%$ & $12 \%$ & $6 \%$ & $18 \%$ & $47 \%$ \\
$\mathbf{1 2 3}$ & - & - & - & - & $31 \%$ & $13 \%$ & $13 \%$ & $13 \%$ & $31 \%$ \\
$\mathbf{1 2 5}$ & - & - & - & - & - & $18 \%$ & $9 \%$ & $27 \%$ & $45 \%$ \\
$\mathbf{1 9 0}$ & - & - & - & - & - & - & $0 \%$ & $43 \%$ & $57 \%$ \\
$\mathbf{1 4 0}$ & - & - & - & - & - & - & - & $49 \%$ & $51 \%$ \\
\hline
\end{tabular}


Tabela A.61 - Matriz da terceira coleta de dados (1/7/2005) - 16:45 hs - Sentido Norte

\begin{tabular}{cccccccc}
\hline $\mathbf{O} / \mathbf{D}$ & $\mathbf{1 5}$ & $\mathbf{6 0}$ & $\mathbf{2 7}$ & $\mathbf{3 2}$ & $\mathbf{3 8}$ & $\mathbf{4 4}$ & $\mathbf{4 6}$ \\
\hline $\mathbf{6}$ & $17 \%$ & $6 \%$ & $2 \%$ & $4 \%$ & $7 \%$ & $8 \%$ & $56 \%$ \\
$\mathbf{2 0}$ & - & $11 \%$ & $22 \%$ & $11 \%$ & $11 \%$ & $6 \%$ & $39 \%$ \\
$\mathbf{2 5}$ & - & - & $25 \%$ & $13 \%$ & $6 \%$ & $0 \%$ & $56 \%$ \\
$\mathbf{2 8}$ & - & - & - & $5 \%$ & $16 \%$ & $5 \%$ & $74 \%$ \\
$\mathbf{3 3}$ & - & - & - & - & $34 \%$ & $14 \%$ & $52 \%$ \\
$\mathbf{4 2}$ & - & - & - & - & - & $10 \%$ & $90 \%$ \\
\hline
\end{tabular}

Tabela A.62 - Matriz da terceira coleta de dados (1/7/2005) - 16:45 hs - Sentido Sul

\begin{tabular}{cccccccccc}
\hline $\mathbf{O} / \mathbf{D}$ & $\mathbf{1 0 9}$ & $\mathbf{1 1 6}$ & $\mathbf{1 1 7}$ & $\mathbf{1 2 2}$ & $\mathbf{1 2 4}$ & $\mathbf{1 2 9}$ & $\mathbf{1 3 4}$ & $\mathbf{1 5 1}$ & $\mathbf{1 5 3}$ \\
\hline $\mathbf{1 7 0}$ & $6 \%$ & $4 \%$ & $8 \%$ & $2 \%$ & $4 \%$ & $6 \%$ & $2 \%$ & $13 \%$ & $54 \%$ \\
$\mathbf{1 0 7}$ & $21 \%$ & $1 \%$ & $12 \%$ & $3 \%$ & $5 \%$ & $10 \%$ & $3 \%$ & $8 \%$ & $38 \%$ \\
$\mathbf{1 1 1}$ & - & $11 \%$ & $11 \%$ & $3 \%$ & $8 \%$ & $8 \%$ & $3 \%$ & $19 \%$ & $38 \%$ \\
$\mathbf{1 8 0}$ & - & - & $58 \%$ & $0 \%$ & $4 \%$ & $8 \%$ & $4 \%$ & $8 \%$ & $17 \%$ \\
$\mathbf{1 1 8}$ & - & - & - & $0 \%$ & $8 \%$ & $12 \%$ & $0 \%$ & $16 \%$ & $64 \%$ \\
$\mathbf{1 2 3}$ & - & - & - & - & $22 \%$ & $17 \%$ & $11 \%$ & $17 \%$ & $33 \%$ \\
$\mathbf{1 2 5}$ & - & - & - & - & - & $14 \%$ & $14 \%$ & $29 \%$ & $43 \%$ \\
$\mathbf{1 9 0}$ & - & - & - & - & - & - & $0 \%$ & $50 \%$ & $50 \%$ \\
$\mathbf{1 4 0}$ & - & - & - & - & - & - & - & $63 \%$ & $37 \%$ \\
\hline
\end{tabular}

Tabela A.63 - Matriz da terceira coleta de dados (1/7/2005) - 17:00 hs - Sentido Norte

\begin{tabular}{cccccccc}
\hline $\mathbf{O} / \mathbf{D}$ & $\mathbf{1 5}$ & $\mathbf{6 0}$ & $\mathbf{2 7}$ & $\mathbf{3 2}$ & $\mathbf{3 8}$ & $\mathbf{4 4}$ & $\mathbf{4 6}$ \\
\hline $\mathbf{6}$ & $29 \%$ & $5 \%$ & $4 \%$ & $5 \%$ & $8 \%$ & $7 \%$ & $43 \%$ \\
$\mathbf{2 0}$ & - & $7 \%$ & $36 \%$ & $14 \%$ & $7 \%$ & $0 \%$ & $36 \%$ \\
$\mathbf{2 5}$ & - & - & $47 \%$ & $27 \%$ & $7 \%$ & $0 \%$ & $20 \%$ \\
$\mathbf{2 8}$ & - & - & - & $12 \%$ & $21 \%$ & $9 \%$ & $58 \%$ \\
$\mathbf{3 3}$ & - & - & - & - & $35 \%$ & $12 \%$ & $53 \%$ \\
$\mathbf{4 2}$ & - & - & - & - & - & $14 \%$ & $86 \%$ \\
\hline
\end{tabular}

Tabela A.64 - Matriz da terceira coleta de dados (1/7/2005) - 17:00 hs - Sentido Sul

\begin{tabular}{|c|c|c|c|c|c|c|c|c|c|}
\hline $\mathrm{O} / \mathrm{D}$ & 109 & 116 & 117 & 122 & 124 & 129 & 134 & 151 & 153 \\
\hline 170 & $7 \%$ & $5 \%$ & $10 \%$ & $1 \%$ & $8 \%$ & $6 \%$ & $3 \%$ & $11 \%$ & $49 \%$ \\
\hline 107 & $21 \%$ & $0 \%$ & $12 \%$ & $2 \%$ & $7 \%$ & $11 \%$ & $4 \%$ & $7 \%$ & $37 \%$ \\
\hline 111 & - & $10 \%$ & $15 \%$ & $3 \%$ & $23 \%$ & $8 \%$ & $3 \%$ & $15 \%$ & $23 \%$ \\
\hline 180 & - & - & $72 \%$ & $0 \%$ & $8 \%$ & $8 \%$ & $4 \%$ & $8 \%$ & $0 \%$ \\
\hline 118 & - & - & - & $0 \%$ & $13 \%$ & $13 \%$ & $4 \%$ & $13 \%$ & $58 \%$ \\
\hline 123 & - & - & - & - & $39 \%$ & $17 \%$ & $22 \%$ & $11 \%$ & $11 \%$ \\
\hline 125 & - & - & - & - & - & $19 \%$ & $25 \%$ & $25 \%$ & $31 \%$ \\
\hline 190 & - & - & - & - & - & - & $0 \%$ & $33 \%$ & $67 \%$ \\
\hline 140 & - & - & - & - & - & - & - & $52 \%$ & $48 \%$ \\
\hline
\end{tabular}

